\title{
Observations: Ocean
}

\author{
Coordinating Lead Authors:
}

Monika Rhein (Germany), Stephen R. Rintoul (Australia)

\section{Lead Authors:}

Shigeru Aoki (Japan), Edmo Campos (Brazil), Don Chambers (USA), Richard A. Feely (USA), Sergey Gulev (Russian Federation), Gregory C. Johnson (USA), Simon A. Josey (UK), Andrey Kostianoy (Russian Federation), Cecilie Mauritzen (Norway), Dean Roemmich (USA), Lynne D. Talley (USA), Fan Wang (China)

\section{Contributing Authors:}

Ian Allison (Australia), Michio Aoyama (Japan), Molly Baringer (USA), Nicholas R. Bates (Bermuda), Timothy Boyer (USA), Robert H. Byrne (USA), Sarah Cooley (USA), Stuart Cunningham (UK), Thierry Delcroix (France), Catia M. Domingues (Australia), Scott Doney (USA), John Dore (USA), Paul. J. Durack (USA/Australia), Rana Fine (USA), Melchor González-Dávila (Spain), Simon Good (UK), Nicolas Gruber (Switzerland), Mark Hemer (Australia), David Hydes (UK), Masayoshi Ishii (Japan), Stanley Jacobs (USA), Torsten Kanzow (Germany), David Karl (USA), Georg Kaser (Austria/Italy), Alexander Kazmin (Russian Federation), Robert Key (USA), Samar Khatiwala (USA), Joan Kleypas (USA), Ronald Kwok (USA), Kitack Lee (Republic of Korea), Eric Leuliette (USA), Melisa Menéndez (Spain), Calvin Mordy (USA), Jon Olafsson (Iceland), James Orr (France), Alejandro Orsi (USA), Geun-Ha Park (Republic of Korea), Igor Polyakov (USA), Sarah G. Purkey (USA), Bo Qiu (USA), Gilles Reverdin (France), Anastasia Romanou (USA), Sunke Schmidtko (UK), Raymond Schmitt (USA), Koji Shimada (Japan), Doug Smith (UK), Thomas M. Smith (USA), Uwe Stöber (Germany), Lothar Stramma (Germany), Toshio Suga (Japan), Neil Swart (Canada/ South Africa), Taro Takahashi (USA), Toste Tanhua (Germany), Karina von Schuckmann (France), Hans von Storch (Germany), Xiaolan Wang (Canada), Rik Wanninkhof (USA), Susan Wijffels (Australia), Philip Woodworth (UK), Igor Yashayaev (Canada), Lisan Yu (USA)

\section{Review Editors:}

Howard Freeland (Canada), Silvia Garzoli (USA), Yukihiro Nojiri (Japan)

This chapter should be cited as:

Rhein, M., S.R. Rintoul, S. Aoki, E. Campos, D. Chambers, R.A. Feely, S. Gulev, G.C. Johnson, S.A. Josey, A. Kostianoy, C. Mauritzen, D. Roemmich, L.D. Talley and F. Wang, 2013: Observations: Ocean. In: Climate Change 2013: The Physical Science Basis. Contribution of Working Group I to the Fifth Assessment Report of the Intergovernmental Panel on Climate Change [Stocker, T.F., D. Qin, G.-K. Plattner, M. Tignor, S.K. Allen, J. Boschung, A. Nauels, Y. Xia, V. Bex and P.M. Midgley (eds.)]. Cambridge University Press, Cambridge, United Kingdom and New York, NY, USA. 
Executive Summary 257

3.1 Introduction 260

3.2 Changes in Ocean Temperature and Heat Content 260

3.2.1 Effects of Sampling on Ocean Heat Content Estimates................................................. 260

3.2.2 Upper Ocean Temperature....................................... 261

3.2.3 Upper Ocean Heat Content ....................................... 262

3.2.4 Deep Ocean Temperature and Heat Content............. 263

3.2.5 Conclusions............................................................ 263

Box 3.1: Change in Global Energy Inventory ....................... 264

3.3 Changes in Salinity and Freshwater Content ......... 265

3.3.1 Introduction ............................................................. 265

3.3.2 Global to Basin-Scale Trends ................................. 267

3.3.3 Regional Changes in Upper Ocean Salinity .............. 271

3.3.4 Evidence for Change of the Hydrological Cycle from Salinity Changes ............................................. 273

3.3.5 Conclusions.......................................................... 273

3.4 Changes in Ocean Surface Fluxes................................ 273

3.4.1 Introduction .......................................................... 273

3.4.2 Air-Sea Heat Fluxes ................................................ 274

3.4.3 Ocean Precipitation and Freshwater Flux.................. 275

3.4.4 Wind Stress ............................................................. 276

3.4.5 Changes in Surface Waves ..................................... 277

3.4.6 Conclusions....................................................... 278

3.5 Changes in Water-Mass Properties .............................. 278

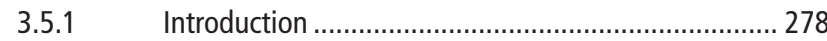

3.5.2 Intermediate Waters............................................... 278

3.5.3 Deep and Bottom Waters ......................................... 279

3.5.4 Conclusions........................................................ 280

3.6 Changes in Ocean Circulation .................................... 281

3.6.1 Global Observations of Ocean Circulation Variability

3.6.2 Wind-Driven Circulation Variability in the Pacific Ocean 281

3.6.3 The Atlantic Meridional Overturning Circulation ....... 282
3.6.4 The Antarctic Meridional Overturning Circulation ..... 284

3.6.5 Water Exchange Between Ocean Basins ................... 284

3.6.6 Conclusions............................................................ 285

3.7 Sea Level Change, Including Extremes ...................... 285

3.7.1 Introduction and Overview of Sea Leve Measurements 285

3.7.2 Trends in Global Mean Sea Leve and Components................................................... 286

3.7.3 Regional Distribution of Sea Level Change ............... 288

3.7.4 Assessment of Evidence for Accelerations in Sea Level Rise ....................................................... 289

3.7.5 Changes in Extreme Sea Level ................................ 290

3.7.6 Conclusions........................................................... 291

3.8 Ocean Biogeochemical Changes, Including Anthropogenic Ocean Acidification ........................... 291

3.8.1 Carbon .................................................................. 292

3.8.2 Anthropogenic Ocean Acidification........................... 293

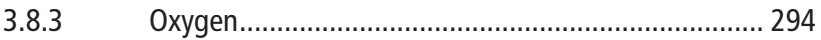

Box 3.2: Ocean Acidification .................................................... 295

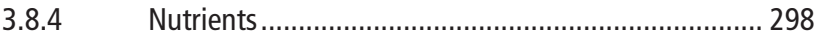

3.8.5 Conclusions...................................................... 300

Synthesis ........................................................ 301

References ……................................................................ 303

Appendix 3.A: Availability of Observations for Assessment of Change in the Oceans. 311

3.A.1 Subsurface Ocean Temperature and Heat Content.... 311

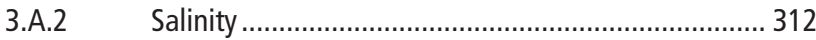

3.A.3 Sea Level.................................................................... 312

3.A.4 Biogeochemistry ................................................... 312

\section{Frequently Asked Questions}

FAQ 3.1 Is the Ocean Warming?........................................... 266

FAQ 3.2 Is There Evidence for Changes in the Earth's Water Cycle? 269

FAQ 3.3 How Does Anthropogenic Ocean Acidification Relate to Climate Change? 297 


\section{Executive Summary}

\section{Temperature and Heat Content Changes}

It is virtually certain ${ }^{1}$ that the upper ocean (above $700 \mathrm{~m}$ ) has warmed from 1971 to 2010, and likely that it has warmed from the 1870 s to 1971 . Confidence in the assessment for the time period since 1971 is high ${ }^{2}$ based on increased data coverage after this date and on a high level of agreement among independent observations of subsurface temperature [3.2], sea surface temperature [2.4.2], and sea level rise, which is known to include a substantial component due to thermal expansion [3.7, Chapter 13]. There is less certainty in changes prior to 1971 because of relatively sparse sampling in earlier time periods. The strongest warming is found near the sea surface $(0.11[0.09$ to 0.13$]^{\circ} \mathrm{C}$ per decade in the upper $75 \mathrm{~m}$ between 1971 and 2010), decreasing to about $0.015^{\circ} \mathrm{C}$ per decade at $700 \mathrm{~m}$. It is very likely that the surface intensification of this warming signal increased the thermal stratification of the upper ocean by about $4 \%$ between 0 and 200 $\mathrm{m}$ depth. Instrumental biases in historical upper ocean temperature measurements have been identified and reduced since AR4, diminishing artificial decadal variation in temperature and upper ocean heat content, most prominent during the 1970s and 1980s. \{3.2.1-3.2.3, Figures $3.1,3.2$ and 3.9$\}$

It is likely that the ocean warmed between 700 and $2000 \mathrm{~m}$ from 1957 to 2009, based on 5-year averages. It is likely that the ocean warmed from $3000 \mathrm{~m}$ to the bottom from 1992 to 2005, while no significant trends in global average temperature were observed between 2000 and $3000 \mathrm{~m}$ depth during this period. Warming below $3000 \mathrm{~m}$ is largest in the Southern Ocean $\{3.2 .4,3.5 .1$, Figures $3.2 \mathrm{~b}$ and 3.3, FAQ 3.1\}

It is virtually certain that upper ocean ( 0 to $700 \mathrm{~m}$ ) heat content increased during the relatively well-sampled 40 -year period from 1971 to 2010. Published rates for that time period range from $74 \mathrm{TW}$ to $137 \mathrm{TW}$, with generally smaller trends for estimates that assume zero anomalies in regions with sparse data. Using a statistical analysis of ocean variability to estimate change in sparsely sampled areas and to estimate uncertainties results in a rate of increase of global upper ocean heat content of 137 [120-154] TW (medium confidence). Although not all trends agree within their statistical uncertainties, all are positive, and all are statistically different from zero. \{3.2.3, Figure 3.2\}

Warming of the ocean between 700 and $2000 \mathrm{~m}$ likely contributed about $30 \%$ of the total increase in global ocean heat content $(0$ to $2000 \mathrm{~m})$ between 1957 and 2009 . Although globally integrated ocean heat content in some of the 0 to $700 \mathrm{~m}$ estimates increased more slowly from 2003 to 2010 than over the previous decade, ocean heat uptake from 700 to $2000 \mathrm{~m}$ likely continued unabated during this period. \{3.2.4, Figure 3.2, Box 9.2\}

Ocean warming dominates the global energy change inventory. Warming of the ocean accounts for about $93 \%$ of the increase in the Earth's energy inventory between 1971 and 2010 (high confidence), with warming of the upper (0 to $700 \mathrm{~m}$ ) ocean accounting for about $64 \%$ of the total. Melting ice (including Arctic sea ice, ice sheets and glaciers) and warming of the continents and atmosphere account for the remainder of the change in energy. The estimated net increase in the Earth's energy storage between 1971 and 2010 is 274 [196 to 351] ZJ ( $\mathrm{ZJ}=10^{21}$ Joules), with a heating rate of 213 TW from a linear fit to annual inventories over that time period, equivalent to $0.42 \mathrm{~W} \mathrm{~m}^{-2}$ heating applied continuously over the Earth's entire surface, and $0.55 \mathrm{~W} \mathrm{~m}^{-2}$ for the portion due to ocean warming applied over the ocean surface area. \{Section 3.2.3, Figure 3.2, Box 3.1\}

\section{Salinity and Freshwater Content Changes}

It is very likely that regional trends have enhanced the mean geographical contrasts in sea surface salinity since the 1950s: saline surface waters in the evaporation-dominated midlatitudes have become more saline, while relatively fresh surface waters in rainfall-dominated tropical and polar regions have become fresher. The mean contrast between high- and lowsalinity regions increased by 0.13 [0.08 to 0.17 ] from 1950 to 2008 . It is very likely that the interbasin contrast in freshwater content has increased: the Atlantic has become saltier and the Pacific and Southern oceans have freshened. Although similar conclusions were reached in AR4, recent studies based on expanded data sets and new analysis approaches provide high confidence in the assessment of trends in ocean salinity. \{3.3.2, 3.3.3, 3.3.5, Figures 3.4, 3.5 and 3.21d, FAQ 3.2\}

It is very likely that large-scale trends in salinity have also occurred in the ocean interior. It is likely that both the subduction of surface water anomalies formed by changes in evaporation - precipitation $(E-P)$ and the movement of density surfaces due to warming have contributed to the observed changes in subsurface salinity. \{3.3.2-3.3.4, Figures 3.5 and 3.9\}

The spatial patterns of the salinity trends, mean salinity and the mean distribution of $\mathrm{E}-\mathrm{P}$ are all similar. This provides, with medium confidence, indirect evidence that the pattern of $\mathrm{E}-\mathrm{P}$ over the oceans has been enhanced since the 1950s. \{3.3.2-3.3.4, Figures 3.4, 3.5 and $3.20 \mathrm{~d}$, FAQ 3.2$\}$.

1 In this Report, the following terms have been used to indicate the assessed likelihood of an outcome or a result: Virtually certain 99-100\% probability, Very likely 90-100\%, Likely $66-100 \%$, About as likely as not 33-66\%, Unlikely 0-33\%, Very unlikely 0-10\%, Exceptionally unlikely 0-1\%. Additional terms (Extremely likely: 95-100\%, More likely than not $>50-100 \%$, and Extremely unlikely 0-5\%) may also be used when appropriate. Assessed likelihood is typeset in italics, e.g., very likely (see Section 1.4 and Box TS.1 for more details).

2 In this Report, the following summary terms are used to describe the available evidence: limited, medium, or robust; and for the degree of agreement: low, medium, or high. A level of confidence is expressed using five qualifiers: very low, low, medium, high, and very high, and typeset in italics, e.g., medium confidence. For a given evidence and agreement statement, different confidence levels can be assigned, but increasing levels of evidence and degrees of agreement are correlated with increasing confidence (see Section 1.4 and Box TS.1 for more details). 


\section{Air-Sea Flux and Wave Height Changes}

Uncertainties in air-sea heat flux data sets are too large to allow detection of the change in global mean net air-sea heat flux, of the order of $0.5 \mathrm{~W} \mathrm{~m}^{-2}$ since 1971, required for consistency with the observed ocean heat content increase. The products cannot yet be reliably used to directly identify trends in the regional or global distribution of evaporation or precipitation over the oceans on the time scale of the observed salinity changes since 1950. \{3.4.2, 3.4.3, Figures 3.6 and 3.7$\}$

Basin-scale wind stress trends at decadal to centennial time scales have been observed in the North Atlantic, Tropical Pacific and Southern Ocean with low to medium confidence. These results are based largely on atmospheric reanalyses, in some cases a single product, and the confidence level is dependent on region and time scale considered. The evidence is strongest for the Southern Ocean, for which there is medium confidence that zonal mean wind stress has increased in strength since the early 1980s. \{3.4.4, Figure $3.8\}$

There is medium confidence based on ship observations and reanalysis forced wave model hindcasts that mean significant wave height has increased since the 1950s over much of the North Atlantic north of $45^{\circ} \mathrm{N}$, with typical winter season trends of up to $20 \mathrm{~cm}$ per decade. $\{3.4 .5\}$

\section{Changes in Water Masses and Circulation}

Observed changes in water mass properties likely reflect the combined effect of long-term trends in surface forcing (e.g., warming of the surface ocean and changes in $\mathrm{E}-\mathrm{P}$ ) and interannual-to-multi-decadal variability related to climate modes. Most of the observed temperature and salinity changes in the ocean interior can be explained by subduction and spreading of water masses with properties that have been modified at the sea surface. From 1950 to 2000 , it is likely that subtropical salinity maximum waters became more saline, while fresh intermediate waters formed at higher latitude have generally become fresher. For Upper North Atlantic Deep Water changes in properties and formation rates are very likely dominated by decadal variability. The Lower North Atlantic Deep Water has likely cooled from 1955 to 2005, and the freshening trend highlighted in AR4 reversed in the mid-1990s. It is likely that the Antarctic Bottom Water warmed and contracted globally since the 1980s and freshened in the Indian/Pacific sectors from 1970 to 2008. \{3.5, FAQ 3.1\}

Recent observations have strengthened evidence for variability in major ocean circulation systems on time scales from years to decades. It is very likely that the subtropical gyres in the North Pacific and South Pacific have expanded and strengthened since 1993. It is about as likely as not that this is linked to decadal variability in wind forcing rather than being part of a longer-term trend. Based on measurements of the full Atlantic Meridional Overturning Circulation and its individual components at various latitudes and different time periods, there is no evidence of a long-term trend. There is also no evidence for trends in the transports of the Indonesian Throughflow, the Antarctic
Circumpolar Current (ACC), or between the Atlantic Ocean and Nordic Seas. However, there is medium confidence that the ACC shifted south between 1950 and 2010 , at a rate equivalent to about $1^{\circ}$ of latitude in 40 years. \{3.6, Figures $3.10,3.11\}$

\section{Sea Level Change}

Global mean sea level (GMSL) has risen by 0.19 [0.17 to 0.21$] \mathrm{m}$ over the period 1901-2010, calculated using the mean rate over these 110 years, based on tide gauge records and since 1993 additionally on satellite data. It is very likely that the mean rate was 1.7 [1.5 to 1.9] mm yr-1 between 1901 and 2010 and increased to 3.2 [2.8 to 3.6] mm yr-1 between 1993 and 2010 . This assessment is based on high agreement among multiple studies using different methods, long tide gauge records corrected for vertical land motion and independent observing systems (tide gauges and altimetry) since 1993 (see also TFE.2, Figure 1). It is likely that GMSL rose between 1920 and 1950 at a rate comparable to that observed between 1993 and 2010, as individual tide gauges around the world and reconstructions of GMSL show increased rates of sea level rise during this period. Rates of sea level rise over broad regions can be several times larger or smaller than that of GMSL for periods of several decades due to fluctuations in ocean circulation. High agreement between studies with and without corrections for vertical land motion suggests that it is very unlikely that estimates of the global average rate of sea level change are significantly biased owing to vertical land motion that has been unaccounted for. $\{3.7 .2,3.7 .3$, Table 3.1, Figures $3.12,3.13,3.14\}$

It is very likely that warming of the upper $700 \mathrm{~m}$ has been contributing an average of 0.6 [0.4 to 0.8$] \mathrm{mm} \mathrm{yr}^{-1}$ of sea level rise since 1971. It is likely that warming between $700 \mathrm{~m}$ and $2000 \mathrm{~m}$ has been contributing an additional $0.1 \mathrm{~mm} \mathrm{yr}^{-1}$ [0 to 0.2$]$ of sea level rise since 1971, and that warming below $2000 \mathrm{~m}$ has been contributing another 0.1 [0.0 to 0.2$] \mathrm{mm} \mathrm{yr}^{-1}$ of sea level rise since the early $1990 \mathrm{~s}$. $\{3.7 .2$, Figure 3.13$\}$

It is likely that the rate of sea level rise increased from the early 19th century to the early 20th century, and increased further over the 20th century. The inference of 19th century change is based on a small number of very long tide gauge records from northern Europe and North America. Multiple long tide gauge records and reconstructions of global mean sea level confirm a higher rate of rise from the late 19th century. It is likely that the average acceleration over the 20th century is [-0.002 to 0.019$] \mathrm{mm} \mathrm{yr}^{-2}$, as two of three reconstructions extending back to at least 1900 show an acceleration during the 20th century. $\{3.7 .4\}$

It is likely that the magnitude of extreme high sea level events has increased since 1970. A rise in mean sea level can explain most of the increase in extreme sea levels: changes in extreme high sea levels are reduced to less than $5 \mathrm{~mm} \mathrm{yr} r^{-1}$ at $94 \%$ of tide gauges once the rise in mean sea level is accounted for. $\{3.7 .5$, Figure 3.15$\}$ 


\section{Changes in Ocean Biogeochemistry}

Based on high agreement between independent estimates using different methods and data sets (e.g., oceanic carbon, oxygen, and transient tracer data), it is very likely that the global ocean inventory of anthropogenic carbon $\left(C_{\text {ant }}\right)$ increased from 1994 to 2010. The oceanic $C_{\text {ant }}$ inventory in 2010 is estimated to be 155 $\mathrm{PgC}$ with an uncertainty of $\pm 20 \%$. The annual global oceanic uptake rates calculated from independent data sets (from oceanic $C_{\text {ant }}$ inventory changes, from atmospheric $\mathrm{O}_{2} / \mathrm{N}_{2}$ measurements or from partial pressure of carbon dioxide $\left(\mathrm{pCO}_{2}\right)$ data) and for different time periods agree with each other within their uncertainties and very likely are in the range of 1.0 to $3.2 \mathrm{PgC} r^{-1}\{3.8 .1$, Figure 3.16$\}$

Uptake of anthropogenic $\mathrm{CO}_{2}$ results in gradual acidification of the ocean. The $\mathrm{pH}$ of surface seawater has decreased by 0.1 since the beginning of the industrial era, corresponding to a $26 \%$ increase in hydrogen ion concentration (high confidence). The observed $\mathrm{pH}$ trends range between -0.0014 and $-0.0024 \mathrm{yr}^{-1}$ in surface waters. In the ocean interior, natural physical and biological processes, as well as uptake of anthropogenic $\mathrm{CO}_{2}$, can cause changes in pH over decadal and longer time scales. \{3.8.2, Table 3.2, Box 3.2, Figures 3.18, 3.19, FAQ 3.3\}

High agreement among analyses provides medium confidence that oxygen concentrations have decreased in the open ocean thermocline in many ocean regions since the 1960s. The general decline is consistent with the expectation that warming-induced stratification leads to a decrease in the supply of oxygen to the thermocline from near surface waters, that warmer waters can hold less oxygen, and that changes in wind-driven circulation affect oxygen concentrations. It is likely that the tropical oxygen minimum zones have expanded in recent decades. $\{3.8 .3$, Figure 3.20$\}$

\section{Synthesis}

The observations summarized in this chapter provide strong evidence that ocean properties of relevance to climate have changed during the past 40 years, including temperature, salinity, sea level, carbon, pH, and oxygen. The observed patterns of change in the subsurface ocean are consistent with changes in the surface ocean in response to climate change and natural variability and with known physical and biogeochemical processes in the ocean, providing high confidence in this assessment. $\{3.9$, Figures $3.21,3.22\}$ 


\subsection{Introduction}

The ocean influences climate by storing and transporting large amounts of heat, freshwater, and carbon, and by exchanging these properties with the atmosphere. About $93 \%$ of the excess heat energy stored by the Earth over the last 50 years is found in the ocean (Church et al., 2011; Levitus et al., 2012). The ability of the ocean to store vast amounts of heat reflects the large mass and heat capacity of seawater relative to air and the fact that ocean circulation connects the surface and interior ocean. More than three quarters of the total exchange of water between the atmosphere and the Earth's surface through evaporation and precipitation takes place over the oceans (Schmitt, 2008). The ocean contains 50 times more carbon than the atmosphere (Sabine et al., 2004) and is at present acting to slow the rate of climate change by absorbing about $30 \%$ of human emissions of carbon dioxide $\left(\mathrm{CO}_{2}\right)$ from fossil fuel burning, cement production, deforestation and other land use change (Mikaloff-Fletcher et al., 2006; Le Quéré et al., 2010). Changes in the ocean may result in climate feedbacks that either increase or reduce the rate of climate change. Climate variability and change on time scales from seasons to millennia is therefore closely linked to the ocean and its interactions with the atmosphere and cryosphere. The large inertia of the oceans means that they naturally integrate over short-term variability and often provide a clearer signal of longer-term change than other components of the climate system. Observations of ocean change therefore provide a means to track the evolution of climate change, and a relevant benchmark for climate models.

The lack of long-term measurements of the global ocean and changes in the observing system over time makes documenting and understanding change in the oceans a difficult challenge (Appendix 3.A). Many of the issues raised in Box 2.1 regarding uncertainty in atmospheric climate records are common to oceanographic data. Despite the limitations of historical records, AR4 identified significant trends in a number of ocean variables relevant to climate change, including ocean heat content, sea level, regional patterns of salinity, and biogeochemical parameters (Bindoff et al., 2007). Since AR4, substantial progress has been made in improving the quality and coverage of ocean observations. Biases in historical measurements have been identified and reduced, providing a clearer record of past change. The Argo array of profiling floats has provided near-global, year-round measurements of temperature and salinity in the upper $2000 \mathrm{~m}$ since 2005. The satellite altimetry record is now more than 20 years in length. Longer continuous time series of important components of the meridional overturning circulation and tropical oceans have been obtained. The spatial and temporal coverage of biogeochemical measurements in the ocean has expanded. As a result of these advances, there is now stronger evidence of change in the ocean, and our understanding of the causes of ocean change is improved.

This chapter summarizes the observational evidence of change in the ocean, with an emphasis on basin- and global-scale changes relevant to climate, with a focus on studies published since the AR4. As in Chapter 2 , the robustness of observed changes is assessed relative to sources of observational uncertainty. The attribution of ocean change, including the degree to which observed changes are consistent with anthropogenic climate change, is addressed in Chapter 10. The evidence for changes in subsurface ocean temperature and heat content is assessed in Section 3.2; changes in sea surface temperature (SST) are covered in Chapter 2. Changes in ocean heat content dominate changes in the global energy inventory (Box 3.1). Recent studies have strengthened the evidence for regional changes in ocean salinity and their link to changes in evaporation and precipitation over the oceans (Section 3.3), a connection already identified in AR4. Evidence for changes in the fluxes of heat, water and momentum (wind stress) across the air-sea interface is assessed in Section 3.4. Considering ocean changes from a water-mass perspective adds additional insight into the nature and causes of ocean change (Section 3.5). Although direct observations of ocean circulation are more limited than those of temperature and salinity, there is growing evidence of variability and change of ocean current patterns relevant to climate (Section 3.6). Observations of sea level change are summarized in Section 3.7; Chapter 13 builds on the evidence presented in this and other chapters to provide an overall synthesis of past and future sea level change. Biogeochemical changes in the ocean, including ocean acidification, are covered in Section 3.8. Chapter 6 combines observations with models to discuss past and present changes in the carbon cycle. Section 3.9 provides an overall synthesis of changes observed in the ocean during the instrumental period and highlights key uncertainties. Unless otherwise noted, uncertainties (in square brackets) represent 5 to $95 \%$ confidence intervals.

\subsection{Changes in Ocean Temperature and Heat Content}

\subsubsection{Effects of Sampling on Ocean Heat Content Estimates}

Temperature is the most often measured subsurface ocean variable. Historically, a variety of instruments have been used to measure temperature, with differing accuracies, precisions, and sampling depths. Both the mix of instruments and the overall sampling patterns have changed in time and space (Boyer et al., 2009), complicating efforts to determine and interpret long-term change. The evolution of the observing system for ocean temperature is summarized in Appendix 3.A. Upper ocean temperature (hence heat content) varies over multiple time scales including seasonal (e.g., Roemmich and Gilson, 2009), interannual (e.g. associated with El Niño, which has a strong influence on ocean heat uptake, Roemmich and Gilson, 2011), decadal (e.g., Carson and Harrison, 2010), and centennial (Gouretski et al., 2012; Roemmich et al., 2012). Ocean data assimilation products using these data exhibit similar significant variations (e.g., Xue et al., 2012). Sparse historical sampling coupled with large amplitude variations on shorter time and spatial scales raise challenges for estimating globally averaged upper ocean temperature changes. Uncertainty analyses indicate that the historical data set begins to be reasonably well suited for this purpose starting around 1970 (e.g., Domingues et al., 2008; Lyman and Johnson, 2008; Palmer and Brohan, 2011). UOHC uncertainty estimates shrink after 1970 with improved sampling, so this assessment focuses on changes since 1971. Estimates of UOHC have been extended back to 1950 by averaging over longer time intervals, such as 5 -year running means, to compensate for sparse data distributions in earlier time periods (e.g., Levitus et al., 2012). These estimates may be most appropriate in the deeper ocean, where strong interannual variability in upper ocean temperature distributions such as that associated with El Niño (Roemmich and Gilson, 2011) is less likely to be aliased. 
Since AR4 the significant impact of measurement biases in some of the widely used instruments (the expendable (XBT) and mechanical bathythermograph (MBT) as well as a subset of Argo floats) on estimates of ocean temperature and upper ( 0 to $700 \mathrm{~m}$ ) ocean heat content (hereafter $\mathrm{UOHC}$ ) changes has been recognized (Gouretski and Koltermann, 2007; Barker et al., 2011). Careful comparison of measurements from the less accurate instruments with those from the more accurate ones has allowed some of the biases to be identified and reduced (Wijffels et al., 2008; Ishii and Kimoto, 2009; Levitus et al., 2009; Gouretski and Reseghetti, 2010; Hamon et al., 2012). One major consequence of this bias reduction has been the reduction of an artificial decadal variation in upper ocean heat content that was apparent in the observational assessment for AR4, in notable contrast to climate model output (Domingues et al., 2008). Substantial time-dependent XBT and MBT biases introduced spurious warming in the 1970s and cooling in the early 1980s in the analyses assessed in AR4. Most ocean state estimates that assimilate biased data (Carton and Santorelli, 2008) also showed this artificial decadal variability while one (Stammer et al., 2010) apparently rejected these data on dynamical grounds. More recent estimates assimilating better-corrected data sets (Giese et al., 2011) also result in reduced artificial decadal variability during this time period.

Recent estimates of upper ocean temperature change also differ in their treatment of unsampled regions. Some studies (e.g., Ishii and Kimoto, 2009; Levitus et al., 2012) effectively assume a temperature anomaly of zero in these regions, while other studies (Palmer et al., 2007; Lyman and Johnson, 2008) assume that the averages of sampled regions are representative of the global mean in any given year, and yet others (Smith and Murphy, 2007; Domingues et al., 2008) use ocean statistics (from numerical model output and satellite altimeter data, respectively) to extrapolate temperature anomalies in sparsely sampled areas and estimate uncertainties. These differences in approach, coupled with choice of background climatology, can lead to significant divergence in basin-scale averages (Gleckler et al., 2012), especially in sparsely sampled regions (e.g., the extratropical Southern Hemisphere (SH) prior to Argo), and as a result can produce different global averages (Lyman et al., 2010). However, for well-sampled regions and times, the various analyses of temperature changes yield results in closer agreement, as do reanalyses (Xue et al., 2012).

\subsubsection{Upper Ocean Temperature}

Depth-averaged 0 to $700 \mathrm{~m}$ ocean temperature trends from 1971 to 2010 are positive over most of the globe (Levitus et al., 2009; Figure 3.1a). The warming is more prominent in the Northern Hemisphere (NH), especially the North Atlantic. This result holds in different analyses, using different time periods, bias corrections and data sources (e.g., with or without XBT or MBT data) (e.g., Palmer et al., 2007; Durack and Wijffels, 2010; Gleckler et al., 2012; Figures 3.1 and 3.9). However, the greater volume of the $\mathrm{SH}$ oceans increases the contribution of their warming to global heat content. Zonally averaged upper ocean temperature trends show warming at nearly all latitudes and depths (Levitus et al., 2009, Figure 3.1b). A maximum in warming south of $30^{\circ} \mathrm{S}$ appears in Figure $3.1 \mathrm{~b}$, but is not as strong as in other analyses (e.g., Gille, 2008), likely because the data are relatively sparse in this location so anomalies are attenuated by the objectively analyzed fields used for Figure 3.1 and because warming in the upper $1000 \mathrm{~m}$ of the Southern Ocean was stronger between the 1930s and the 1970s than between the 1970s and 1990s (Gille, 2008). Another warming maximum is present at $25^{\circ} \mathrm{N}$ to $65^{\circ} \mathrm{N}$. Both warming signals extend to 700 $\mathrm{m}$ (Levitus et al., 2009, Figure 3.1b), and are consistent with poleward displacement of the mean temperature field. Other zonally averaged temperature changes are also consistent with poleward displacement of the mean temperatures. For example, cooling at depth between $30^{\circ} \mathrm{S}$ and the equator (Figure $3.1 \mathrm{~b}$ ) is consistent with a southward shift of cooler water near the equator. Poleward displacements of some subtropical and subpolar zonal currents and associated wind changes are discussed in Section 3.6.

Globally averaged ocean temperature anomalies as a function of depth and time (Figure 3.1c) relative to a 1971-2010 mean reveal warming at all depths in the upper $700 \mathrm{~m}$ over the relatively well-sampled 40 -year period considered. Strongest warming is found closest to the
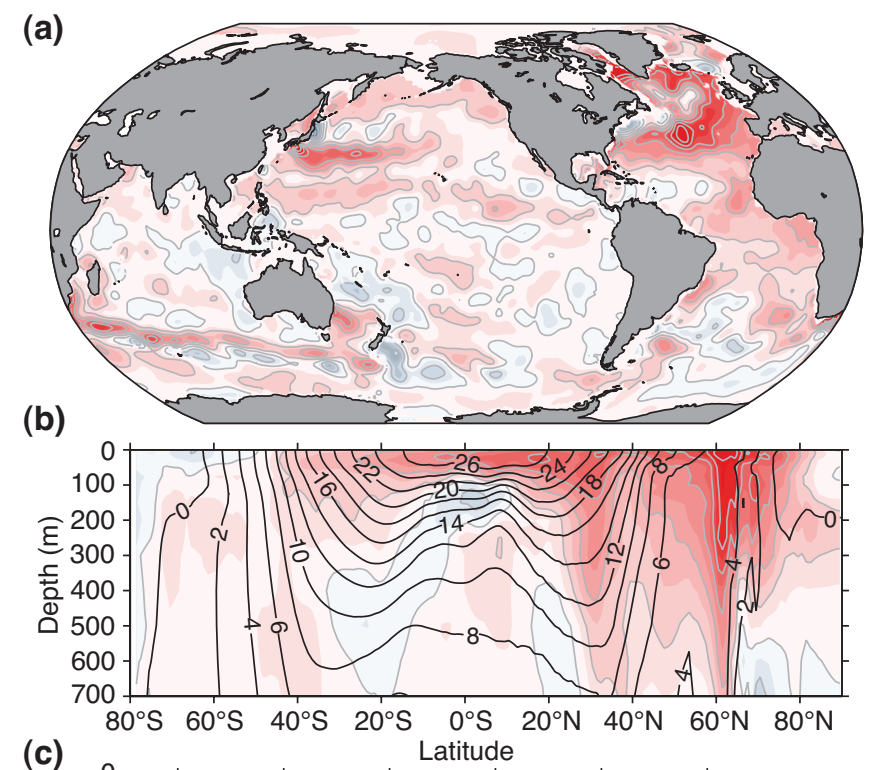

(c)
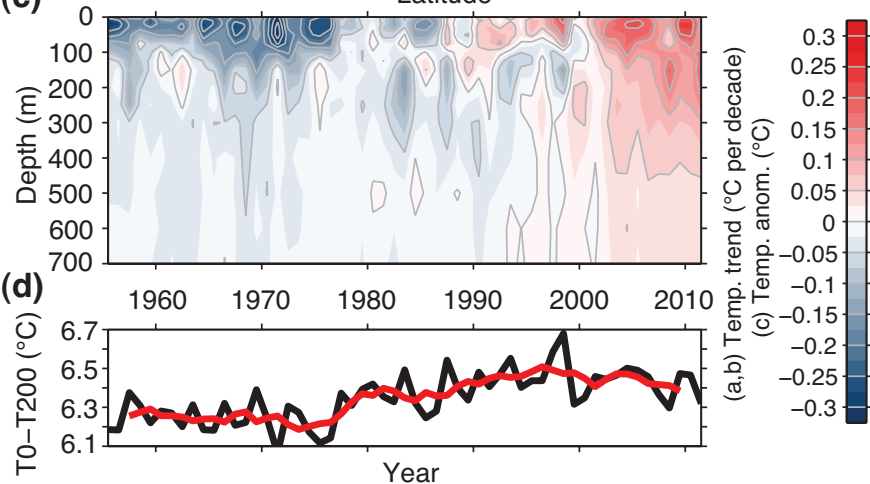

Figure 3.1 | (a) Depth-averaged 0 to $700 \mathrm{~m}$ temperature trend for 1971-2010 (longitude vs. latitude, colours and grey contours in degrees Celsius per decade). (b) Zonally averaged temperature trends (latitude vs. depth, colours and grey contours in degrees (elsius per decade) for 1971-2010 with zonally averaged mean temperature over-plotted (black contours in degrees Celsius). (c) Globally averaged temperature anomaly (time vs. depth, colours and grey contours in degrees Celsius) relative to the 1971-2010 mean. (d) Globally averaged temperature difference between the ocean surface and $200 \mathrm{~m}$ depth (black: annual values, red: 5-year running mean). All panels are constructed from an update of the annual analysis of Levitus et al. (2009). 
sea surface, and the near-surface trends are consistent with independently measured SST (Chapter 2). The global average warming over this period is 0.11 [ 0.09 to 0.13 ] ${ }^{\circ} \mathrm{C}$ per decade in the upper $75 \mathrm{~m}$, decreasing to $0.015^{\circ} \mathrm{C}$ per decade by $700 \mathrm{~m}$ (Figure 3.1c). Comparison of Argo data to Challenger expedition data from the 1870s suggests that warming started earlier than 1971, and was also larger in the Atlantic than in the Pacific over that longer time interval (Roemmich et al., 2012). An observational analysis of temperature in the upper 400 $\mathrm{m}$ of the global ocean starting in the year 1900 (Gouretski et al., 2012) finds warming between about 1900 and 1945, as well as after 1970, with some evidence of slight cooling between 1945 and 1970.

The globally averaged temperature difference between the ocean surface and $200 \mathrm{~m}$ (Figure 3.1d) increased by about $0.25^{\circ} \mathrm{C}$ from 1971 to 2010 (Levitus et al., 2009). This change, which corresponds to a $4 \%$ increase in density stratification, is widespread in all the oceans north of about $40^{\circ} \mathrm{S}$.

A potentially important impact of ocean warming is the effect on sea ice, floating glacial ice and ice sheet dynamics (see Chapter 4 for a discussion of these topics). Although some of the global integrals of UOHC neglect changes poleward of $\pm 60^{\circ}$ (Ishii and Kimoto, 2009) or $\pm 65^{\circ}$ (Domingues et al., 2008) latitude, at least some parts of the Arctic have warmed: In the Arctic Ocean, subsurface pulses of relatively warm water of Atlantic origin can be traced around the Eurasian Basin, and analyses of data from 1950-2010 show a decadal warming of this water mass since the late 1970s (Polyakov et al., 2012), as well as a shoaling, by 75 to $90 \mathrm{~m}$ (Polyakov et al., 2010). Arctic surface waters have also warmed, at least in the Canada Basin, from 1993 to 2007 (Jackson et al., 2010).

\subsubsection{Upper Ocean Heat Content}

Global integrals of 0 to $700 \mathrm{~m} \mathrm{UOHC} \mathrm{(Figure} \mathrm{3.2a)} \mathrm{estimated} \mathrm{from} \mathrm{ocean}$ temperature measurements all show a gain from 1971 to 2010 (Palmer et al., 2007; Smith and Murphy, 2007; e.g., Domingues et al., 2008; Ishii and Kimoto, 2009; Levitus et al., 2012) . These estimates usually start around 1950, although as noted in Section 3.2.1 and discussed in the Appendix, historical data coverage is sparse, so global integrals are increasingly uncertain for earlier years, especially prior to 1970. There is some convergence towards agreement in instrument bias correction algorithms since AR4 (Section 3.2.1), but other sources of uncertainty include the different assumptions regarding mapping and integrating UOHCs in sparsely sampled regions, differences in quality control of temperature data, and differences among baseline climatologies used for estimating changes in heat content (Lyman et al., 2010). Although there are still apparent interannual variations about the upward trend of global UOHC since 1970, different global estimates have variations at different times and for different periods, suggesting that sub-decadal variability in the time rate of change is still quite uncertain in the historical record. Most of the estimates in Figure 3.2a do exhibit decreases for a few years immediately following major volcanic eruptions in 1963, 1982 and 1991 (Domingues et al., 2008).

Again, all of the global integrals of UOHC in Figure 3.2a have increased between 1971 and 2010. Linear trends fit to the UOHC estimates for the relatively well-sampled 40-year period from 1971 to 2010 estimate
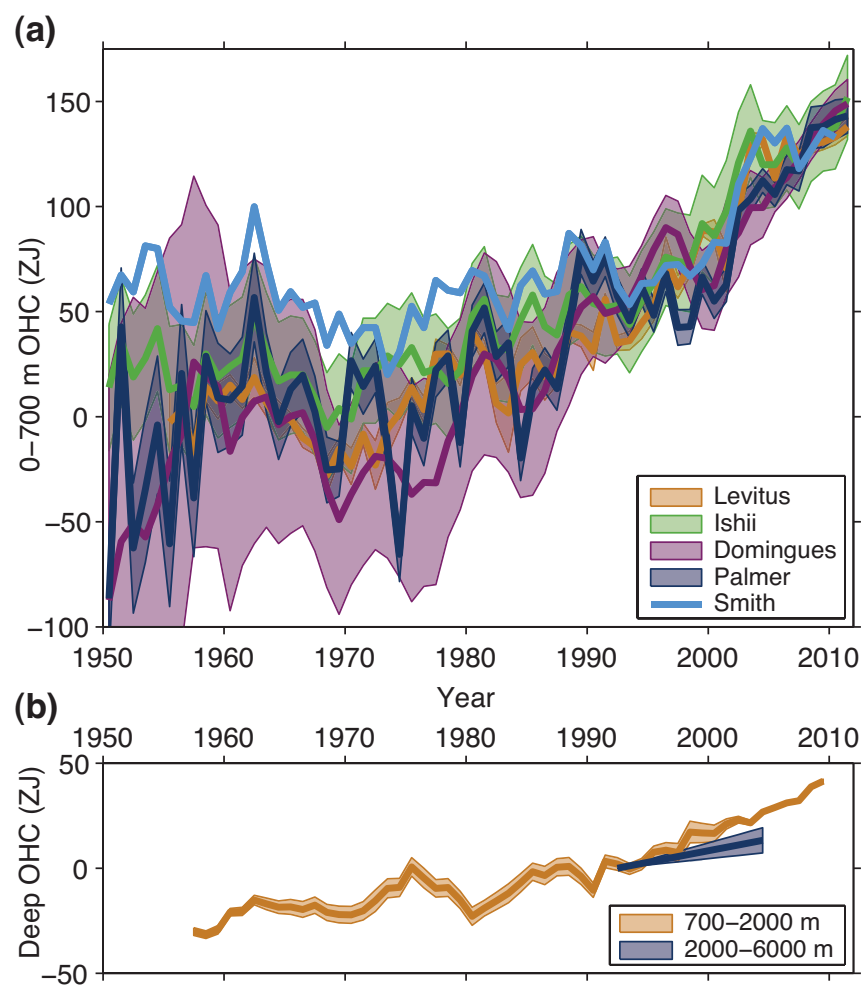

Figure 3.2: | (a) Observation-based estimates of annual global mean upper (0 to 700 $\mathrm{m}$ ) ocean heat content in ZJ ( $1 \mathrm{ZJ}=10^{21}$ Joules) updated from (see legend): Levitus et al. (2012), Ishii and Kimoto (2009), Domingues et al. (2008), Palmer et al. (2007) and Smith and Murphy (2007). Uncertainties are shaded and plotted as published (at the one standard error level, except one standard deviation for Levitus, with no uncertainties provided for Smith). Estimates are shifted to align for 2006-2010, 5 years that are well measured by Argo, and then plotted relative to the resulting mean of all curves for 1971, the starting year for trend calculations. (b) Observation-based estimates of annual 5-year running mean global mean mid-depth (700 to $2000 \mathrm{~m}$ ) ocean heat content in ZJ (Levitus et al., 2012) and the deep (2000 to $6000 \mathrm{~m}$ ) global ocean heat content trend from 1992 to 2005 (Purkey and Johnson, 2010), both with one standard error uncertainties shaded (see legend).

the heating rate required to account for this warming: 118 [82 to 154] TW (1 TW $=10^{12}$ watts) for Levitus et al. (2012), 98 [67 to 130] TW for Ishii and Kimoto (2009), 137 [120 to 154] TW for Domingues et al. (2008), 108 [80 to 136] TW for Palmer et al. (2007), and 74 [43 to 105] TW for Smith and Murphy (2007). Uncertainties are calculated as $90 \%$ confidence intervals for an ordinary least squares fit, taking into account the reduction in the degrees of freedom implied by the temporal correlation of the residuals. Although these rates of energy gain do not all agree within their statistical uncertainties, all are positive, and all are statistically different from zero. Generally the smaller trends are for estimates that assume zero anomalies in areas of sparse data, as expected for that choice, which will tend to reduce trends and variability. Hence the assessment of the Earth's energy uptake (Box 3.1) employs a global UOHC estimate (Domingues et al., 2008) chosen because it fills in sparsely sampled areas and estimates uncertainties using a statistical analysis of ocean variability patterns.

Globally integrated ocean heat content in three of the five 0 to $700 \mathrm{~m}$ estimates appear to be increasing more slowly from 2003 to 2010 than over the previous decade (Figure 3.2a). Although this apparent change 
is concurrent with a slowing of the increase global mean surface temperature, as discussed in Box 9.2, this is also a time period when the ocean observing system transitioned from predominantly XBT to predominantly Argo temperature measurements (Johnson and Wijffels, 2011). Shifts in observing systems can sometimes introduce spurious signals, so this apparent recent change should be viewed with caution.

\subsubsection{Deep Ocean Temperature and Heat Content}

Below $700 \mathrm{~m}$ data coverage is too sparse to produce annual global ocean heat content estimates prior to about 2005, but from 2005 to 2010 and 0 to $1500 \mathrm{~m}$ the global ocean warmed (von Schuckmann and Le Traon, 2011). Five-year running mean estimates yield a 700 to 2000 m global ocean heat content trend from 1957 to 2009 (Figure 3.2b) that is about $30 \%$ of that for 0 to 2000 m over the length of the record (Levitus et al., 2012). Ocean heat uptake from 700 to $2000 \mathrm{~m}$ likely continues unabated since 2003 (Figure 3.2b); as a result, ocean heat content from 0 to $2000 \mathrm{~m}$ shows less slowing after 2003 than does 0 to $700 \mathrm{~m}$ heat content (Levitus et al., 2012).

Global sampling of the ocean below $2000 \mathrm{~m}$ is limited to a number of repeat oceanographic transects, many occupied only in the last few decades (Figure 3.3b), and several time-series stations, some of which extend over decades. This sparse sampling in space and time makes assessment of global deep ocean heat content variability less certain than that for the upper ocean (Ponte, 2012), especially at middepths, where vertical gradients are still sufficiently large for transient variations (ocean eddies, internal waves, and internal tides) to alias estimates made from sparse data sets. However, the deep North Atlantic Ocean is better sampled than the rest of the globe, making estimates of full-depth deep ocean heat content changes there feasible north of $20^{\circ} \mathrm{N}$ since the mid-1950s (Mauritzen et al., 2012).

Based on the limited information available, it is likely that the global ocean did not show a significant temperature trend between 2000 and $3000 \mathrm{~m}$ depth from about 1992-2005 (Figures 3.2b and 3.3a; Kouketsu et al., 2011). At these depths it has been around a millennium on average since waters in the Indian and Pacific Oceans were last exposed to air-sea interaction (Gebbie and Huybers, 2012).

Warming from 1992 to 2005 is likely greater than zero from $3000 \mathrm{~m}$ to the ocean floor (Figures 3.2b and 3.3a; Kouketsu et al., 2011), especially in recently formed Antarctic Bottom Water (AABW). South of the Sub-Antarctic Front (Figure 3.3b), much of the water column warmed between 1992 and 2005 (Purkey and Johnson, 2010). Globally, deep warming rates are highest near $4500 \mathrm{~m}$ (Figure 3.3a), usually near the sea floor where the AABW influence is strongest, and attenuate towards the north (Figure 3.3b), where the AABW influence weakens. Global scale abyssal warming on relatively short multi-decadal time scales is possible because of communication of signals by planetary waves originating within the Southern Ocean, reaching even such remote regions as the North Pacific (Kawano et al., 2010; Masuda et al., 2010). This AABW warming may partly reflect a recovery from cool conditions induced by the 1970s Weddell Sea Polynya (Robertson et al., 2002), but further north, in the Vema Channel of the South Atlantic, observations since 1970 suggest strong bottom water warming did not commence there until about 1991 (Zenk and Morozov, 2007). (a)

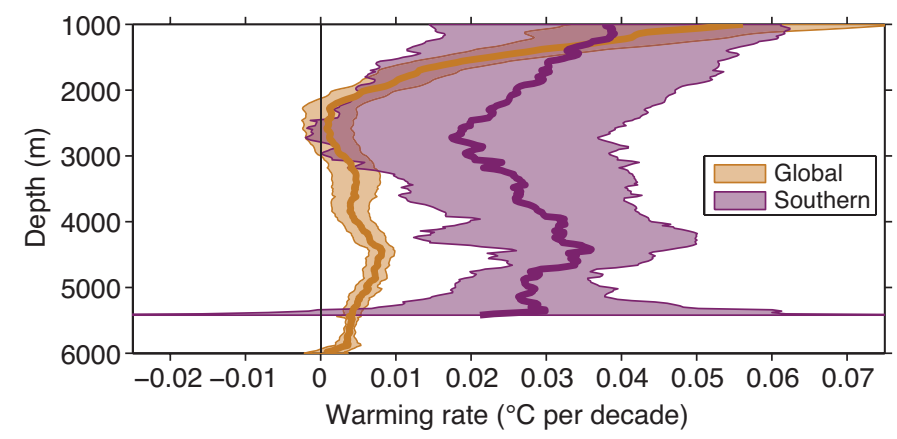

(b)

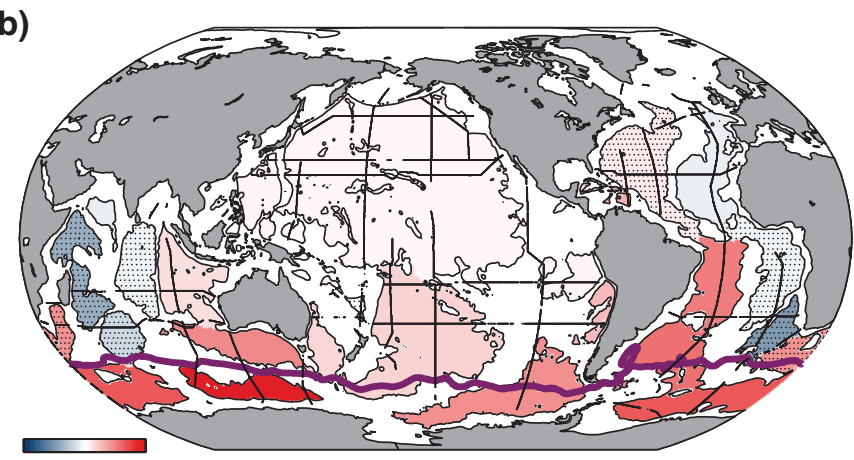

$-0.0500 .05$

$\left({ }^{\circ} \mathrm{C}\right.$ per decade)

Figure 3.3 | (a) Areal mean warming rates $\left({ }^{\circ} \mathrm{C}\right.$ per decade) versus depth (thick lines) with 5 to $95 \%$ confidence limits (shading), both global (orange) and south of the Sub-Antarctic Front (purple), centred on 1992-2005. (b) Mean warming rates $\left({ }^{\circ} \mathrm{C}\right.$ per decade) below $4000 \mathrm{~m}$ (colour bar) estimated for deep ocean basins (thin black outlines), centred on 1992-2005. Stippled basin warming rates are not significantly different from zero at $95 \%$ confidence. The positions of the Sub-Antarctic Front (purple line) and the repeat oceanographic transects from which these warming rates are estimated (thick black lines) also shown. (Data from Purkey and Johnson, 2010.)

In the North Atlantic, strong decadal variability in North Atlantic Deep Water (NADW) temperature and salinity (Wang et al., 2010), largely associated with the North Atlantic Oscillation (NAO, Box 2.5) (e.g., Yashayaev, 2007; Sarafanov et al., 2008), complicates efforts to determine long-term trends from the historical record. Heat content in the North Atlantic north of $20^{\circ} \mathrm{N}$ from $2000 \mathrm{~m}$ to the ocean floor increased slightly from 1955 to 1975 , and then decreased more strongly from 1975 to 2005 (Mauritzen et al., 2012), with a net cooling trend of -4 TW from 1955-2005 estimated from a linear fit. The global trend estimate below $2000 \mathrm{~m}$ is +35 TW from 1992 to 2005 (Purkey and Johnson, 2010), with strong warming in the Southern Ocean.

\subsubsection{Conclusions}

It is virtually certain that the upper ocean $(0$ to $700 \mathrm{~m}$ ) warmed from 1971 to 2010 . This result is supported by three independent and consistent methods of observation including (1) multiple analyses of subsurface temperature measurements described here; (2) SST data (Section 2.4.2) from satellites and in situ measurements from surface drifters and ships; and (3) the record of sea level rise, which is known to include a substantial component owing to thermosteric expansion (Section 3.7 and Chapter 13). The warming rate is $0.11[0.09 \text { to } 0.13]^{\circ} \mathrm{C}$ per decade in the upper $75 \mathrm{~m}$, decreasing to about $0.015^{\circ} \mathrm{C}$ per decade by $700 \mathrm{~m}$. It is very likely that surface intensification of the warming 


\section{Box 3.1 | Change in Global Energy Inventory}

The Earth has been in radiative imbalance, with less energy exiting the top of the atmosphere than entering, since at least about 1970 (Murphy et al., 2009; Church et al., 2011; Levitus et al., 2012). Quantifying this energy gain is essential for understanding the response of the climate system to radiative forcing. Small amounts of this excess energy warm the atmosphere and continents, evaporate water and melt ice, but the bulk of it warms the ocean (Box 3.1, Figure 1). The ocean dominates the change in energy because of its large mass and high heat capacity compared to the atmosphere. In addition, the ocean has a very low albedo and absorbs solar radiation much more readily than ice.

The global atmospheric energy change inventory accounting for specific heating and water evaporation is estimated by combining satellite estimates for temperature anomalies in the lower troposphere (Mears and Wentz, 2009a; updated to version 3.3) from 70 ${ }^{\circ} \mathrm{S}$ to $82.5^{\circ} \mathrm{N}$ and the lower stratosphere (Mears and Wentz, 2009b; updated to version 3.3) from $82.5^{\circ} \mathrm{S}$ to $82.5^{\circ} \mathrm{N}$ weighted by the ratio of the portions of atmospheric mass they sample ( 0.87 and 0.13 , respectively). These temperature anomalies are converted to energy changes using a total atmospheric mass of $5.14 \times 10^{18} \mathrm{~kg}$, a mean total water vapor mass of $12.7 \times 10^{15} \mathrm{~kg}$ (Trenberth and Smith, 2005), a heat capacity of $1 \mathrm{~J} \mathrm{~g}^{-1}{ }^{\circ} \mathrm{C}^{-1}$, a latent heat of vaporization of $2.464 \mathrm{~J} \mathrm{~kg}^{-1}$ and a fractional increase of integrated water vapor content of $0.075{ }^{\circ} \mathrm{C}^{-1}$ (Held and Soden, 2006). Smaller changes in potential and kinetic energy are considered negligible. Standard deviations for each year of data are used for uncertainties, and the time series starts in 1979. The warming trend from a linear fit from 1979 to 2010 amounts to 2 TW (1 TW $=10^{12}$ watts).

The global average rate of continental warming and its uncertainty has been estimated from borehole temperature profiles from 1500 to 2000 at 50-year intervals (Beltrami et al., 2002). The 1950-2000 estimate of land warming, 6 TW, is extended into the first decade of the 21st century, although that extrapolation is almost certainly an underestimate of the energy absorbed, as land surface air temperatures for years since 2000 are some of the warmest on record (Section 2.4.1).

All annual ice melt rates (for glaciers and ice-caps, ice sheets and sea ice from Chapter 4) are converted into energy change using a heat of fusion $\left(334 \times 10^{3} \mathrm{~J} \mathrm{~kg}^{-1}\right)$ and density $(920 \mathrm{~kg}$ $\mathrm{m}^{-3}$ ) for freshwater ice. The heat of fusion and density of ice may vary, but only slightly among the different ice types, and warming the ice from sub-freezing temperatures requires much less energy than that to melt it, so these second-order contributions are neglected here. The linear trend of energy storage from 1971 to 2010 is 7 TW.

For the oceans, an estimate of global upper (0 to $700 \mathrm{~m}$ depth) ocean heat content change using ocean statistics to extrapolate to sparsely sampled regions and estimate uncertainties (Domingues et al., 2008) is used (see Section 3.2), with a linear trend from 1971 to 2010 of 137 TW. For the ocean from 700 to $2000 \mathrm{~m}$, annual 5-year running mean estimates are used from 1970 to 2009 and annual estimates for 2010-2011 (Levitus et al., 2012). For the ocean from $2000 \mathrm{~m}$ to bottom, a uniform rate of energy gain of 35 [6 to 61] TW from warming rates centred on 1992-2005 (Purkey and Johnson, 2010) is applied from 1992 to 2011, with no warming below $2000 \mathrm{~m}$ assumed prior to 1992. Their 5 to $95 \%$ uncertainty estimate may be too small, as it (continued on next page)

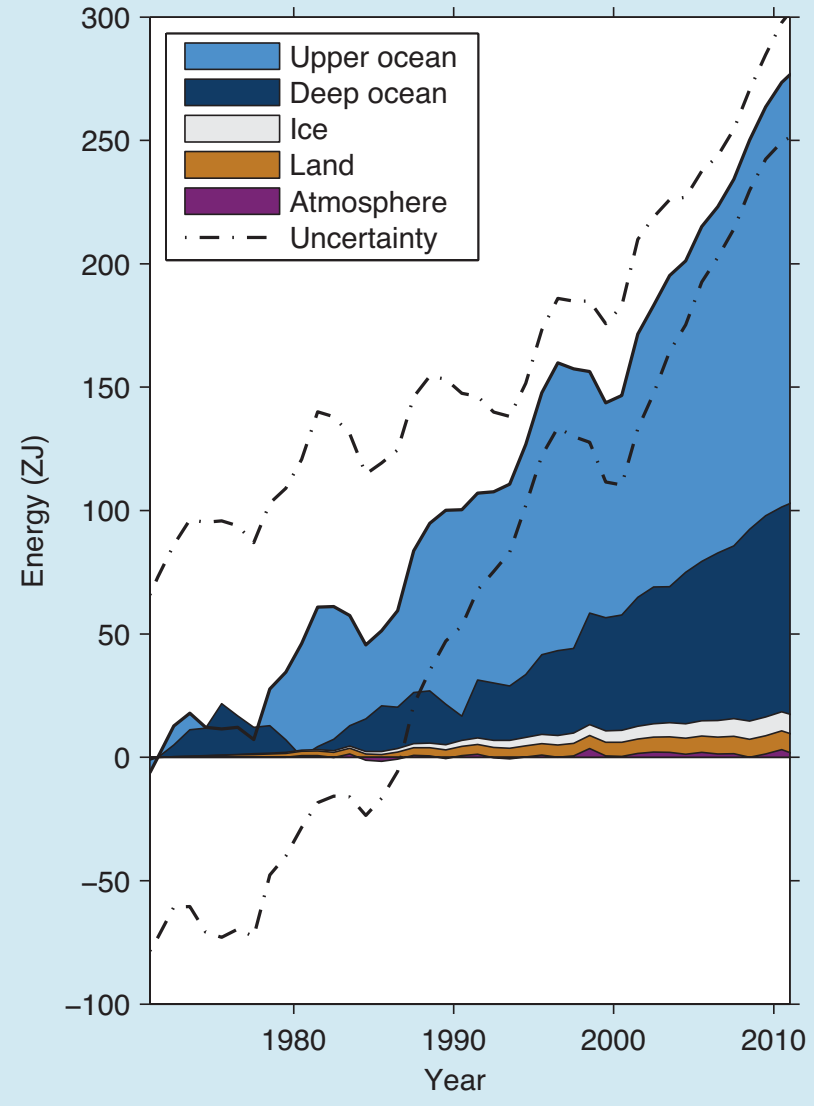

Box 3.1, Figure 1 | Plot of energy accumulation in ZJ (1 ZJ = $\left.10^{21} \mathrm{~J}\right)$ within distinct components of the Earth's climate system relative to 1971 and from 1971 to 2010 unless otherwise indicated. See text for data sources. Ocean warming (heat content change) dominates, with the upper ocean (light blue, above $700 \mathrm{~m}$ ) contributing more than the mid-depth and deep ocean (dark blue, below $700 \mathrm{~m}$; including below 2000 m estimates starting from 1992). Ice melt (light grey; for glaciers and ice caps, Greenland and Antarctic ice sheet estimates starting from 1992, and Arctic sea ice estimate from 1979 to 2008); continental (land) warming (orange); and atmospheric warming (purple; estimate starting from 1979) make smaller contributions. Uncertainty in the ocean estimate also dominates the total uncertainty (dot-dashed lines about the error from all five components at $90 \%$ confidence intervals). 
Box 3.1 (continued)

assumes the usually sparse sampling in each deep ocean basin analysed is representative of the mean trend in that basin. The linear trend for heating the ocean below $700 \mathrm{~m}$ is 62 TW for 1971-2010.

It is virtually certain that the Earth has gained substantial energy from 1971 to 2010 - the estimated increase in energy inventory between 1971 and 2010 is 274 [196 to 351] ZJ ( $\left.1 \mathrm{ZJ}=10^{21} \mathrm{~J}\right)$, with a rate of $213 \mathrm{TW}$ from a linear fit to the annual values over that time period (Box 3.1, Figure 1). An energy gain of $274 \mathrm{ZJ}$ is equivalent to a heating rate of $0.42 \mathrm{~W} \mathrm{~m}^{-2}$ applied continuously over the surface area of the earth $\left(5.10 \times 10^{14} \mathrm{~m}^{2}\right)$. Ocean warming dominates the total energy change inventory, accounting for roughly $93 \%$ on average from 1971 to 2010 (high confidence). The upper ocean $(0-700 \mathrm{~m})$ accounts for about $64 \%$ of the total energy change inventory. Melting ice (including Arctic sea ice, ice sheets and glaciers) accounts for $3 \%$ of the total, and warming of the continents $3 \%$. Warming of the atmosphere makes up the remaining 1\%. The 1971-2010 estimated rate of oceanic energy gain is 199 TW from a linear fit to data over that time period, implying a mean heat flux of $0.55 \mathrm{~W} \mathrm{~m}^{-2}$ across the global ocean surface area $\left(3.60 \times 10^{14} \mathrm{~m}^{2}\right)$. The Earth's net estimated energy increase from 1993 to 2010 is 163 [127 to 201] ZJ with a trend estimate of 275 TW. The ocean portion of the trend for 1993-2010 is $257 \mathrm{TW}$, equivalent to a mean heat flux into the ocean of $0.71 \mathrm{~W} \mathrm{~m}^{-2}$ over the global ocean surface area.

signal increased the thermal stratification of the upper ocean by about 4\% (between 0 and $200 \mathrm{~m}$ depth) from 1971 to 2010. It is also likely that the upper ocean warmed over the first half of the 20th century, based again on these same three independent and consistent, although much sparser, observations. Deeper in the ocean, it is likely that the waters from 700 to $2000 \mathrm{~m}$ have warmed on average between 1957 and 2009 and likely that no significant trend was observed between 2000 and $3000 \mathrm{~m}$ from 1992 to 2005. It is very likely that the deep (2000 m to bottom) North Atlantic Ocean north of $20^{\circ} \mathrm{N}$ warmed from 1955 to 1975 , and then cooled from 1975 to 2005, with an overall cooling trend. It is likely that most of the water column south of the Sub-Antarctic Front warmed at a rate of about $0.03^{\circ} \mathrm{C}$ per decade from 1992 to 2005, and waters of Antarctic origin warmed below $3000 \mathrm{~m}$ at a global average rate approaching $0.01^{\circ} \mathrm{C}$ per decade at $4500 \mathrm{~m}$ over the same time period. For the deep ocean. Sparse sampling is the largest source of uncertainty below $2000 \mathrm{~m}$ depth.

\subsection{Changes in Salinity and Freshwater Content}

\subsubsection{Introduction}

The ocean plays a pivotal role in the global water cycle: about $85 \%$ of the evaporation and $77 \%$ of the precipitation occurs over the ocean (Schmitt, 2008). The horizontal salinity distribution of the upper ocean largely reflects this exchange of freshwater, with high surface salinity generally found in regions where evaporation exceeds precipitation, and low salinity found in regions of excess precipitation and runoff (Figure 3.4a,b). Ocean circulation also affects the regional distribution of surface salinity. The subduction (Section 3.5) of surface waters transfers the surface salinity signal into the ocean interior, so that subsurface salinity distributions are also linked to patterns of evaporation, precipitation and continental run-off at the sea surface. Melting and freezing of ice (both sea ice and glacial ice) also influence ocean salinity.

Regional patterns and amplitudes of atmospheric moisture transport could change in a warmer climate, because warm air can contain more moisture (FAQ 3.2). The water vapour content of the troposphere likely has increased since the 1970s, at a rate consistent with the observed warming (Sections 2.4.4, 2.5.5 and 2.5.6).

It has not been possible to detect robust trends in regional precipitation and evaporation over the ocean because observations over the ocean are sparse and uncertain (Section 3.4.2). Ocean salinity, on the other hand, naturally integrates the small difference between these two terms and has the potential to act as a rain gauge for precipitation minus evaporation over the ocean (e.g., Lewis and Fofonoff, 1979; Schmitt, 2008; Yu, 2011; Pierce et al., 2012; Terray et al., 2012; Section 10.4). Diagnosis and understanding of ocean salinity trends is also important because salinity changes, like temperature changes, affect circulation and stratification, and therefore the ocean's capacity to store heat and carbon as well as to change biological productivity. Salinity changes also contribute to regional sea level change (Steele and Ermold, 2007).

In AR4, surface and subsurface salinity changes consistent with a warmer climate were highlighted, based on linear trends for the period between 1955 and 1998 in the historical global salinity data set (Boyer et al., 2005) as well as on more regional studies. In the early few decades the salinity data distribution was good in the $\mathrm{NH}$, especially the North Atlantic, but the coverage was poor in some regions such as the central South Pacific, central Indian and polar oceans (Appendix 3.A). However, Argo provides much more even spatial and temporal coverage in the 2000s. These additional observations, improvements in the availability and quality of historical data and new analysis approaches now allow a more complete assessment of changes in salinity.

'Salinity' refers to the weight of dissolved salts in a kilogram of seawater. Because the total amount of salt in the ocean does not change, the salinity of seawater can be changed only by addition or removal of fresh water. All salinity values quoted in the chapter are expressed on the Practical Salinity Scale 1978 (PSS78) (Lewis and Fofonoff, 1979). 
Frequently Asked Questions

\section{FAQ 3.1 | Is the Ocean Warming?}

Yes, the ocean is warming over many regions, depth ranges and time periods, although neither everywhere nor constantly. The signature of warming emerges most clearly when considering global, or even ocean basin, averages over time spans of a decade or more.

Ocean temperature at any given location can vary greatly with the seasons. It can also fluctuate substantially from year to year-or even decade to decade-because of variations in ocean currents and the exchange of heat between ocean and atmosphere.

Ocean temperatures have been recorded for centuries, but it was not until around 1971 that measurements were sufficiently comprehensive to estimate the average global temperature of the upper several hundred meters of the ocean confidently for any given year. In fact, before the international Argo temperature/salinity profiling float array first achieved worldwide coverage in 2005 , the global average upper ocean temperature for any given year was sensitive to the methodology used to estimate it.

Global mean upper ocean temperatures have increased over decadal time scales from 1971 to 2010. Despite large uncertainty in most yearly means, this warming is a robust result. In the upper $75 \mathrm{~m}$ of the ocean, the global average warming trend has been $0.11[0.09 \text { to } 0.13]^{\circ} \mathrm{C}$ per decade over this time. That trend generally lessens from the surface to mid-depth, reducing to about $0.04^{\circ} \mathrm{C}$ per decade by $200 \mathrm{~m}$, and to less than $0.02^{\circ} \mathrm{C}$ per decade by $500 \mathrm{~m}$.

Temperature anomalies enter the subsurface ocean by paths in addition to mixing from above (FAQ3.1, Figure 1). Colder-hence denser-waters from high latitudes can sink from the surface, then spread toward the equator beneath warmer, lighter, waters at lower latitudes. At a few locations-the northern North Atlantic Ocean and the Southern Ocean around Antarctica-ocean water is cooled so much that it sinks to great depths, even to the sea floor. This water then spreads out to fill much of the rest of the deep ocean. As ocean surface waters warm, these sinking waters also warm with time, increasing temperatures in the ocean interior much more quickly than would downward mixing of surface heating alone.

In the North Atlantic, the temperature of these deep waters varies from decade to decade-sometimes warming, sometimes cooling-depending on prevailing winter atmospheric patterns. Around Antarctica, bottom waters have warmed detectably from about 1992-2005, perhaps due to the strengthening and southward shift of westerly winds around the Southern Ocean over the last several decades. This warming signal in the deepest coldest bottom waters of the world ocean is detectable, although it weakens northward in the Indian, Atlantic and Pacific Oceans. Deep warming rates are generally less pronounced than ocean surface rates (around $0.03^{\circ} \mathrm{C}$ per decade since the 1990s in the deep and bottom waters around Antarctica, and smaller in many other locations). However, they occur over a large volume, so deep ocean warming contributes significantly to the total increase in ocean heat.

Estimates of historical changes in global average ocean temperature have become more accurate over the past several years, largely thanks to the recognition, and reduction, of systematic measurement errors. By carefully comparing less accurate measurements with sparser, more accurate ones at adjacent locations and similar times, scientists have reduced some spurious instrumental biases in the historical record. These improvements revealed that the global average ocean temperature has increased much more steadily from year to year than was reported prior to 2008. Nevertheless, the global average warming rate may not be uniform in time. In some years, the ocean appears to warm faster than average; in others, the warming rate seems to slow.

The ocean's large mass and high heat capacity allow it to store huge amounts of energy-more than 1000 times that in the atmosphere for an equivalent increase in temperature. The Earth is absorbing more heat than it is emitting back into space, and nearly all this excess heat is entering the oceans and being stored there. The ocean has absorbed about $93 \%$ of the combined heat stored by warmed air, sea, and land, and melted ice between 1971 and 2010.

The ocean's huge heat capacity and slow circulation lend it significant thermal inertia. It takes about a decade for near-surface ocean temperatures to adjust in response to climate forcing (Section 12.5), such as changes in greenhouse gas concentrations. Thus, if greenhouse gas concentrations could be held at present levels into the future, increases in the Earth's surface temperature would begin to slow within about a decade. However, deep ocean temperature would continue to warm for centuries to millennia (Section 12.5), and thus sea levels would continue to rise for centuries to millennia as well (Section 13.5). (continued on next page) 

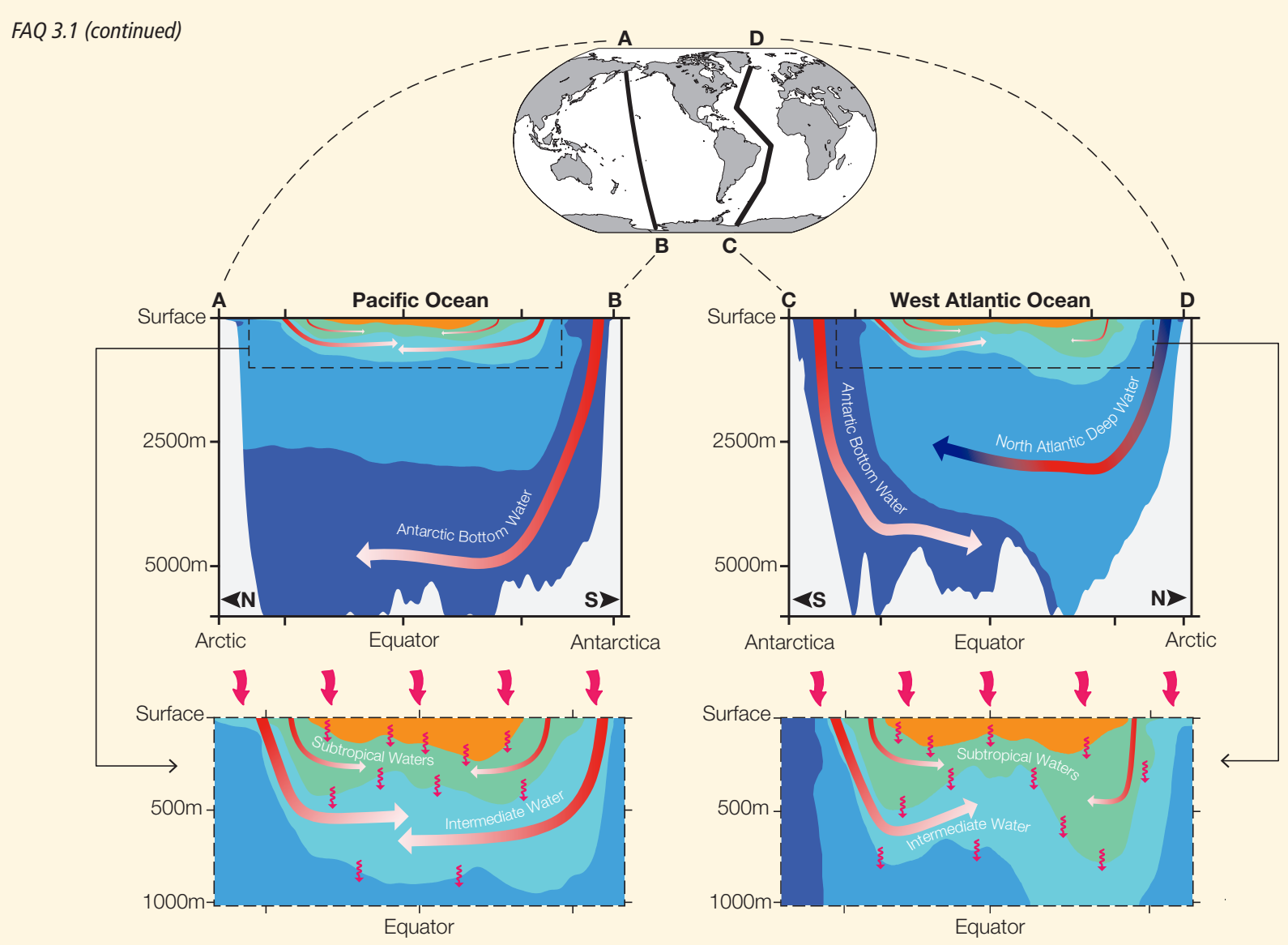

FAQ 3.1, Figure 1| Ocean heat uptake pathways. The ocean is stratified, with the coldest, densest water in the deep ocean (upper panels: use map at top for orientation). Cold Antarctic Bottom Water (dark blue) sinks around Antarctica then spreads northward along the ocean floor into the central Pacific (upper left panel: red arrows fading to white indicate stronger warming of the bottom water most recently in contact with the ocean surface) and western Atlantic oceans (upper right panel), as well as the Indian Ocean (not shown). Less cold, hence lighter, North Atlantic Deep Water (lighter blue) sinks in the northern North Atlantic Ocean (upper right panel: red and blue arrow in the deep water indicates decadal warming and cooling), then spreads south above the Antarctic Bottom Water. Similarly, in the upper ocean (lower left panel shows Pacific Ocean detail, lower right panel the Atlantic), cool Intermediate Waters (cyan) sink in sub-polar regions (red arrows fading to white indicating warming with time), before spreading toward the equator under warmer Subtropical Waters (green), which in turn sink (red arrows fading to white indicate stronger warming of the intermediate and subtropical waters most recently in contact with the surface) and spread toward the equator under tropical waters, the warmest and lightest (orange) in all three oceans. Excess heat or cold entering at the ocean surface (top curvy red arrows) also mixes slowly downward (sub-surface wavy red arrows).

\subsubsection{Global to Basin-Scale Trends}

The salinity of near-surface waters is changing on global and basin scales, with an increase in the more evaporative regions and a decrease in the precipitation-dominant regions in almost all ocean basins.

\subsubsection{Sea Surface Salinity}

Multi-decadal trends in sea surface salinity have been documented in studies published since AR4 (Boyer et al., 2007; Hosoda et al., 2009; Roemmich and Gilson, 2009; Durack and Wijffels, 2010), confirming the trends reported in AR4 based mainly on Boyer et al. (2005). The spatial pattern of surface salinity change is similar to the distribution of surface salinity itself: salinity tends to increase in regions of high mean salinity, where evaporation exceeds precipitation, and tends to decrease in regions of low mean salinity, where precipitation dominates (Figure 3.4). For example, salinity generally increased in the surface salinity maxima formed in the evaporation-dominated subtropical gyres. The surface salinity minima at subpolar latitudes and the intertropical convergence zones have generally freshened. Interbasin salinity differences are also enhanced: the relatively salty Atlantic has become more saline on average, while the relatively fresh Pacific has become fresher (Figures 3.5 and 3.9). No well-defined trend is found in the subpolar North Atlantic, which is dominated by decadal variability from atmospheric modes like the North Atlantic Oscillation (NAO, Box 2.5). The 50-year salinity trends in Figure 3.4c, both positive and negative, are statistically significant at the $99 \%$ level over $43.8 \%$ of the global ocean surface (Durack and Wijffels, 2010); trends were less significant over the remainder of the surface. The patterns of salinity change in the complementary Hosoda et al. (2009) study of differences between the periods 1960-1989 and 2003-2007 (Figure 3.4d), using a different methodology, have a point-to-point correlation of 0.64 with 

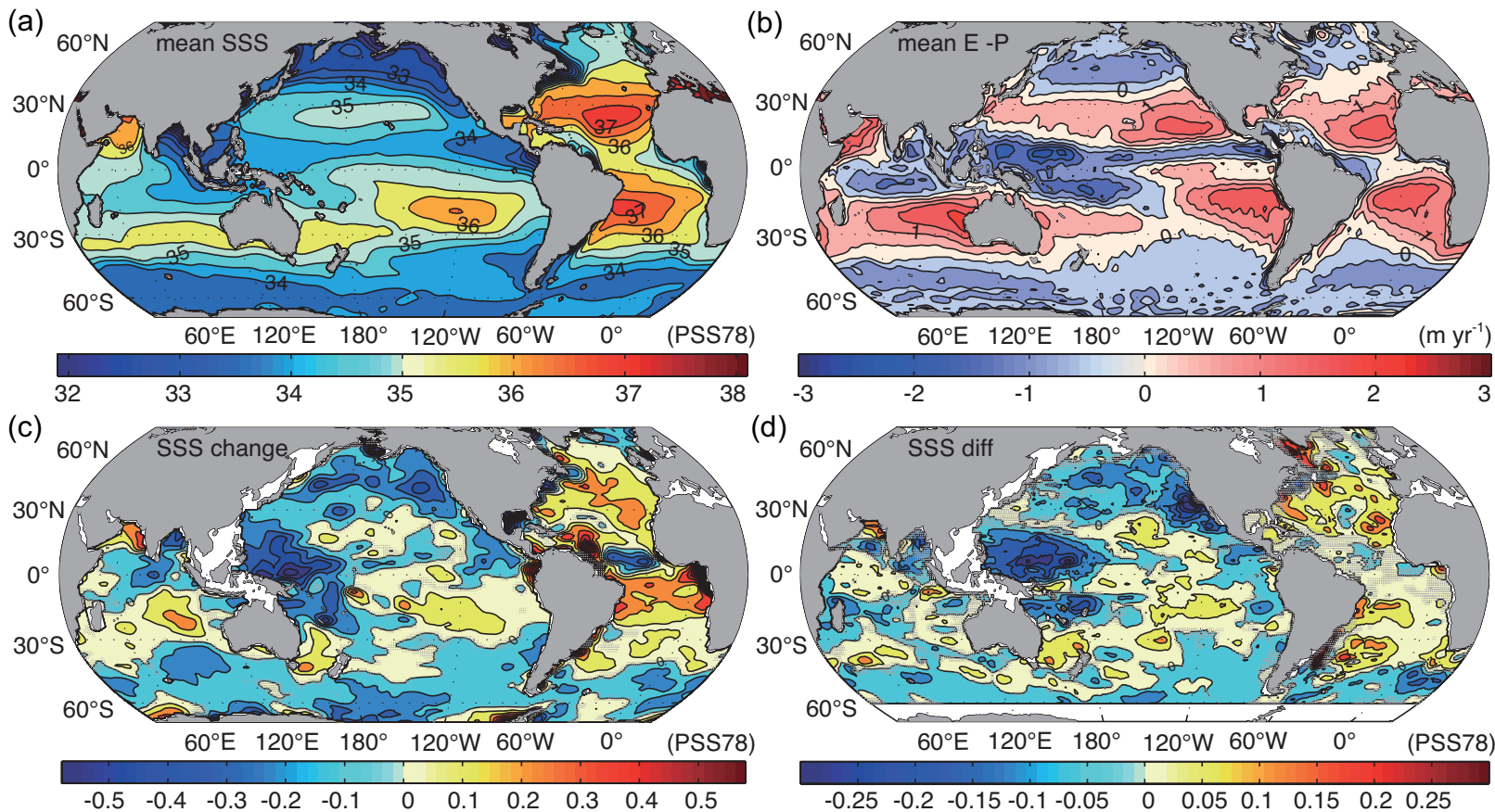

Figure 3.4 | (a) The 1955-2005 climatological-mean sea surface salinity (World Ocean Atlas 2009 of Antonov et al., 2010) colour contoured at 0.5 PSS78 intervals (black lines). (b) Annual mean evaporation-precipitation averaged over the period 1950-2000 (NCEP) colour contoured at $0.5 \mathrm{~m}_{\mathrm{yr}} \mathrm{r}^{-1}$ intervals (black lines). (c) The 58-year (2008 minus 1950) sea surface salinity change derived from the linear trend (PSS78), with seasonal and El Niño-Southern Oscillation (ENSO) signals removed (Durack and Wijffels, 2010) colour contoured at 0.116 PSS78 intervals (black lines). (d) The 30-year (2003-2007 average centred at 2005, minus the 1960-1989 average, centred at 1975) sea surface salinity difference (PSS78) (Hosoda et al., 2009) colour contoured at 0.06 PSS78 intervals (black lines). Contour intervals in (c) and (d) are chosen so that the trends can be easily compared, given the different time intervals in the two analyses. White areas in (c) to (d) are marginal seas where the calculations are not carried out. Regions where the change is not significant at the $99 \%$ confidence level are stippled in grey.

the Durack and Wijffels (2010) results, with significant differences only in limited locations such as adjacent to the West Indies, Labrador Sea, and some coastlines (Figure $3.4 \mathrm{c}$ and d).

It is very likely that the globally averaged contrast between regions of high and low salinity relative to the global mean salinity has increased. The contrast between high and low salinity regions, averaged over the ocean area south of $70^{\circ} \mathrm{N}$, increased by 0.13 [0.08 to 0.17] PSS78 from 1950 to 2008 using the data set of Durack and Wijffels (2010), and by 0.12 [0.10 to 0.15] PSS78 using the data set of Boyer et al. (2009) with the range reported in brackets signifying a $99 \%$ confidence interval (Figure 3.21d).

\subsubsection{Upper Ocean Subsurface Salinity}

Compatible with observed changes in surface salinity, robust multi-decadal trends in subsurface salinity have been detected (Boyer et al., 2005; Boyer et al., 2007; Steele and Ermold, 2007; Böning et al., 2008; Durack and Wijffels, 2010; Helm et al., 2010; Wang et al., 2010). Global, zonally averaged multi-decadal salinity trends (1950-2008) in the upper $500 \mathrm{~m}$ (Figures 3.4, 3.5, 3.9 and Section 3.5) show salinity increases at the salinity maxima of the subtropical gyres, freshening of the low-salinity intermediate waters sinking in the Southern Ocean (Subantarctic Mode Water and Antarctic Intermediate Water) and North Pacific (North Pacific Intermediate Water). On average, the Pacific freshened, and the Atlantic became more saline. These trends, shown in Figures 3.5 and 3.9, are significant at a 95\% confidence interval.
Freshwater content in the upper $500 \mathrm{~m}$ very likely changed, based on the World Ocean Database 2009 (Boyer et al., 2009), analyzed by Durack and Wijffels (2010) and independently as an update to Boyer et al. (2005) for 1955-2010 (Figure 3.5a, b, e, f). Both show freshening in the North Pacific, salinification in the North Atlantic south of $50^{\circ} \mathrm{N}$ and salinification in the northern Indian Ocean (trends significant at $90 \%$ confidence). A significant freshening is observed in the circumpolar Southern Ocean south of 50 S.

Density layers that are ventilated (connected to the sea surface) in precipitation-dominated regions have freshened, while those ventilated in evaporation-dominated regions have increased in salinity, compatible with an enhancement of the mean surface freshwater flux pattern (Helm et al., 2010). In addition, where warming has caused surface outcrops of density layers to move (poleward) into higher salinity surface waters, the subducted salinity in the density layers has increased; where outcrops have moved into fresher surface waters, the subducted salinity decreased (Durack and Wijffels, 2010). Vertical and lateral shifts of density surfaces, due to both changes in water mass renewal rates and wind-driven circulation, have also contributed to the observed subsurface salinity changes (Levitus, 1989; Bindoff and McDougall, 1994).

A change in total, globally integrated freshwater content and salinity requires an addition or removal of freshwater; the only significant source is land ice (ice sheets and glaciers). The estimate of change in globally averaged salinity and freshwater content remains smaller than 
Frequently Asked Questions

\section{FAQ 3.2 | Is There Evidence for Changes in the Earth's Water Cycle?}

The Earth's water cycle involves evaporation and precipitation of moisture at the Earth's surface. Changes in the atmosphere's water vapour content provide strong evidence that the water cycle is already responding to a warming climate. Further evidence comes from changes in the distribution of ocean salinity, which, due to a lack of long-term observations of rain and evaporation over the global oceans, has become an important proxy rain gauge.

The water cycle is expected to intensify in a warmer climate, because warmer air can be moister: the atmosphere can hold about 7\% more water vapour for each degree Celsius of warming. Observations since the 1970s show increases in surface and lower atmospheric water vapour (FAQ 3.2, Figure 1a), at a rate consistent with observed warming. Moreover, evaporation and precipitation are projected to intensify in a warmer climate.

Recorded changes in ocean salinity in the last 50 years support that projection. Seawater contains both salt and fresh water, and its salinity is a function of the weight of dissolved salts it contains. Because the total amount of salt-which comes from the weathering of rocks-does not change over human time scales, seawater's salinity can only be altered-over days or centuries—by the addition or removal of fresh water.

The atmosphere connects the ocean's regions of net fresh water loss to those of fresh water gain by moving evaporated water vapour from one place to another. The distribution of salinity at the ocean surface largely reflects the spatial pattern of evaporation minus precipitation, runoff from land, and sea ice processes. There is some shifting of the patterns relative to each other, because of the ocean's currents.

Subtropical waters are highly saline, because evaporation exceeds rainfall, whereas seawater at high latitudes and in the tropics - where more rain falls than evaporates-is less so (FAQ 3.2, Figure 1b, d). The Atlantic, the saltiest ocean basin, loses more freshwater through evaporation than it gains from precipitation, while the Pacific is nearly neutral (i.e., precipitation gain nearly balances evaporation loss), and the Southern Ocean (region around Antarctica) is dominated by precipitation.

Changes in surface salinity and in the upper ocean have reinforced the mean salinity pattern. The evaporationdominated subtropical regions have become saltier, while the precipitation-dominated subpolar and tropical regions have become fresher. When changes over the top $500 \mathrm{~m}$ are considered, the evaporation-dominated Atlantic has become saltier, while the nearly neutral Pacific and precipitation-dominated Southern Ocean have become fresher (FAQ 3.2, Figure 1c).

Observing changes in precipitation and evaporation directly and globally is difficult, because most of the exchange of fresh water between the atmosphere and the surface happens over the $70 \%$ of the Earth's surface covered by ocean. Long-term precipitation records are available only from over the land, and there are no long-term measurements of evaporation.

Land-based observations show precipitation increases in some regions, and decreases in others, making it difficult to construct a globally integrated picture. Land-based observations have shown more extreme rainfall events, and more flooding associated with earlier snow melt at high northern latitudes, but there is strong regionality in the trends. Land-based observations are so far insufficient to provide evidence of changes in drought.

Ocean salinity, on the other hand, acts as a sensitive and effective rain gauge over the ocean. It naturally reflects and smoothes out the difference between water gained by the ocean from precipitation, and water lost by the ocean through evaporation, both of which are very patchy and episodic. Ocean salinity is also affected by water runoff from the continents, and by the melting and freezing of sea ice or floating glacial ice. Fresh water added by melting ice on land will change global-averaged salinity, but changes to date are too small to observe.

Data from the past 50 years show widespread salinity changes in the upper ocean, which are indicative of systematic changes in precipitation and runoff minus evaporation, as illustrated in FAQ 3.2, Figure 1.

FAQ 3.2 is based on observations reported in Chapters 2 and 3, and on model analyses in Chapters 9 and 12. 


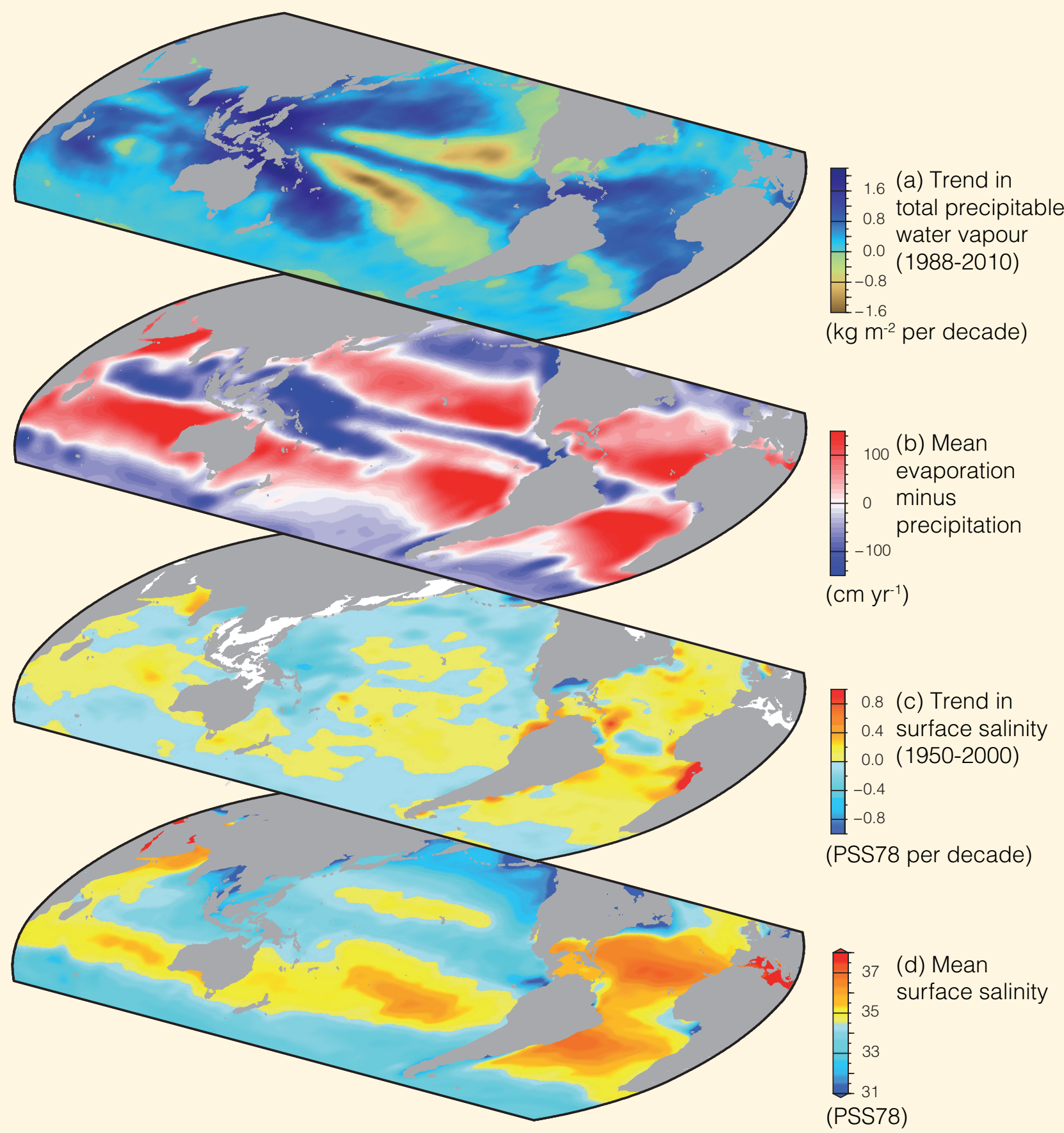

FAQ 3.2, Figure 1 | Changes in sea surface salinity are related to the atmospheric patterns of evaporation minus precipitation ( $E-P)$ and trends in total precipitable water: (a) Linear trend (1988-2010) in total precipitable water (water vapor integrated from the Earth's surface up through the entire atmosphere) (kg $\mathrm{m}^{-2}$ per decade) from satellite observations (Special Sensor Microwave Imager) (after Wentz et al., 2007) (blues: wetter; yellows: drier). (b) The 1979-2005 climatological mean net E -P ( $\mathrm{cm} \mathrm{yr}^{-1}$ ) from meteorological reanalysis (National Centers for Environmental Prediction/National Center for Atmospheric Research; Kalnay et al., 1996) (reds: net evaporation; blues: net precipitation). (c) Trend (1950-2000) in surface salinity (PSS78 per 50 years) (after Durack and Wijfels, 2010) (blues freshening; yellows-reds saltier). (d) The climatological-mean surface salinity (PSS78) (blues: <35; yellows-reds: $>35$ ). 
its uncertainty, as was true in the AR4 assessment. For instance, the globally averaged sea surface salinity change from 1950 to 2008 is small (+0.003 [ -0.056 to 0.062$])$ compared to its error estimate (Durack and Wijffels, 2010). Thus a global freshening due to land ice loss has not yet been discerned in global surface salinity change even if it were assumed that all added freshwater were in the ocean's surface layer.

\subsubsection{Regional Changes in Upper Ocean Salinity}

Regional changes in ocean salinity are broadly consistent with the conclusion that regions of net precipitation (precipitation greater than evaporation) have very likely become fresher, while regions of net evaporation have become more saline. This pattern is seen in salinity trend maps (Figure 3.4); zonally averaged salinity trends and freshwater inventories for each ocean (Figure 3.5); and the globally averaged contrast between regions of high and low salinity (Figure 3.21d). In the high-latitude regions, higher runoff, increased melting of ice and changes in freshwater transport by ocean currents have likely also contributed to observed salinity changes (Bersch et al., 2007; Polyakov et al., 2008; Jacobs and Giulivi, 2010).

\subsubsection{Pacific and Indian Oceans}

In the tropical Pacific, surface salinity has declined by 0.1 to 0.3 over 50 years in the precipitation-dominated western equatorial regions and by up to 0.6 to 0.75 in the Intertropical Convergence Zone and the South Pacific Convergence Zone (Cravatte et al., 2009), while surface salinity has increased by up to 0.1 over the same period in the evaporation-dominated zones in the southeastern and north-central tropical Pacific (Figure 3.9). The fresh, low-density waters in the warm pool of the western equatorial Pacific expanded in area as the surface salinity front migrated eastward by 1500 to $2500 \mathrm{~km}$ over the period 1955-2003 (Delcroix et al., 2007; Cravatte et al., 2009). Similarly, in the Indian Ocean, the net precipitation regions in the Bay of Bengal and the warm pool contiguous with the tropical Pacific warm pool have been freshening by up to 0.1 to 0.2 , while the saline Arabian Sea and south Indian Ocean have been getting saltier by up to 0.2 (Durack and Wijffels, 2010).

In the North Pacific, the subtropical thermocline has freshened by 0.1 since the early 1990s, following surface freshening that began around 1984 (Ren and Riser, 2010); the freshening extends down through the intermediate water that is formed in the northwest Pacific (Nakano et al., 2007), continuing the freshening documented by Wong et al. (1999). Warming of the surface water that subducts to supply the intermediate water is one reason for this signal, as the freshwater from the subpolar North Pacific is now entering the subtropical thermocline at lower density.

Salinity changes, together with temperature changes (Section 3.2.2), affect stratification; salinity has more impact than temperature in some regions. In the western tropical Pacific, for example, the density changes from 1970 to 2003 at a trend of $-0.013 \mathrm{~kg} \mathrm{~m}^{-3} \mathrm{yr}^{-1}$, about $60 \%$ of that due to salinity (Delcroix et al., 2007). The decreasing density trend mainly occurs near the surface only, which should affect stratification across the base of the mixed layer. In the Oyashio region of the western North Pacific, salinity decrease near the surface accounts for about
$60 \%$ of the density decrease of $-0.004 \mathrm{~kg} \mathrm{~m}^{-3} \mathrm{yr}^{-1}$ from 1968 to 1998 (Ono et al., 2001).

\subsubsection{Atlantic Ocean}

The net evaporative North Atlantic has become saltier as a whole over the past 50 years (Figure 3.9; Boyer et al., 2007). The largest increase in the upper 700 m occurred in the Gulf Stream region (0.006 per decade between 1955-1959 and 2002-2006) (Wang et al., 2010). Salinity increase is also evident following the circulation pathway of Mediterranean Outflow Water (Figure 3.9; Fusco et al., 2008). This increase can be traced back to the western basin of the Mediterranean, where salinity of the deep water increased during the period from 1943 to the mid-2000s (Smith et al., 2008; Vargas-Yáñez et al., 2010).

During the time period between 1955-1959 and 2002-2006 (using salinities averaged over the indicated 5-year ranges), the upper 700 $\mathrm{m}$ of the subpolar North Atlantic freshened by up to 0.002 per decade (Wang et al., 2010), while an increase in surface salinity was found between the average taken over 1960-1989 and the 5-year average over 2003-2007 (Hosoda et al., 2009). Decadal and multi-decadal variability in the subpolar gyre and Nordic Seas is vigorous and has been related to various climate modes such as the NAO, the Atlantic multi-decadal oscillation (AMO, Box 2.5), and even El Niño-Southern Oscillation (ENSO; Polyakov et al., 2005; Yashayaev and Loder, 2009), obscuring long-term trends. The 1970s to 1990s freshening of the northern North Atlantic and Nordic Seas (Dickson et al., 2002; Curry et al., 2003; Curry and Mauritzen, 2005) reversed to salinification (0 to $2000 \mathrm{~m}$ depth) starting in the late 1990s (Boyer et al., 2007; Holliday et al., 2008), and the propagation of this signal could be followed along the eastern boundary from south of $60^{\circ} \mathrm{N}$ in the Northeast Atlantic to Fram Strait at $79^{\circ} \mathrm{N}$ (Holliday et al., 2008). Advection has also played a role in moving higher salinity subtropical waters to the subpolar gyre (Hatun et al., 2005; Bersch et al., 2007; Lozier and Stewart, 2008; Valdimarsson et al., 2012). The variability of the cross equatorial transport contribution to this budget is highly uncertain. Reversals of North Atlantic surface salinity of similar amplitude and duration to those observed in the last 50 years are apparent in the early 20th century (Reverdin et al., 2002; Reverdin, 2010). The evaporation-dominated subtropical South Atlantic has become saltier by 0.1 to 0.3 during the period from 1950 to 2008 (Hosoda et al., 2009; Durack and Wijffels, 2010; Figure 3.4).

\subsubsection{Arctic Ocean}

Sea ice in the Arctic has declined significantly in recent decades (Section 4.2), which might be expected to reduce the surface salinity and increase freshwater content as freshwater locked in multi-year sea ice is released. Generally, strong multi-decadal variability, regional variability, and the lack of historical observations have made it difficult to assess long-term trends in ocean salinity and freshwater content for the Arctic as a whole (Rawlins et al., 2010). The signal that is now emerging, including salinity observations from 2005 to 2010, indicates increased freshwater content, with medium confidence.

Over the 20th century (1920-2003) the central Arctic Ocean in the upper $150 \mathrm{~m}$ became fresher in the 1950s and then more saline by 
Latitude

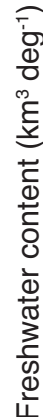

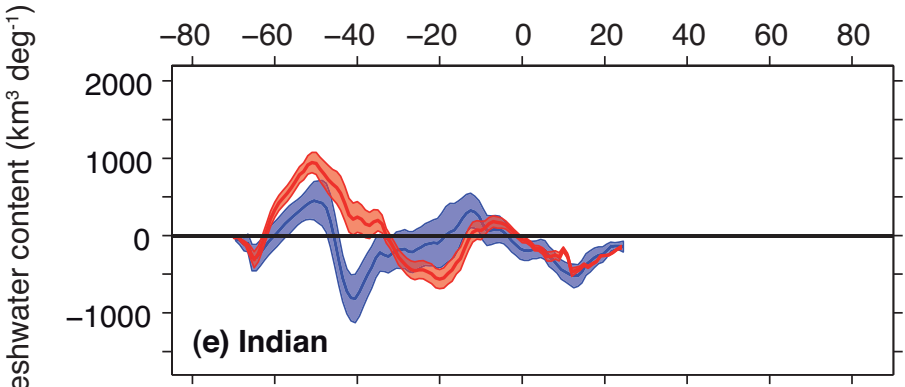

亡ั

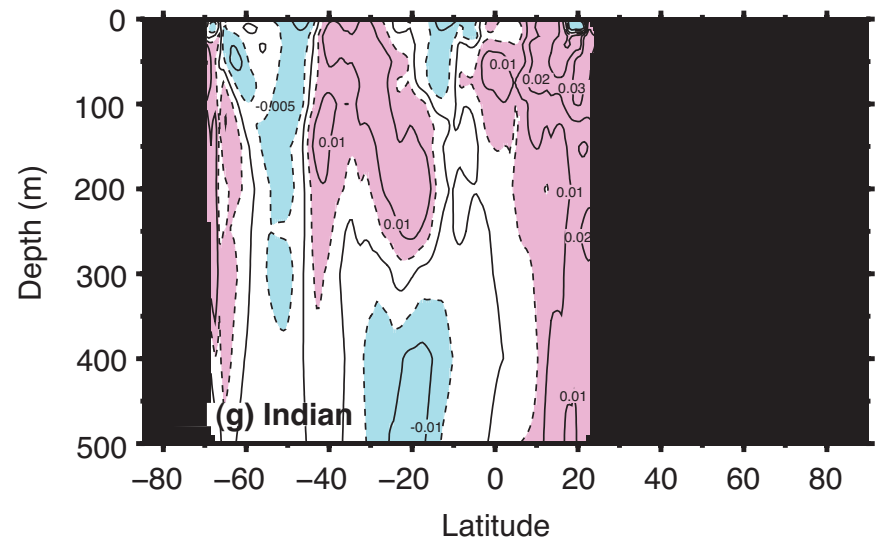

Latitude
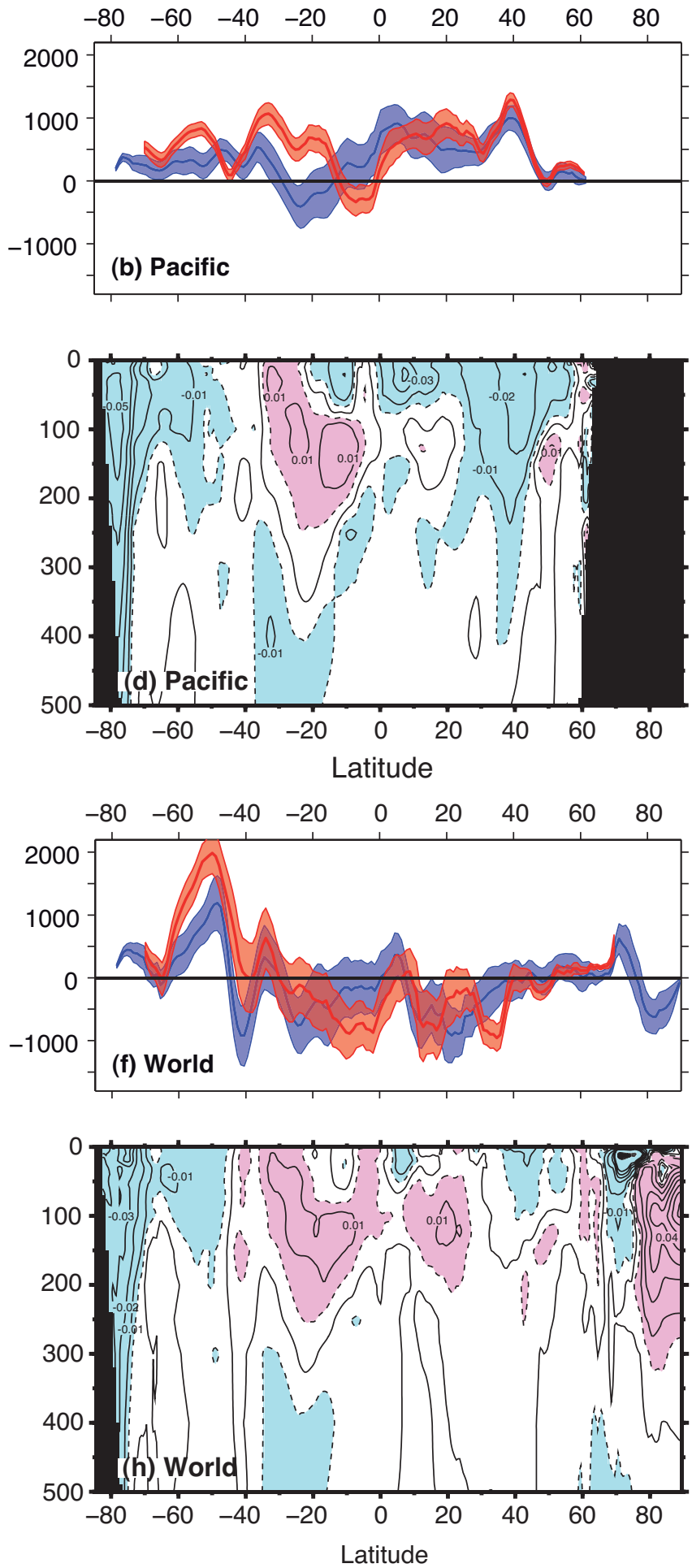

Figure 3.5 Zonally integrated freshwater content changes (FWCC; $\mathrm{km}^{3}$ per degree of latitude) in the upper $500 \mathrm{~m}$ over one-degree zonal bands and linear trends (1955-2010) of zonally averaged salinity (PSS78; lower panels) in the upper $500 \mathrm{~m}$ of the (a) and (c) Atlantic, (b) and (d) Pacific, (e) and (g) Indian and (f) and (h) World Oceans. The FWCC time period is from 1955 to 2010 (Boyer et al., 2005; blue lines) and 1950 to 2008 (Durack and Wiffels, 2010; red lines). Data are updated from Boyer et al. (2005) and calculations of FWCC are done according to the method of Boyer et al. (2007), using 5-year averages of salinity observations and fitting a linear trend to these averages. Error estimates are $95 \%$ confidence intervals. The contour interval of salinity trend in the lower panels is 0.01 PSS78 per decade and dashed contours are 0.005 PSS78 per decade. Red shading indicates values equal to or greater than 0.05 PSS78 per decade and blue shading indicates values equal to or less than -0.005 PSS78 per decade. 
the early 2000s, with a net small salinification over the whole record (Polyakov et al., 2008), while at the Siberian Shelf the river discharge increased (Shiklomanov and Lammers, 2009) and the shelf waters became fresher (Polyakov et al., 2008).

Upper ocean freshening has also been observed regionally in the southern Canada basin from the period 1950-1980 to the period 1990-2000s (Proshutinsky et al., 2009; Yamamoto-Kawai et al., 2009). These are the signals reflected in the freshwater content trend from 1955 to 2010 shown in Figure 3.5a, f: salinification at the highest latitudes and a band of freshening at about $70^{\circ} \mathrm{N}$ to $80^{\circ} \mathrm{N}$. Ice production and sustained export of freshwater from the Arctic Ocean in response to winds are suggested as key contributors to the high- latitude salinification (Polyakov et al., 2008; McPhee et al., 2009). The contrasting changes in different regions of the Arctic have been attributed to the effects of Ekman transport, sea ice formation (and melt) and a shift in the pathway of Eurasian river runoff (McPhee et al., 2009; YamamotoKawai et al., 2009; Morison et al., 2012).

Between the periods 1992-1999 and 2006-2008, not only the central Arctic Ocean freshened (Rabe et al., 2011; Giles et al., 2012), but also freshening is now observed in all regions including those that were becoming more saline through the early 2000s (updated from Polyakov et al., 2008). Moreover, freshwater transport out of the Arctic has increased in that time period (McPhee et al., 2009).

\subsubsection{Southern Ocean}

Widespread freshening (trend of -0.01 per decade, significant at $95 \%$ confidence, from the 1980s to 2000s) of the upper $1000 \mathrm{~m}$ of the Southern Ocean was inferred by taking differences between modern data (mostly Argo) and a long-term climatology along mean streamlines (Böning et al., 2008). Decadal variability, although notable, does not overwhelm this trend (Böning et al., 2008). Both a southward shift of the Antarctic Circumpolar Current and water-mass changes contribute to the observed trends during the period 1992-2009 (Meijers et al., 2011). The zonally averaged freshwater content for each ocean and the world (Figure 3.5) shows this significant Southern Ocean freshening, which exceeds other regional trends and is present in each basin (Indian, Atlantic and Pacific, Figure 3.9).

\subsubsection{Evidence for Change of the Hydrological Cycle from Salinity Changes}

The similarity between the geographic distribution of significant salinity and freshwater content trends (Figures 3.4, 3.5 and 3.21) and both the mean salinity pattern and the distribution of mean evaporation precipitation ( $E-P$; Figure 3.4) indicates, with medium confidence, that the large-scale pattern of net evaporation minus precipitation over the oceans has been enhanced. Whereas the surface salinity pattern could be enhanced by increased stratification due to surface warming, the large-scale changes in column-integrated freshwater content are very unlikely to result from changes in stratification in the thin surface layer. Furthermore, the large spatial scale of the observed changes in freshwater content cannot be explained by changes in ocean circulation such as shifts of gyre boundaries. The observed changes in surface and subsurface salinity require additional horizontal atmospheric water transport from regions of net evaporation to regions of net precipitation. A similar conclusion was reached in AR4 (Bindoff et al., 2007). The water vapour in the troposphere has likely increased since the 1970s, due to warming (2.4.4, 2.5.5, 2.5.6; FAQ 3.2). The inferred enhanced pattern of net $\mathrm{E}-\mathrm{P}$ can be related to water vapor increase, although the linkage is complex (Emori and Brown, 2005; Held and Soden, 2006). From 1950 to 2000, the large-scale pattern of surface salinity has amplified at a rate that is larger than model simulations for the historical 20th century and 21 st century projections. The observed rate of surface salinity amplification is comparable to the rate expected from a water cycle response following the Clausius-Clapeyron relationship (Durack et al., 2012).

Studies published since AR4, based on expanded data sets and new analysis approaches, have substantially decreased the level of uncertainty in the salinity and freshwater content trends (e.g., Stott et al., 2008; Hosoda et al., 2009; Roemmich and Gilson, 2009; Durack and Wijffels, 2010; Helm et al., 2010), and thus increased confidence in the inferred changes of evaporation and precipitation over the ocean.

\subsubsection{Conclusions}

Both positive and negative trends in ocean salinity and freshwater content have been observed throughout much of the ocean, both at the sea surface and in the ocean interior. While similar conclusions were reached in AR4, the recent studies summarized here, based on expanded data sets and new analysis approaches, provide high confidence in the assessment of trends in ocean salinity. It is virtually certain that the salinity contrast between regions of high and low surface salinity has increased since the 1950s. It is very likely that since the 1950s, the mean regional pattern of upper ocean salinity has been enhanced: saline surface waters in the evaporation-dominated mid-latitudes have become more saline, while the relatively fresh surface waters in rainfall-dominated tropical and polar regions have become fresher. Similarly, it is very likely that the interbasin contrast between saline Atlantic and fresh Pacific surface waters has increased, and it is very likely that freshwater content in the Southern Ocean has increased. There is medium confidence that these patterns in salinity trends are caused by increased horizontal moisture transport in the atmosphere, suggesting changes in evaporation and precipitation over the ocean as the lower atmosphere has warmed.

Trends in salinity have been observed in the ocean interior as well. It is likely that the subduction of surface water mass anomalies and the movement of density surfaces have contributed to the observed salinity changes on depth levels. Changes in freshwater flux and the migration of surface density outcrops caused by surface warming (e.g., to regions of lower or higher surface salinity) have likely both contributed to the formation of salinity anomalies on density surfaces.

\subsection{Changes in Ocean Surface Fluxes}

\subsubsection{Introduction}

Exchanges of heat, water and momentum (wind stress) at the sea surface are important factors for driving the ocean circulation. Changes 
in the air-sea fluxes may result from variations in the driving surface meteorological state variables (air temperature and humidity, SST, wind speed, cloud cover, precipitation) and can impact both watermass formation rates and ocean circulation. Air-sea fluxes also influence temperature and humidity in the atmosphere and, therefore, the hydrological cycle and atmospheric circulation. AR4 concluded that, at the global scale, the accuracy of the observations is insufficient to permit a direct assessment of changes in heat flux (AR4 Section 5.2.4). As described in Section 3.4.2, although substantial progress has been made since AR4, that conclusion still holds for this assessment.

The net air-sea heat flux is the sum of two turbulent (latent and sensible) and two radiative (shortwave and longwave) components. Ocean heat gain from the atmosphere is defined to be positive according to the sign convention employed here. The latent and sensible heat fluxes are computed from the state variables using bulk parameterizations; they depend primarily on the products of wind speed and the vertical near-sea-surface gradients of humidity and temperature respectively. The air-sea freshwater flux is the difference of precipitation (P) and evaporation (E). It is linked to heat flux through the relationship between evaporation and latent heat flux. Thus, when considering potential trends in the global hydrological cycle, consistency between observed heat budget and evaporation changes is required in areas where evaporation is the dominant term in hydrological cycle changes. Ocean surface shortwave and longwave radiative fluxes can be inferred from satellite measurements using radiative transfer models, or computed using empirical formulae, involving astronomical parameters, atmospheric humidity, cloud cover and SST. The wind stress is given by the product of the wind speed squared, and the drag coefficient. For detailed discussion of all terms see, for example, Gulev et al. (2010).

Atmospheric reanalyses, discussed in Box 2.3, are referred to frequently in the following sections and for clarity the products cited are summarised here: ECMWF 40-year Reanalysis (referred to as ERA40 hereafter, Uppala et al., 2005), ECMWF Interim Reanalysis (ERAI, Dee et al., 2011), NCEP/NCAR Reanalysis 1 (NCEP1, Kalnay et al., 1996), NCEP/DOE Reanalysis 2 (NCEP2, Kanamitsu et al., 2002), NCEP Climate Forecast System Reanalysis (CFSR, Saha et al., 2010), NASA Modern Era Reanalysis for Research and Applications (MERRA, Rienecker et al., 2011) and NOAA-CIRES 20th Century Reanalysis, version 2 (20CRv2, Compo et al., 2011).

\subsubsection{Air-Sea Heat Fluxes}

\subsubsection{Turbulent Heat Fluxes and Evaporation}

The latent and sensible heat fluxes have a strong regional dependence, with typical values varying in the annual mean from close to zero to $-220 \mathrm{~W} \mathrm{~m}^{-2}$ and $-70 \mathrm{~W} \mathrm{~m}^{-2}$ respectively over strong heat loss sites (Yu and Weller, 2007). Estimates of these terms have many potential sources of error (e.g., sampling issues, instrument biases, changing data sources, uncertainty in the flux computation algorithms). These sources may be spatially and temporally dependent, and are difficult to quantify (Gulev et al., 2007); consequently flux error estimates have a high degree of uncertainty. Spurious temporal trends may arise as a result of variations in measurement method for the driving meteorological state variables, in particular wind speed (Tokinaga and Xie, 2011). The overall uncertainty of the annually averaged global ocean mean for each term is expected to be in the range 10 to $20 \%$. In the case of the latent heat flux term, this corresponds to an uncertainty of up to $20 \mathrm{~W}$ $\mathrm{m}^{-2}$. In comparison, changes in global mean values of individual heat flux components expected as a result of anthropogenic climate change since 1900 are at the level of $<2 \mathrm{~W} \mathrm{~m}^{-2}$ (Pierce et al., 2006).

Many new turbulent heat flux data sets have become available since AR4 including products based on atmospheric reanalyses, satellite and in situ observations, and hybrid or synthesized data sets that combine information from these three different sources. It is not possible to identify a single best product as each has its own strengths and weaknesses (Gulev et al., 2010); several data sets are summarised here to illustrate the key issues. The Hamburg Ocean-Atmosphere Parameters and Fluxes from Satellite (HOAPS) data product provides global turbulent heat fluxes (and precipitation) developed from observations at microwave and infrared wavelengths (Andersson et al., 2011). In common with other satellite data sets it provides globally complete fields, however, it spans a relatively short period (1987 onwards) and is thus of limited utility for identifying long-term changes. A significant advance in flux data set development methodology is the $1 \times 1$ degree grid Objectively Analysed Air-Sea heat flux (OAFlux) data set that covers 1958 onwards and for the first time synthesizes state variables (SST, air temperature and humidity, wind speed) from reanalyses and satellite observations, prior to flux calculation (Yu and Weller, 2007). OAFlux has the potential to minimize severe spatial sampling errors that limit the usefulness of data sets based on ship observations alone and provides a new resource for temporal variability studies. However, the data sources for OAFlux changed in the 1980s, with the advent of satellite data, and the consequences of this change need to be assessed. In an alternative approach, Large and Yeager (2009) modified NCEP1 reanalysis state variables prior to flux calculation using various adjustment techniques, to produce the hybrid Coordinated Ocean-ice Reference Experiments (CORE) turbulent fluxes for 1948-2007 (Griffies et al., 2009). However, as the adjustments employed to produce the CORE fluxes were based on limited periods (e.g., 2000-2004 for wind speed) it is not clear to what extent CORE can be reliably used for studies of interdecadal variability over the 60 -year period that it spans.

Analysis of OAFlux suggests that global mean evaporation may vary at inter-decadal time scales, with the variability being relatively small compared to the mean (Yu, 2007; Li et al., 2011; Figure 3.6a). Changing data sources, particularly as satellite observations became available in the 1980s, may contribute to this variability (Schanze et al., 2010) and it is not yet possible to identify how much of the variability is due to changes in the observing system. The latent heat flux variations (Figure 3.6b) closely follow those in evaporation (with allowance for the sign definition which results in negative values of latent heat flux corresponding to positive values of evaporation) but do not scale exactly as there is an additional minor dependence on SST through the latent heat of evaporation. The large uncertainty ranges that are evident in each of the time series highlight the difficulty in establishing whether there is a trend in global ocean mean evaporation or latent heat flux. The uncertainty range for latent heat flux is much larger than the $0.5 \mathrm{~W}$ $\mathrm{m}^{-2}$ level of net heat flux change expected from the ocean heat content increase (Box 3.1). Thus, it is not yet possible to use such data sets to establish global ocean multi-decadal trends in evaporation or latent 

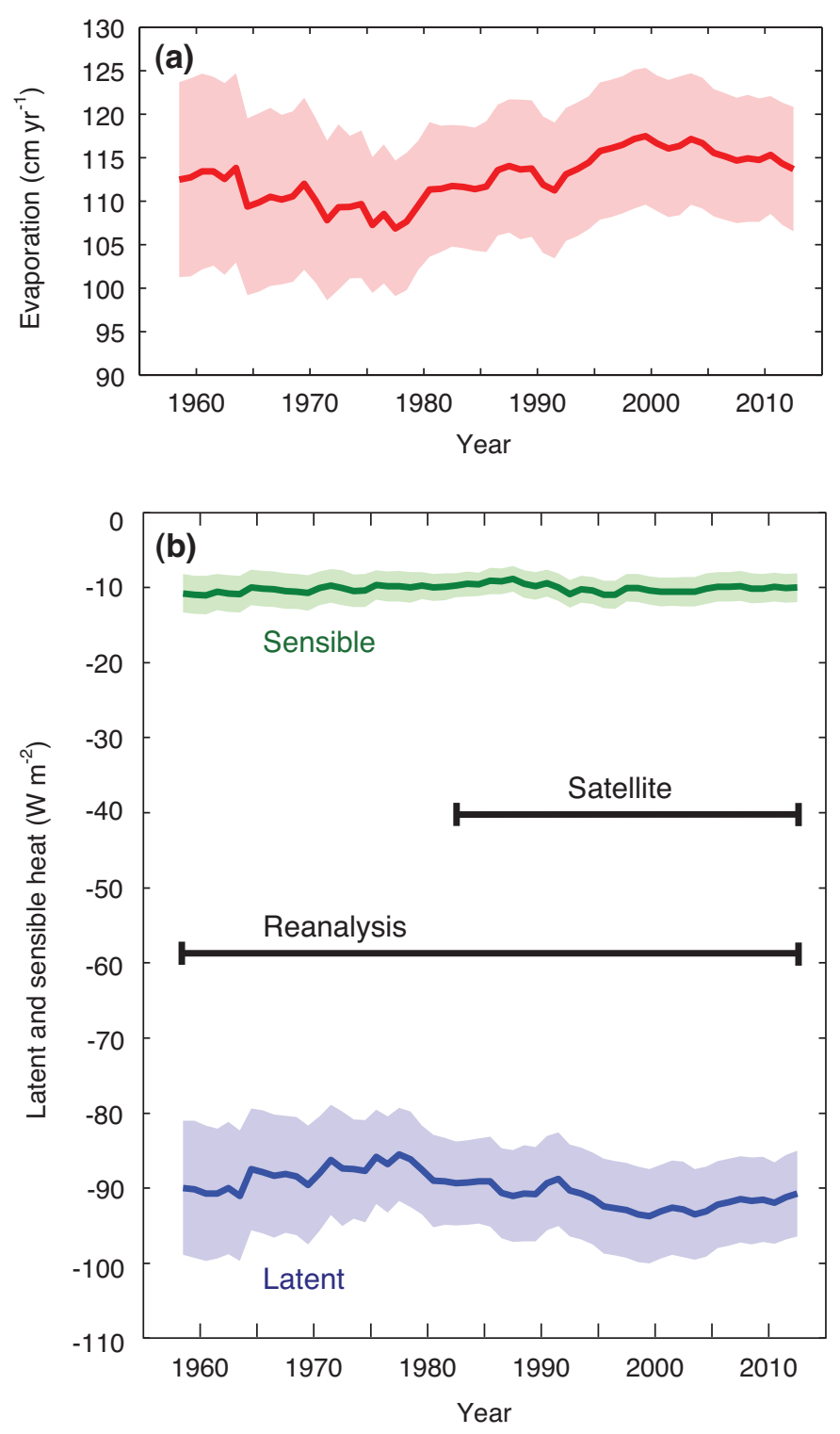

Figure 3.6 | Time series of annual mean global ocean average evaporation (red line, a), sensible heat flux (green line, b) and latent heat flux (blue line, b) from 1958 to 2012 determined by Yu from a revised and updated version of the original OAFlux data set Yu and Weller (2007). Shaded bands show uncertainty estimates and the black horizontal bars in (b) show the time periods for which reanalysis output and satellite observations were employed in the OAFlux analysis; they apply to both panels.

heat flux at this level. The globally averaged sensible heat flux is smaller in magnitude than the latent heat flux and has a smaller absolute range of uncertainty (Figure 3.6b).

\subsubsection{Surface Fluxes of Shortwave and Longwave Radiation}

The surface shortwave flux has a strong latitudinal dependence with typical annual mean values of $250 \mathrm{~W} \mathrm{~m}^{-2}$ in the tropics. The annual mean surface net longwave flux ranges from -30 to $-70 \mathrm{~W} \mathrm{~m}^{-2}$. Estimates of these terms are available from in situ climatologies, from atmospheric reanalyses, and, since the 1980s, from satellite observations. These data sets have many potential sources of error that include: uncertainty in the satellite retrieval algorithms and in situ formulae, cloud representation in reanalyses, sampling issues and changing satellite sensors (Gulev et al., 2010). As for the turbulent fluxes, the uncertainty of the annually averaged global ocean mean shortwave or longwave flux is difficult to determine and in the range $10-20 \%$.

High accuracy in situ radiometer measurements are available at land sites since the 1960s (see Wild, 2009 Figure 1), allowing analysis of decadal variations in the surface shortwave flux. However, this is not the case over the oceans, where there are very few in situ measurements (the exception being moored buoy observations in the tropical band $15^{\circ} \mathrm{S}$ to $15^{\circ} \mathrm{N}$ since the $1990 \mathrm{~s}$, Pinker et al., 2009). Consequently, for global ocean shortwave analyses it is necessary to rely on satellite observations, which are less accurate (compared to in situ determination of radiative fluxes), restrict the period that can be considered to the mid-1980s onwards, but do provide homogeneous sampling. Detailed discussion of variations in global (land and ocean) averaged surface solar radiation is given in Section 2.3.3; confidence in variability of radiation averaged over the global ocean is low owing to the lack of direct observations.

\subsubsection{Net Heat Flux and Ocean Heat Storage Constraints}

The most reliable source of information for changes in the global mean net air-sea heat flux comes from the constraints provided by analyses of changes in ocean heat storage. The estimate of increase in global ocean heat content for 1971-2010 quantified in Box 3.1 corresponds to an increase in mean net heat flux from the atmosphere to the ocean of $0.55 \mathrm{~W} \mathrm{~m}^{-2}$. In contrast, closure of the global ocean mean net surface heat flux budget to within $20 \mathrm{~W} \mathrm{~m}^{-2}$ from observation based surface flux data sets has still not been reliably achieved (e.g., Trenberth et al., 2009). The increase in mean net air-sea heat flux is thus small compared to the uncertainties of the global mean. Large and Yeager (2012) examined global ocean average net heat flux variability using the CORE data set over 1984-2006 and concluded that natural variability, rather than long-term climate change, dominates heat flux changes over this relatively short, recent period. Since AR4, some studies have shown consistency in regional net heat flux variability at sub-basin scale since the 1980s, notably in the Tropical Indian Ocean (Yu et al., 2007) and North Pacific (Kawai et al., 2008). However, detection of a change in air-sea fluxes responsible for the long-term ocean warming remains beyond the ability of currently available surface flux data sets.

\subsubsection{Ocean Precipitation and Freshwater Flux}

Assessment of changes in ocean precipitation at multi-decadal time scales is very difficult owing to the lack of reliable observation based data sets prior to the satellite era. The few studies available rely on reconstruction techniques. Remote sensing based precipitation observations from the Global Precipitation Climatology Project (GPCP) for 1979-2003 have been used by Smith et al. $(2009,2012)$ to reconstruct precipitation for $1900-2008$ (over $75^{\circ} \mathrm{S}$ to $75^{\circ} \mathrm{N}$ ) by employing statistical techniques that make use of the correlation between precipitation and both SST and sea level pressure (SLP). Each of the reconstructions shows both centennial and decadal variability in global ocean mean precipitation (Figure 3.7). The trend from 1900 to 2008 is $1.5 \mathrm{~mm}$ per month per century according to Smith et al. (2012). For the period of overlap, the reconstructed global ocean mean precipitation 


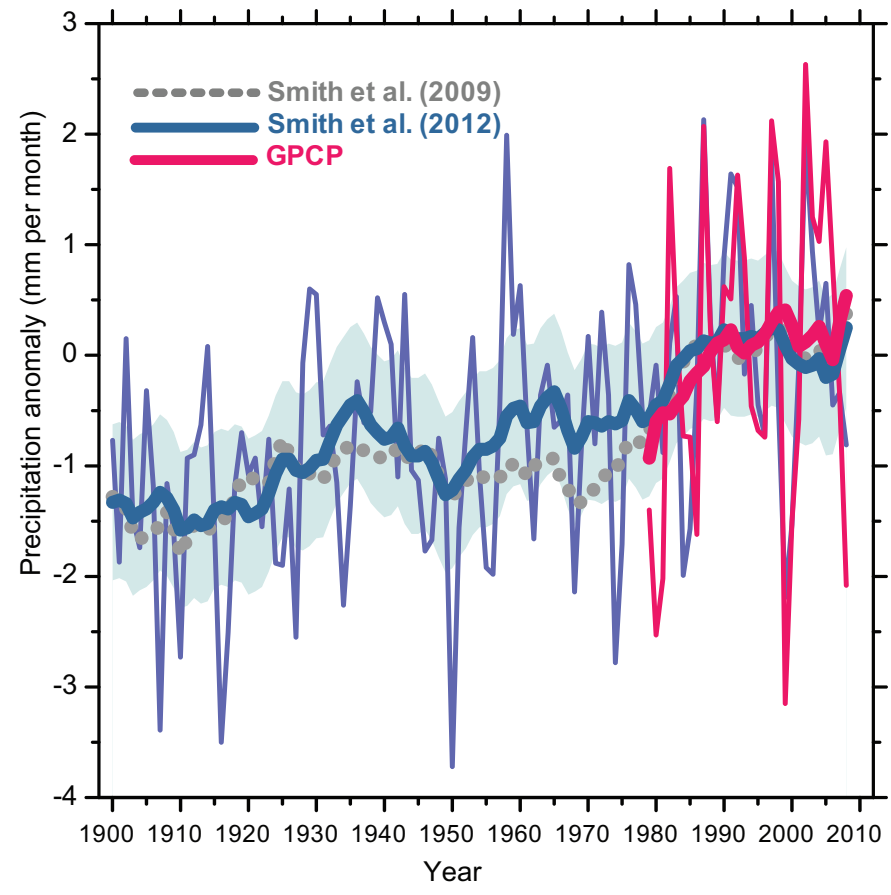

Figure 3.7 | Long-term reconstruction of ocean precipitation anomaly averaged over $75^{\circ} \mathrm{S}$ to $75^{\circ} \mathrm{N}$ from Smith et al. (2012): Annual values, thin blue line; low-pass filtered (15-year running mean) values, bold blue line with uncertainty estimates (shading). Smith et al. (2009) low-pass filtered values, dotted grey line. Also shown is the corresponding GPCPv2.2 derived ocean precipitation anomaly time series averaged over the same latitudinal range (annual values, thin magenta line; low-pass filtered values, bold magenta line); note Smith et al. (2012) employed an earlier version of the GPCP data set leading to minor differences relative to the published time series in their paper Precipitation anomalies were taken relative to the 1979-2008 period.

time series show consistent variability with GPCP as is to be expected (Figure 3.7). Focusing on the Tropical Ocean $\left(25^{\circ} \mathrm{S}\right.$ to $\left.25^{\circ} \mathrm{N}\right)$ for the recent period 1979-2005, Gu et al. (2007) have identified a precipitation trend of $0.06 \mathrm{~mm}_{\text {day }}{ }^{-1}$ per decade using GPCP. Concerns have been expressed in the cited studies over the need for further work both to determine the most reliable approach to precipitation reconstruction and to evaluate the remotely sensed precipitation data sets. Given these concerns, confidence in ocean precipitation trend results is low.

Evaporation and precipitation fields from atmospheric reanalyses can be tested for internal consistency of different components of the hydrological cycle. Specifically, the climatological mean value for $\mathrm{E}-\mathrm{P}$ averaged over the global ocean should equal both the corresponding mean for $\mathrm{P}-\mathrm{E}$ averaged over land and the moisture transport from ocean to land. Trenberth et al. (2011) find in an assessment of eight atmospheric reanalyses that this is not the case for each product considered, and they also report spurious trends due to variations in the observing system with time. Schanze et al. (2010) examine interannual variability within the OAFlux evaporation and GPCP precipitation data sets, and find that use of satellite data prior to 1987 is limited by discontinuities attributable to variations in data type. Thus, it is not yet possible to use such data sets to establish whether there are significant multi-decadal trends in mean $\mathrm{E}-\mathrm{P}$. However, regional trends in surface salinity since the 1950s do suggest trends in $\mathrm{E}-\mathrm{P}$ over the same time (see Section 3.3.4).

\subsubsection{Wind Stress}

Wind stress fields are available from reanalyses, satellite-based data sets, and in situ observations. Basin scale wind stress trends at decadal to centennial time scales have been reported for the Southern Ocean the North Atlantic and the Tropical Pacific as detailed below. However, these results are based largely on atmospheric reanalyses, in some cases a single product, and consequently the confidence level is low to medium depending on region and time scale considered.

In the Southern Ocean, the majority of reanalyses in the most comprehensive study available show an increase in the annual mean zonal wind stress (Swart and Fyfe, 2012; Figure 3.8). They find an increase in annual mean wind stress strength in four (NCEP1, NCEP2, ERAI and 20CRv2) of the six reanalyses considered (Figure 3.8). The mean of all reanalyses available at a given time (Figure 3.8, black line) also shows an upward trend from about $0.15 \mathrm{~N} \mathrm{~m}^{-2}$ in the early 1950 s to $0.20 \mathrm{~N}$ $\mathrm{m}^{-2}$ in the early 2010s. An earlier study, covering 1979-2009, found a wind stress increase in two of four reanalyses considered (Xue et al., 2010). A positive trend of zonal wind stress from 1980 to 2000 was also reported by Yang et al. (2007) using a single reanalysis (ERA40) and found to be consistent with increases in wind speed observations made on Macquarie Island $\left(54.5^{\circ} \mathrm{S}, 158.9^{\circ} \mathrm{E}\right)$ and by the SSM/I satellite (data from 1987 onwards). The wind stress strengthening is found by Yang et al. (2007) to have a seasonal dependence, with strongest trends in January, and has been linked by them to changes in the Southern Annular Mode (SAM, Box 2.5), which has continued to show an upward trend since AR4 (Section 2.7.8). Taken as a whole, these studies provide medium confidence that Southern Ocean wind stress has strengthened since the early 1980s. A strengthening of the related wind speed field in the Southern Ocean, consistent with the increasing trend in the SAM, has also been noted in Section 2.7.2 from satellite-based analyses and atmospheric reanalyses.

In the Tropical Pacific, a reanalysis based study found a strengthening of the trade wind associated wind stress for 1990-2009, but for the earlier period 1959-1989 there is no clear trend (Merrifield, 2011). Strengthening of the related Tropical Pacific Ocean wind speed field in recent decades is evident in reanalysis and satellite based data sets. Taken together with evidence for rates of sea level rise in the western Pacific larger than the global mean (Section 3.7.3) these studies provide medium confidence that Tropical Pacific wind stress has increased since 1990. This increase may be related to the Pacific Decadal Oscillation (Merrifield et al., 2012). At centennial time scales, attempts have been made to reconstruct the wind stress field in the Tropical Pacific by making use of the relationship between wind stress and SLP in combination with historic SLP data. Vecchi et al. (2006), using this approach, found a reduction of $7 \%$ in zonal mean wind stress across the Equatorial Pacific from the 1860 s to the 1990 s and related it to a possible weakening of the tropical Walker circulation. Observations discussed in Section 2.7.5 indicate that this weakening has largely been offset by a stronger Walker circulation since the 1990s.

Changes in winter season wind stress curl over the North Atlantic from 1950 to early 2000s from NCEP1 and ERA40 have leading modes that are highly correlated with the NAO and East Atlantic circulation patterns; each of these patterns demonstrates a trend towards more 
positive index values superimposed on pronounced decadal variability over the period from the early 1960s to the late 1990s (Sugimoto and Hanawa, 2010). Wu et al. (2012) find a poleward shift over the past century of the zero wind stress curl line by $2.5^{\circ}\left[1.5^{\circ}\right.$ to $\left.3.5^{\circ}\right]$ in the North Atlantic and $3.0^{\circ}\left[1.6^{\circ}\right.$ to $\left.4.4^{\circ}\right]$ in the North Pacific from $20 \mathrm{CRv} 2$. Confidence in these results is low as they are based on a single product, 20CRv2 (the only century time scale reanalysis), which may be affected by temporal inhomogeneity in the number of observations assimilated (Krueger et al., 2013).

\subsubsection{Changes in Surface Waves}

Surface wind waves are generated by wind forcing and are partitioned into two components, namely wind-sea (wind-forced waves propagating slower than surface wind) and swell (resulting from the wind-sea development and propagating typically faster than surface wind). Significant wave height (SWH) represents the measure of the wind wave field consisting of wind-sea and swell and is approximately equal to the highest one-third of wave heights. Local wind changes influence wind-sea properties, while changes in remote storms affect swell. Thus, patterns of wind wave and surface wind variability may differ because wind waves integrate wind properties over a larger domain. As wind waves integrate characteristics of atmospheric dynamics over a range of scales they potentially serve as an indicator of climate variability and change. Global and regional time series of wind waves characteristics are available from buoy data, Voluntary Observing Ship (VOS) reports, satellite measurements and model wave hindcasts. No source is superior, as all have their strengths and weaknesses (Sterl and Caires, 2005; Gulev and Grigorieva, 2006; Wentz and Ricciardulli, 2011).

\subsubsection{Changes in Surface Waves from Voluntary Observing Ship and Wave Model Hindcasts Forced by Reanalyses}

AR4 reported statistically significant positive SWH trends during 1900 2002 in the North Pacific (up to 8 to $10 \mathrm{~cm}$ per decade) and stronger trends (up to $14 \mathrm{~cm}$ per decade) from 1950 to 2002 for most of the mid-latitudinal North Atlantic and North Pacific, with insignificant trends, or small negative trends, in most other regions (Trenberth et al., 2007). Studies since AR4 have provided further evidence for SWH trends with more detailed quantification and regionalization.

Model hindcasts based on 20CRv2 (spanning 1871-2010) and ERA40 (spanning 1958-2001) show increases in annual and winter mean SWH in the north-east Atlantic, although the trend magnitudes depend on the reanalysis products used (Sterl and Caires, 2005; Wang et al., 2009, 2012; Semedo et al., 2011). Analysis of VOS observations for 1958-2002 reveals increases in winter mean SWH over much of the North Atlantic, north of $45^{\circ} \mathrm{N}$, and the central to eastern mid-latitude North Pacific with typical trends of up to $20 \mathrm{~cm}$ per decade (Gulev and Grigorieva, 2006).

\subsubsection{Changes in Surface Waves from Buoy Data}

Positive regional trends in extreme wave heights have been reported at several buoy locations since the late 1970s, with some evidence for seasonal dependence, including at sites on the east and west coasts of

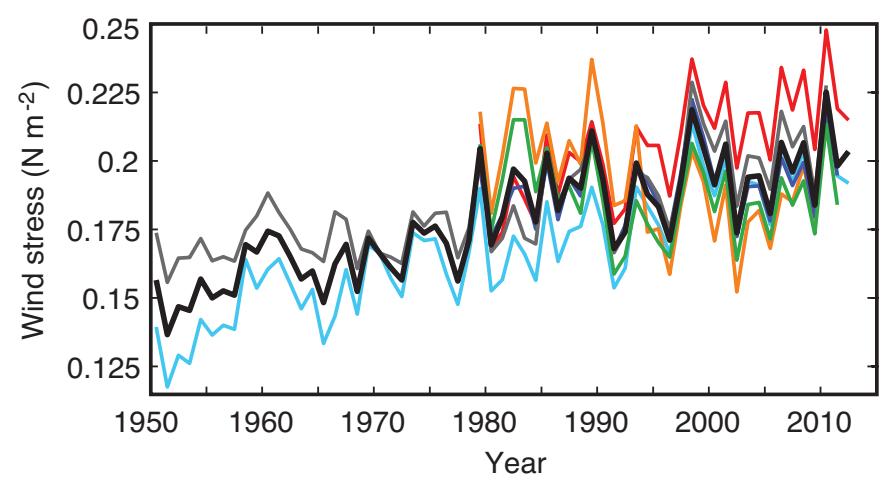

Figure 3.8 | Time series of annual average maximum zonal-mean zonal wind stress $\left(\mathrm{N} \mathrm{m}^{-2}\right)$ over the Southern Ocean for various atmospheric reanalyses: CFSR (orange), NCEP1 (cyan), NCEP2 (red), ERAI (dark blue), MERRA (green), 20CR (grey), and mean of all reanalyses at a given time (thick black), see Box 2.3 for details of reanalyses, Updated version of Figure 1a in Swart and Fyfe (2012), with CFSR, MERRA and the mean of all reanalyses added.

the USA (Komar and Allan, 2008; Ruggiero et al., 2010) and the northeast Pacific coast (Menéndez et al., 2008). However, Gemmrich et al. (2011) found for the Pacific buoys that some trends may be artefacts due to step-type historical changes in the instrument types, observational practices and post-processing procedures. Analysis of data from a single buoy deployed west of Tasmania showed no significant trend in the frequency of extreme waves contrary to a significant positive trend seen in the ERA40 reanalysis (Hemer, 2010).

\subsubsection{Changes in Surface Waves from Satellite Data}

Satellite altimeter observations provide a further data source for wave height variability since the mid-1980s. Altimetry is of particular value in the southern hemisphere, and in some poorly sampled regions of the northern hemisphere, where analysis of SWH trends remains a challenge due to limited in situ data and temporal inhomogeneity in the data used for reanalysis products. In the Southern Ocean, altimeter-derived SWH and model output both show regions with increasing wave height although these regions cover narrower areas in the altimeter analysis than in the models and have smaller trends (Hemer et al., 2010). Young et al. (2011a) compiled global maps of mean and extreme (90th and 99th percentile) surface wind speed and SWH trends for 1985-2008 using altimeter measurements. As the length of the data set is short, it is not possible to determine whether their results reflect long-term SWH and wind speed trends, or are part of a multi-decadal oscillation. For mean $\mathrm{SWH}$, their analysis shows positive linear trends of up to 10 to $15 \mathrm{~cm}$ per decade in some parts of the Southern Ocean (with the strongest changes between $80^{\circ} \mathrm{E}$ and $160^{\circ} \mathrm{W}$ ) that may reflect the increase in strength of the wind stress since the early 1980s (see Section 3.4.4). Young et al. (2011a) note, however, that globally the level of statistical significance is generally low in the mean and 90th percentile SWH trends but increases for the 99th percentile. Small negative mean SWH trends are found in many $\mathrm{NH}$ ocean regions and these are of opposite sign to, and thus inconsistent with, trends in wind speed — the latter being primarily positive. Nevertheless, for the 99th SWH percentile, strong positive trends up to 50 to $60 \mathrm{~cm}$ per decade were identified in the Southern Ocean, North 
Atlantic and North Pacific and these are consistent in sign with the extreme wind speed trends. Subsequent analysis has shown that the Young et al. (2011a) wind speed trends tend to be biased high when compared with microwave radiometer data (Wentz and Ricciardulli, 2011; Young et al., 2011b).

\subsubsection{Conclusions}

Uncertainties in air-sea heat flux data sets are too large to allow detection of the change in global mean net air-sea heat flux, on the order of $0.5 \mathrm{~W} \mathrm{~m}^{-2}$ since 1971, required for consistency with the observed ocean heat content increase. The accuracy of reanalysis and satellite observation based freshwater flux products is limited by changing data sources. Consequently, the products cannot yet be reliably used to directly identify trends in the regional or global distribution of evaporation or precipitation over the oceans on the time scale of the observed salinity changes since 1950 .

Basin scale wind stress trends at decadal to centennial time scales have been observed in the North Atlantic, Tropical Pacific, and Southern Oceans with low to medium confidence. These results are based largely on atmospheric reanalyses, in some cases a single product, and the confidence level is dependent on region and time scale considered. The evidence is strongest for the Southern Ocean for which there is medium confidence that zonal mean wind stress has increased in strength since the early $1980 \mathrm{~s}$.

There is medium confidence based on ship observations and reanalysis forced wave model hindcasts that mean significant wave height has increased since the 1950s over much of the North Atlantic north of $45^{\circ} \mathrm{N}$, with typical winter season trends of up to $20 \mathrm{~cm}$ per decade.

\subsection{Changes in Water-Mass Properties}

\subsubsection{Introduction}

To a large degree, water properties are set at the sea surface through interaction between the ocean and the overlying atmosphere (and ice, in polar regions). The water characteristics resulting from these interactions (e.g., temperature, salinity and concentrations of dissolved gases and nutrients) are transferred to various depths in the world ocean, depending on the density of the water. Warm, light water masses supply (or "ventilate") the upper ocean at low to mid-latitudes, while the colder, denser water masses formed at higher latitudes supply the intermediate and deep layers of the ocean (see schematic in FAQ 3.1, Figure 1). The formation and subduction of water masses are important for the ocean's capacity to store heat, freshwater, carbon, oxygen and other properties relevant to climate. In this section, the evidence for change in some of the major water masses of the world ocean is assessed.

The zonal-mean distributions of salinity, density, and temperature in each ocean basin (black contours in Figure 3.9) reflect the formation of water masses at the sea surface and their subsequent spreading into the ocean interior. For example, warm, salty waters formed in the regions of net evaporation between $10^{\circ}$ and $30^{\circ}$ latitude (Figure 3.4b) supply the subtropical salinity maximum waters found in the upper few hundred meters in each basin (Figure 3.9). Relatively fresh water masses produced at higher latitude, where precipitation exceeds evaporation, sink and spread equatorward to form salinity minimum layers at intermediate depths. Outflow of saline water from the Mediterranean Sea and Red Sea, where evaporation is very strong, accounts for the relatively high salinity observed in the upper $1000 \mathrm{~m}$ in the subtropical North Atlantic and North Indian basins, respectively.

Many of the observed changes in zonally averaged salinity, density and temperature are aligned with the spreading paths of the major water masses (Figure 3.9, trends from 1950 to 2000 shown in colours and white contours), illustrating how the formation and spreading of water masses transfer anomalies in surface climate to the ocean interior. The strongest anomalies in a water mass are found near its source region. For instance, bottom and deep water anomalies are strongest in the Southern Ocean and the northern North Atlantic, with lessening amplitudes along the spreading paths of these water masses. In each basin, the subtropical salinity maximum waters have become more saline, while the low-salinity intermediate waters have become fresher (Figure $3.9 \mathrm{a}, \mathrm{d}, \mathrm{g}$, j; see also Section 3.3). Strongest warming is observed in the upper $100 \mathrm{~m}$, which has warmed almost everywhere, with reduced warming (Atlantic) or regions of cooling (Indian and Pacific) observed between 100 and $500 \mathrm{~m}$ depth.

Warming is observed throughout the upper $2000 \mathrm{~m}$ south of $40^{\circ} \mathrm{S}$ in each basin. Shifts in the location of ocean circulation features can also contribute to the observed trends in temperature and salinity, as discussed in Section 3.2. Density decreased throughout most of the upper $2000 \mathrm{~m}$ of the global ocean (middle column of Figure 3.9). The decrease in near-surface density (hence increase in stratification) is largest in the Pacific, where warming and freshening both act to reduce density, and smallest in the Atlantic where the salinity and temperature trends have opposite effects on density.

The remainder of this section focuses on evidence of change in globally relevant intermediate, deep and bottom water masses.

\subsubsection{Intermediate Waters}

\subsubsection{North Pacific Intermediate Water}

The North Pacific Intermediate Water (NPIW) has freshened over the last two decades (Wong et al., 1999; Nakano et al., 2007; Figure $3.9 \mathrm{~g}$ ) and has warmed since the 1950s, as reported in AR4, Chapter 5. NPIW in the northwestern North Pacific warmed by $0.5^{\circ} \mathrm{C}$ from 1955 to 2004 and is now entering the subtropics at lower density; oxygen concentrations in the NPIW have declined, indicating weaker ventilation (Nakanowatari et al., 2007; Kouketsu et al., 2010). The strongest trends are in the Sea of Okhotsk, where NPIW is formed, and have been tentatively linked to increased air temperature and decreased sea-ice extent in winter (Nakanowatari et al., 2007; Figure 3.9i).

\subsubsection{Antarctic Intermediate Water}

In AR4, Chapter 5, Antarctic Intermediate Water (AAIW) was reported to have warmed and freshened since the 1960s (Figure 3.9). In most 
recent studies, usually — but not always - a dipole pattern was found: on isopycnals denser than the AAIW salinity minimum, a warming and salinification was observed and on isopycnals lighter than the AAIW salinity minimum, a cooling and freshening trend (Böning et al., 2008; Durack and Wijffels, 2010; Helm et al., 2010; McCarthy et al., 2011). The salinity minimum core of the AAIW also underwent changes consistent with these patterns on isopycnals: In 1970-2009, south of $30^{\circ} \mathrm{S}$, the AAIW salinity minimum core showed a strong, large-scale shoaling (30 to $50 \mathrm{dbar}$ per decade) and warming $\left(0.05^{\circ} \mathrm{C}\right.$ to $0.15^{\circ} \mathrm{C}$ per decade), leading to lighter densities (up to $0.03 \mathrm{~kg} \mathrm{~m}^{-3}$ per decade), while the salinity trends varied regionally. A long-term freshening of the AAIW core is found in the southwest Atlantic, southeast Pacific, and south-central Indian oceans, with salinification south of Africa and Australia. All trends were strongest close to the AAIW formation latitude just north of the Antarctic Circumpolar Current (Schmidtko and Johnson, 2012).

Both an increase in precipitation-evaporation and poleward migration of density surfaces caused by warming have likely contributed to the observed trends (Section 3.3; Böning et al., 2008; Durack and Wijffels, 2010; Helm et al., 2010; McCarthy et al., 2011). Changes in AAIW properties in particular locations have also been linked to other processes, including exchange between the Indian and Atlantic basins (McCarthy et al., 2011) and changes in surface forcing related to modes of climate variability like ENSO and the SAM (Garabato et al., 2009). Whether these changes in properties also affected the formation rates of AAIW cannot be assessed from the available observations.

\subsubsection{Deep and Bottom Waters}

Deep and bottom layers of the ocean are supplied by roughly equal volumes of dense water sinking in the northern North Atlantic (Lower North Atlantic Deep Water, LNADW) and around Antarctica (Antarctic Bottom Water, AABW) (FAQ 3.1, Figure 1).

\subsubsection{Upper North Atlantic Deep Water}

Upper North Atlantic Deep Water (UNADW) is formed by deep convection in the Labrador Sea between Canada and Greenland, so is also known as Labrador Sea Water (LSW). It is the shallowest component of the NADW, located above the overflow water masses that supply the Lower North Atlantic Deep Water (LNADW). AR4 Chapter 5 assessed the variability in water mass properties of LSW from the 1950s. Recent studies have confirmed the large interannual-to-multi-decadeal variability of LSW properties and provided new information on variability in formation rates and the impact on heat and carbon (Section 3.8.1) uptake by the deep ocean.

During the 1970s and 1980s and especially the 1990s the UNADW has been cold and fresh. In Figure 3.9A it is the strong freshening signal from the 1960s to the 1990s that dominates the trend. This freshening trend reversed in the late 1990s (Boyer et al., 2007; Holliday et al., 2008; see Section 3.3.3.2). Estimates of the LSW formation rate ${ }^{3}$ decreased from about 7.6 to $8.9 \mathrm{~Sv}$ in 1997-1999 (Kieke et al., 2006) to roughly 0.5 Sv in 2003-2005 (Rhein et al., 2011), and since 1997, only less dense LSW was formed compared to the high NAO years before. There is, however, evidence that formation of denser LSW occurred in 2008 (Våge et al., 2009; Yashayaev and Loder, 2009), but not in the following years (Yashayaev and Loder, 2009; Rhein et al., 2011).

The strong variability in the formation of UNADW affected significantly the heat transfer into the deep North Atlantic (Mauritzen et al., 2012). Substantial heat entered the deep North Atlantic during the low NAO years of the 1960s, when salinity was large enough to compensate for the high temperatures, and dense LSW was still formed and exported to the subtropics.

\subsubsection{Lower North Atlantic Deep Water}

Dense waters overflowing the sills between Greenland and Scotland supply the Lower North Atlantic Deep Water (LNADW). Both overflows freshened from the mid-1960s to the mid-1990s (Dickson et al., 2008). The salinity of the Faroe Bank overflow increased by 0.015 to 0.02 from 1997 to 2004, implying a density increase on the order of 0.01 $\mathrm{kg} \mathrm{m}^{-3}$ (Hansen and Osterhus, 2007). The other main overflow, through Denmark Strait, shows large interannual variability in temperature and salinity, but no trends for the time period 1996-2011 (Jochumsen et al., 2012). Observations of the transport of the dense overflows are dominated by short-term variability and there is no evidence of a trend in the short time series available (see Section 3.6). As both overflow components descend into the North Atlantic, they entrain substantial amounts of ambient subpolar waters to create LNADW. As a whole, the LNADW in the North Atlantic cooled from the 1950s to 2005 (Mauritzen et al., 2012), a signal thus stemming primarily from the entrained waters, possibly an adjustment from an unusually warm period observed in the 1920s and 1930s (Drinkwater, 2006).

\subsubsection{Antarctic Bottom Water}

The Antarctic Bottom Water (AABW) has warmed since the 1980s or 1990s, most noticeably near Antarctica (Aoki et al., 2005; Rintoul, 2007; Johnson et al., 2008a; Purkey and Johnson, 2010; Kouketsu et al., 2011), but with warming detectable into the North Pacific and North Atlantic Oceans (Johnson et al., 2008b; Kawano et al., 2010). The warming of AABW between the 1990 s and 2000 s contributed to global ocean heat uptake (Section 3.2). The global volume of the AABW layer decreased by 8.2 [5.6 to 10.8] Sv during the last two decades (Johnson et al., 2008b; Mauritzen et al., 2012; Purkey and Johnson, 2012), making it more likely than not that at least the export rate of AABW from the Southern Ocean declined during this period.

The sources of AABW in the Indian and Pacific sectors of the Southern Ocean have freshened in recent decades. The strongest signal $(0.03$ per decade, between 1970 and 2008) is observed in the Ross Sea and has been linked to inflow of glacial melt water from the Amundsen and Bellingshausen Seas (Shepherd et al., 2004; Rignot et al., 2008; Jacobs and Giulivi, 2010). Freshening has been observed in AABW since the 1970s in the Indian sector (Rintoul, 2007) and between the

3 The formation rate of a water mass is the volume of water per year that is transformed into the density range of this water mass by surface processes (for instance cooling), eventually modified through ocean interior processes (for instance mixing). Formation rates are reported in Sverdrups (Sv). 1 Sv equals $10^{6} \mathrm{~m}^{3} \mathrm{~s}^{-1}$. 
1990s and 2000s in the Pacific sector (Swift and Orsi, 2012; Purkey and Johnson, 2013).

In the Weddell Sea (the primary source of AABW in the Atlantic), a contraction of the bottom water mass was observed between 1984 and 2008 at the Prime Meridian, accompanied by warming of about $0.015^{\circ} \mathrm{C}$, and by salinity variability on a multi-annual time scale. Transient tracer observations between 1984 and 2011 confirmed that the AABW there has become less well ventilated over that time period. The changes in the AABW, however, seem to be caused by the much stronger trends observed in the Warm Deep Water, as WDW is entrained into the AABW while sinking to the bottom, and not by changes in the AABW formation rate (Huhn et al., 2008; Huhn et al., 2013).

\subsubsection{Conclusions}

AR4 Chapter 5 concluded that observed changes in upper ocean water masses reflect the combination of long-term trends and interannual to decadal variability related to climate modes like ENSO, NAO and SAM. The time series are still generally too short and incomplete to distinguish decadal variability from long-term trends, but understanding of the nature and causes of variability has improved in this assessment. The observed patterns of change in subsurface temperature and salinity (Sections 3.2 and 3.3) are consistent with understanding of how and where water masses form, enhancing the level of confidence in the assessment of the observed changes.
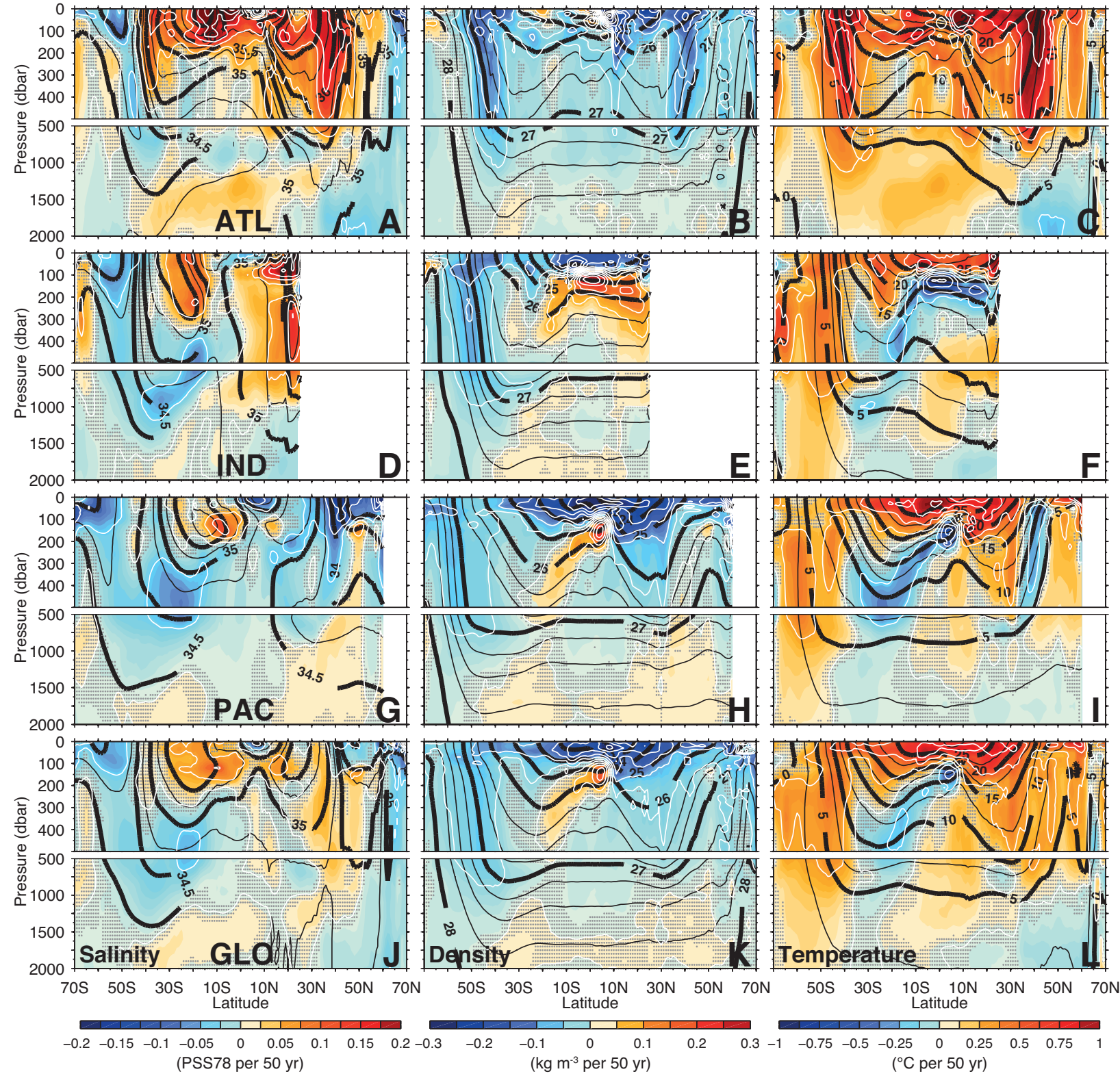

Figure 3.9 | Upper 2000 dbar zonally-averaged linear trend (1950 to 2000) (colours with white contours) of salinity changes (column 1, PSS-78 per 50 yr), neutral density changes (column 2, $\mathrm{kg} \mathrm{m}^{-3}$ per $50 \mathrm{yr}$ ), and potential temperature changes (column $3,{ }^{\circ} \mathrm{C}$ per $50 \mathrm{yr}$ ), for the Atlantic Ocean (ATL) in row 1, Indian Ocean (IND), row 2, Pacific Ocean (PAC), row 3, and global ocean (GLO) in row 4. Mean fields are shown as black lines (salinity: thick black contours 0.5 PSS-78, thin contours 0.25 PSS-78; neutral density: thick black contours $1.0 \mathrm{~kg} \mathrm{~m}^{-3}$, thin contours $0.25 \mathrm{~kg} \mathrm{~m}^{-3}$; potential temperature: thick black contours $5.0^{\circ} \mathrm{C}$, thin contours $\left.2.5^{\circ} \mathrm{C}\right)$. Trends are calculated on pressure surfaces $(1 \mathrm{dbar}$ pressure is approximately equal to $1 \mathrm{~m}$ in depth). Regions where the resolved linear trend is not significant at the $90 \%$ confidence level are stippled in grey. Salinity results are republished from Durack and Wijfels (2010) with the unpublished temperature and density results from that study also presented. 
Recent studies showed that the warming of the upper ocean (Section 3.2.2) very likely affects properties of water masses in the interior, in direct and indirect ways. Transport of SST and SSS anomalies caused by changes in surface heat and freshwater fluxes are brought into the ocean's interior by contact with the surface ocean (Sections 3.2 and 3.3). Vertical and horizontal displacements of isopycnals due to surface warming could change salinity and temperature (Section 3.3). Circulation changes (Section 3.6) could also change salinity by shifting the outcrop area of this isopycnal in regions with higher (or lower) E - P. Properties of several deep and bottom water masses are the product of near surface processes and significant mixing or entrainment of other ambient water masses (Section 3.5). Changes in the properties of the entrained or admixed water mass could dominate the observed deep and bottom water mass changes, for instance, in the LNADW and the AABW in the Weddell Sea.

From 1950 to 2000, it is likely that subtropical salinity maximum waters have become more saline, while fresh intermediate waters formed at higher latitudes have generally become fresher. In the extratropical North Atlantic, it is very likely that the temperature, salinity, and formation rate of the UNADW is dominated by strong decadal variability related to NAO. It is likely that LNADW has cooled from 1955 to 2005. It is likely that the abyssal layer ventilated by AABW warmed over much of the globe since the 1980s or 1990s respectively, and the volume of cold AABW has been reduced over this time period.

\subsection{Changes in Ocean Circulation}

\subsubsection{Global Observations of Ocean Circulation Variability}

The present-day ocean observing system includes global observations of velocity made at the sea surface by the Global Drifter Program (Dohan et al., 2010), and at $1000 \mathrm{~m}$ depth by the Argo Program (Freeland et al., 2010). In addition, Argo observes the geostrophic shear between $2000 \mathrm{~m}$ and the sea surface. These two recently implemented observing systems, if sustained, will continue to document the large-spatial scale, long-time-scale variability of circulation in the upper ocean. The drifter program achieved its target of 1250 drifters in 2005, and Argo its target of 3000 floats in 2007.

Historically, global measurements of ocean circulation are much sparser, so estimates of decadal and longer-term changes in circulation are very limited. Since 1992, high-precision satellite altimetry has measured the time variations in sea surface height (SSH), whose horizontal gradients are proportional to the surface geostrophic velocity. In addition, a single global top-to-bottom hydrographic survey was carried out by the World Ocean Circulation Experiment (WOCE), mostly during 1991-1997, measuring geostrophic shear as well as velocity from middepth floats and from lowered acoustic Doppler current profilers. A subset of WOCE and pre-WOCE transects is being repeated at 5- to 10-year intervals (Hood et al., 2010).

Ocean circulation studies in relation to climate have focused on variability in the wind-driven gyres (Section 3.6.2) and changes in the meridional overturning circulations (MOCs, Sections 3.6.3 and 3.6.4) influenced by buoyancy loss and water-mass formation as well as wind forcing. The MOCs are responsible for much of the ocean's capacity to carry excess heat from the tropics to middle latitudes, and also are important in the ocean's sequestration of carbon. The connections between ocean basins (Section 3.6.5) have also been subject to study because of the significance of inter-basin exchanges in wind-driven and thermohaline variability, and also because these can be logistically advantageous regions for measurement ("chokepoints"). An assessment is now possible of the recent mean and the changes in global geostrophic circulation over the previous decade (Figure 3.10, and discussion in Section 3.6.2). In general, changes in the slope of SSH across ocean basins indicate changes in the major gyres and the interior component of MOCs. Changes occurring in high gradient regions such as the Antarctic Circumpolar Current (ACC) may indicate shifts in the location of those currents. In the following, the best-studied and most significant aspects of circulation variability and change are assessed including wind-driven circulation in the Pacific, the Atlantic and Antarctic MOCs, and selected interbasin exchanges.

\subsubsection{Wind-Driven Circulation Variability in the Pacific Ocean}

The Pacific covers over half of the global ocean area and its winddriven variability is of interest both for its consistency with wind stress observations and for potential air-sea feedbacks that could influence climate. Changes in Pacific Ocean circulation since the early 1990s to the present, from the subarctic gyre to the southern ocean, observed with satellite ocean data and in situ ocean measurements, are in good agreement and consistent with the expected dynamical response to observed changes in wind stress forcing.

The subarctic gyre in the North Pacific poleward of $40^{\circ} \mathrm{N}$ consists of the Alaska Gyre to the east and the Western Subarctic Gyre (WSG). Since 1993, the cyclonic Alaska Gyre has intensified while decreasing in size. The shrinking is seen in the northward shift of the North Pacific Current

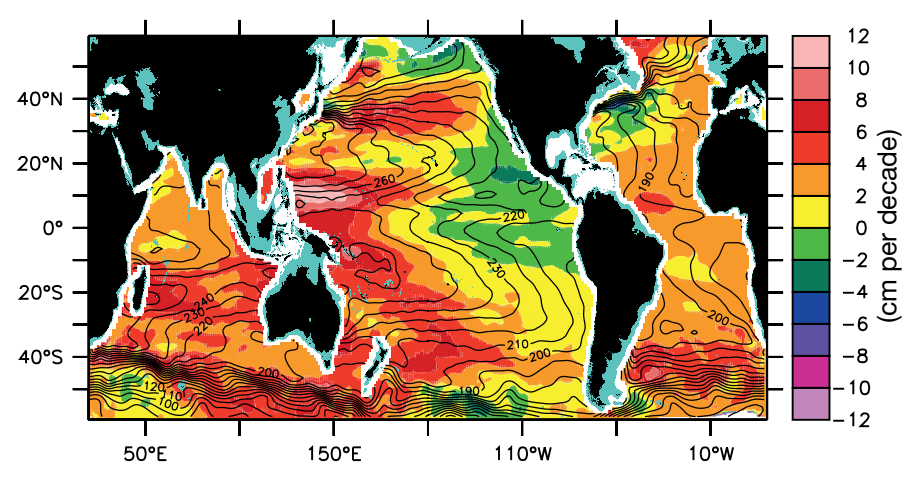

Figure 3.10 | Mean steric height of the sea surface relative to 2000 decibars (black contours at $10-\mathrm{cm}$ intervals) shows the pattern of geostrophic flow for the Argo era (2004-2012) based on Argo profile data, updated from Roemmich and Gilson (2009). The sea surface height (SSH) trend ( $\mathrm{cm}$ per decade, colour shading) for the period 1993-2011 is based on the AVISO altimetry "reference" product (Ducet et al., 2000). Spatial gradients in the SSH trend, divided by the (latitude-dependant) Coriolis parameter, are proportional to changes in surface geostrophic velocity. For display, the mean steric height contours and SSH trends are spatially smoothed over $5^{\circ}$ longitude and $3^{\circ}$ latitude. 
(NPC, the high gradient region centred about $40^{\circ} \mathrm{N}$ in Figure 3.10) and has been described using the satellite altimeter, XBT/hydrography, and, more recently, Argo profiling float data (Douglass et al., 2006; Cummins and Freeland, 2007). A similar 20-year trend is detected in the WSG, with the northern WSG in the Bering Sea having intensified while the southern WSG south of the Aleutian Islands has weakened. These decadal changes are attributable to strengthening and northward expansion of the Pacific High and Aleutian Low atmospheric pressure systems over the subarctic North Pacific Ocean (Carton et al., 2005).

The subtropical gyre in the North Pacific also expanded along its southern boundary over the past two decades. The North Equatorial Current (NEC) shifted southward along the $137^{\circ} \mathrm{E}$ meridian (Qiu and Chen, 2012; also note the SSH increase east of the Philippines in Figure 3.10 indicating the southward shift). The NEC's bifurcation latitude along the Philippine coast migrated southward from a mean latitude of $13^{\circ} \mathrm{N}$ in the early $1990 \mathrm{~s}$ to $11^{\circ} \mathrm{N}$ in the late $2000 \mathrm{~s}$ (Qiu and Chen, 2010). These changes are due to a recent strengthening of the Walker circulation generating a positive wind stress curl anomaly (Tanaka et al., 2004; Mitas and Clement, 2005). The enhanced regional sea level rise, $>10 \mathrm{~mm} \mathrm{yr}^{-1}$ in the western tropical North Pacific Ocean (Timmermann et al., 2010, Figure 3.10), is indicative of the changes in ocean circulation. The 20-year time-scale expansion of the North Pacific subtropical gyre has high confidence owing to the good agreement seen in satellite altimetry, subsurface ocean data and wind stress changes. This sea level increase in the western tropical Pacific also indicates a strengthening of the equatorward geostrophic limb of the subtropical cells. However, the 20-year increase reversed a longer term weakening of the subtropical cells (Feng et al., 2010), illustrating the high difficulty of separating secular trends from multi-decadal variability.

Variability in the mid-latitude South Pacific over the past two decades is characterized by a broad increase in SSH in the $35^{\circ} \mathrm{S}$ to $50^{\circ} \mathrm{S}$ band and a lesser increase south of $50^{\circ} \mathrm{S}$ along the path of the ACC (Figure 3.10). These SSH fluctuations are induced by the intensification in the SH westerlies (i.e., the SAM; see also Section 3.4.4), generating positive and negative wind stress curl anomalies north and south of $50^{\circ} \mathrm{S}$. In response, the southern limb of the South Pacific subtropical gyre has intensified in the past two decades (Cai, 2006; Qiu and Chen, 2006; Roemmich et al., 2007) along with a southward expansion of the East Australian Current (EAC) into the Tasman Sea (Hill et al., 2008). The intensification in the South Pacific gyre extends to a greater depth ( $>1800 \mathrm{~m}$ ) than that in the North Pacific gyre (Roemmich and Gilson, 2009). As in the north, the 20-year changes in the South Pacific are seen with high confidence as they occur consistently in multiple lines of medium and high-quality data. Multiple linear regression analysis of the 20-year Pacific SSH field (Zhang and Church, 2012) indicated that interannual and decadal modes explain part of the circulation variability seen in SSH gradients, and once the aliasing by these modes is removed, the SSH trends are weaker and more spatially uniform than in a single variable trend analysis.

The strengthening of $\mathrm{SH}$ westerlies is a multi-decadal signal, as seen in SLP difference between middle and high southern latitudes from 1949 to 2009 (Gillett and Stott, 2009; also Section 3.4.4). The multi-decadal warming in the Southern Ocean (e.g., Figure 3.1, and Gille, 2008, for the past 50 to 70 years) is consistent with a poleward displacement of the ACC and the southern limb of the subtropical gyres, by about $1^{\circ}$ of latitude per 40 years (Gille, 2008). The warming and corresponding sea level rise signals are not confined to the South Pacific, but are seen globally in zonal mean fields (e.g., at $40^{\circ} \mathrm{S}$ to $50^{\circ} \mathrm{S}$ in Figures $3.9 \mathrm{I}$ and 3.10). Alory et al. (2007) describe the broad warming consistent with a southward shift of the ACC in the South Indian Ocean. In the Atlantic, a southward trend in the location of the Brazil-Malvinas confluence (at around $39^{\circ} \mathrm{S}$ ) is described from surface drifters and altimetry by Lumpkin and Garzoli (2011), and in the location of the Brazil Current separation point from SST and altimetry by Goni et al. (2011). Enhanced surface warming and poleward displacement, globally, of the western boundary currents is described by Wu et al. (2012).

Changes in Pacific Ocean circulation over the past two decades since 1993, observed with medium to high confidence, include intensification of the North Pacific subpolar gyre, the South Pacific subtropical gyre, and the subtropical cells, plus expansion of the North Pacific subtropical gyre and a southward shift of the ACC. It is likely that these wind-driven changes are predominantly due to interannual-to-decadal variability, and in the case of the subtropical cells represent reversal of earlier multi-decadal change. Sustained time series of wind stress forcing and ocean circulation will permit increased skill in separating interannual and decadal variability from long-term trends (e.g., Zhang and Church, 2012).

\subsubsection{The Atlantic Meridional Overturning Circulation}

The Atlantic Meridional Overturning Circulation (AMOC) consists of an upper limb with net northward transport between the surface and approximately $1200 \mathrm{~m}$ depth, and a lower limb of denser, colder, fresher waters returning southward between $1200 \mathrm{~m}$ and $5000 \mathrm{~m}$. The $A M O C$ is responsible for most of the meridional transport of heat and carbon by the mid-latitude $\mathrm{NH}$ ocean and associated with the production of about half of the global ocean's deep waters in the northern North Atlantic. Coupled climate models find that a slowdown of the AMOC in the next decades is very likely, though with uncertain magnitude (Section 11.3.3.3). Observations of the AMOC are directed toward detecting possible long-term changes in its amplitude, its northward energy transport, and in the ocean's capacity to absorb excess heat and greenhouse gases, as well as characterizing short-term variability and its relationship to changes in forcing.

Presently, variability in the full AMOC and meridional heat flux are being estimated on the basis of direct observations at $26.5^{\circ} \mathrm{N}$ by the RAPID/MOCHA array (Cunningham et al., 2007; Kanzow et al., 2007; Johns et al., 2011). The array showed a mean AMOC magnitude of 18 \pm 1.0 Sv ( \pm 1 standard deviation of annual means) between April 2004 and April 2009, with 10-day values ranging from 3 to 32 Sv (McCarthy et al., 2012). Earlier estimates of AMOC strength from five shipboard expeditions over 47 years at $24^{\circ} \mathrm{N}$ (Bryden et al., 2005) were in the range of variability seen by RAPID/MOCHA. For the 1-year period 1 April 2009 to 31 March 2010, the AMOC mean strength decreased to $12.8 \mathrm{~Sv}$. This decrease was manifest in a shift of southward interior transport from the deep layers to the upper $1000 \mathrm{~m}$. Although the AMOC weakening in 2009/2010 was large, it subsequently rebounded and with the large year-to-year changes no trend is detected in the updated time-series (Figure 3.11b). 


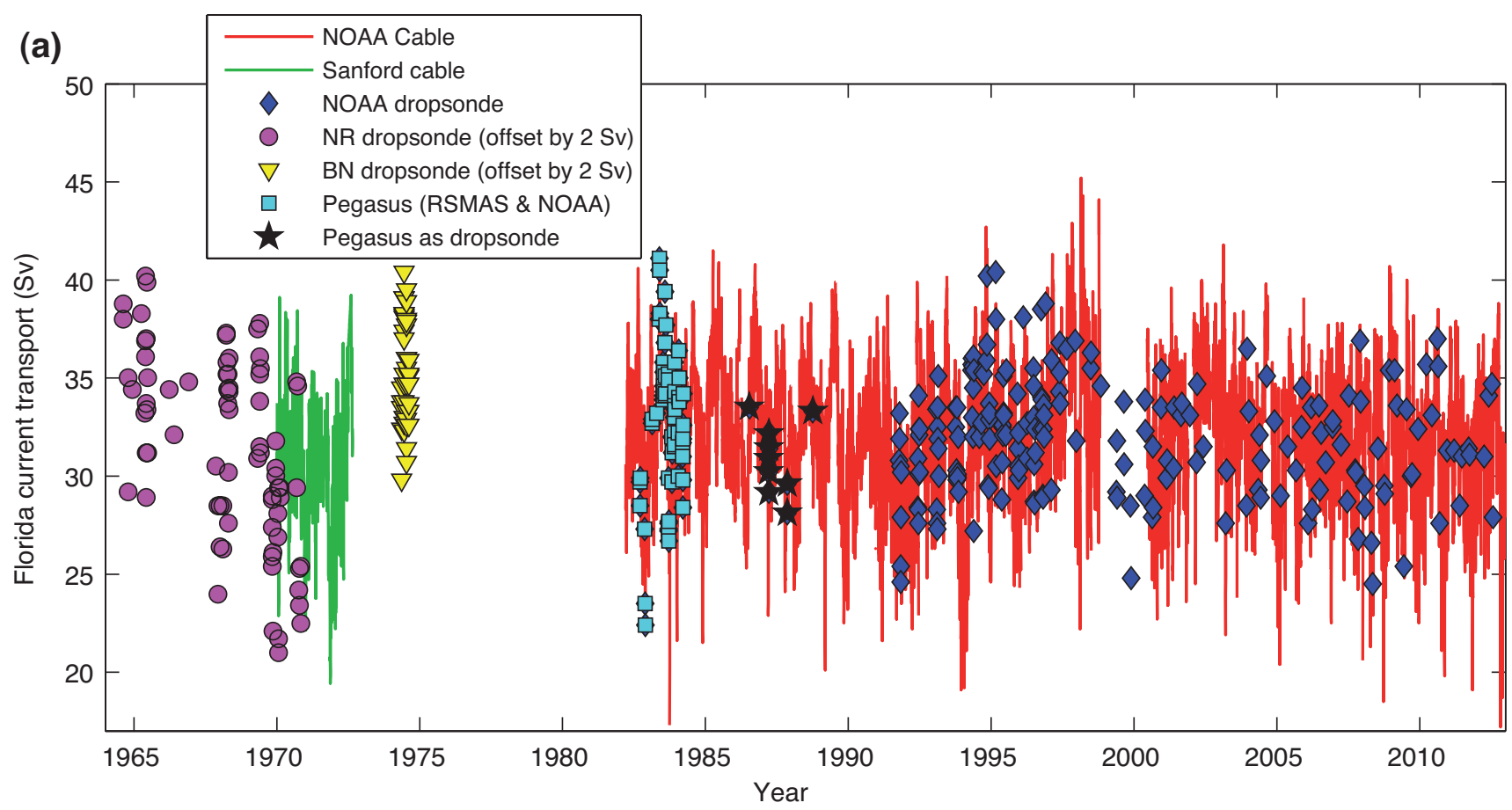

(b)

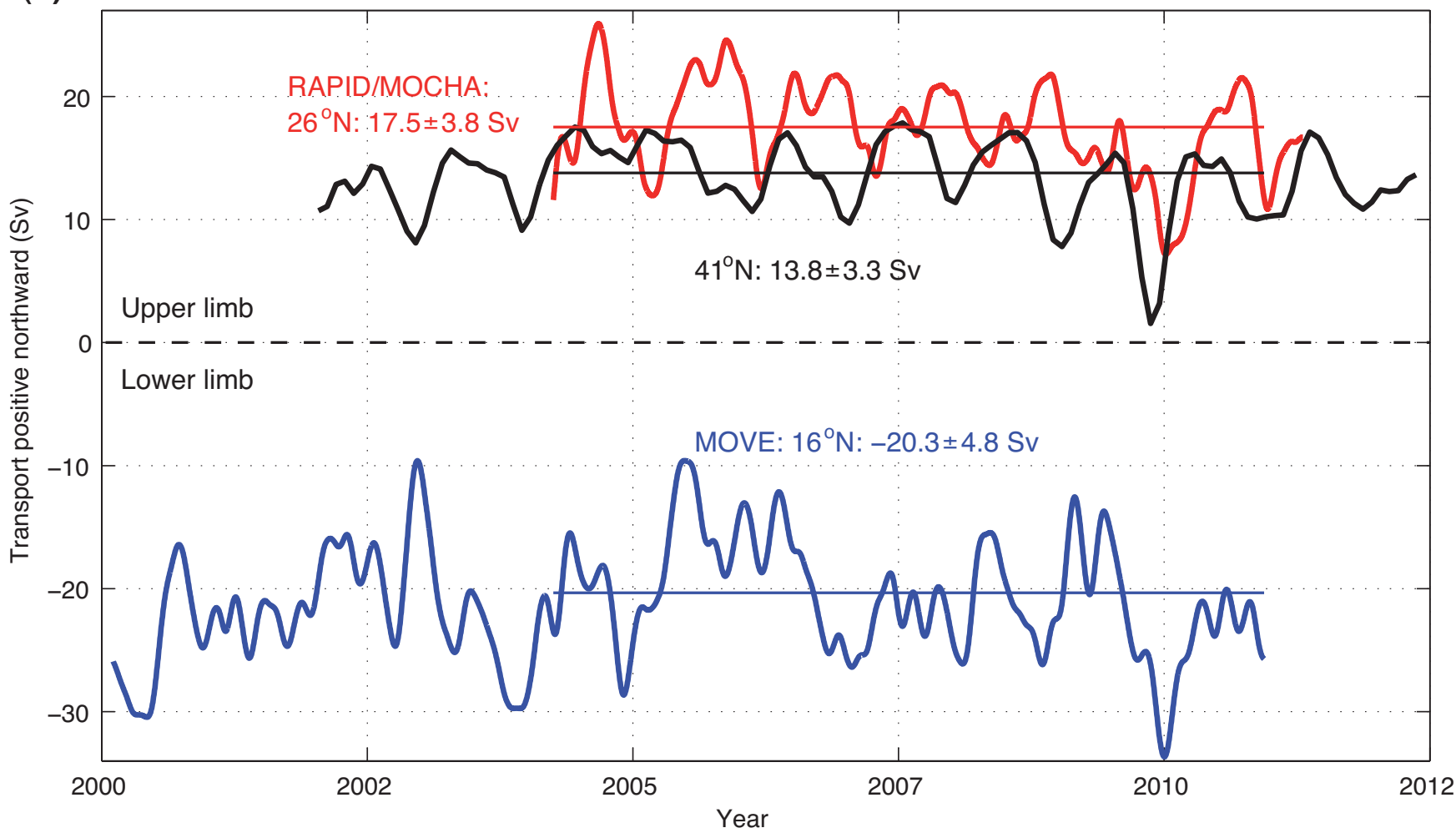

Figure 3.11 | (a) Volume transport in Sverdrups (Sv; where $1 \mathrm{~Sv}=10^{6} \mathrm{~m}^{3} \mathrm{~s}^{-1}$ ) of the Florida Current between Florida and the Bahamas, from dropsonde measurements (symbols) and cable voltages (continuous line), extending the time-series shown in Meinen et al. (2010) (b) Atlantic Meridional Overturning Circulation (AMOC) transport estimates (Sv): 1. RAPID/MOCHA (Rapid Climate Change programme / Meridional Ocean Circulation and Heatflux Array) at $26.5^{\circ} \mathrm{N}$ (red). The array monitors the top-to-bottom Atlantic wide circulation, ensuring a closed mass balance across the section, and hence a direct measure of the upper and lower limbs of the AMOC. 2. $41^{\circ} \mathrm{N}$ (black): An index of maximum AMOC strength from Argo float measurements in the upper $2000 \mathrm{~m}$ only, combined with satellite altimeter data. The lower limb is not measured. 3. Meridional Overturning Variability Experiment (MOVE) at $16^{\circ} \mathrm{N}$ (blue) measuring transport of North Atlantic Deep Water in the lower limb of the AMOC between $1100 \mathrm{~m}$ and $4800 \mathrm{~m}$ depth between the Caribbean and the mid-Atlantic Ridge. This transport is thought to be representative of maximum MOC variability based on model validation experiments. The temporal resolution of the three time series is 10 days for $16^{\circ} \mathrm{N}$ and $26^{\circ} \mathrm{N}$ and 1 month for $41^{\circ} \mathrm{N}$. The data have been 3-month low-pass filtered. Means and standard deviations for the common period of 2 April 2004 to 1 April 2010 are $17.5 \pm 3.8 \mathrm{~Sv}, 13.8 \pm 3.3 \mathrm{~Sv}$ and $-20.3 \pm 4.8 \mathrm{~Sv}$ (negative indicating the southward lower limb) for $26.5^{\circ} \mathrm{N}, 41^{\circ} \mathrm{N}$ and $16^{\circ} \mathrm{N}$ respectively. The means over this period are indicated by the horizontal line on each time series. 
Observations targeting one limb of the AMOC include Willis (2010) at $41^{\circ} \mathrm{N}$ combining velocities from Argo drift trajectories, Argo temperature/salinity profiles, and satellite altimeter data (Figure 3.11b). Here the upper limb AMOC magnitude is $15.5 \mathrm{~Sv} \pm 2.4$ from 2002 to 2009 (Figure $3.11 \mathrm{~b}$ ). This study suggests an increase in the AMOC strength by about 2.6 Sv from 1993 to 2010, though with low confidence because it is based on SSH alone in the pre-Argo interval of 1993-2001. At $16^{\circ} \mathrm{N}$, geostrophic array-based estimates of the southward transport of the AMOC's lower limb, in the depth range 1100 to $4700 \mathrm{~m}$, have been made continuously since 2000 (Kanzow et al., 2008). These are the longest continuous measurements of the southward flow of NADW in the western basin. Whereas the period 2000 to mid-2009 suggested a downward trend (Send et al., 2011), the updated time series (Figure $3.11 \mathrm{~b})$ has no apparent trend. In the South Atlantic at $35^{\circ} \mathrm{S}$, estimates of the AMOC upper limb were made using 27 high-resolution XBT transects (2002-2011) and Argo float data (Garzoli et al., 2013). The upperlimb AMOC magnitude was 18.1 Sv \pm 2.3 (1 standard deviation based on cruise values), consistent with the $\mathrm{NH}$ estimates.

The continuous $\mathrm{AMOC}$ estimates at $16^{\circ} \mathrm{N}, 26.5^{\circ} \mathrm{N}$ and $41^{\circ} \mathrm{N}$ have time series of length 11, 7, and 9 years respectively (Figure $3.11 \mathrm{~b}$ ). All show a substantial variability of $\sim 3$ to $5 \mathrm{~Sv}$ for 3-month low-pass time series, with a peak-to-peak interannual variability of $5 \mathrm{~Sv}$. The shortness of these time series and the relatively large interannual variability emerging in them suggests that trend estimates be treated cautiously, and no trends are seen at $95 \%$ confidence in any of the time series.

Continuous time series of AMOC components, longer than those of the complete system at $26.5^{\circ} \mathrm{N}$, have been obtained using moored instrumentation. These include the inflow into the Arctic through Fram Strait (since 1997, Schauer and Beszczynska-Möller, 2009) and through the Barents Sea (since 1997, Ingvaldsen et al., 2004; Mauritzen et al., 2011), dense inflows across sills between Greenland and Scotland (since 1999 and 1995 respectively, Olsen et al., 2008; Jochumsen et al., 2012) and North Atlantic Deep Water carried southward within the Deep Western Boundary Current at 53N (since 1997, Fischer et al., 2010) and at $39^{\circ} \mathrm{N}$ (Line W, since 2004, Toole et al., 2011). The longest time series of observations of ocean transport in the world (dropsonde and cable voltage measurements in the Florida Straits), extend from the mid-1960s to the present (Meinen et al., 2010), with small decadal variability of about $1 \mathrm{~Sv}$ and no evidence of a multi-decadal trend (Figure 3.11a). Similarly, none of the other direct, continuous transport estimates of single components of the AMOC exhibit long-term trends at $95 \%$ significance.

Indirect estimates of the annual average $\mathrm{AMOC}$ strength and variability can be made (Grist et al., 2009; Josey et al., 2009) from diapycnal transports driven by air-sea fluxes (NCEP-NCAR reanalysis fields from 1960 to 2007) or by inverse techniques (Lumpkin and Speer, 2007). Decadal fluctuations of up to $2 \mathrm{~Sv}$ are seen, but no trend. Consistent with Grist et al. (2009), the sea level index of the strength of the AMOC, based on several coherent western boundary tide gauge records between $39^{\circ} \mathrm{N}$ and $43^{\circ} \mathrm{N}$ at the American coast (Bingham and Hughes, 2009) shows no long-term trend from 1960 to 2007.

In summary, measurements of the AMOC and of circulation elements contributing to it, at various latitudes and covering different time periods, agree that the range of interannual variability is $5 \mathrm{~Sv}$ (Figure $3.11 \mathrm{~b})$. These estimates do not have trends, in either the subtropical or the subpolar gyre. However, the observational record of AMOC variability is short, and there is insufficient evidence to support a finding of change in the transport of the AMOC.

\subsubsection{The Antarctic Meridional Overturning Circulation}

Sinking of AABW near Antarctica supplies about half of the deep and abyssal waters in the global ocean (Orsi et al., 1999). AABW spreads northward as part of the global overturning circulation and ventilates the bottom-most portions of much of the ocean. Observed widespread warming of AABW in recent decades (Section 3.5.4) implies a concomitant reduction in its northward spread. Reductions of 1 to $4 \mathrm{~Sv}$ in northward transports of AABW across $24^{\circ} \mathrm{N}$ have been estimated by geostrophic calculations using repeat oceanographic section data between 1981 and 2010 in the North Atlantic Ocean (Johnson et al., 2008b; Frajka-Williams et al., 2011) and between 1985 and 2005 in the North Pacific (Kouketsu et al., 2009). A global full-depth ocean data assimilation study shows a reduction of northward AABW flow across $35^{\circ} \mathrm{S}$ of $>2$ Sv in the South Pacific starting around 1985 and $>1$ Sv in the western South Atlantic since around 1975 (Kouketsu et al., 2011). This reduction is consistent with the contraction in volume of AABW (Purkey and Johnson, 2012) discussed in Section 3.5.4.

Several model studies have suggested that changes in wind stress over the Southern Ocean (Section 3.4) may drive a change in the Southern Ocean overturning circulation (e.g., Le Quéré et al., 2007). A recent analysis of changes in chlorofluorocarbon (CFC) concentrations in the Southern Ocean supports the idea that the overturning cell formed by upwelling of deep water and sinking of intermediate waters has slowed, but does not quantify the change in transport (Waugh et al., 2013).

\subsubsection{Water Exchange Between Ocean Basins}

\subsubsection{The Indonesian Throughflow}

The transport of water from the Pacific to the Indian Ocean via the Indonesian archipelago is the only low-latitude exchange between oceans, and is significant because it is a fluctuating sink/source for very warm tropical water in the two oceans. The Indonesian Throughflow (ITF) transport has been estimated from hydrographic and XBT transects between Australia and Indonesia, and as a synthesis of these together with satellite altimetry, wind stress, and other data (Wunsch, 2010), and from moorings in the principal Indonesian passages. The most comprehensive observations were obtained in 2004-2006 in three passages by the INSTANT mooring array (Sprintall et al., 2009), and show a westward transport of $15.0( \pm 4)$ Sv. For the main passage, Makassar Strait, Susanto et al. (2012) find $13.3( \pm 3.6)$ Sv in the period 2004-2009, with small year-to-year differences. On a longer time scale, the Wunsch (2010) estimate for 1992-2007 was $11.5 \mathrm{~Sv}$ $( \pm 2.4)$ westward, and thus consistent with INSTANT. Wainwright et al. (2008) analyzed data between Australia and Indonesia beginning in the early 1950s, and found a change in the slope of the thermocline for data before and after 1976, indicating a decrease in geostrophic transport by $23 \%$, consistent with a weakening of the tradewinds (e.g., 
Vecchi et al. (2006), who described a downward trend in the Walker circulation since the late 19th century). Other transport estimates based on the IX1 transect show correlation with ENSO variability (Potemra and Schneider, 2007) and no significant trend for the period since 1984 having continuous sampling along IX1 (Sprintall et al., 2002). Overall, the limited evidence provides low confidence that a trend in ITF transport has been observed.

\subsubsection{The Antarctic Circumpolar Current}

There is medium confidence that the westerly winds in the Southern Ocean have increased since the early 1980s (Section 3.4.4), associated with a positive trend in the SAM (Marshall, 2003); also see Sections 3.4.4 and 3.6.3). Although a few observational studies have found evidence for correlation between SAM and ACC transport on subseasonal to interannual scales (e.g., Hughes et al., 2003; Meredith et al., 2004), there is no significant observational evidence of an increase in ACC transport associated with the multi-decadal trend in wind forcing over the Southern Ocean. Repeat hydrographic sections spread unevenly over 35 years in Drake Passage (e.g., Cunningham et al., 2003; Koshlyakov et al., 2007, 2011; Gladyshev et al., 2008), south of Africa (Swart et al., 2008) and south of Australia (Rintoul et al., 2002) reveal moderate variability but no significant trends in these sparse and discontinuous records. A comparison of recent Argo data and a long-term climatology showed that the slope of density surfaces (hence baroclinic transport) associated with the ACC had not changed in recent decades (Böning et al., 2008). Eddy-resolving models suggest the ACC transport is relatively insensitive to trends in wind forcing, consistent with the ACC being in an "eddy-saturated" state where increases in wind forcing are compensated by changes in the eddy field (Hallberg and Gnanadesikan, 2006; Farneti et al., 2010; Spence et al., 2010). While there is limited evidence for (or against) multi-decadal changes in transport of the ACC, observations of changes in temperature, salinity and SSH indicate the current system has shifted poleward (medium confidence) (Böning et al., 2008; Gille, 2008; Morrow et al., 2008; Sokolov and Rintoul, 2009; Kazmin, 2012).

\subsubsection{North Atlantic/Nordic Seas Exchange}

There is no observational evidence of changes during the past two decades in the flow across the Greenland-Scotland Ridge, which connects the North Atlantic with the Norwegian and Greenland Seas. Direct current measurements since the mid-1990s have not shown any significant trends in volume transport for any of the three inflow branches (Østerhus et al., 2005; Hansen et al., 2010; Mauritzen et al., 2011; Jónsson and Valdimarsson, 2012).

The two primary pathways for the deep southward overflows across the Greenland-Scotland Ridge are the Denmark Strait and Faroe Bank Channel. Moored measurements of the Denmark Strait overflow demonstrate significant interannual transport variations (Macrander et al., 2005; Jochumsen et al., 2012), but the time series is not long enough to detect a multi-decadal trend. Similarly, a 10-year time series of moored measurements in the Faroe Bank channel (Olsen et al., 2008) does not show a trend in transport.

\subsubsection{Conclusions}

Recent observations have greatly increased the knowledge of the amplitude of variability in major ocean circulation systems on time scales from years to decades. It is very likely that the subtropical gyres in the North Pacific and South Pacific have expanded and strengthened since 1993, but it is about as likely as not that this reflects a decadal oscillation linked to changes in wind forcing, including changes in winds associated with the modes of climate variability. There is no evidence for a long-term trend in the AMOC amplitude, based on a decade of continuous observations plus several decades of sparse hydrographic transects, or in the longer records of components of the AMOC such as the Florida Current (since 1965), although there are large interannual fluctuations. Nor is there evidence of a trend in the transports of the ITF (over about 20 years), the ACC (about 30 years sparsely sampled), or between the Atlantic and Nordic Seas (about 20 years). Given the short duration of direct measurements of ocean circulation, we have very low confidence that multi-decadal trends can be separated from decadal variability.

\subsection{Sea Level Change, Including Extremes}

\subsubsection{Introduction and Overview of Sea Level Measurements}

Sea level varies as the ocean warms or cools, as water is transferred between the ocean and continents, between the ocean and ice sheets, and as water is redistributed within the ocean due to the tides and changes in the oceanic and atmospheric circulation. Sea level can rise or fall on time scales ranging from hours to centuries, spatial scales from $<1 \mathrm{~km}$ to global, and with height changes from a few millimeters to a meter or more (due to tides). Sea level integrates and reflects multiple climatic and dynamical signals. Measurements of sea level are the longest-running ocean observation system. This section assesses interannual and longer variations in non-tidal sea level from the instrumented period (late 18th century to the present). Sections 4.3 .3 and 4.4.2 assess contributions of glaciers and ice sheets to sea level, Section 5.6 assess reconstructions of sea level from the geological record, Section 10.4.3 assesses detection and attribution of human influences on sea level change, and Chapter 13 synthesizes results and assesses projections of sea level change.

The sea level observing system has evolved over time. There are intermittent records of sea level at four sites in Northern Europe starting in the 1700s. By the late 1800s, there were more tide gauges being operated in Northern Europe, on both North American coasts, and in Australia and New Zealand in the SH (Appendix 3.A). Tide gauges began to be placed on islands far from continental coasts starting in the early 20th century, but a majority of deep-ocean islands did not have an operating tide gauge suitable for climate studies until the early 1970 s.

Tide gauge records measure the combined effect of ocean volume change and vertical land motion (VLM). For detecting climate related variability of the ocean volume, the VLM signal must be removed. One component that can be accounted for to a certain extent is the VLM 
associated with glacial isostatic adjustment (GIA) (Peltier, 2001). In some areas, however, VLM from tectonic activity, groundwater mining, or hydrocarbon extraction is greater than GIA (e.g., Wöppelmann et al., 2009; King et al., 2012); these effects can be reduced by selecting gauges with no known tectonic or subsidence issues (e.g., Douglas, 2001) or by selecting gauges where GIA models have small differences (Spada and Galassi, 2012). More recently, Global Positioning System (GPS) receivers have been installed at tide gauge sites to measure VLM as directly as possible (e.g., Wöppelmann et al., 2009; King et al., 2012). However, these measurements of VLM are only available since the late 1990s at the earliest, and either have to be extrapolated into the past to apply to older records, or used to identify sites without extensive VLM.

Satellite radar altimeters in the 1970s and 1980s made the first nearly global observations of sea level, but these early measurements were highly uncertain and of short duration. The first precise record began with the launch of TOPEX/Poseidon (T/P) in 1992. This satellite and its successors (Jason-1, Jason-2) have provided continuous measurements of sea level variability at 10 -day intervals between approximately $\pm 66^{\circ}$ latitude. Additional altimeters in different orbits (ERS-1, ERS-2, Envisat, Geosat Follow-on) have allowed for measurements up to $\pm 82^{\circ}$ latitude and at different temporal sampling ( 3 to 35 days), although these measurements are not as accurate as those from the T/P and Jason satellites. Unlike tide gauges, altimetry measures sea level relative to a geodetic reference frame (classically a reference ellipsoid that coincides with the mean shape of the Earth, defined within a globally realized terrestrial reference frame) and thus will not be affected by VLM, although a small correction that depends on the area covered by the satellite $\left(\sim 0.3 \mathrm{~mm} \mathrm{yr}^{-1}\right)$ must be added to account for the change in location of the ocean bottom due to GIA relative to the reference frame of the satellite (Peltier, 2001; see also Section 13.1.2).

Tide gauges and satellite altimetry measure the combined effect of ocean warming and mass changes on ocean volume. Although variations in the density related to upper-ocean salinity changes cause regional changes in sea level, when globally averaged their effect on sea level rise is an order of magnitude or more smaller than thermal effects (Lowe and Gregory, 2006). The thermal contribution to sea level can be calculated from in situ temperature measurements (Section 3.2). It has only been possible to directly measure the mass component of sea level since the launch of the Gravity Recovery and Climate Experiment (GRACE) in 2002 (Chambers et al., 2004). Before that, estimates were based either on estimates of glacier and ice sheet mass losses or using residuals between sea level measured by altimetry or tide gauges and estimates of the thermosteric component (e.g., Willis et al., 2004; Domingues et al., 2008), which allowed for the estimation of seasonal and interannual variations as well. GIA also causes a gravitational signal in GRACE data that must be removed in order to determine present-day mass changes; this correction is of the same order of magnitude as the expected trend and is still uncertain at the 30\% level (Chambers et al., 2010).

\subsubsection{Trends in Global Mean Sea Level and Components}

Tide gauges with the longest nearly continuous records of sea level show increasing sea level over the 20th century (Figure 3.12; Woodworth et al., 2009; Mitchum et al., 2010). There are, however, significant interannual and decadal-scale fluctuations about the average rate of sea level rise in all records. Different approaches have been used to compute the mean rate of 20th century global mean sea level (GMSL) rise from the available tide gauge data: computing average rates from only very long, nearly continuous records (Douglas, 2001; Holgate, 2007); using more numerous but shorter records and filters to separate nonlinear trends from decadal-scale quasi-periodic variability (Jevrejeva et al., 2006, 2008); neural network methods (Wenzel and Schroeter, 2010); computing regional sea level for specific basins then

(a)
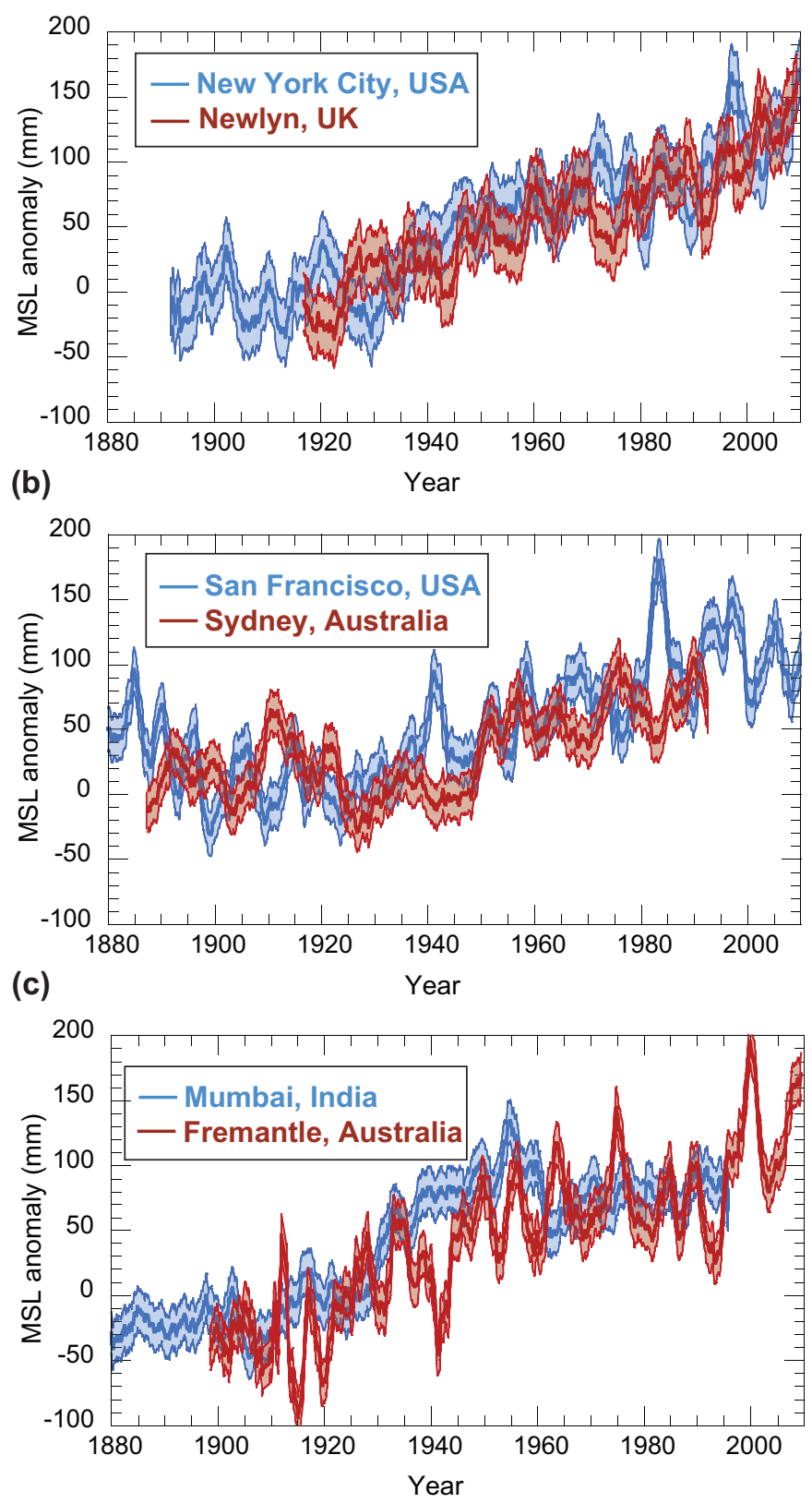

Figure 3.12 3-year running mean sea level anomalies (in millimeters) relative to 1900-1905 from long tide gauge records representing each ocean basin from the Permanent Service for Mean Sea Level (PSMSL) (http://www.psmsl.org), obtained May 2011. Data have been corrected for Glacial Isostatic Adjustment (GIA) (Peltier, 2004), using values available from http://www.psmsl.org/train_and_info/geo_signals/gia/peltier/. Error bars reflect the 5 to $95 \%$ confidence interval, based on the residual monthly variability about the 3 -year running mean. 
(a)

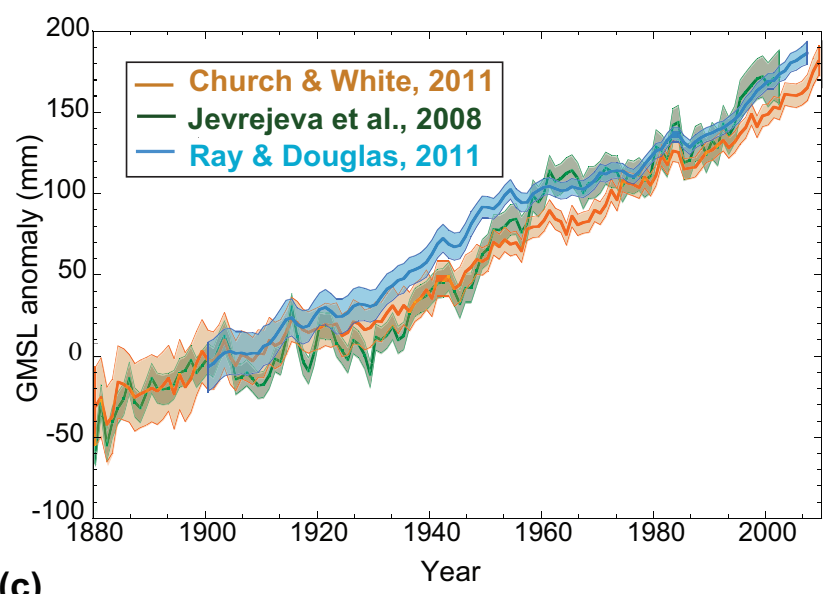

(c)

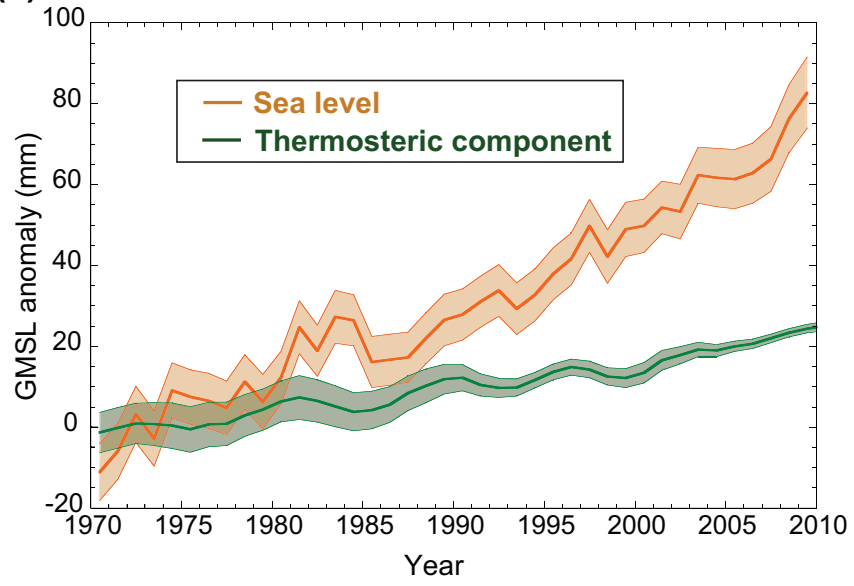

(b)
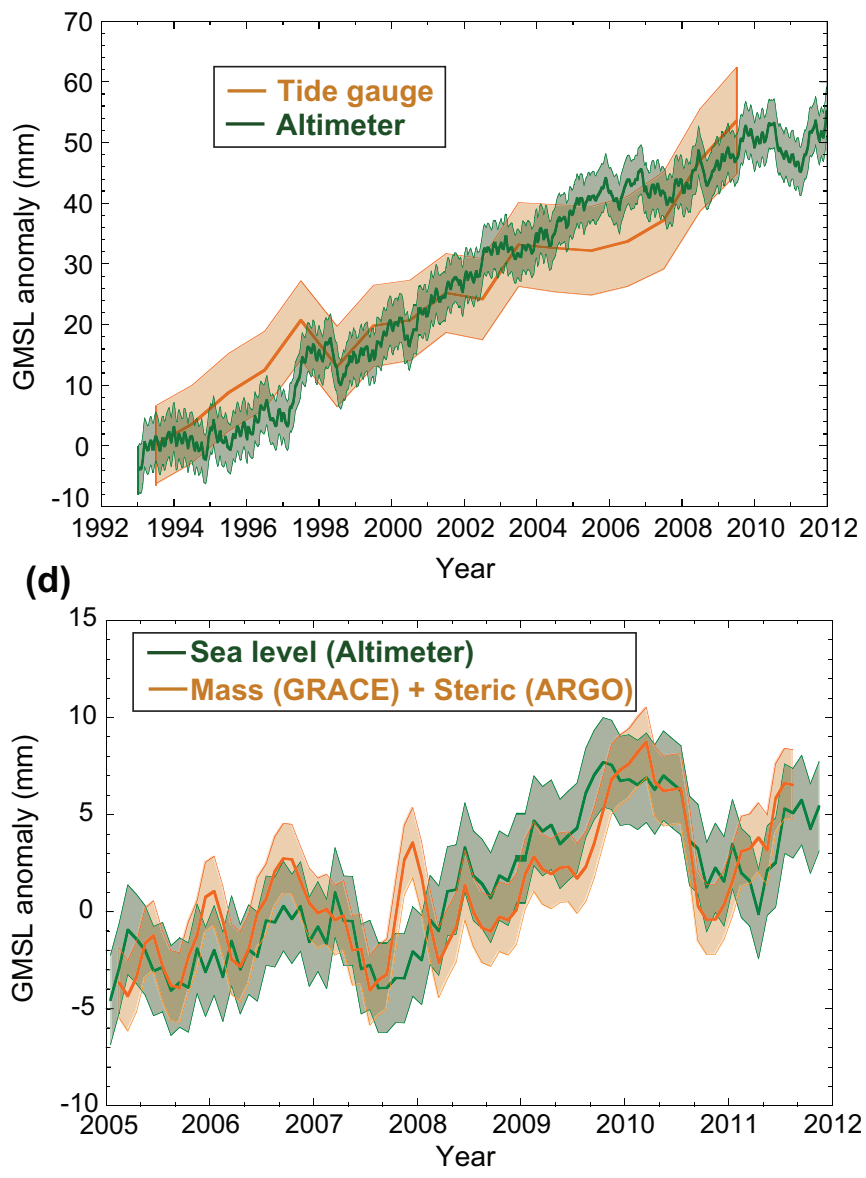

Figure 3.13 | Global mean sea level anomalies (in $\mathrm{mm}$ ) from the different measuring systems as they have evolved in time, plotted relative to 5 -year mean values that start at (a) 1900, (b) 1993, (c) 1970 and (d) 2005. (a) Yearly average GMSL reconstructed from tide gauges (1900-2010) by three different approaches (Jevrejeva et al., 2008; Church and White, 2011; Ray and Douglas, 2011). (b) GMSL (1993-2010) from tide gauges and altimetry (Nerem et al., 2010) with seasonal variations removed and smoothed with a 60-day running mean. (c) GMSL (1970-2010) from tide gauges along with the thermosteric component to $700 \mathrm{~m}$ (3-year running mean) estimated from in situ temperature profiles (updated from Domingues et al., 2008). (d) The GMSL (nonseasonal) from altimetry and that computed from the mass component (GRACE) and steric component (Argo) from 2005 to 2010 (Leuliette and Willis, 2011), all with a 3-month running mean filter. All uncertainty bars are one standard error as reported by the authors. The thermosteric component is just a portion of total sea level, and is not expected to agree with total sea level.

averaging (Jevrejeva et al., 2006, 2008; Merrifield et al., 2009; Wöppelmann et al., 2009); or projecting tide gauge records onto empirical orthogonal functions (EOFs) computed from modern altimetry (Church et al., 2004; Church and White, 2011; Ray and Douglas, 2011) or EOFs from ocean models (Llovel et al., 2009; Meyssignac et al., 2012). Different approaches show very similar long-term trends, but noticeably different interannual and decadal-scale variability (Figure 3.13a). Only the time series from Church and White (2011) extends to 2010, so it is used in the assessment of rates of sea level rise. The rate from 1901 to 2010 is 1.7 [1.5 to 1.9] $\mathrm{mm} \mathrm{yr}^{-1}$ (Table 3.1), which is unchanged from the value in AR4. Rates computed using alternative approaches over the longest common interval (1900-2003) agree with this estimate within the uncertainty.

Since AR4, significant progress has been made in quantifying the uncertainty in GMSL associated with unknown VLM and uncertainty in GIA models. Differences between rates of GMSL rise computed with and without VLM from GPS are smaller than the estimated uncertainties (Merrifield et al., 2009; Wöppelmann et al., 2009). Use of different GIA models to correct tide gauge measurements results in differences less than $0.2 \mathrm{~mm} \mathrm{yr}^{-1}$ (one standard error), and rates of GMSL rise computed from uncorrected tide gauges differ from rates computed from GIA-corrected gauges by only $0.4 \mathrm{~mm} \mathrm{yr}^{-1}$ (Spada and Galassi, 2012), again within uncertainty estimates. This agreement gives increased confidence that the 20th century rate of GMSL rise is not biased high due to unmodeled VLM at the gauges.

Satellite altimetry can resolve interannual fluctuations in GMSL better than tide gauge records because less temporal smoothing is required (Figure 3.13b). It is clear that deviations from the long-term trend can exist for periods of several years, especially during El Niño (e.g., 19971998) and La Niña (e.g., 2011) events (Nerem et al., 1999; Boening et al., 2012; Cazenave et al., 2012). The rate of GMSL rise from 19932010 is 3.2 [2.8 to 3.6$] \mathrm{mm} \mathrm{yr}^{-1}$ based on the average of altimeter time series published by multiple groups (Ablain et al., 2009; Beckley et al., 2010; Leuliette and Scharroo, 2010; Nerem et al., 2010; Church and White, 2011; Masters et al., 2012, Figure 3.13). As noted in AR4, this rate continues to be statistically higher than that for the 20th century 
(Table 3.1). There is high confidence that this change is real and not an artefact of the different sampling or change in instrumentation, as the trends estimated over the same period from tide gauges and altimetry are consistent. Although the rate of GMSL rise has a slightly lower trend between 2005 and 2010 (Nerem et al., 2010), this variation is consistent with earlier interannual fluctuations in the record (e.g., 1993-1997), mostly attributable to El Niño/La Niña cycles (Box 9.2). At least 15 years of data are required to reduce the impact of interannual variations associated with El Niño or La Niña on estimated trends (Nerem et al., 1999).

Since AR4, estimates of both the thermosteric component and mass component of GMSL rise have improved, although estimates of the mass component are possible only since the start of the GRACE measurements in 2002. After correcting for biases in older XBT data [3.2], the rate of thermosteric sea level rise in the upper $700 \mathrm{~m}$ since 1971 is $50 \%$ higher than estimates used for AR4 (Domingues et al., 2008; Wijffels et al., 2008). Because of much sparser upper ocean measurements before 1971, we estimate the trend only since then (Section 3.2). The warming of the upper $700 \mathrm{~m}$ from 1971 to 2010 caused an estimated mean thermosteric rate of rise of 0.6 [0.4 to 0.8$] \mathrm{mm} \mathrm{yr}^{-1}$ ( $90 \%$ confidence), which is $30 \%$ of the observed rate of GMSL rise for the same period (Table 3.1; Figure 3.13c). Although still a short record, more numerous, better distributed, and higher quality profile measurements from the Argo program are now being used to estimate the steric component for the upper $700 \mathrm{~m}$ as well as for the upper $2000 \mathrm{~m}$ (Domingues et al., 2008; Willis et al., 2008, 2010; Cazenave et al., 2009; Leuliette and Miller, 2009; Leuliette and Willis, 2011; Llovel et al., 2011; von Schuckmann and Le Traon, 2011; Levitus et al., 2012). However, these data have been shown to be best suited for global analyses after 2005 owing to a combination of interannual variability and large biases when using data before 2005 owing to sparser sampling (Leuliette and Miller, 2009; von Schuckmann and Le Traon, 2011). Comparison of sparse but accurate temperature measurements from the World Ocean Circulation Experiment in the 1990s with Argo data from 2006 to 2008 also indicates a significant rise in global thermosteric sea level, although the estimate is uncertain owing to relatively sparse 1990s sampling (Freeland and Gilbert, 2009).

Observations of the contribution to sea level rise from warming below $700 \mathrm{~m}$ are still uncertain due to limited historical data, especially in the Southern Ocean (Section 3.2). Before Argo, they are based on 5-year averages to $2000 \mathrm{~m}$ depth (Levitus et al., 2012). From 1971 to 2010, the estimated trend for the contribution between $700 \mathrm{~m}$ and $2000 \mathrm{~m}$ is 0.1 [0 to 0.2] mm yr ${ }^{-1}$ (Table 3.1; Levitus et al., 2012). To measure the contribution of warming below $2000 \mathrm{~m}$, much sparser but very accurate temperature profiles along repeat hydrographic sections are utilized (Purkey and Johnson, 2010; Kouketsu et al., 2011). The studies have found a significant warming trend between 1000 and $4000 \mathrm{~m}$ within and south of the Sub-Antarctic Front (Figure 3.3). The estimated total contribution of warming below $2000 \mathrm{~m}$ to global mean sea level rise between about 1992 and 2005 is 0.1 [0.0 to 0.2] mm yr-1 (95\% confidence as reported by authors; Purkey and Johnson, 2010).

Detection of the mass component of sea level from the GRACE mission was not assessed in AR4, as the record was too short and there was still considerable uncertainty in the measurements and corrections required. Considerable progress has been made since AR4, and the mass component of sea level measured by GRACE has been increasing at a rate between 1 and $2 \mathrm{~mm} \mathrm{yr}^{-1}$ since 2002 (Willis et al., 2008, 2010; Cazenave et al., 2009; Leuliette and Miller, 2009; Chambers et al., 2010; Llovel et al., 2010; Leuliette and Willis, 2011). Differences between studies are due partially to the time periods used to compute trends, as there are significant interannual variations in the mass component of GMSL (Willis et al., 2008; Chambers et al., 2010; Llovel et al., 2010; Boening et al., 2012), but also to substantial differences in GIA corrections applied, of order $1 \mathrm{~mm} \mathrm{yr}^{-1}$. Recent evaluations of the GIA correction have found explanations for the difference (Chambers et al., 2010; Peltier et al., 2012), but uncertainty of $0.3 \mathrm{~mm} \mathrm{yr}^{-1}$ is still probable. Measurements of sea level from altimetry and the sum of observed steric and mass components are also consistent at monthly scales during the time period when Argo data have global distribution (Figure 3.13d), which gives high confidence that the current ocean observing system is capable of resolving the rate of sea level rise and its components.

\subsubsection{Regional Distribution of Sea Level Change}

Large-scale spatial patterns of sea level change are known to high precision only since 1993, when satellite altimetry became available (Figure 3.10). These data have shown a persistent pattern of change since the early 1990s in the Pacific, with rates of rise in the Warm Pool of the western Pacific up to three times larger than those for GMSL, while rates over much of the eastern Pacific are near zero or negative (Beckley et al., 2010). The increasing sea level in the Warm Pool started shortly before the launch of TOPEX/Poseidon (Merrifield, 2011), and is caused by an intensification of the trade winds (Merrifield and Maltrud, 2011) since the late 1980s that may be related to the Pacific Decadal Oscillation (PDO) (Merrifield et al., 2012; Zhang and Church, 2012). The lower rate of sea level rise since 1993 along the western coast of the United States has also been attributed to changes in the wind stress curl over the North Pacific associated with the PDO (Bromirski et al., 2011). While global maps can be created using EOF analysis (e.g., Church et al., 2004; Llovel et al., 2009), pre-1993 results are still uncertain, as the method assumes that the EOFs since 1993 are capable of representing the patterns in previous decades, and results may be biased in the middle of the ocean where there are no tide gauges to constrain the estimate (Ray and Douglas, 2011). Several studies have examined individual long tide gauge records in the North Atlantic and found coherent decadal-scale fluctuations along both the USA east coast (Sturges and Hong, 1995; Hong et al., 2000; Miller and Douglas, 2007), the European coast (Woodworth et al., 2010; Sturges and Douglas, 2011; Calafat et al., 2012), and the marginal seas in the western North Pacific (Marcos et al., 2012), all related to natural climate variability.

There is still considerable uncertainty on how long large-scale patterns of regional sea level change can persist, especially in the Pacific where the majority of tide gauge records are less than 40 years long. Based on analyses of the longest records in the Atlantic, Indian and Pacific Oceans (including the available gauges in the Southern Ocean) there are significant multi-decadal variations in regional sea level (Holgate, 2007; Woodworth et al., 2009, 2011; Mitchum et al., 2010; Chambers et al., 2012). Hence local rates of sea level rise can 
be considerably higher or lower than the global mean rate for periods of a decade or more.

The preceding discussion of regional sea level trends has focused on effects that appear to be related to regional ocean volume change, and not those due to vertical land motion. As discussed in Section 3.7.1, vertical land motion can dramatically affect local sea level change. Some extreme examples of vertical land motion are in Neah Bay, Washington, where the signal is $+3.8 \mathrm{~mm} \mathrm{yr}^{-1}$ (uplift from tectonic activity); Galveston, Texas, where the value is $-5.9 \mathrm{~mm} \mathrm{yr}^{-1}$ (subsidence from groundwater mining); and Nedre Gavle, Sweden where the value is $+7.1 \mathrm{~mm} \mathrm{yr}^{-1}$ (uplift from GIA), all computed from nearby GPS receivers (Wöppelmann et al., 2009). These areas will all have longterm rates of sea level rise that are significantly higher or lower than those due to ocean volume change alone, but as these rates are not related to climate change, they are not discussed here.

\subsubsection{Assessment of Evidence for Accelerations in Sea Level Rise}

AR4 concluded that there was "high confidence that the rate of global sea level rise increased from the 19th to the 20th century" but could not be certain as to whether the higher rate since 1993 was reflective of decadal variability or a further increase in the longer-term trend. Since AR4, there has been considerable effort to quantify the level of decadal and multi-decadal variability and to detect acceleration in GMSL and mean sea level at individual tide gauges. It has been clear for some time that there was a significant increase in the rate of sea level rise in the four oldest records from Northern Europe starting in the early to mid-19th century (Ekman, 1988; Woodworth, 1990, 1999; Mitchum et al., 2010). Estimates of the change in the rate have been computed, either by comparing trends over 100-year intervals for the Stockholm site (Ekman, 1988; Woodworth, 1990), or by fitting a quadratic term to all the long records starting before 1850 (Woodworth, 1990, 1999). The results are consistent and indicate a significant acceleration that started in the early to mid-19th century (Woodworth, 1990, 1999), although some have argued it may have started in the late 1700s (Jevrejeva et al., 2008). The increase in the rate of sea level rise at Stockholm (the longest record that extends past 1900) has been based on differencing 100-year trends from 1774-1884 and 1885-1985. The estimated change is 1.0 [0.7 to 1.3$] \mathrm{mm} \mathrm{yr}^{-1}$ per century (1 standard error, as calculated by Woodworth, 1990). Although sites in other ocean basins do show an increased trend after 1860 (e.g., Figure 3.12), it is impossible to detect a change in the early to mid-1800s in other parts of the ocean using tide gauge data alone, as there are no observations.

Numerous studies have attempted to quantify if a detectable acceleration has continued into the 20th century, typically by fitting a quadratic to data at individual tide gauges (Woodworth, 1990; Woodworth et al., 2009, 2011; Houston and Dean, 2011; Watson, 2011) as well as to reconstructed time series of GMSL (Church and White, 2006; Jevrejeva et al., 2008; Church and White, 2011; Rahmstorf and Vermeer, 2011), or by examining differences in long-term rates computed at different tide gauges (Sallenger et al., 2012). Woodworth et al. (2011) find significant quadratic terms at the sites that begin before 1860 (all in the NH). Other authors using more numerous but significantly shorter records have found either insignificant or small negative quadratic terms in sea level around the United States and Australia since 1920 (Houston and Dean, 2011; Watson, 2011), or large positive quadratic values since 1950 along the U.S. east coast (Sallenger et al., 2012). However, fitting a quadratic term to tide gauge data after 1920 results in highly variable, insignificant quadratic terms (Rahmstorf and Vermeer, 2011), and so only studies that use data before 1920 and that extend until 2000 or beyond are suitable for evaluating long-term acceleration of sea level.

A long time scale is needed because significant multi-decadal variability appears in numerous tide gauge records during the 20th century (Holgate, 2007; Woodworth et al., 2009, 2011; Mitchum et al., 2010; Chambers et al., 2012). The multi-decadal variability is marked by an increasing trend starting in 1910-1920, a downward trend (i.e., leveling of sea level if a long-term trend is not removed) starting around 1950, and an increasing trend starting around 1980. The pattern can be seen in New York, Mumbai and Fremantle records, for instance (Figure 3.12), as well as 14 other gauges representing all ocean basins (Chambers et al., 2012), and in all reconstructions (Figure 3.14). It is also seen in an analysis of upper $400 \mathrm{~m}$ temperature (Gouretski et al., 2012; Section 3.3.2). Although the calculations of 18-year rates of GMSL rise based on the different reconstruction methods disagree by as much as $2 \mathrm{~mm} \mathrm{yr}^{-1}$ before 1950 and on details of the variability (Figure 3.14), all do indicate 18-year trends that were significantly higher than the 20th century average at certain times (1920-1950, 1990-present) and lower at other periods (1910-1920, 1955-1980), likely related to multi-decadal variability. Several studies have suggested these variations may be linked to climate fluctuations like the Atlantic Multi-decadal Oscillation (AMO) and/or Pacific Decadal Oscillation (PDO, Box 2.5) (Holgate, 2007; Jevrejeva et al., 2008; Chambers et al., 2012), but these results are not conclusive.

While technically correct that these multi-decadal changes represent acceleration/deceleration of sea level, they should not be interpreted as change in the longer-term rate of sea level rise, as a time series longer than the variability is required to detect those trends. Using data

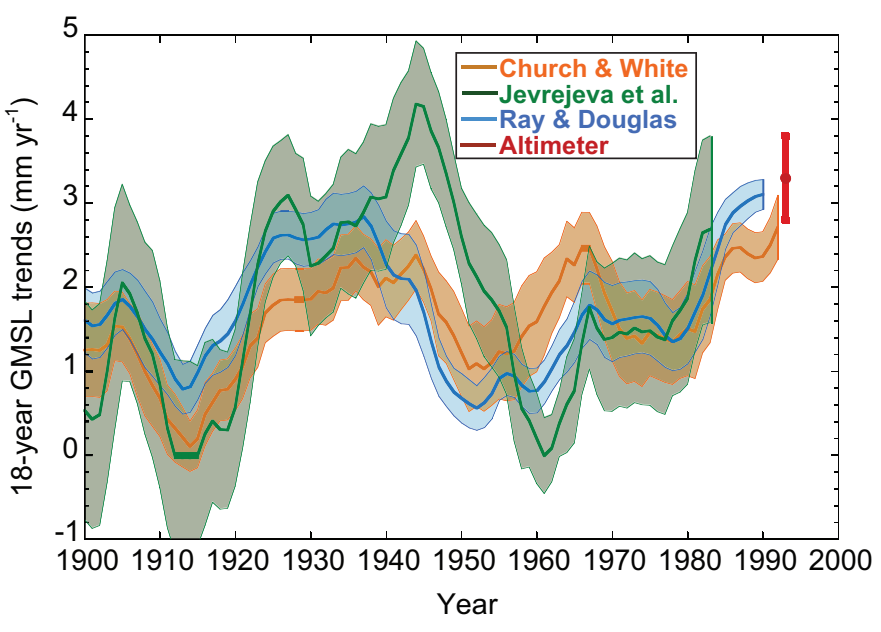

Figure 3.14 | 18-year trends of GMSL rise estimated at 1-year intervals. The time is the start date of the 18-year period, and the shading represents the $90 \%$ confidence. The estimate from satellite altimetry is also given, with the $90 \%$ confidence given as an error bar. Uncertainty is estimated by the variance of the residuals about the fit, and accounts for serial correlation in the residuals as quantified by the lag-1 autocorrelation. 
extending from 1900 to after 2000, the quadratic term computed from both individual tide gauge records and GMSL reconstructions is significantly positive (Jevrejeva et al., 2008; Church and White, 2011; Rahmstorf and Vermeer, 2011; Woodworth et al., 2011). Church and White (2006) report that the estimated acceleration term in GMSL (twice the quadratic parameter) is 0.009 [0.006 to 0.012 ] $\mathrm{mm} \mathrm{yr}^{-2}$ (1 standard deviation) from 1880 to 2009 , which is consistent with the other published estimates (e.g., Jevrejeva et al., 2008; Woodworth et al., 2009) that use records longer than 100 years. Chambers et al. (2012) find that modelling a period near 60 years removes much of the multi-decadal variability of the 20th century in the tide gauge reconstruction time series. When a 60 -year oscillation is modeled along with an acceleration term, the estimated acceleration in GMSL since 1900 ranges from: 0.000 [ -0.002 to 0.002$] \mathrm{mm} \mathrm{yr}^{-2}$ in the Ray and Douglas (2011) record, 0.013 [0.007 to 0.019] $\mathrm{mm} \mathrm{yr}^{-2}$ in the Jevrejeva et al. (2008) record, and 0.012 [0.009 to 0.015] $\mathrm{mm} \mathrm{yr}^{-2}$ in the Church and White (2011) record. Thus, while there is more disagreement on the value of a 20th century acceleration in GMSL when accounting for multi-decadal fluctuations, two out of three records still indicate a significant positive value. The trend in GMSL observed since 1993, however, is not significantly larger than the estimate of 18-year trends in previous decades (e.g., 1920-1950).

\subsubsection{Changes in Extreme Sea Level}

Aside from non-climatic events such as tsunamis, extremes in sea level (i.e., coastal flooding, storm surge, high water events, etc.) tend to be caused by large storms, especially when they occur at times of high tide. However, any low-pressure system offshore with associated high winds can cause a coastal flooding event depending on the duration and direction of the winds. Evaluation of changes in frequency and intensity of storms have been treated in Sections 2.6.3 and 2.6.4, as well as SREX Chapter 3 (Section 3.5.2). The main conclusions from both are that there is low confidence of any trend or long term change in tropical or extratropic storm frequency or intensity in any ocean basin, although there is robust evidence for an increase in the most intense tropical cyclones in the North Atlantic basin since the 1970s. The magnitude and frequency of extreme events can still increase without a change in storm intensity, however, if the mean water level is also increasing. AR4 concluded that the highest water levels have been increasing since the 1950s in most regions of the world, caused mainly by increasing mean sea level. Studies published since AR4 continue to support this conclusion, although higher regional extremes are also caused by large interannual and multi-decadal variations in sea level associated with climate fluctuations such as ENSO, the North Atlantic Oscillation and the Atlantic Multi-decadal Oscillation, among others (e.g., Abeysirigunawardena and Walker, 2008; Haigh et al., 2010; Menéndez and Woodworth, 2010; Park et al., 2011).

Global analyses of the changes in extreme sea level are limited, and most reports are based on analysis of regional data (see Lowe et al., 2010 for a review). Estimates of changes in extremes rely either on the analysis of local tide gauge data, or on multi-decadal hindcasts of a dynamical model (WASA-Group, 1998). Most analyses have focused on specific regions and find that extreme values have been increasing since the 1950s, using various statistical measures such as annual maximum surge, annual maximum surge-at-high-water, monthly mean high water level, changes in number of high storm surge events, or changes in 99th percentile events (e.g., Church et al., 2006; D'Onofrio et al., 2008; Marcos et al., 2009; Haigh et al., 2010; Letetrel et al., 2010; Tsimplis and Shaw, 2010; Vilibic and Sepic, 2010; Grinsted et al., 2012). A global analysis of tide gauge records has been performed for data from the 1970s onwards when the global data sampling has been robust and finds that the magnitude of extreme sea level events has increased in all regions studied since that time (Woodworth and Blackman, 2004; Menéndez and Woodworth, 2010; Woodworth et al., 2011).

The height of a 50-year flood event has increased anywhere from 2 to more than $10 \mathrm{~cm}$ per decade since 1970 (Figure 3.15a), although some areas have seen a negative rate because vertical land motion is much larger than the rate of mean sea level rise. However, when the annual median height at each gauge is removed to reduce the effect of local mean sea level rise, interannual and decadal fluctuations, and vertical land motion, the rate of extreme sea level change drops in $49 \%$ of the gauges to below significance (Figure 3.15b), while at $45 \%$ it fell to less than $5 \mathrm{~mm} \mathrm{yr}^{-1}$. Only $6 \%$ of tide gauge records evaluated had a change in the amplitude of more than $5 \mathrm{~mm} \mathrm{yr}^{-1}$ after removing mean sea level variations, mainly in the southeast United States, the western Pacific, Southeast Asia and a few locations in Northern Europe. The higher rates in the southeastern United States have been linked to larger storm surge events unconnected to global sea level rise (Grinsted et al., 2012).

(a)

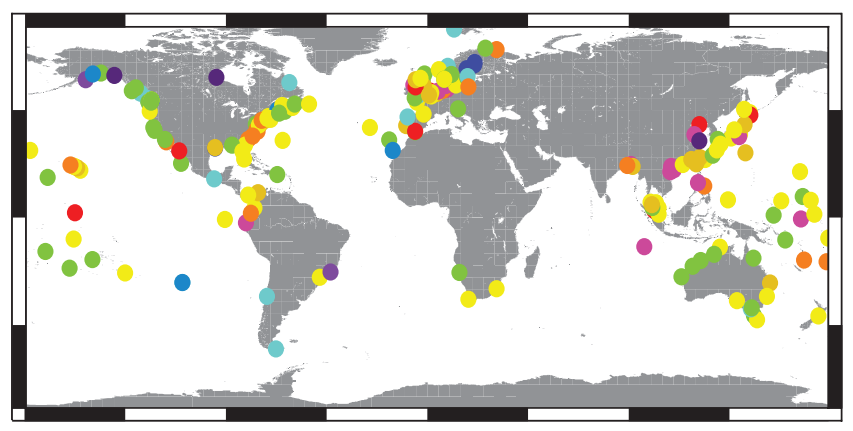

(b)

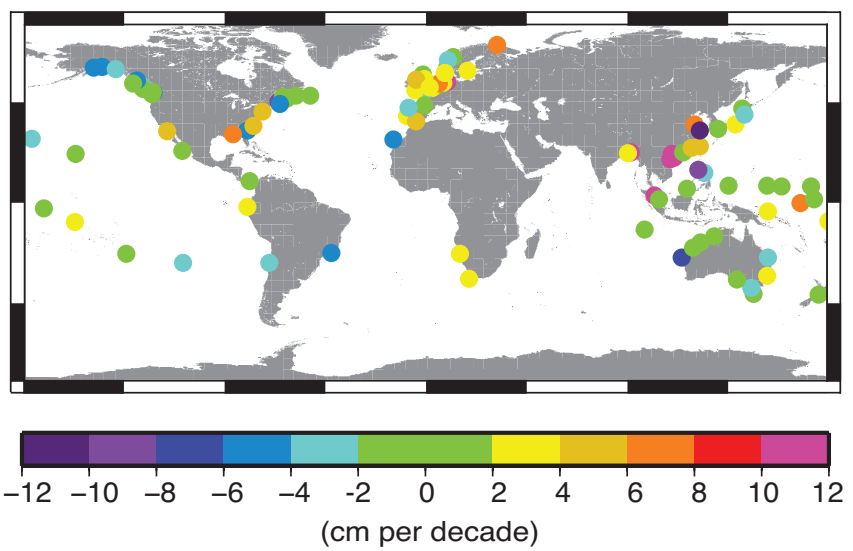

Figure 3.15 | Estimated trends ( $\mathrm{cm}$ per decade) in the height of a 50-year event in extreme sea level from (a) total elevation and (b) total elevation after removal of annual medians. Only trends significant at the $95 \%$ confidence level are shown. (Data are from Menéndez and Woodworth, 2010.) 


\subsubsection{Conclusions}

It is virtually certain that globally averaged sea level has risen over the 20th century, with a very likely mean rate between 1900 and 2010 of 1.7 [1.5 to 1.9$] \mathrm{mm} \mathrm{yr}^{-1}$ and 3.2 [2.8 and 3.6] mm yr $\mathrm{r}^{-1}$ between 1993 and 2010. This assessment is based on high agreement among multiple studies using different methods, and from independent observing systems (tide gauges and altimetry) since 1993. It is likely that a rate comparable to that since 1993 occurred between 1920 and 1950, possibly due to a multi-decadal climate variation, as individual tide gauges around the world and all reconstructions of GMSL show increased rates of sea level rise during this period. Although local vertical land motion can cause even larger rates of sea level rise (or fall) relative to the coastline, it is very likely that this does not affect the estimates of the global average rate, based on multiple estimations of the average with and without VLM corrections.

It is virtually certain that interannual and decadal changes in the large-scale winds and ocean circulation can cause significantly higher or lower rates over shorter periods at individual locations, as this has been observed in tide gauge records around the world. Warming of the upper $700 \mathrm{~m}$ of the ocean has very likely contributed an average of 0.6 [0.4 to 0.8$] \mathrm{mm} \mathrm{yr}^{-1}$ of sea level change since 1971 . Warming between $700 \mathrm{~m}$ and $2000 \mathrm{~m}$ has likely been contributing an additional $0.1 \mathrm{~mm}$ $\mathrm{yr}^{-1}$ [0 to 0.2 ] of sea level rise since 1971, and warming below 2000 $\mathrm{m}$ likely has been contributing another $0.1[0.0$ to 0.2$] \mathrm{mm} \mathrm{yr}^{-1}$ of sea level rise since the early 1990 s.

It is very likely that the rate of mean sea level rise along Northern European coastlines has accelerated since the early 1800 s and that this has continued through the 20th century, as the increased rate since 1875 has been observed in multiple long tide gauge records and by different groups using different analysis techniques. It is likely that sea level rise throughout the NH has also accelerated since 1850, as this is also observed in a smaller number of gauges along the coast of North America. Two of the three time series based on reconstructing GMSL from tide gauge data back to 1900 or earlier indicate a significant positive acceleration, while one does not. The range is -0.002 to 0.019 $\mathrm{mm} \mathrm{yr}^{2}$, so it is likely that GMSL has accelerated since 1900. Finally, it is likely that extreme sea levels have increased since 1970, largely as a result of the rise in mean sea level.

\subsection{Ocean Biogeochemical Changes, Including Anthropogenic Ocean Acidification}

The oceans can store large amounts of $\mathrm{CO}_{2}$. The reservoir of inorganic carbon in the ocean is roughly 50 times that of the atmosphere (Sabine et al., 2004). Therefore even small changes in the ocean reservoir can have an impact on the atmospheric concentration of $\mathrm{CO}_{2}$. The ocean

Table 3.1 Estimated trends in GMSL and components over different periods from representative time-series. Trends and uncertainty have been estimated from a time series provided by the authors using ordinary least squares with the uncertainty representing the $90 \%$ confidence interval. The model fit for yearly averaged time series was a bias + trend the model fit for monthly and 10-day averaged data was a bias + trend + seasonal sinusoids. Uncertainty accounts for correlations in the residuals.

\begin{tabular}{|c|c|c|c|c|}
\hline Quantity & Period & $\begin{array}{c}\text { Trend } \\
\left(\mathrm{mm} \mathrm{yr}^{-1}\right)\end{array}$ & Source & Resolution \\
\hline \multirow{3}{*}{ GMSL } & $1901-2010$ & $1.7[1.5$ to 1.9$]$ & Tide Gauge Reconstruction (Church and White, 2011) & Yearly \\
\hline & $1971-2010$ & $2.0[1.7$ to 2.3$]$ & Tide Gauge Reconstruction (Church and White, 2011) & Yearly \\
\hline & $1993-2010$ & $2.8[2.3$ to 3.3$]$ & Tide Gauge Reconstruction (Church and White, 2011) & Yearly \\
\hline \multirow{2}{*}{$\begin{array}{l}\text { Thermosteric Component } \\
\text { (upper } 700 \mathrm{~m} \text { ) }\end{array}$} & $1971-2010$ & $0.6[0.4$ to 0.8$]$ & XBT Reconstruction (updated from Domingues et al., 2008) & 3-Year running means \\
\hline & 1993-2010 & $0.8[0.5$ to 1.1$]$ & XBT Reconstruction (updated from Domingues et al., 2008) & 3-Year running means \\
\hline $\begin{array}{l}\text { Thermosteric Component } \\
\text { (700 to } 2000 \mathrm{~m})\end{array}$ & $1971-2010$ & $0.1[0$ to 0.2$]$ & Objective mapping of historical temperature data (Levitus et al., 2012) & 5-Year averages \\
\hline \multirow{2}{*}{$\begin{array}{l}\text { Thermosteric Component } \\
\text { (whole depth) }\end{array}$} & $1971-2010$ & $0.8[0.5 \text { to } 1.1]^{\mathrm{c}}$ & Combination of estimates from 0 to $700 \mathrm{~m}, 700$ to $2000 \mathrm{~m}$, and below $2000 \mathrm{mc}^{\mathrm{c}}$ & Trend only \\
\hline & $1993-2010$ & $1.1[0.8 \text { to } 1.4]^{\mathrm{c}}$ & Combination of estimates from $0-700 \mathrm{~m}, 700$ to $2000 \mathrm{~m}$, and below $2000 \mathrm{~m}^{\mathrm{c}}$ & Trend only \\
\hline
\end{tabular}

Notes:

a Uncertainty estimated from fit to Nerem et al. (2010) time series and includes potential systematic error owing to drift of altimeter, estimated to be \pm 0.4 mm yr ${ }^{-1}$ (Beckley et al., 2010 ; Nerem et al., 2010), applied as the root-sum-square (RSS) with the least squares error estimate. The uncertainty in drift contains uncertainty in the reference frame, orbit and instrument.

b Trend value taken from Purkey and Johnson (2010), Table 1. Uncertainty represents the $2.5-97.5 \%$ confidence interval.

c Assumes no trend below $2000 \mathrm{~m}$ before 1 January 1992, then value from Purkey and Johnson (2010) afterwards. Uncertainty for 0 to $700 \mathrm{~m}, 700$ to $2000 \mathrm{~m}$ and below $2000 \mathrm{~m}$ is assumed to be uncorrelated, and uncertainty is calculated as RSS of the uncertainty for each layer. 
also provides an important sink for carbon dioxide released by human activities, the anthropogenic $\mathrm{CO}_{2}\left(\mathrm{C}_{\text {ant }}\right)$. Currently, an amount of $\mathrm{CO}_{2}$ equivalent to approximately $30 \%$ of the total human emissions of $\mathrm{CO}_{2}$ to the atmosphere is accumulating in the ocean (Mikaloff-Fletcher et al., 2006; Le Quéré et al., 2010). In this section, observations of change in the ocean uptake of carbon, the inventory of $C_{a n t}$ and ocean acidification are assessed, as well as changes in oxygen and nutrients. Chapter 6 provides a synthesis of the overall carbon cycle, including the ocean, atmosphere and biosphere and considering both past trends and future projections.

\subsubsection{Carbon}

\subsubsection{Ocean Uptake of Carbon}

The air-sea flux of $\mathrm{CO}_{2}$ is computed from the observed difference in the partial pressure of $\mathrm{CO}_{2}\left(\mathrm{pCO}_{2}\right)$ across the air-water interface $\left(\triangle \mathrm{pCO}_{2}\right.$ $=\mathrm{pCO}_{2, \mathrm{sw}}-\mathrm{pCO}_{2, \text { air }}$ ), the solubility of $\mathrm{CO}_{2}$ in seawater, and the gas transfer velocity (Wanninkhof et al., 2009). However, the limited geographic and temporal coverage of the $\triangle \mathrm{pCO}_{2}$ measurement as well as uncertainties in wind forcing and transfer velocity parameterizations mean that uncertainties in global and regional fluxes calculated from measurements of $\triangle \mathrm{pCO}_{2}$ can be as larges as $\pm 50 \%$ (Wanninkhof et al., 2013). Using $\triangle \mathrm{pCO}_{2}$ data in combination with the riverine input Gruber et al. (2009) estimated a global uptake rate of 1.9 [1.2 to 2.5] PgC $\mathrm{yr}^{-1}$ for the time period 1995-2000 and Takahashi et al. (2009) found 2.0 [1.0 to 3.0] PgC $\mathrm{yr}^{-1}$ normalized to the year 2000. Uncertainties in fluxes calculated from $\triangle p \mathrm{CO}_{2}$ are too large to detect trends in global ocean carbon uptake.

Trends in surface ocean $p \mathrm{CO}_{2}$ are calculated from ocean time series stations and repeat hydrographic sections in the North Atlantic and North Pacific (Table 3.2). At all locations and for all time periods shown, $\mathrm{pCO}_{2}$ in both the atmosphere and ocean has increased, while $\mathrm{pH}$ and $\left[\mathrm{CO}_{3}{ }^{2-}\right]$ have decreased. At some sites, oceanic surface $\mathrm{pCO}_{2}$ increased faster than the atmospheric trend, implying a decreasing uptake of atmospheric $\mathrm{CO}_{2}$ at those locations. The oceanic $\mathrm{pCO}_{2}$ trend can differ from that in the atmosphere owing to changes in the intensity of biological production and changes in physical conditions, for instance between El Niño and La Niña (Keeling et al., 2004; Midorikawa et al., 2005; Yoshikawa-Inoue and Ishii, 2005; Takahashi et al., 2006, 2009; Schuster and Watson, 2007; Ishii et al., 2009; McKinley et al., 2011; Bates, 2012; Lenton et al., 2012).

Although local variations of $\triangle \mathrm{pCO}_{2}$ with time have little effect on the atmospheric $\mathrm{CO}_{2}$ growth rate in the short term, they provide important information on the dynamics of the ocean carbon cycle and the potential for longer-term climate feedbacks. For example, El Niño and La Niña can drive large changes in the efflux of $\mathrm{CO}_{2}$ in the Pacific. Differences in $\triangle \mathrm{pCO}_{2}$ can exceed $100 \mu \mathrm{atm}$ in the eastern and central equatorial Pacific between El Niño and La Niña; an increase in $\triangle \mathrm{pCO}_{2}$ observed between 1998 and 2004 was attributed to wind and circulation changes associated with the Pacific Decadal Oscillation (Feely et al., 2006). $\mathrm{CO}_{2}$ uptake in the North Atlantic decreased by 0.24 [0.190.29] PgC yr-1 between 1994 and 2003 (Schuster and Watson, 2007) and has partially recovered since then (Watson et al., 2009). Linear trends for the North Atlantic from 1995 to 2009 reveal an increased uptake (Schuster et al., 2013). Uptake of $\mathrm{CO}_{2}$ in the Subtropical Mode Water (STMW) of the North Atlantic was enhanced during the 1990s, a predominantly positive phase of the $\mathrm{NAO}$, and much reduced in the 2000s when the NAO phase was neutral or negative (Bates, 2012). Observations in the Indian and Pacific sectors of the Southern Ocean were interpreted as evidence for reduced winter-time $\mathrm{CO}_{2}$ uptake as a result of increased winds, increased upwelling and outgassing of natural $\mathrm{CO}_{2}$ (Metzl, 2009; Lenton et al., 2012).

\subsubsection{Changes in the Oceanic Inventory of Anthropogenic Carbon Dioxide}

Ocean carbon uptake and storage is inferred from changes in the inventory of anthropogenic carbon. $C_{\text {ant }}$ cannot be measured directly but is calculated from observations of ocean properties (Appendix 3.A discusses the sampling on which the ocean carbon inventory is based). Two independent data-based methods to calculate anthropogenic carbon inventories exist: the $\Delta C^{*}$ method (Sabine et al., 2004), and the transit time distribution (TTD) method (Waugh et al., 2006). The Green's function approach that applies the maximum entropy de-convolution methodology (Khatiwala et al., 2009) is related to the latter. These approaches use different tracer data, for instance, the TTD method is based mostly on chlorofluorcarbon measurements. Changes due to variability in ocean productivity (Chavez et al., 2011) are not considered.

Estimates of the global inventory of $C_{\text {ant }}$ (including marginal seas) calculated using these methods have a mean value of $118 \mathrm{PgC}$ and a range of 93 to $137 \mathrm{PgC}$ in 1994 and a mean of $160 \mathrm{PgC}$ and range of 134 to 186 PgC in 2010 (Sabine et al., 2004; Waugh et al., 2006; Khatiwala et al., 2009, 2013). When combined with model results (MikaloffFletcher et al., 2006; Doney et al., 2009; Gerber et al., 2009; Graven et al., 2012), Khatiwala et al. (2013) arrive at a "best" estimate of the global ocean inventory (including marginal seas) of anthropogenic carbon from 1750 to 2010 of $155 \mathrm{PgC}$ with an uncertainty of $\pm 20 \%$ (Figure 3.16). While the estimates of total inventory agree within their uncertainty, the different methods result in significant differences in the inferred spatial distribution of $C_{\text {ant }}$, particularly at high latitudes.

The $C_{\text {ant }}$ inventory "best" estimate of 155 PgC (Khatiwala et al., 2013; Figure 3.16) corresponds to an uptake rate of 2.3 (range of 1.7 to 2.9) $\mathrm{PgC} \mathrm{yr}^{-1}$ from 2000 to 2010, in close agreement with an independent estimate of 2.5 (range of 1.8 to 3.2) $\mathrm{PgC} \mathrm{yr}{ }^{-1}$ based on atmospheric $\mathrm{O}_{2} /$ $\mathrm{N}_{2}$ measurements obtained for the same period (Ishidoya et al., 2012). The $\mathrm{O}_{2} / \mathrm{N}_{2}$ method resulted in $2.2 \pm 0.6 \mathrm{PgC} \mathrm{yr}^{-1}$ for the time period 1990 to 2000 and $2.5 \pm 0.6$ for the period from 2000 to 2010 (Keeling and Manning, 2014). These estimates are also consistent with an independent estimate of $1.9 \pm 0.4 \mathrm{PgC}^{-1}{ }^{-1}$ for the period between 1970 and 1990 based on depth-integrated $\delta^{13} \mathrm{C}$ changes (Quay et al., 2003) and with estimates inferred from $\triangle \mathrm{pCO}_{2}$.

The storage rate of anthropogenic $\mathrm{CO}_{2}$ is assessed by calculating the change in $\mathrm{C}_{\text {ant }}$ concentrations between two time periods. Regional observations of the storage rate are in general agreement with that expected from the increase in atmospheric $\mathrm{CO}_{2}$ concentrations and with the tracer-based estimates. However, there are significant spatial and temporal variations in the degree to which the inventory of $C_{a n t}$ 

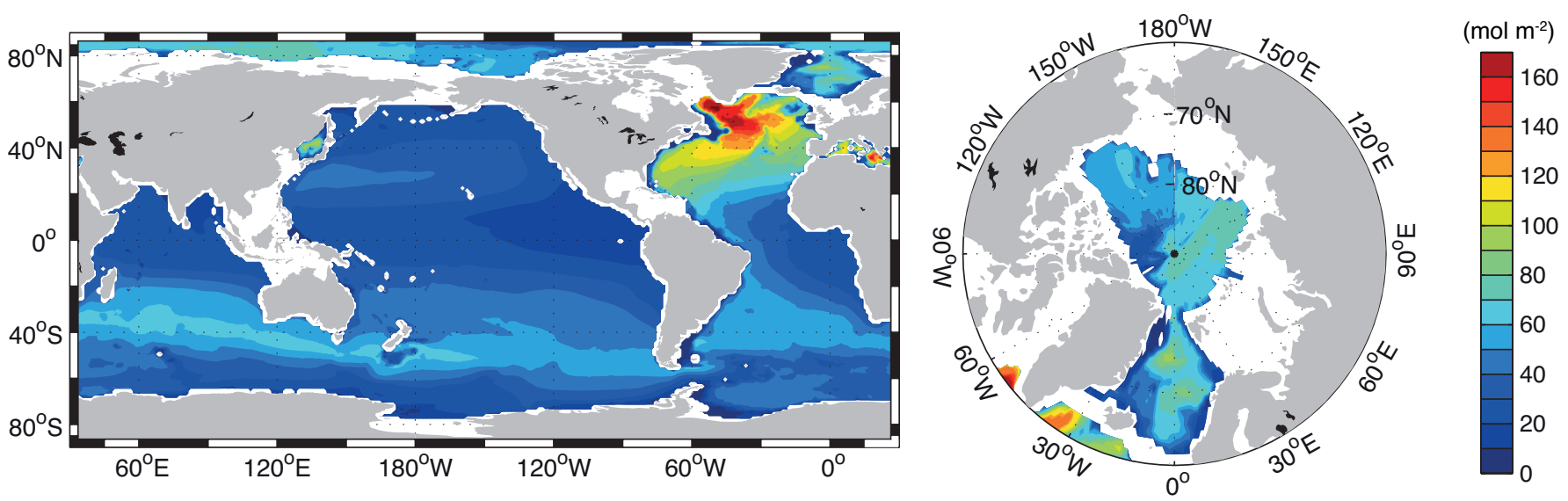

Figure 3.16 Compilation of the 2010 column inventories $\left(\mathrm{mol} \mathrm{m}^{-2}\right.$ ) of anthropogenic $\mathrm{CO}_{2}$ : the global Ocean excluding the marginal seas (updated from Khatiwala et al., 2009) $150 \pm 26$ PgC; Arctic Ocean (Tanhua et al., 2009) 2.7 to 3.5 PgC; the Nordic Seas (Olsen et al., 2010) 1.0 to 1.6 PgC; the Mediterranean Sea (Schneider et al., 2010 ) 1.6 to 2.5 PgC; the Sea of Japan(Park et al., 2006) $0.40 \pm 0.06$ PgC. From Khatiwala et al. (2013).

tracks changes in the atmosphere (Figure 3.17). The North Atlantic, in particular, is an area with high variability in circulation and deep water formation, influencing the $C_{\text {ant }}$ inventory. As a result of the decline in Labrador Sea Water (LSW) formation since 1997 (Rhein et al., 2011), the $C_{\text {ant }}$ increase between 1997 and 2003 was smaller in the subpolar North Atlantic than expected from the atmospheric increase, in contrast to the subtropical and equatorial Atlantic (Steinfeldt et al., 2009). Perez et al. (2010) also noted the dependence of the $C_{\text {ant }}$ storage rate in the North Atlantic on the NAO, with high $\mathrm{C}_{\text {ant }}$ storage rate during phases of high NAO (i.e., high LSW formation rates) and low storage during phases of low NAO (low formation). Wanninkhof et al. (2010) found a smaller inventory increase in the North Atlantic compared to the South Atlantic between 1989 and 2005.

Ocean observations are insufficient to assess whether there has been a change in the rate of total (anthropogenic plus natural) carbon uptake by the global ocean. Evidence from regional ocean studies (often covering relatively short time periods), atmospheric observations and models is equivocal, with some studies suggesting the ocean uptake rate of total $\mathrm{CO}_{2}$ may have declined (Le Quéré et al., 2007; Schuster and Watson, 2007; McKinley et al., 2011) while others conclude that there is little evidence for a decline (Knorr, 2009; Gloor et al., 2010; Sarmiento et al., 2010). A study based on atmospheric $\mathrm{CO}_{2}$ observations and emission inventories concluded that global carbon uptake by land and oceans doubled from 1960 to 2010, implying that it is unlikely that on a global scale both land and ocean sinks decreased (Ballantyne et al., 2012).

In summary, the high agreement between multiple lines of independent evidence for increases in the ocean inventory of $C_{\text {ant }}$ underpins the conclusion that it is virtually certain that the ocean is sequestering anthropogenic carbon dioxide and very likely that the oceanic $C_{\text {ant }}$ inventory increased from 1994 to 2010. Oceanic carbon uptake rates calculated using different data sets and methods agree within their uncertainties and very likely range between 1.0 and $3.2 \mathrm{PgC} \mathrm{yr}^{-1}$.

\subsubsection{Anthropogenic Ocean Acidification}

The uptake of $\mathrm{CO}_{2}$ by the ocean changes the chemical balance of seawater through the thermodynamic equilibrium of $\mathrm{CO}_{2}$ with seawater. Dissolved $\mathrm{CO}_{2}$ forms a weak acid $\left(\mathrm{H}_{2} \mathrm{CO}_{3}\right)$ and, as $\mathrm{CO}_{2}$ in seawater increases, the $\mathrm{pH}$, carbonate ion $\left(\mathrm{CO}_{3}{ }^{2-}\right)$, and calcium carbonate $\left(\mathrm{CaCO}_{3}\right)$ saturation state of seawater decrease while bicarbonate ion $\left(\mathrm{HCO}_{3}^{-}\right)$increases (FAQ 3.3). Variations in oceanic total dissolved inorganic carbon $\left(\mathrm{C}_{\mathrm{T}}=\mathrm{CO}_{2}+\mathrm{CO}_{3}{ }^{2-}+\mathrm{HCO}_{3}{ }^{-}\right)$and $\mathrm{pCO}$ reflect changes in both the natural carbon cycle and the uptake of anthropogenic $\mathrm{CO}_{2}$ from the atmosphere. The mean $\mathrm{pH}$ (total scale) of surface waters ranges between 7.8 and 8.4 in the open ocean, so the ocean remains mildly basic (pH > 7) at present (Orr et al., 2005a; Feely et al., 2009). Ocean uptake of $\mathrm{CO}_{2}$ results in gradual acidification of seawater; this
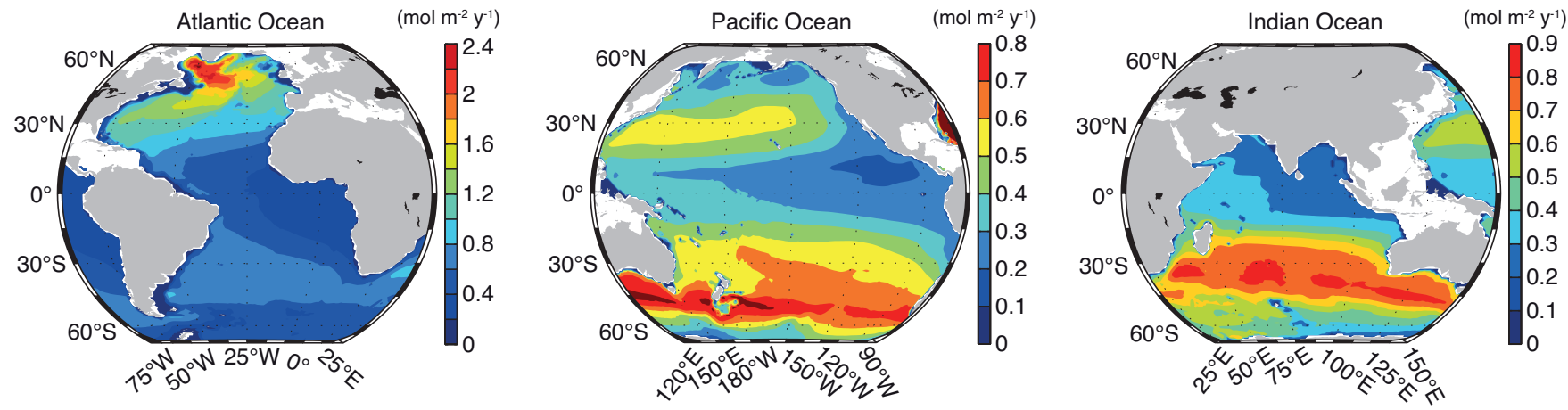

Figure 3.17| Maps of storage rate distribution of anthropogenic carbon ( $\left.\mathrm{mol} \mathrm{m}^{-2} \mathrm{yr}^{-1}\right)$ for the three ocean basins (left to right: Atlantic, Pacific and Indian Ocean) averaged over 1980-2005 estimated by the Green's function approach (Khatiwala et al., 2009). Note that a different colour scale is used in each basin. 
process is termed ocean acidification (Box 3.2) (Broecker and Clark, 2001; Caldeira and Wickett, 2003). The observed decrease in ocean $\mathrm{pH}$ of 0.1 since the beginning of the industrial era corresponds to a $26 \%$ increase in the hydrogen ion concentration $\left[\mathrm{H}^{+}\right]$concentration of seawater (Orr et al., 2005b; Feely et al., 2009). The consequences of changes in $\mathrm{pH}_{1} \mathrm{CO}_{3}{ }^{2-}$, and the saturation state of $\mathrm{CaCO}_{3}$ minerals for marine organisms and ecosystems are just beginning to be understood (see WGII Chapters 5, 6, 28 and 30).

A global mean decrease in surface water $\mathrm{pH}$ of 0.08 from 1765 to 1994 was calculated based on the inventory of anthropogenic $\mathrm{CO}_{2}$ (Sabine et al., 2004), with the largest reduction $(-0.10)$ in the northern North Atlantic and the smallest reduction $(-0.05)$ in the subtropical South Pacific. These regional variations in the size of the $\mathrm{pH}$ decrease are consistent with the generally lower buffer capacities of the high latitude oceans compared to lower latitudes (Egleston et al., 2010).

Direct measurements on ocean time-series stations in the North Atlantic and North Pacific record decreasing $\mathrm{pH}$ with rates ranging between -0.0014 and $-0.0024 \mathrm{yr}^{-1}$ (Table 3.2, Figure 3.18; Bates, 2007, 2012; Santana-Casiano et al., 2007; Dore et al., 2009; Olafsson et al., 2009; González-Dávila et al., 2010). Directly measured pH differences in the surface mixed layer along repeat transects in the central North Pacific Ocean between Hawaii and Alaska showed a $-0.0017 \mathrm{yr}^{-1}$ decline in pH between 1991 and 2006, in agreement with observations at the time-series sites (Byrne et al., 2010). This rate of $\mathrm{pH}$ change is also consistent with repeat transects of $\mathrm{CO}_{2}$ and $\mathrm{pH}$ measurements in the western North Pacific (winter: $-0.0018 \pm 0.0002 \mathrm{yr}^{-1}$; summer: -0.0013 $\pm 0.0005 \mathrm{yr}^{-1}$ ) (Midorikawa et al., 2010). The pH changes in southern ocean surface waters are less certain because of the paucity of longterm time-series observations there, but $\mathrm{pCO}_{2}$ measurements collected by ships-of-opportunity indicate similar rates of $\mathrm{pH}$ decrease there (Takahashi et al., 2009).

Uptake of anthropogenic $\mathrm{CO}_{2}$ is the dominant cause of observed changes in the carbonate chemistry of surface waters (Doney et al., 2009). Changes in carbonate chemistry in subsurface waters can also reflect local physical and biological variability. As an example, while pH changes in the mixed layer of the North Pacific Ocean can be explained solely by equilibration with atmospheric $\mathrm{CO}_{2}$, declines in $\mathrm{pH}$ between $800 \mathrm{~m}$ and the mixed layer in the time period 1991-2006 were attributed in approximately equal measure to anthropogenic and natural variations (Byrne et al., 2010). Figure 3.19 shows the portion of $\mathrm{pH}$ changes between the surface and $1000 \mathrm{~m}$ that were attributed solely to the effects of anthropogenic $\mathrm{CO}_{2}$. Seawater $\mathrm{pH}$ and $\left[\mathrm{CO}_{3}{ }^{2-}\right]$ decreased by 0.0014 to $0.0024 \mathrm{yr}^{-1}$ and $\sim 0.4$ to $0.9 \mu \mathrm{mol} \mathrm{kg}^{-1} \mathrm{yr}^{-1}$, respectively, between 1988 and 2009 (Table 3.2). Over longer time periods, anthropogenic changes in ocean chemistry are expected to become increasingly prominent relative to changes imparted by physical and biological variability.

The consistency of these observations demonstrates that the $\mathrm{pH}$ of surface waters has decreased as a result of ocean uptake of anthropogenic $\mathrm{CO}_{2}$ from the atmosphere. There is high confidence that the $\mathrm{pH}$ decreased by 0.1 since the preindustrial era.
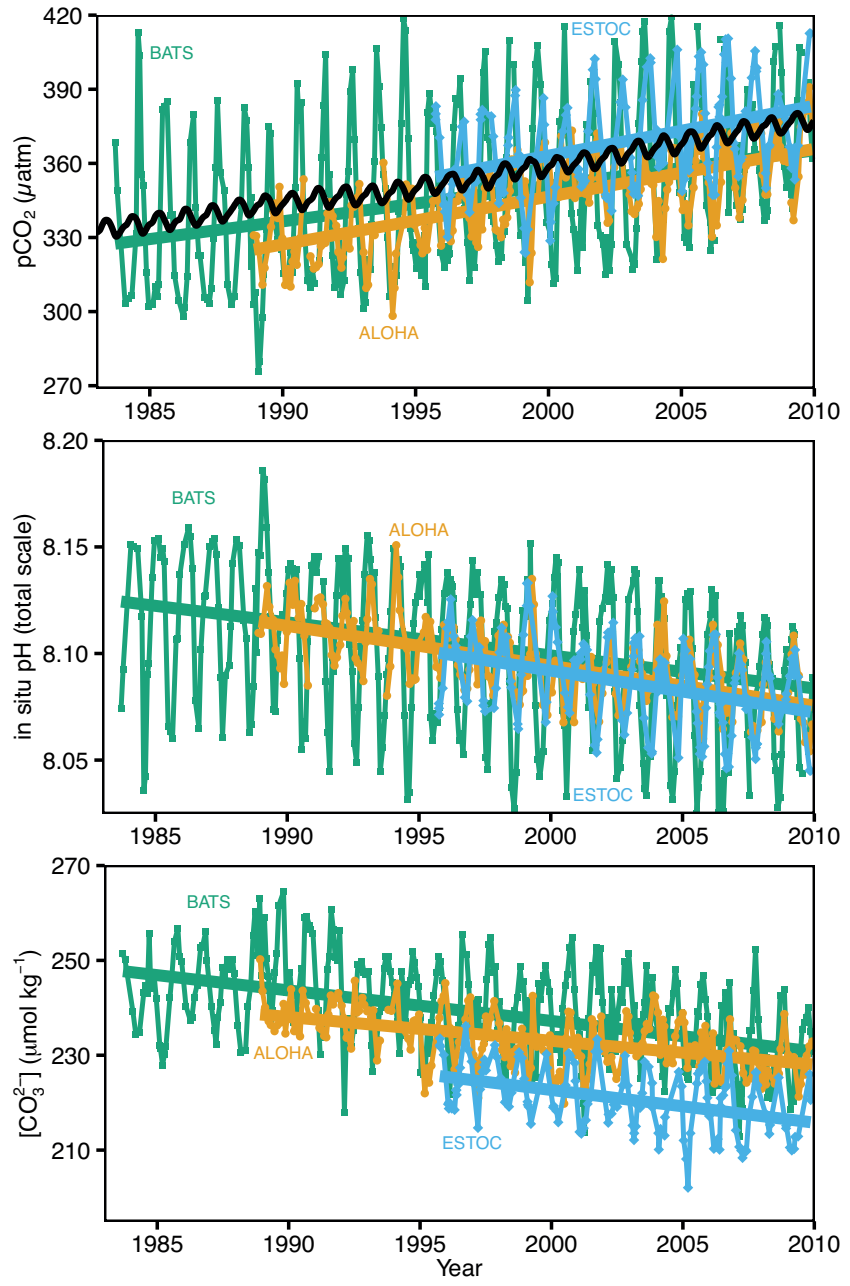

Figure 3.18 | Long-term trends of surface seawater $\mathrm{pCO}_{2}$ (top), $\mathrm{pH}$ (middle) and carbonate ion (bottom) concentration at three subtropical ocean time series in the North Atlantic and North Pacific Oceans, including (a) Bermuda Atlantic Time-series Study (BATS, $31^{\circ} 40^{\prime} \mathrm{N}, 64^{\circ} 10^{\prime} \mathrm{W}$; green) and Hydrostation S (32 $10^{\prime}, 64^{\circ} 30^{\prime} \mathrm{W}$ ) from 1983 to present (updated from Bates, 2007); (b) Hawaii Ocean Time-series (HOT) at Station ALOHA (A Long-term Oligotrophic Habitat Assessment; $22^{\circ} 45^{\prime} \mathrm{N}, 158^{\circ} 00^{\prime} \mathrm{W}$; orange) from 1988 to present (updated from Dore et al., 2009) and (c) European Station for Time series in the Ocean (ESTOC, $29^{\circ} 10^{\prime} \mathrm{N}, 15^{\circ} 30^{\prime} \mathrm{W}$; blue) from 1994 to present (updated from González-Dávila et al., 2010). Atmospheric $\mathrm{pCO}_{2}$ (black) from the Mauna Loa Observatory Hawaii is shown in the top panel. Lines show linear fits to the data, whereas Table 3.2 give results for harmonic fits to the data (updated from Orr, 2011).

\subsubsection{Oxygen}

As a consequence of the early introduction of standardized methods and the relatively wide interest in the distribution of dissolved oxygen, the historical record of marine oxygen observations is generally richer than that of other biogeochemical parameters, although still sparse compared to measurements of temperature and salinity (Appendix 3.A). Dissolved oxygen changes in the ocean thermocline has generally decreased since 1960, but with strong regional variations (Keeling et al., 2010; Keeling and Manning, 2014). Oxygen concentrations at 300 dbar decreased between $50^{\circ} \mathrm{S}$ and $50^{\circ} \mathrm{N}$ at a mean rate of $0.63 \mu \mathrm{mol}$ $\mathrm{kg}^{-1}$ per decade between 1960 and 2010 (Stramma et al., 2012). For the period 1970 to 1990, the mean annual global oxygen loss between $100 \mathrm{~m}$ and $1000 \mathrm{~m}$ was calculated to be $0.55 \pm 0.13 \times 10^{14} \mathrm{~mol} \mathrm{yr}^{-1}$ (Helm et al., 2011). 


\section{Box 3.2 | Ocean Acidification}

Ocean acidification refers to a reduction in $\mathrm{pH}$ of the ocean over an extended period, typically decades or longer, caused primarily by the uptake of carbon dioxide $\left(\mathrm{CO}_{2}\right)$ from the atmosphere. Ocean acidification can also be caused by other chemical additions or subtractions from the oceans that are natural (e.g., increased volcanic activity, methane hydrate releases, long-term changes in net respiration) or human-induced (e.g., release of nitrogen and sulphur compounds into the atmosphere). Anthropogenic ocean acidification refers to the component of pH reduction that is caused by human activity (IPCC, 2011).

Since the beginning of the industrial era, the release of $\mathrm{CO}_{2}$ from industrial and agricultural activities has resulted in atmospheric $\mathrm{CO}_{2}$ concentrations that have increased from approximately 280 ppm to about 392 ppm in 2012 (Chapter 6). The oceans have absorbed approximately $155 \mathrm{PgC}$ from the atmosphere over the last two and a half centuries (Sabine et al., 2004; Khatiwala et al., 2013). This natural process of absorption has benefited humankind by significantly reducing the greenhouse gas levels in the atmosphere and abating some of the impacts of global warming. However, the ocean's uptake of carbon dioxide is having a significant impact on the chemistry of seawater. The average $\mathrm{pH}$ of ocean surface waters has already fallen by about 0.1 units, from about 8.2 to 8.1 (total scale), since the beginning of the industrial revolution (Orr et al., 2005a; Figure 1; Feely et al., 2009). Estimates of future atmospheric and oceanic carbon dioxide concentrations indicate that, by the end of this century, the average surface ocean $\mathrm{pH}$ could be lower than it has been for more than 50 million years (Caldeira and Wickett, 2003).

The major controls on seawater $\mathrm{pH}$ are atmospheric $\mathrm{CO}_{2}$ exchange, the production and respiration of dissolved and particulate organic matter in the water column, and the formation and dissolution of calcium carbonate minerals. Oxidation of organic matter lowers dissolved oxygen concentrations, adds $\mathrm{CO}_{2}$ to solution, reduces $\mathrm{pH}$, carbonate ion $\left(\mathrm{CO}_{3}{ }^{2-}\right)$ and calcium carbonate $\left(\mathrm{CaCO}_{3}\right)$ saturation states (Box 3.2, Figure 2), and lowers the $\mathrm{pH}$ of seawater in subsurface waters (Byrne et al., 2010). As a result of these processes, minimum $\mathrm{pH}$ values in the oceanic water column are generally found near the depths of the oxygen minimum layer. When $\mathrm{CO}_{2}$ reacts with seawater it forms carbonic acid $\left(\mathrm{H}_{2} \mathrm{CO}_{3}\right)$, which is highly reactive and reduces the concentration of carbonate ion (Box 3.2, Figure 2) and can affect shell formation for marine animals such as corals, plankton, and shellfish. This process could affect fundamental biological and chemical processes of the sea in coming decades (Fabry et al., 2008; Doney et al., 2009; WGII Chapters 5, 6, 28 and 30). (continued on next page)
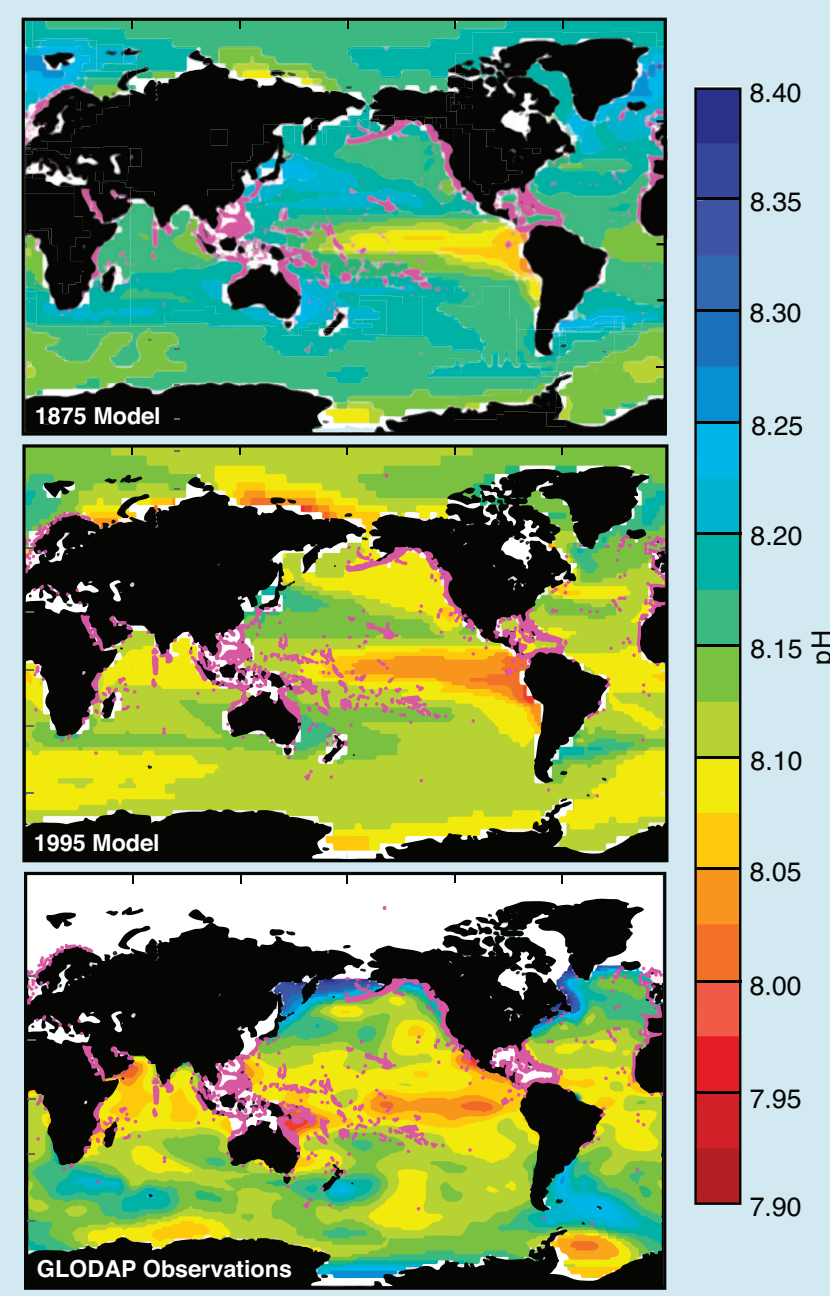

Box 3.2, Figure 1 | National Center for Atmospheric Research Community Climate System Model 3.1 (CCSM3)-modeled decadal mean pH at the sea surface centred on the years 1875 (top) and 1995 (middle). Global Ocean Data Analysis Project (GLODAP)-based pH at the sea surface, nominally for 1995 (bottom). Deep and shallow-water coral reefs are indicated with magenta dots. White areas indicate regions with no data. (After Feely et al., 2009.)
The long-term deoxygenation of the open ocean thermocline is consistent with the expectation that warmer waters can hold less dissolved oxygen (solubility effect), and that warming-induced stratification leads to a decrease in the transport of dissolved oxygen from surface to subsurface waters (stratification effect) (Matear and Hirst, 2003; Deutsch et al., 2005; Frölicher et al., 2009). Observations of oxygen change suggested that about $15 \%$ of the oxygen decline between 1970 and 1990 could be explained by warming and the remainder by reduced ventilation due to increased stratification (Helm et al., 2011; see Table 6.14).

Oxygen concentrations in the tropical ocean thermocline decreased in each of the ocean basins over the last 50 years (Ono et al., 2001; Stramma et al., 2008; Keeling et al., 2010; Helm et al., 2011), resulting in an expansion of the dissolved oxygen minimum zones. A comparison of data between 1960 and 1974 with those from 1990 to 2008 showed 
Box 3.2 (continued)
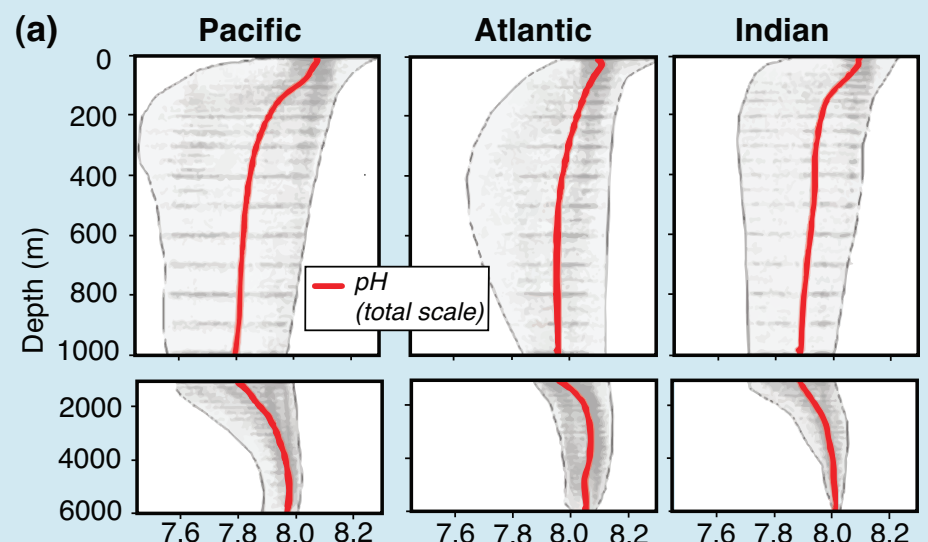

\section{(b)}
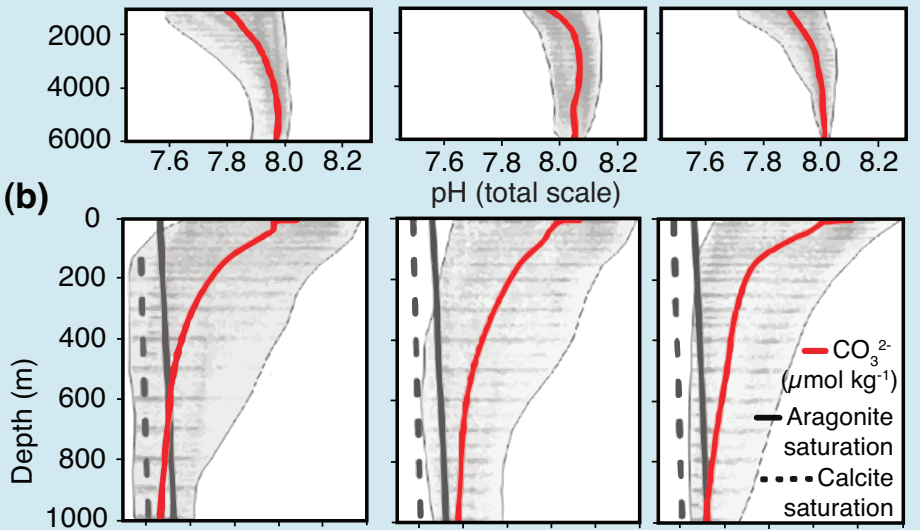
$\mathrm{pH}$ (total scale)

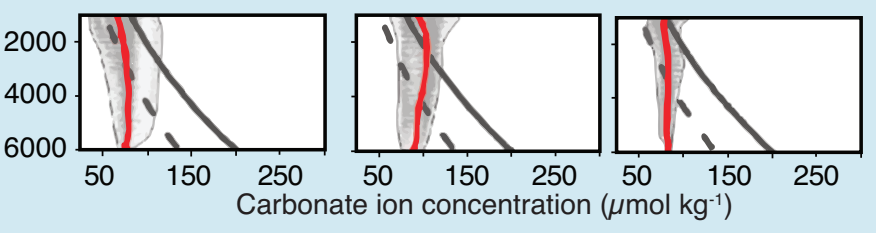

Box 3.2, Figure 2 | Distribution of (a) pH and (b) carbonate $\left(\mathrm{CO}_{3}{ }^{2-}\right)$ ion concentration in the Pacific, Atlantic and Indian Oceans. The data are from the World Ocean Circulation Experiment/Joint Global Ocean Flux Study/Ocean Atmosphere Carbon Exchange Study global carbon dioxide $\left(\mathrm{CO}_{2}\right)$ survey $(\mathrm{Sabine}$ et al., 2005). The lines show the mean $\mathrm{pH}$ (red solid line, top panel), mean $\mathrm{CO}_{3}{ }^{2-}$ (red solid line, bottom panel), and aragonite and calcite (black solid and dashed lines, bottom panel) saturation values for each of these basins (modified from Feely et al., 2009). The shaded areas show the range of values within the ocean basins. Dissolution of aragonite and calcite shells and skeletons occurs when $\mathrm{CO}_{3}{ }^{2-}$ concentrations drop below the saturation level, reducing the ability of calcifying organisms to produce their shells and skeletons.

that oxygen concentrations decreased in most tropical regions at an average rate of 2 to $3 \mu \mathrm{mol} \mathrm{kg}{ }^{-1}$ per decade (Figure 3.20; Stramma et al., 2010). Data from one of the longest time-series sites in the subpolar North Pacific (Station Papa, $50^{\circ} \mathrm{N}, 145^{\circ} \mathrm{W}$ ) reveal a persistent declining oxygen trend in the thermocline over the last 50 years (Whitney et al., 2007), superimposed on oscillations with time scales of a few years to two decades. Stendardo and Gruber (2012) found dissolved oxygen decreases in upper water masses of the North Atlantic and increases in intermediate water masses. The changes were caused by changes in solubility as well as changes in ventilation and circulation over time. In contrast to the widely distributed oxygen declines, oxygen increased in the thermoclines of the Indian and South Pacific Oceans from the 1990s to the 2000s (McDonagh et al., 2005; Álvarez et al., 2011), apparently due to strengthened circulation driven by stronger winds (Cai, 2006; Roemmich et al., 2007). In the southern Indian Ocean below the thermocline, east of $75^{\circ} \mathrm{E}$, oxygen decreased between 1960 and 2010 most prominently on the isopycnals $\sigma_{\theta}=26.9$ to 27.0 (Kobayashi et al., 2012). While some studies suggest a widespread decline of oxygen in the Southern Ocean (e.g., Helm et al., 2011), other studies show regions of alternating sign (e.g., Stramma et al., 2010), reflecting differences in data and period considered.

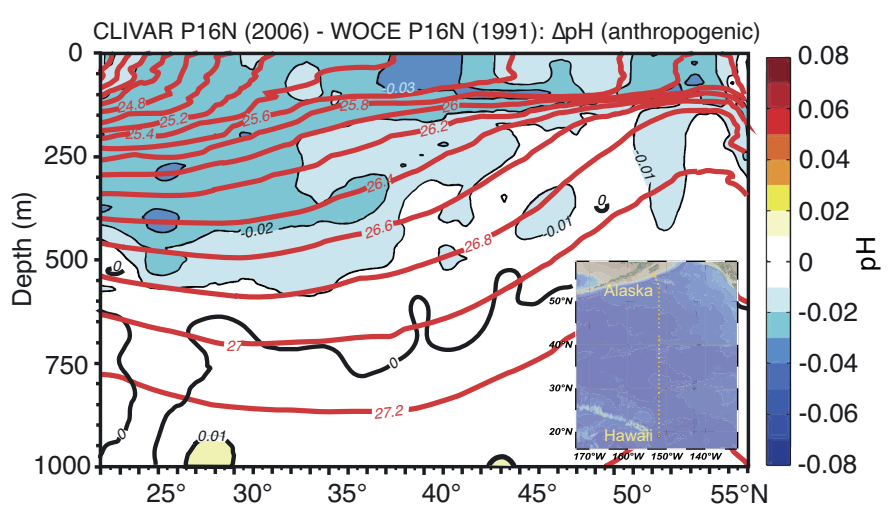

Figure 3.19 $\triangle \mathrm{pH}_{\text {ant: }}$ : $\mathrm{HH}$ change attributed to the uptake of anthropogenic carbon between 1991 and 2006, at about 150W, Pacific Ocean (from Byrne et al., 2010). The red lines show the layers of constant density. 
Frequently Asked Questions

\section{FAQ 3.3 | How Does Anthropogenic Ocean Acidification Relate to Climate Change?}

Both anthropogenic climate change and anthropogenic ocean acidification are caused by increasing carbon dioxide concentrations in the atmosphere. Rising levels of carbon dioxide $\left(\mathrm{CO}_{2}\right)$, along with other greenhouse gases, indirectly alter the climate system by trapping heat as it is reflected back from the Earth's surface. Anthropogenic ocean acidification is a direct consequence of rising $\mathrm{CO}_{2}$ concentrations as seawater currently absorbs about $30 \%$ of the anthropogenic $\mathrm{CO}_{2}$ from the atmosphere.

Ocean acidification refers to a reduction in $\mathrm{pH}$ over an extended period, typically decades or longer, caused primarily by the uptake of $\mathrm{CO}_{2}$ from the atmosphere. $\mathrm{pH}$ is a dimensionless measure of acidity. Ocean acidification describes the direction of $\mathrm{pH}$ change rather than the end point; that is, ocean $\mathrm{pH}$ is decreasing but is not expected to become acidic $(\mathrm{pH}<7)$. Ocean acidification can also be caused by other chemical additions or subtractions from the oceans that are natural (e.g., increased volcanic activity, methane hydrate releases, long-term changes in net respiration) or human-induced (e.g., release of nitrogen and sulphur compounds into the atmosphere). Anthropogenic ocean acidification refers to the component of $\mathrm{pH}$ reduction that is caused by human activity.

Since about 1750, the release of $\mathrm{CO}_{2}$ from industrial and agricultural activities has resulted in global average atmospheric $\mathrm{CO}_{2}$ concentrations that have increased from 278 to 390.5 ppm in 2011. The atmospheric concentration of $\mathrm{CO}_{2}$ is now higher than experienced on the Earth for at least the last 800,000 years and is expected to continue to rise because of our dependence on fossil fuels for energy. To date, the oceans have absorbed approximately $155 \pm$ $30 \mathrm{PgC}$ from the atmosphere, which corresponds to roughly one-fourth of the total amount of $\mathrm{CO}_{2}$ emitted $(555 \pm$ $85 \mathrm{PgC}$ ) by human activities since preindustrial times. This natural process of absorption has significantly reduced the greenhouse gas levels in the atmosphere and minimized some of the impacts of global warming. However, the ocean's uptake of $\mathrm{CO}_{2}$ is having a significant impact on the chemistry of seawater. The average pH of ocean surface waters has already fallen by about 0.1 units, from about 8.2 to 8.1 since the beginning of the Industrial Revolution. Estimates of projected future atmospheric and oceanic $\mathrm{CO}_{2}$ concentrations indicate that, by the end of this century, the average surface ocean $\mathrm{pH}$ could be 0.2 to 0.4 lower than it is today. The $\mathrm{pH}$ scale is logarithmic, so a change of 1 unit corresponds to a 10 -fold change in hydrogen ion concentration.

When atmospheric $\mathrm{CO}_{2}$ exchanges across the air-sea interface it reacts with seawater through a series of four chemical reactions that increase the concentrations of the carbon species: dissolved carbon dioxide $\left(\mathrm{CO}_{2(\mathrm{aq})}\right)$, carbonic acid $\left(\mathrm{H}_{2} \mathrm{CO}_{3}\right)$ and bicarbonate $\left(\mathrm{HCO}_{3}{ }^{-}\right)$:

$$
\begin{array}{lll}
\mathrm{CO}_{2 \text { (atmos) }} & \rightleftarrows & \mathrm{CO}_{2 \text { (aq) }} \\
\mathrm{CO}_{2 \text { (aq) }}+\mathrm{H}_{2} \mathrm{O} & \rightleftarrows & \mathrm{H}_{2} \mathrm{CO}_{3} \\
\mathrm{H}_{2} \mathrm{CO}_{3} & \rightleftarrows & \mathrm{H}^{+}+\mathrm{HCO}_{3}^{-} \\
\mathrm{HCO}_{3}^{-} & \rightleftarrows & \mathrm{H}^{+}+\mathrm{CO}_{3}^{2-}
\end{array}
$$

Hydrogen ions $\left(\mathrm{H}^{+}\right)$are produced by these reactions. This increase in the ocean's hydrogen ion concentration corresponds to a reduction in $\mathrm{pH}$, or an increase in acidity. Under normal seawater conditions, more than $99.99 \%$ of the hydrogen ions that are produced will combine with carbonate ion $\left(\mathrm{CO}_{3}{ }^{2-}\right)$ to produce additional $\mathrm{HCO}_{3}^{-}$. Thus, the addition of anthropogenic $\mathrm{CO}_{2}$ into the oceans lowers the $\mathrm{pH}$ and consumes carbonate ion. These reactions are fully reversible and the basic thermodynamics of these reactions in seawater are well known, such that at a $\mathrm{pH}$ of approximately 8.1 approximately $90 \%$ the carbon is in the form of bicarbonate ion, $9 \%$ in the form of carbonate ion, and only about $1 \%$ of the carbon is in the form of dissolved $\mathrm{CO}_{2}$. Results from laboratory, field, and modeling studies, as well as evidence from the geological record, clearly indicate that marine ecosystems are highly susceptible to the increases in oceanic $\mathrm{CO}_{2}$ and the corresponding decreases in $\mathrm{pH}$ and carbonate ion.

Climate change and anthropogenic ocean acidification do not act independently. Although the $\mathrm{CO}_{2}$ that is taken up by the ocean does not contribute to greenhouse warming, ocean warming reduces the solubility of carbon dioxide in seawater; and thus reduces the amount of $\mathrm{CO}_{2}$ the oceans can absorb from the atmosphere. For example, under doubled preindustrial $\mathrm{CO}_{2}$ concentrations and a $2{ }^{\circ} \mathrm{C}$ temperature increase, seawater absorbs about $10 \%$ less $\mathrm{CO}_{2}$ $\left(10 \%\right.$ less total carbon, $\left.C_{T}\right)$ than it would with no temperature increase (compare columns 4 and 6 in Table 1), but the $\mathrm{pH}$ remains almost unchanged. Thus, a warmer ocean has less capacity to remove $\mathrm{CO}_{2}$ from the atmosphere, yet still experiences ocean acidification. The reason for this is that bicarbonate is converted to carbonate in a warmer ocean, releasing a hydrogen ion thus stabilizing the $\mathrm{pH}$. (continued on next page) 
FAQ 3.3 (continued)

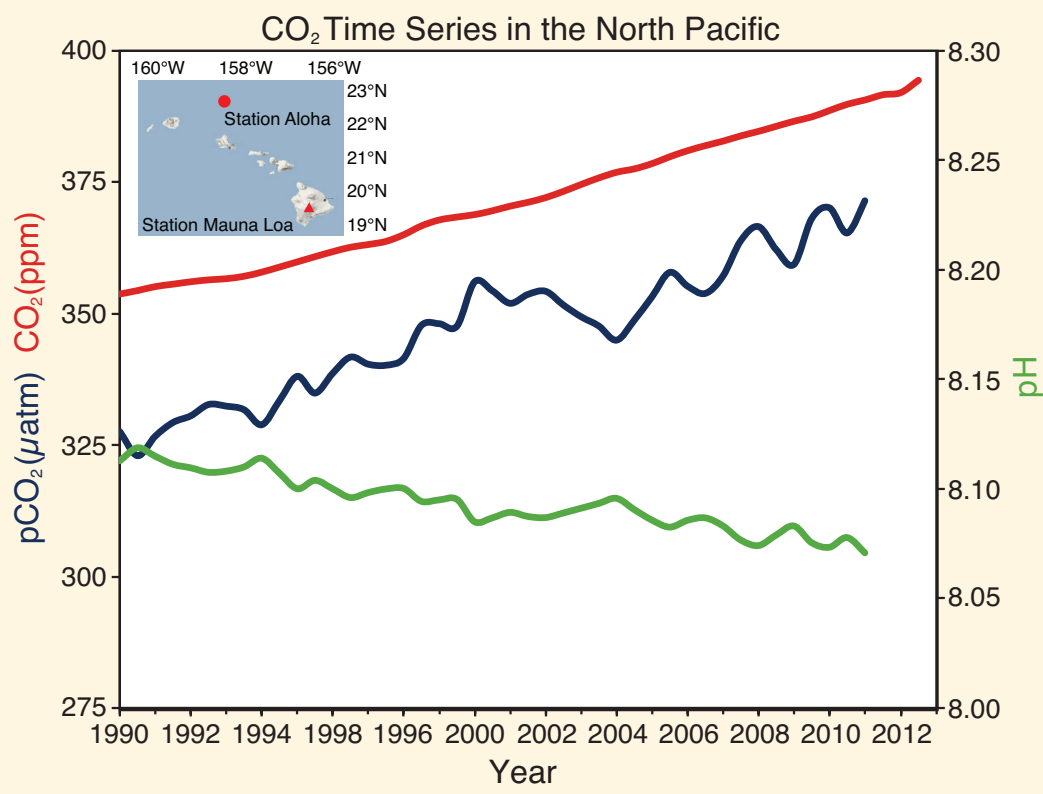

FAQ 3.3, Figure 1 | A smoothed time series of atmospheric $\mathrm{CO}_{2}$ mole fraction (in ppm) at the atmospheric Mauna Loa Observatory (top red line), surface ocean partial pressure of $\mathrm{CO}_{2}\left(\mathrm{pCO}_{2}\right.$; middle blue line) and surface ocean $\mathrm{pH}$ (bottom green line) at Station ALOHA in the subtropical North Pacific north of Hawaii for the period from 1990-2011 (after Doney et al., 2009; data from Dore et al., 2009). The results indicate that the surface ocean $\mathrm{pCO}_{2}$ trend is generally consistent with the atmospheric increase but is more variable due to large-scale interannual variability of oceanic processes.

FAQ 3.3, Table 1 | Oceanic $\mathrm{pH}$ and carbon system parameter changes in surface water for a $\mathrm{CO}_{2}$ doubling from the preindustrial atmosphere without and with a $2^{\circ} \mathrm{C}$ warming ${ }^{a}$.

\begin{tabular}{|c|c|c|c|c|c|}
\hline Parameter & $\begin{array}{l}\text { Pre-industrial } \\
\text { (280 ppmv) } \\
20^{\circ} \mathrm{C}\end{array}$ & $\begin{array}{c}2 \times \text { Pre-industrial } \\
(560 \mathrm{ppmv}) \\
20^{\circ} \mathrm{C}\end{array}$ & $\begin{array}{l}\text { (\% change relative } \\
\text { to pre-industrial) }\end{array}$ & $\begin{array}{c}2 \times \text { Pre-industrial } \\
(560 \mathrm{ppmv}) \\
22^{\circ} \mathrm{C}\end{array}$ & $\begin{array}{l}\text { (\% change relative } \\
\text { to pre-industrial) }\end{array}$ \\
\hline $\mathrm{pH}$ & 8.1714 & 7.9202 & - & 7.9207 & - \\
\hline $\mathrm{H}^{+}\left(\mathrm{mol} \mathrm{kg}^{-1}\right)$ & $6.739 \mathrm{e}^{-9}$ & $1.202 \mathrm{e}^{-8}$ & (78.4) & $1.200 \mathrm{e}^{-8}$ & (78.1) \\
\hline $\mathrm{CO}_{2(\text { aq) }}\left(\mu \mathrm{mol} \mathrm{kg}{ }^{-1}\right)$ & 9.10 & 18.10 & $(98.9)$ & 17.2 & $(89.0)$ \\
\hline $\mathrm{HCO}_{3}{ }^{-}\left(\mu \mathrm{mol} \mathrm{kg}^{-1}\right)$ & 1723.4 & 1932.8 & $(12.15)$ & 1910.4 & $(10.9)$ \\
\hline $\mathrm{CO}_{3}{ }^{2-}\left(\mu \mathrm{mol} \mathrm{kg}{ }^{-1}\right)$ & 228.3 & 143.6 & $(-37.1)$ & 152.9 & $(-33.0)$ \\
\hline $\mathrm{C}_{\mathrm{T}}\left(\mu \mathrm{mol} \mathrm{kg}^{-1}\right)$ & 1960.8 & 2094.5 & $(6.82)$ & 2080.5 & $(6.10)$ \\
\hline
\end{tabular}

Notes:

a $\mathrm{CO}_{2(\mathrm{aq})}=$ dissolved $\mathrm{CO}_{2}, \mathrm{H}_{2} \mathrm{CO}_{3}=$ carbonic acid, $\mathrm{HCO}_{3}{ }^{-}=$bicarbonate, $\mathrm{CO}_{3}{ }^{2-}=$ carbonate, $\mathrm{C}_{\mathrm{T}}=$ total carbon $\left.=\mathrm{CO}_{2(\mathrm{aq})}+\mathrm{HCO}_{3}{ }^{-}+\mathrm{CO}_{3}{ }^{2-}\right)$.

Coastal regions have also experienced long-term dissolved oxygen changes. Bograd et al. (2008) reported a substantial reduction of the thermocline oxygen content in the southern part of the California Current from 1984 to 2002, resulting in a shoaling of the hypoxic boundary (marked by oxygen concentrations of about $60 \mu \mathrm{mol} \mathrm{kg}^{-1}$ ). Off the British Columbia coast, oxygen concentrations in the near bottom

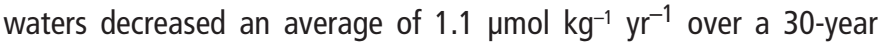
period (Chan et al., 2008). These changes along the west coast of North America appear to have been largely caused by the open ocean dissolved oxygen decrease and local processes associated with decreased vertical dissolved oxygen transport following near-surface warming and increased stratification. Gilbert et al. (2010) found evidence that for the time period 1976-2000 oxygen concentrations between 0 and $300 \mathrm{~m}$ depth were declining about 10 times faster in the coastal ocean than in the open ocean, and an increase in the number of hypoxic zones was observed since the 1960s (Diaz and Rosenberg, 2008).

\subsubsection{Nutrients}

Nutrient concentrations in the surface ocean surface are influenced by human impacts on coastal runoff and on atmospheric deposition, and by changing nutrient supply from the ocean's interior into the mixed layer (for instance due to increased stratification). Changing nutrient distributions might influence the magnitude and variability of the ocean's biological carbon pump.

Globally, the manufacture of nitrogen fertilizers has continued to increase (Galloway et al., 2008) accompanied by increasing eutrophi- 
Table 3.2 2 Published and updated long-term trends of atmospheric $\left(\mathrm{pCO}_{2}{ }^{\text {atm }}\right)$ and seawater carbonate chemistry (i.e., surface-water $\mathrm{pCO}_{2}$, and corresponding calculated pH, $\mathrm{CO}_{3}{ }^{2-}$, and aragonite saturation state $(\Omega \mathrm{a})$ at four ocean time series in the North Atlantic and North Pacific oceans: (1) Bermuda Atlantic Time-series Study (BATS, 31 ${ }^{\circ} 40^{\prime} \mathrm{N}, 64^{\circ} 10^{\prime} \mathrm{W}$ ) and Hydrostation S $\left(32^{\circ} 10^{\prime} \mathrm{N}, 64^{\circ} 30^{\prime} \mathrm{W}\right)$ from 1983 to present (Bates, 2007); (2) Hawaii Ocean Time series (HOT) at Station ALOHA (A Long-term Oligotrophic Habitat Assessment; $22^{\circ} 45^{\prime} \mathrm{N}, 158^{\circ} 00^{\prime} \mathrm{W}$ ) from 1988 to the present (Dore et al., 2009); (3) European Station for Time series in the Ocean (ESTOC, $29^{\circ} 10^{\prime} \mathrm{N}, 15^{\circ} 30^{\prime} \mathrm{W}$ ) from 1994 to the present (González-Dávila et al., 2010); and (4) Iceland Sea (IS, 68.0 N, 12.67 W) from 1985 to 2006 (Olafsson et al., 2009). Trends at the first three time-series sites are from observations with the seasonal cycle removed. Also reported are the wintertime trends in the Iceland Sea as well as the pH difference trend for the North Pacific Ocean between transects in 1991 and 2006 (Byrne et al., 2010) and repeat sections in the western North Pacific between 1983 and 2008 (Midorikawa et al., 2010).

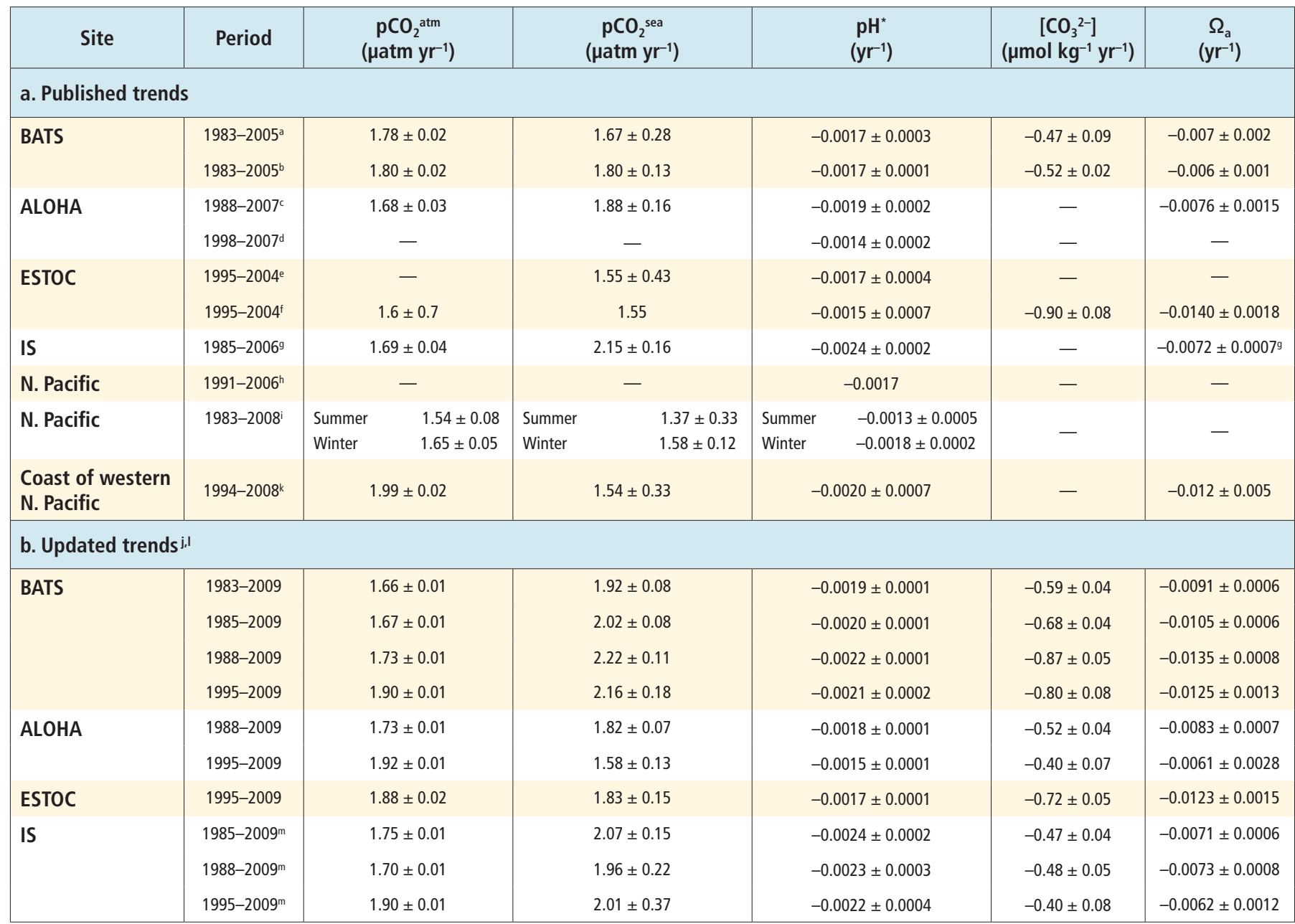

Notes:

* $\mathrm{pH}$ on the total scale.

Bates (2007, Table 1): Simple linear fit.

b Bates (2007, Table 2): Seasonally detrended (including linear term for time).

Dore et al. (2009): Linear fit with calculated pH and $\mathrm{pCO}_{2}$ from measured DIC and TA (full time series); corresponding $\Omega$ a from Feely et al. (2009).

d Dore et al. (2009): Linear fit with measured pH (partial time series).

e Santana-Casiano et al. (2007): Seasonal detrending (including linear terms for time and temperature).

González-Dávila et al. (2010): Seasonal detrending (including linear terms for time, temperature and mixed-layer depth).

Olafsson et al. (2009): Multivariable linear regression (linear terms for time and temperature) for winter data only.

Byrne et al. (2010): Meridional section originally occupied in 1991 and repeated in 2006.

Midorikawa et al. (2010): Winter and summer observations along $137^{\circ} \mathrm{E}$.

Trends are for linear time term in seasonal detrending with harmonic periods of 12, 6 and 4 months. Harmonic analysis made after interpolating data to regular monthly grids (except for IS, which was sampled much less frequently):

1983-2009 = September 1983 to December 2009 (BATS/Hydrostation S sampling period),

1985-2009 = February 1985 to December 2009 (IS sampling period),

1988-2009 = November 1988 to December 2009 (ALOHA/HOT sampling period), and

1995-2009 = September 1995 to December 2009 (ESTOC sampling period).

k Ishii et al. (2011) - time-series observations in the coast of western North Pacific, with the seasonal cycle removed

Atmospheric $\mathrm{pCO}_{2}$ trends computed from same harmonic analysis (12-, 6- and 4-month periods) on the GLOBALVIEW- $\mathrm{CO}_{2}(2010)$ data product for the marine boundary layer referenced to the latitude of the nearest atmospheric measurement station (BME = Bermuda; $\mathrm{MLO}=\mathrm{ALOHA}$; IZO = ESTOC; ICE = Iceland).

m Winter ocean data, collected during dark period (between 19 January and 7 March), as per Olafsson et al. (2009) to reduce scatter from large interannual variations in intense short-term bloom events, undersampled in time, fit linearly $(y=a t+b T+c)$. 
cation of coastal waters (Diaz and Rosenberg, 2008; Seitzinger et al., 2010; Kim et al., 2011), which amplifies the drawdown of $\mathrm{CO}_{2}$ (Borges and Gypens, 2010; Provoost et al., 2010). In addition, atmospheric deposition of anthropogenic fixed nitrogen may now account for up to about $3 \%$ of oceanic new production, and this nutrient source is projected to increase (Duce et al., 2008).

Satellite observations of chlorophyll reveal that oligotrophic provinces in four of the world's major oceans expanded at average rates of 0.8 to $4.3 \% \mathrm{yr}^{-1}$ from 1998 to 2006 (Polovina et al., 2008; Irwin and Oliver, 2009), consistent with a reduction in nutrient availability owing to increases in stratification. Model and observational studies suggest interannual and multi-decadal fluctuations in nutrients are coupled with variability of mode water and the NAO in the Atlantic Ocean (Cianca et al., 2007; Pérez et al., 2010), climate modes of variability in the Pacific Ocean (Wong et al., 2007; Di Lorenzo et al., 2009), and variability of subtropical gyre circulation in the Indian Ocean (Álvarez et al., 2011). However, there are no published studies quantifying longterm trends in ocean nutrient concentrations.

\subsubsection{Conclusions}

Based on high agreement between independent estimates using different methods and data sets (e.g., oceanic carbon, oxygen, and transient tracer data), it is very likely that the global ocean inventory of anthropogenic carbon $\left(C_{\text {ant }}\right)$ increased from 1994 to 2010. The oceanic $C_{\text {ant }}$ inventory in 2010 is estimated to be $155 \mathrm{PgC}$ with an uncertainty of $\pm 20 \%$. The annual global oceanic uptake rates calculated from independent data sets (from oceanic $\mathrm{C}_{\text {ant }}$ inventory changes, from atmospheric $\mathrm{O}_{2} /$ $\mathrm{N}_{2}$ measurements or from $\mathrm{pCO}_{2}$ data) and for different time periods agree with each other within their uncertainties and very likely are in the range of 1.0 to $3.2 \mathrm{PgC} \mathrm{yr}^{-1}$. (Section 3.8.1, Figures 3.16 and 3.17)

Oceanic uptake of anthropogenic $\mathrm{CO}_{2}$ results in gradual acidification of the ocean. The $\mathrm{pH}$ of surface seawater has decreased by 0.1 since the beginning of the industrial era, corresponding to a $26 \%$ increase in hydrogen ion concentration. The observed $\mathrm{pH}$ trends range between -0.0014 and $-0.0024 \mathrm{yr}^{-1}$ in surface waters. In the ocean interior, natural physical and biological processes, as well as uptake of anthropogenic $\mathrm{CO}_{2}$, can cause changes in $\mathrm{pH}$ over decadal and longer time scales (Section 3.8.2, Table 3.2, Box 3.2, Figures 3.18 and 3.19, FAQ 3.3).

High agreement among analyses provides medium confidence that oxygen concentrations have decreased in the open ocean thermocline in many ocean regions since the 1960s. The general decline is consistent with the expectation that warming-induced stratification leads to a decrease in the supply of oxygen to the thermocline from near surface
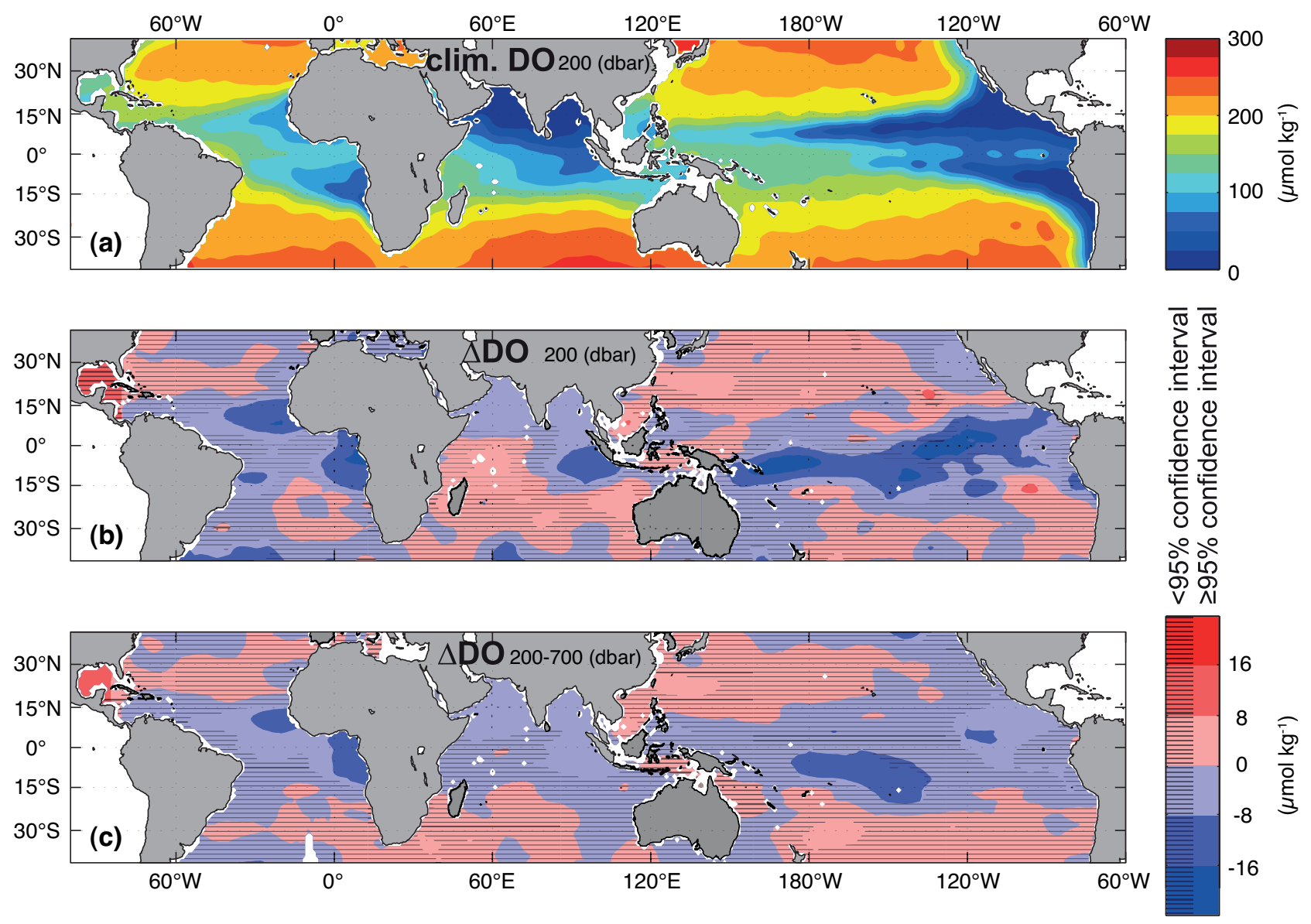

Figure 3.20 | Dissolved oxygen (DO) distributions (in $\mu \mathrm{mol} \mathrm{kg}^{-1}$ ) between $40^{\circ} \mathrm{S}$ and $40^{\circ} \mathrm{N}$ for: (a) the climatological mean (Boyer et al., 2006) at $200 \mathrm{dbar}$, as well as changes between 1960 and 1974 and 1990 and 2008 of (b) dissolved oxygen ( $\triangle \mathrm{DD}$ ) at $200 \mathrm{dbar}$ and (c) $\Delta \mathrm{DO}$ vertically averaged over 200 to $700 \mathrm{dbar}$. In (b) and (c) increases are red and decreases blue, and areas with differences below the 95\% confidence interval are shaded by black horizontal lines. (After Stramma et al., 2010.) 
waters, that warmer waters can hold less oxygen, and that changes in wind-driven circulation affect oxygen concentrations. It is likely that the tropical oxygen minimum zones have expanded in recent decades (Section 3.8.3, Figure 3.20).

\subsection{Synthesis}

Substantial progress has been made since AR4 in documenting and understanding change in the ocean. The major findings of this chapter are largely consistent with those of AR4, but in many cases statements can now be made with greater confidence because more data are available, biases in historical data have been identified and reduced, and new analytical approaches have been applied.

Changes have been observed in a number of ocean properties of relevance to climate. It is virtually certain that the upper ocean (0 to $700 \mathrm{~m}$ ) has warmed from 1971 to 2010 (Section 3.2.2, Figures 3.1 and 3.2). Warming between 700 and $2000 \mathrm{~m}$ likely contributed about $30 \%$ of the total increase in global ocean heat content between 1957 and 2009 (Section 3.2.4, Figure 3.2). Global mean sea level has risen by 0.19 [0.17 to 0.21$] \mathrm{m}$ over the period $1901-2010$. It is very likely that the mean rate was 1.7 [1.5 to 1.9] $\mathrm{mm} \mathrm{yr}^{-1}$ between 1901 and 2010 and increased to 3.2 [2.8 to 3.6] $\mathrm{mm} \mathrm{yr}^{-1}$ between 1993 and 2010 (Section 3.7, Figure 3.13). The rise in mean sea level can explain most of the observed increase in extreme sea levels (Figure 3.15). Regional trends in sea surface salinity have very likely enhanced the mean geographical contrasts in sea surface salinity since the 1950s: saline surface waters in evaporation-dominated regions have become more saline, while fresh surface waters in rainfall-dominated regions have become fresher. It is very likely that trends in salinity have also occurred in the ocean interior. These salinity changes provide indirect evidence that the pattern of evaporation minus precipitation over the oceans has been enhanced since the 1950s (Section 3.4, Figures 3.4 and 3.5]. Observed changes in water mass properties likely reflect the combined effect of long-term trends in surface forcing (e.g., warming and changes in evaporation minus precipitation) and variability associated with climate modes (Section 3.5, Figure 3.9). It is virtually certain that the ocean is storing anthropogenic $\mathrm{CO}_{2}$ and very likely that the ocean inventory of anthropogenic $\mathrm{CO}_{2}$ increased from 1994 to 2010 (Section 3.8, Figures 3.16 and 3.17). The uptake of anthropogenic $\mathrm{CO}_{2}$ has very likely caused acidification of the ocean (Section 3.8.2, Box 3.2).

For some ocean properties, the short and incomplete observational record is not sufficient to detect trends. For example, there is no observational evidence for or against a change in the strength of the AMOC (Section 3.6, Figure 3.11). However, recent observations have strengthened evidence for variability in major ocean circulation systems and water mass properties on time scales from years to decades. Much of the variability observed in ocean currents and in water masses can be linked to changes in surface forcing, including wind changes associated with the major modes of climate variability such as the NAO, SAM, ENSO, PDO and the AMO (Section 3.6, Box 2.5).

The consistency between the patterns of change in a number of independent ocean parameters enhances confidence in the assessment that the physical and biogeochemical state of the oceans has changed.
This consistency is illustrated here with two simple figures (Figures 3.21 and 3.22). Four global measures of ocean change have increased since the 1950s: the inventory of anthropogenic $\mathrm{CO}_{2}$, global mean sea level, upper ocean heat content, and the salinity contrast between regions of high and low sea surface salinity (Figure 3.21). High agreement among multiple lines of evidence based on independent data and different methods provides high confidence in the observed increase in these global metrics of ocean change.

The distributions of trends in subsurface water properties, summarized in a schematic zonally averaged view in Figure 3.22, are consistent both with each other and with well-understood dynamics of ocean circulation and water mass formation. The largest changes in temperature, salinity, anthropogenic $\mathrm{CO}_{2}$, and other properties are observed along known ventilation pathways (indicated by arrows in Figure 3.22), where surface waters are transferred to the ocean interior, or in regions where changes in ocean circulation (e.g., contraction or expansion of gyres, or a southward shift of the Antarctic Circumpolar
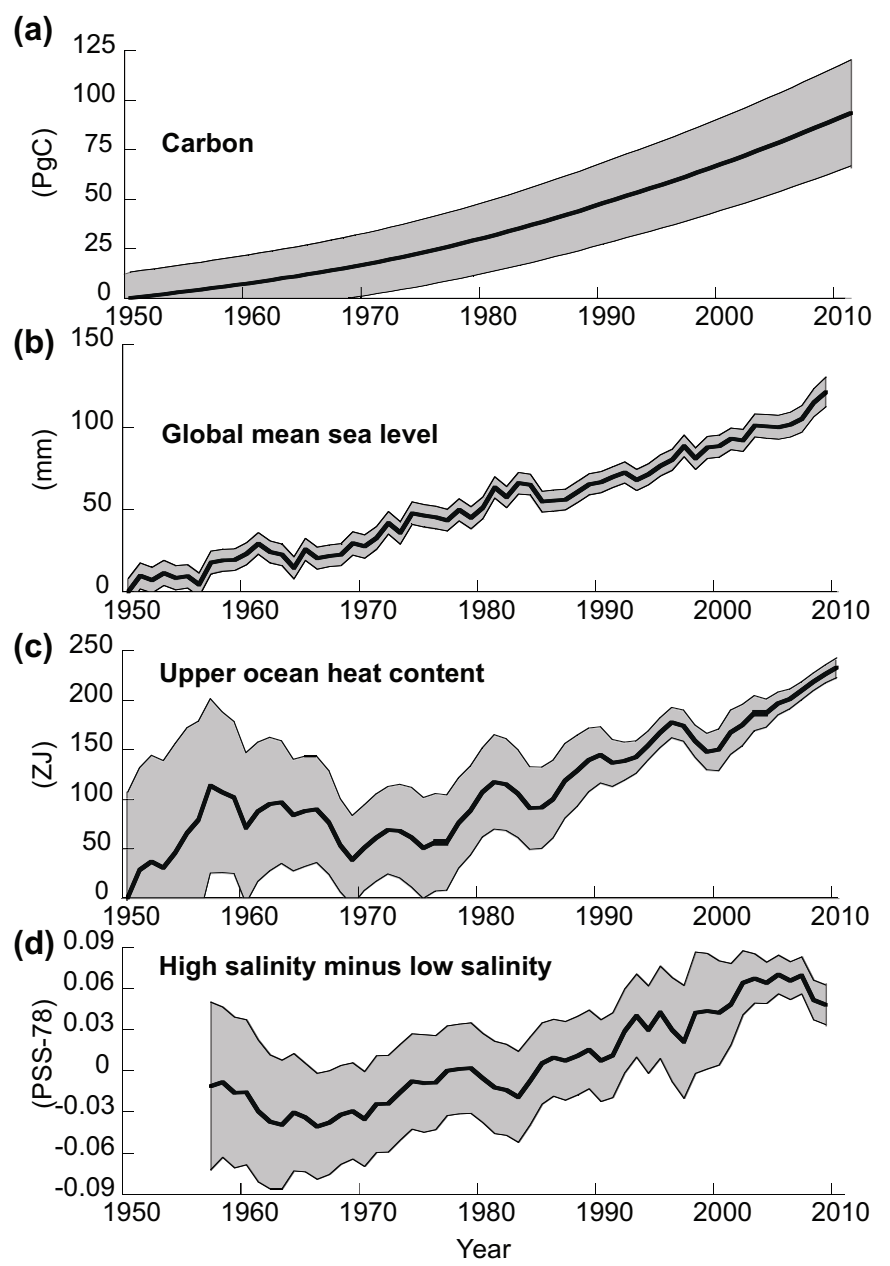

Figure 3.21 | Time series of changes in large-scale ocean climate properties. From top to bottom: global ocean inventory of anthropogenic carbon dioxide, updated from Khatiwala et al. (2009); global mean sea level (GMSL), from Church and White (2011); global upper ocean heat content anomaly, updated from Domingues et al. (2008); the difference between salinity averaged over regions where the sea surface salinity is greater than the global mean sea surface salinity ("High Salinity") and salinity averaged over regions values below the global mean ("Low Salinity"), from Boyer et al. (2009). 
Current) result in large anomalies. Zonally averaged warming trends are widespread throughout the upper 2000 m, with largest warming near the sea surface. Water masses formed in the precipitationdominated mid to high latitudes have freshened, while water masses formed in the evaporation-dominated subtropics have become saltier. Anthropogenic $\mathrm{CO}_{2}$ has accumulated in surface waters and been transferred into the interior, primarily by water masses formed in the North Atlantic and Southern Oceans.

In summary, changes have been observed in ocean properties of relevance to climate during the past 40 years, including temperature, salinity, sea level, carbon, $\mathrm{pH}$, and oxygen. The observed patterns of change are consistent with changes in the surface ocean (warming, changes in salinity and an increase in $\mathrm{C}_{\text {ant }}$ ) in response to climate change and variability and with known physical and biogeochemical processes in the ocean, providing high confidence in this assessment. Chapter 10 discusses the extent to which these observed changes can be attributed to human or natural forcing.
Improvements in the quality and quantity of ocean observations has allowed for a more definitive assessment of ocean change than was possible in AR4. However, substantial uncertainties remain. In many cases, the observational record is still too short or incomplete to detect trends in the presence of energetic variability on time scales of years to decades. Recent improvements in the ocean observing system, most notably the Argo profiling float array, mean that temperature and salinity are now being sampled routinely in most of the ocean above $2000 \mathrm{~m}$ depth for the first time. However, sparse sampling of the deep ocean and of many biogeochemical variables continues to limit the ability to detect and understand changes in the global ocean.

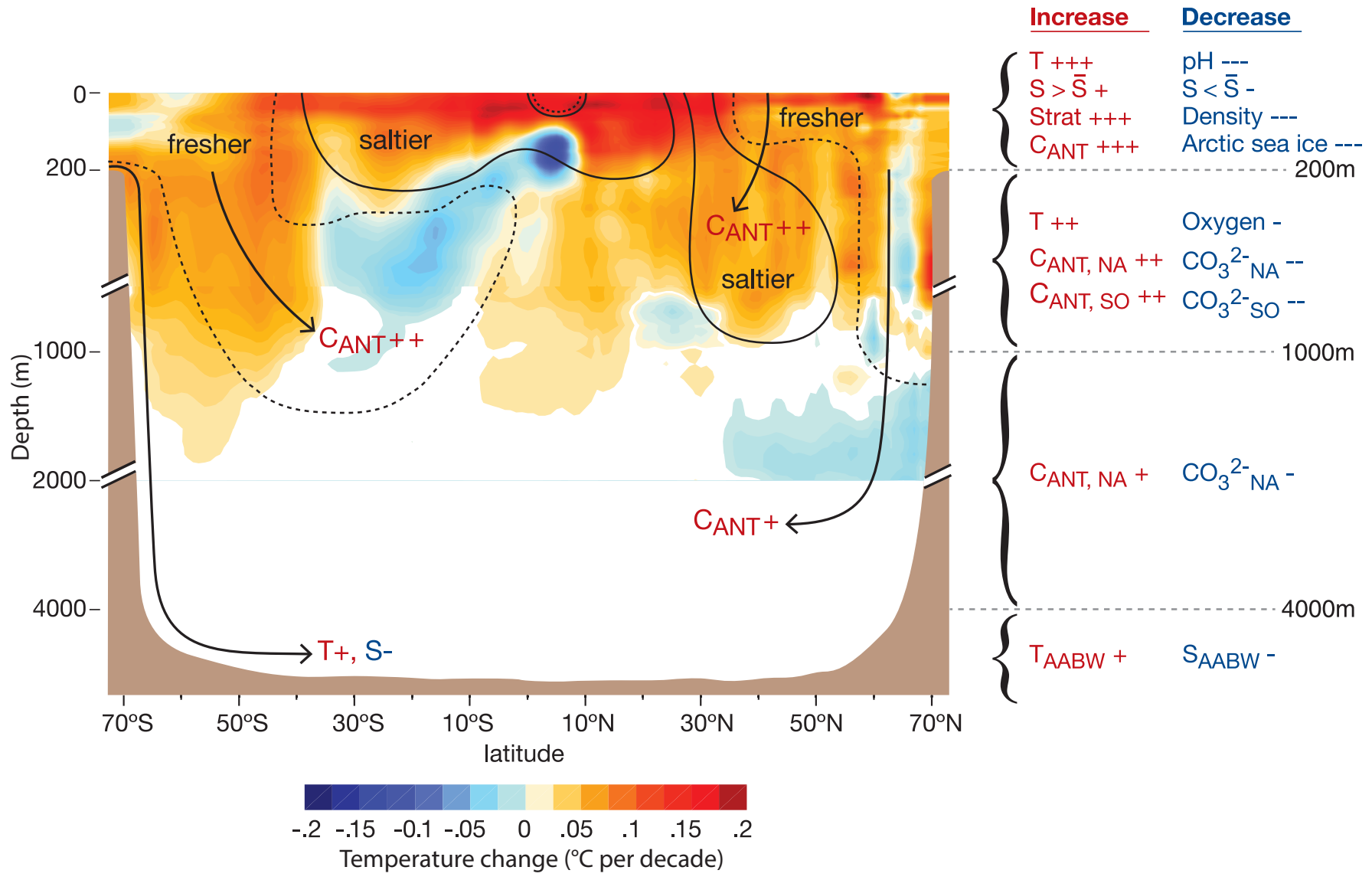

Figure 3.22 | Summary of observed changes in zonal averages of global ocean properties. Temperature trends (degrees Celsius per decade) are indicated in colour (red = warming, blue $=$ cooling); salinity trends are indicated by contour lines (dashed = fresher; solid = saltier) for the upper $2000 \mathrm{~m}$ of the water column (50-year trends from data set of Durack and Wijffels (2010); trends significant at >90\% confidence are shown). Arrows indicate primary ventilation pathways. Changes in other physical and chemical properties are summarised to the right of the figure, for each depth range (broken axes symbols delimit changes in vertical scale). Increases are shown in red, followed by a plus sign; decreases are shown in blue, followed by a minus sign; the number of + and - signs indicates the level of confidence associated with the observation of change (+++, high confidence; ++, medium confidence; + , low confidence). $\mathrm{T}=$ temperature, $\mathrm{S}=$ salinity, Strat $=$ stratification, $\mathrm{C}_{\text {ant }}=$ anthropogenic carbon, $\mathrm{CO}_{3}{ }^{2-}=$ carbonate ion, $\mathrm{NA}=$ North $\mathrm{Atlantic}, \mathrm{SO}=\mathrm{Southern}$ Ocean, AABW = Antarctic Bottom Water. $\mathrm{S}>\overline{\mathrm{S}}$ refers to the salinity averaged over regions where the sea surface salinity is greater than the global mean sea surface salinity; $S<$ $\bar{S}$ refers to the average over regions with values below the global mean. 


\section{References}

Abeysirigunawardena, D. S., and I. J. Walker, 2008: Sea level responses to climatic variability and change in Northern British Columbia. Atmos. Ocean, 46, 277296.

Ablain, M., A. Cazenave, S. Guinehut, and G. Valladeau, 2009: A new assessment of global mean sea level from altimeters highlights a reduction of global slope from 2005 to 2008 in agreement with in-situ measurements. Ocean Sci., 5, 193 $-201$.

Alory, G., S. Wijffels, and G. Meyers, 2007: Observed temperature trends in the Indian Ocean over 1960-1999 and associated mechanisms. Geophys. Res. Lett., 34, L02606.

Álvarez, M., T. Tanhua, H. Brix, C. Lo Monaco, N. Metzl, E. L. McDonagh, and H. L. Bryden, 2011: Decadal biogeochemical changes in the subtropical Indian Ocean associated with Subantarctic Mode Water. J. Geophys. Res. Oceans, 116, C09016.

Andersson, A., C. Klepp, K. Fennig, S. Bakan, H. Grassl, and J. Schulz, 2011: Evaluation of HOAPS-3 ocean surface freshwater flux components. J. Appl. Meteorol. Climatol., 50, 379-398.

Antonov, J. I., et al., 2010: World Ocean Atlas 2009, Vol. 2: Salinity. NOAA Atlas NESDIS 68. S. Levitus, Ed. U.S. Government Printing Office, Washington, DC, USA, $184 \mathrm{pp}$.

Aoki, S., S. R. Rintoul, S. Ushio, S. Watanabe, and N. L. Bindoff, 2005: Freshening of the Adelie Land Bottom Water near $140^{\circ}$ E. Geophys. Res. Lett., 32, L23601.

Ballantyne, A. P., C. B. Alden, J. B. Miller, P. P. Tans, and J. W. C. White, 2012: Increase in observed net carbon dioxide uptake by land and oceans during the past 50 years. Nature, 488, 70-72.

Barker, P. M., J. R. Dunn, C. M. Domingues, and S. E. Wijffels, 2011: Pressure sensor drifts in Argo and their impacts. J. Atmos. Ocean. Technol., 28, 1036-1049.

Bates, N. R., 2007: Interannual variability of the oceanic $\mathrm{CO}_{2}$ sink in the subtropical gyre of the North Atlantic Ocean over the last 2 decades. J. Geophys. Res. Oceans, 112, C09013.

Bates, N. R., 2012: Multi-decadal uptake of carbon dioxide into subtropical mode water of the North Atlantic Ocean. Biogeosciences, 9, 2649-2659.

Beckley, B. D., et al., 2010: Assessment of the Jason-2 extension to the TOPEX/ Poseidon, Jason-1 sea-surface height time series for global mean sea level monitoring. Mar. Geodesy, 33, 447-471.

Beltrami, H., J. E. Smerdon, H. N. Pollack, and S. P. Huang, 2002: Continental heat gain in the global climate system. Geophys. Res. Lett., $29,3$.

Bersch, M., I. Yashayaev, and K. P. Koltermann, 2007: Recent changes of the thermohaline circulation in the subpolar North Atlantic. Ocean Dyn., 57, 223235.

Bindoff, N. L., and T. J. McDougall, 1994: Diagnosing climate-change and ocean ventilation using hydrographic data. J. Phys. Oceanogr., 24, 1137-1152.

Bindoff, N. L., et al., 2007: Observations: Oceanic climate change and sea level. In: Climate Change 2007: The Physical Science Basis. Contribution of Working Group I to the Fourth Assessment Report of the Intergovernmental Panel on Climate Change [Solomon, S., D. Qin, M. Manning, Z. Chen, M. Marquis, K. B. Averyt, M. Tignor and H. L. Miller (eds.)] Cambridge University Press, Cambridge, United Kingdom and New York, NY, USA.

Bingham, R. J., and C. W. Hughes, 2009: Signature of the Atlantic meridional overturning circulation in sea level along the east coast of North America. Geophys. Res. Lett., 36, L02603.

Boening, C., J. K. Willis, F. W. Landerer, R. S. Nerem, and J. Fasullo, 2012: The 2011 La Niña: So strong, the oceans fell. Geophys. Res. Lett., 39, L19602.

Bograd, S. J., C. G. Castro, E. Di Lorenzo, D. M. Palacios, H. Bailey, W. Gilly, and F. P. Chavez, 2008: Oxygen declines and the shoaling of the hypoxic boundary in the California Current. Geophys. Res. Lett., 35, L12607.

Böning, C. W., A. Dispert, M. Visbeck, S. R. Rintoul, and F. U. Schwarzkopf, 2008: The response of the Antarctic Circumpolar Current to recent climate change. Nature Geosci., 1, 864-869.

Borges, A. V., and N. Gypens, 2010: Carbonate chemistry in the coastal zone responds more strongly to eutrophication than to ocean acidification. Limnol. Oceanogr., 55, 346-353.

Boyer, T., S. Levitus, J. Antonov, R. Locarnini, A. Mishonov, H. Garcia, and S. A. Josey, 2007: Changes in freshwater content in the North Atlantic Ocean 1955-2006. Geophys. Res. Lett., 34, L16603.
Boyer, T. P., S. Levitus, J. I. Antonov, R. A. Locarnini, and H. E. Garcia, 2005: Linear trends in salinity for the World Ocean, 1955-1998. Geophys. Res. Lett., 32, L01604.

Boyer, T. P., et al., 2006: Introduction. World Ocean Database 2005 (DVD), NOAAAtlas NESDIS, Vol. 60 [S. Levitus, (ed.)]. US Government Printing Office, Washington, DC, pp. 15-37.

Boyer, T. P., et al., 2009: Chapter 1: Introduction. World Ocean Database 2009, NOAA Atlas NESDIS 66, DVD ed., S. Levitus, Ed., U.S. Gov. Printing Office, Wash., D.C., USA, pp. 216.

Broecker, W., and E. Clark, 2001: A dramatic Atlantic dissolution event at the onset of the last glaciation. Geochem. Geophys. Geosyst., 2, 2001GC000185.

Bromirski, P. D., A. J. Miller, R. E. Flick, and G. Auad, 2011: Dynamical suppression of sea level rise along the Pacific coast of North America: Indications for imminent acceleration. J. Geophys. Res. Oceans, 116, C07005.

Bryden, H. L., H. R. Longworth, and S. A. Cunningham, 2005: Slowing of the Atlantic meridional overturning circulation at $25^{\circ} \mathrm{N}$. Nature, 438, 655-657.

Byrne, R. H., S. Mecking, R. A. Feely, and X. W. Liu, 2010: Direct observations of basinwide acidification of the North Pacific Ocean. Geophys. Res. Lett., 37, L02601.

Cai, W., 2006: Antarctic ozone depletion causes an intensification of the Southern Ocean super-gyre circulation. Geophys. Res. Lett., 33, L03712.

Calafat, F. M., D. P. Chambers, and M. N. Tsimplis, 2012: Mechanisms of decadal sea level variability in the eastern North Atlantic and the Mediterranean Sea. J. Geophys. Res. Oceans, 117, C09022.

Caldeira, K., and M. E. Wickett, 2003: Anthropogenic carbon and ocean pH. Nature, 425, 365-365.

Carson, M., and D. E. Harrison, 2010: Regional interdecadal variability in biascorrected ocean temperature data. J. Clim., 23, 2847-2855.

Carton, J. A., and A. Santorelli, 2008: Global decadal upper-ocean heat content as viewed in nine analyses. J. Clim., 21, 6015-6035.

Carton, J. A., B. S. Giese, and S. A. Grodsky, 2005: Sea level rise and the warming of the oceans in the Simple Ocean Data Assimilation (SODA) ocean reanalysis. J. Geophys. Res. Oceans, 110, 009006.

Cazenave, A., et al., 2009: Sea level budget over 2003-2008: A re-evaluation from GRACE space gravimetry, satellite altimetry and Argo. Mar. Geodesy, 65, 447 $-471$.

Cazenave, A., et al., 2012: Estimating ENSO influence on the global mean sea level, 1993-2010. Mar. Geodesy, 35, 82-97.

Chambers, D. P., J. Wahr, and R. S. Nerem, 2004: Preliminary observations of global ocean mass variations with GRACE. Geophys. Res. Lett., 31, L13310.

Chambers, D. P., M. A. Merrifield, and R. S. Nerem, 2012: Is there a 60 -year oscillation in global mean sea level? Geophys. Res. Lett., 39, L18607.

Chambers, D. P., J. Wahr, M. E. Tamisiea, and R. S. Nerem, 2010: Ocean mass from GRACE and glacial isostatic adjustment. J. Geophys. Res.-Sol. Ea., 115, B11415.

Chan, F., J. A. Barth, J. Lubchenco, A. Kirincich, H. Weeks, W. T. Peterson, and B. A. Menge, 2008: Emergence of anoxia in the California current large marine ecosystem. Science, 319, 920-920.

Chavez, F. P., M. Messié, and J. T. Pennington, 2011: Marine primary production in relation to climate variability and change. Annu. Rev. Mar. Sci., 3, 227-260.

Church, J. A., and N. J. White, 2006: A 20th century acceleration in global sea-level rise. Geophys. Res. Lett., 33, L01602.

Church, J. A., and N. J. White, 2011: Sea-level rise from the late 19th to the early $21 \mathrm{st}$ century. Surv. Geophys., 32, 585-602.

Church, J. A., J. R. Hunter, K. L. McInnes, and N. J. White, 2006: Sea-level rise around the Australian coastline and the changing frequency of extreme sea-level events. Aust. Meteorol. Mag., 55, 253-260.

Church, J. A., N. J. White, R. Coleman, K. Lambeck, and J. X. Mitrovica, 2004: Estimates of the regional distribution of sea level rise over the 1950-2000 period. J. Clim., 17, 2609-2625.

Church, J. A., et al., 2011: Revisiting the Earth's sea-level and energy budgets from 1961 to 2008. Geophys. Res. Lett., 38, L18601.

Cianca, A., P. Helmke, B. Mourino, M. J. Rueda, O. Llinas, and S. Neuer, 2007: Decadal analysis of hydrography and in situ nutrient budgets in the western and eastern North Atlantic subtropical gyre. J. Geophys. Res. Oceans, 112, C07025.

Compo, G. P., et al., 2011: The Twentieth Century Reanalysis Project. Q. J. R. Meteor. Soc., 137, 1-28. 
Cravatte, S., T. Delcroix, D. X. Zhang, M. McPhaden, and J. Leloup, 2009: Observed freshening and warming of the western Pacific Warm Pool. Clim. Dyn., 33, 565589.

Cummins, P. F., and H. J. Freeland, 2007: Variability of the North Pacific current and its bifurcation. Prog. Oceanogr., 75, 253-265.

Cunningham, S. A., S. G. Alderson, B. A. King, and M. A. Brandon, 2003: Transport and variability of the Antarctic Circumpolar Current in Drake Passage. J. Geophys. Res. Oceans, 108, 8084.

Cunningham, S. A., et al., 2007: Temporal variability of the Atlantic meridional overturning circulation at $26.5^{\circ} \mathrm{N}$. Science, $317,935-938$.

Curry, R., and C. Mauritzen, 2005: Dilution of the northern North Atlantic Ocean in recent decades. Science, 308, 1772-1774.

Curry, R., B. Dickson, and I. Yashayaev, 2003: A change in the freshwater balance of the Atlantic Ocean over the past four decades. Nature, 426, 826-829.

D'Onofrio, E. E., M. M. E. Fiore, and J. L. Pousa, 2008: Changes in the regime of storm surges at Buenos Aires, Argentina. J. Coast. Res., 24, 260-265.

Dee, D. P., et al., 2011: The ERA-Interim reanalysis: Configuration and performance of the data assimilation system. Q. J. R. Meteor. Soc., 137, 553-597.

Delcroix, T., S. Cravatte, and M. J. McPhaden, 2007: Decadal variations and trends in tropical Pacific sea surface salinity since 1970. J. Geophys. Res. Oceans, 112 C03012.

Deutsch, C., S. Emerson, and L. Thompson, 2005: Fingerprints of climate change in North Pacific oxygen. Geophys. Res. Lett., 32, L16604.

Di Lorenzo, E., et al., 2009: Nutrient and salinity decadal variations in the central and eastern North Pacific. Geophys. Res. Lett., 36, L14601.

Diaz, R. J., and R. Rosenberg, 2008: Spreading dead zones and consequences for marine ecosystems. Science, 321, 926-929.

3 Dickson, B., I. Yashayaev, J. Meincke, B. Turrell, S. Dye, and J. Holfort, 2002: Rapid freshening of the deep North Atlantic Ocean over the past four decades. Nature, 416, 832-837.

Dickson, R. R., et al., 2008: The overflow flux west of Iceland: variability, origins and forcing. In: Arctic-Subarctic Ocean Fluxes [R. R. Dickson, J. Meincke, and P. B. Rhines (eds.)] Springer Science+Business Media, New York, NY, USA, and Heidelberg, Germany, 443-474.

Dohan, K., et al., 2010: Measuring the global ocean surface circulation with satellite and in situ observations. In: Proceedings of OceanObs'09: Sustained Ocean Observations and Information for Society (Vol. 2). Venice, Italy, 21-25 September 2009, Hall, J., Harrison, D.E. \& Stammer, D., Eds., European Space Agency, ESA Publication WPP-306, doi:10.5270/0ceanObs09.cwp.23

Domingues, C. M., J. A. Church, N. J. White, P. J. Gleckler, S. E. Wijffels, P. M. Barker, and J. R. Dunn, 2008: Improved estimates of upper-ocean warming and multidecadal sea-level rise. Nature, 453, 1090-1093.

Doney, S. C., V. J. Fabry, R. A. Feely, and J. A. Kleypas, 2009: Ocean Acidification: The other $\mathrm{CO}_{2}$ problem. Annu. Rev. Mar. Sci, 1, 169-192.

Dore, J. E., R. Lukas, D. W. Sadler, M. J. Church, and D. M. Karl, 2009: Physical and biogeochemical modulation of ocean acidification in the central North Pacific. Proc. Natl. Acad. Sci. U.S.A., 106, 12235-12240.

Douglas, B. C., 2001: Sea level change in the era of the recording tide gauge. In: Sea Level Rise: History and Consequences [B. C. Douglas, M. S. Kearney, and S. P. Leatherman (eds.)]. Academic Press, San Diego,CA, USA, pp. 37-64.

Douglass, E., D. Roemmich, and D. Stammer, 2006: Interannual variability in northeast Pacific circulation. J. Geophys. Res. Oceans, 111, C04001.

Drinkwater, K. F., 2006: The regime shift of the 1920s and 1930s in the North Atlantic. Prog. Oceanogr., 68, 134-151.

Duce, R. A., et al., 2008: Impacts of atmospheric anthropogenic nitrogen on the open ocean. Science, 320, 893-897.

Ducet, N., P. Y. Le Traon, and G. Reverdin, 2000: Global high-resolution mapping of ocean circulation from TOPEX/Poseidon and ERS-1 and-2. J. Geophys. Res. Oceans, 105, 19477-19498.

Durack, P. J., and S. E. Wijffels, 2010: Fifty-year trends in global ocean salinities and their relationship to broad-scale warming. J. Clim., 23, 4342-4362.

Durack, P. J., S. E. Wiiffels, and R. J. Matear, 2012: Ocean salinities reveal strong global water cycle intensification during 1950 to 2000. Science, 336, 455-458.

Egleston, E. S., C. L. Sabine, and F. M. M. Morel, 2010: Revelle revisited: Buffer factors that quantify the response of ocean chemistry to changes in DIC and alkalinity. Global Biogeochem. Cycles, 24, GB1002.

Ekman, M., 1988: The world's longest continued series of sea-level observations. Pure Appl. Geophys., 127, 73-77.
Emori, S., and S. J. Brown, 2005: Dynamic and thermodynamic changes in mean and extreme precipitation under changed climate. Geophys. Res. Lett., 32, L17706.

Fabry, V. J., B. A. Seibel, R. A. Feely, and J. C. Orr, 2008: Impacts of ocean acidification on marine fauna and ecosystem processes. Ices J. Mar. Sci., 65, 414-432.

Farneti, R., T. L. Delworth, A. J. Rosati, S. M. Griffies, and F. Zeng, 2010: The role of mesoscale eddies in the rectification of the Southern Ocean response to climate change. J. Phys. Oceanogr., 40, 1539-1557.

Feely, R. A., S. C. Doney, and S. R. Cooley, 2009: Ocean acidification: Present conditions and future changes in a high- $\mathrm{CO}_{2}$ world. Oceanography, 22, 36-47.

Feely, R. A., T. Takahashi, R. Wanninkhof, M. J. McPhaden, C. E. Cosca, S. C. Sutherland, and M. E. Carr, 2006: Decadal variability of the air-sea $\mathrm{CO}_{2}$ fluxes in the equatorial Pacific Ocean. J. Geophys. Res. Oceans, 111, C08s90.

Feng, M., M. J. McPhaden, and T. Lee, 2010: Decadal variability of the Pacific subtropical cells and their influence on the southeast Indian Ocean. Geophys. Res. Lett., 37, L09606.

Fischer, J., M. Visbeck, R. Zantopp, and N. Nunes, 2010: Interannual to decadal variability of outflow from the Labrador Sea. Geophys. Res. Lett., 37, L24610.

Frajka-Williams, E., S. A. Cunningham, H. Bryden, and B. A. King, 2011: Variability of Antarctic Bottom Water at $24.5^{\circ} \mathrm{N}$ in the Atlantic. J. Geophys. Res. Oceans, 116, C11026.

Freeland, H., et al., 2010: Argo-A decade of progress. In: Proceedings of OceanObs'09: Sustained Ocean Observations and Information for Society (Vol. 2). Venice, Italy, 21-25 September 2009, Hall, J., Harrison, D.E. \& Stammer, D., Eds., European Space Agency, ESA Publication WPP-306, doi:10.5270/OceanObs09. cwp.32

Freeland, H. J., and D. Gilbert, 2009: Estimate of the steric contribution to global sea level rise from a comparison of the WOCE one-time survey with 2006-2008 Argo observations. Atmos. Ocean, 47, 292-298.

Frölicher, T. L., F. Joos, G. K. Plattner, M. Steinacher, and S. C. Doney, 2009: Natural variability and anthropogenic trends in oceanic oxygen in a coupled carbon cycle-climate model ensemble. Global Biogeochem. Cycles, 23, Gb1003.

Fusco, G., V. Artale, Y. Cotroneo, and G. Sannino, 2008: Thermohaline variability of Mediterranean Water in the Gulf of Cadiz, 1948-1999. Deep-Sea Res. Pt. I, 55, 1624-1638.

Galloway, J. N., et al., 2008: Transformation of the nitrogen cycle: Recent trends, questions, and potential solutions. Science, 320, 889-892.

Garabato, A. C. N., L. Jullion, D. P. Stevens, K. J. Heywood, and B. A. King, 2009: Variability of Subantarctic Mode Water and Antarctic Intermediate Water in the Drake Passage during the late-twentieth and early-twenty-first centuries. J. Clim., 22, 3661-3688.

Garzoli, S. L., M. O. Baringer, S. F. Dong, R. C. Perez, and Q. Yao, 2013: South Atlantic meridional fluxes. Deep-Sea Res. Pt. I, 71, 21-32.

Gebbie, G., and P. Huybers, 2012: The mean age of ocean waters inferred from radiocarbon observations: sensitivity to surface sources and accounting for mixing histories. J. Phys. Oceanogr., 42, 291-305.

Gemmrich, J., B. Thomas, and R. Bouchard, 2011: Observational changes and trends in northeast Pacific wave records. Geophys. Res. Lett., 38, L22601.

Gerber, M., F. Joos, M. Vázquez-Rodríguez, F. Touratier, and C. Goyet, 2009: Regional air-sea fluxes of anthropogenic carbon inferred with an Ensemble Kalman Filter. Global Biogeochem. Cycles, 23, Gb1013.

Giese, B. S., G. A. Chepurin, J. A. Carton, T. P. Boyer, and H. F. Seidel, 2011: Impact of bathythermograph temperature bias models on an ocean reanalysis. J. Clim., 24, 84-93.

Gilbert, D., N. N. Rabalais, R. J. Diaz, and J. Zhang, 2010: Evidence for greater oxygen decline rates in the coastal ocean than in the open ocean. Biogeosciences, 7, 2283-2296.

Giles, K. A., S. W. Laxon, A. L. Ridout, D. J. Wingham, and S. Bacon, 2012: Western Arctic Ocean freshwater storage increased by wind-driven spin-up of the Beaufort Gyre. Nature Geosci., 5, 194-197.

Gille, S. T., 2008: Decadal-scale temperature trends in the Southern Hemisphere ocean. J. Clim., 21, 4749-4765.

Gillett, N. P., and P. A. Stott, 2009: Attribution of anthropogenic influence on seasonal sea level pressure. Geophys. Res. Lett., 36, L23709.

Gladyshev, S. V., M. N. Koshlyakov, and R. Y. Tarakanov, 2008: Currents in the Drake Passage based on observations in 2007. Oceanology, 48, 759-770.

Gleckler, P. J., et al., 2012: Human-induced global ocean warming on multidecadal timescales. Nature Clim. Change, 2, 524-529. 
Gloor, M., J. L. Sarmiento, and N. Gruber, 2010: What can be learned about carbon cycle climate feedbacks from the $\mathrm{CO}_{2}$ airborne fraction? Atmos. Chem. Phys., 10, 7739-7751.

Goni, G. J., F. Bringas, and P. N. DiNezio, 2011: Observed low frequency variability of the Brazil Current front. J. Geophys. Res. Oceans, 116, C10037.

González-Dávila, M., J. M. Santana-Casiano, M. J. Rueda, and O. Llinas, 2010: The water column distribution of carbonate system variables at the ESTOC site from 1995 to 2004. Biogeosciences, 7, 3067-3081.

Gouretski, V., and K. P. Koltermann, 2007: How much is the ocean really warming? Geophys. Res. Lett., 34, L01610.

Gouretski, V., and F. Reseghetti, 2010: On depth and temperature biases in bathythermograph data: Development of a new correction scheme based on analysis of a global ocean database. Deep-Sea Res. Pt. I, 57, 812-833.

Gouretski, V., J. Kennedy, T. Boyer, and A. Kohl, 2012: Consistent near-surface ocean warming since 1900 in two largely independent observing networks. Geophys. Res. Lett., 39, L19606.

Graven, H. D., N. Gruber, R. Key, S. Khatiwala, and X. Giraud, 2012: Changing controls on oceanic radiocarbon: New insights on shallow-to-deep ocean exchange and anthropogenic $\mathrm{CO}_{2}$ uptake. J. Geophys. Res. Oceans, 117, C10005.

Griffies, S. M., et al., 2009: Coordinated Ocean-ice Reference Experiments (COREs). Ocean Model., 26, 1-46.

Grinsted, A., J. C. Moore, and S. Jevrejeva, 2012: Homogeneous record of Atlantic hurricane surge threat since 1923. Proc. Natl. Acad. Sci. U.S.A., 109, 1960119605.

Grist, J. P., R. Marsh, and S. A. Josey, 2009: On the relationship between the North Atlantic Meridional Overturning Circulation and the surface-forced overturning streamfunction. J. Clim., 22, 4989-5002.

Gruber, N., et al., 2009: Oceanic sources, sinks, and transport of atmospheric $\mathrm{CO}_{2}$. Global Biogeochem. Cycles, 23, Gb1005.

Gu, G. J., R. F. Adler, G. J. Huffman, and S. Curtis, 2007: Tropical rainfall variability on interannual-to-interdecadal and longer time scales derived from the GPCP monthly product. J. Clim., 20, 4033-4046.

Gulev, S., T. Jung, and E. Ruprecht, 2007: Estimation of the impact of sampling errors in the VOS observations on air-sea fluxes. Part II: Impact on trends and interannual variability. J. Clim., 20, 302-315.

Gulev, S., et al., 2010: Surface Energy and $\mathrm{CO}_{2}$ Fluxes in the Global Ocean-AtmosphereIce System. In: Proceedings of OceanObs'09: Sustained Ocean Observations and Information for Society. Venice, Italy. 21-25 September 2009, Hall, J., Harrison, D.E. \& Stammer, D., Eds., European Space Agency, ESA Publication WPP-306, doi:10.5270/OceanObs09.pp.19

Gulev, S. K., and V. Grigorieva, 2006: Variability of the winter wind waves and swell in the North Atlantic and North Pacific as revealed by the voluntary observing ship data. J. Clim., 19, 5667-5685.

Haigh, I., R. Nicholls, and N. Wells, 2010: Assessing changes in extreme sea levels: Application to the English Channel, 1900-2006. Cont. Shelf Res., 30, 1042-1055.

Hallberg, R., and A. Gnanadesikan, 2006: The role of eddies in determining the structure and response of the wind-driven Southern Hemisphere overturning: Results from the Modeling Eddies in the Southern Ocean (MESO) project. J. Phys. Oceanogr., 36, 2232-2252.

Hamon, M., G. Reverdin, and P. Y. Le Traon, 2012: Empirical correction of XBT data. J. Atmos. Ocean. Technol., 29, 960-973.

Hansen, B., and S. Osterhus, 2007: Faroe Bank Channel overflow 1995-2005. Prog. Oceanogr., 75, 817-856.

Hansen, B., H. Hatun, R. Kristiansen, S. M. Olsen, and S. Osterhus, 2010: Stability and forcing of the Iceland-Faroe inflow of water, heat, and salt to the Arctic. Ocean Sci., 6, 1013-1026.

Hatun, H., A. B. Sando, H. Drange, B. Hansen, and H. Valdimarsson, 2005: Influence of the Atlantic subpolar gyre on the thermohaline circulation. Science, 309, 1841-1844.

Held, I. M., and B. J. Soden, 2006: Robust responses of the hydrological cycle to global warming. J. Clim., 19, 5686-5699.

Helm, K. P., N. L. Bindoff, and J. A. Church, 2010: Changes in the global hydrologicalcycle inferred from ocean salinity. Geophys. Res. Lett., 37, L18701.

Helm, K. P., N. L. Bindoff, and J. A. Church, 2011: Observed decreases in oxygen content of the global ocean. Geophys. Res. Lett., 38, L23602.

Hemer, M. A., 2010: Historical trends in Southern Ocean storminess: Long-term variability of extreme wave heights at Cape Sorell, Tasmania. Geophys. Res. Lett., 37, L18601.
Hemer, M. A., J. A. Church, and J. R. Hunter, 2010: Variability and trends in the directional wave climate of the Southern Hemisphere. Int. J. Climatol., 30, 475491.

Hill, K. L., S. R. Rintoul, R. Coleman, and K. R. Ridgway, 2008: Wind forced low frequency variability of the East Australia Current. Geophys. Res. Lett., 35, L08602.

Holgate, S. J., 2007: On the decadal rates of sea level change during the twentieth century. Geophys. Res. Lett., 34, L01602.

Holliday, N., et al., 2008: Reversal of the 1960s to 1990s freshening trend in the northeast North Atlantic and Nordic Seas. Geophys. Res. Lett., 35, L03614.

Hong, B. G., W. Sturges, and A. J. Clarke, 2000: Sea level on the US East Coast: Decadal variability caused by open ocean wind-curl forcing. J. Phys. Oceanogr., 30, 2088-2098.

Hood, M., et al., 2010: Ship-based repeat hydrography: A strategy for a sustained global program. In: Proceedings of OceanObs'09: Sustained Ocean Observations and Information for Society (Vol. 2). Venice, Italy. 21-25 September 2009, Hall, J., Harrison, D.E. \& Stammer, D., Eds., European Space Agency, ESA Publication WPP-306, doi:10.5270/0ceanObs09.cwp.44

Hosoda, S., T. Suga, N. Shikama, and K. Mizuno, 2009: Global surface layer salinity change detected by Argo and its implication for hydrological cycle intensification. J. Oceanogr., 65, 579-586.

Houston, J. R., and R. G. Dean, 2011: Sea-level acceleration based on US tide gauges and extensions of previous global-gauge analyses. J. Coast. Res., 27, 409-417.

Hughes, C. W., P. L. Woodworth, M. P. Meredith, V. Stepanov, T. Whitworth, and A. R. Pyne, 2003: Coherence of Antarctic sea levels, Southern Hemisphere Annular Mode, and flow through Drake Passage. Geophys. Res. Lett., 30, 1464.

Huhn, O., M. Rhein, M. Hoppema, and S. van Heuven, 2013: Decline of deep and bottom water ventilation and slowing down of anthropogenic carbon storage in the Weddell Sea, 1984-2011. Deep-Sea Res. Pt. I, 76, 66-84.

Huhn, O., H. H. Hellmer, M. Rhein, C. Rodehacke, W. G. Roether, M. P. Schodlok, and M. Schröder, 2008: Evidence of deep- and bottom-water formation in the western Weddell Sea. Deep-Sea Res. Pt. II, 55, 1098-1116.

Ingvaldsen, R. B., L. Asplin, and H. Loeng, 2004: Velocity field of the western entrance to the Barents Sea. J. Geophys. Res. Oceans, 109, C03021.

IPCC, 2011: Workshop Report of the Intergovernmental Panel on Climate Change Workshop on Impacts of Ocean Acidification on Marine Biology and Ecosystems [C. B. Field, V. Barros, T. F. Stocker, D. Qin, K. J. Mach, G.-K. Plattner, M. D. Mastrandrea, M. Tignor and K. L. Ebi (eds.)]. IPCC Working Group II Technical Support Unit, Carnegie Institution, Stanford, CA, USA 164 pp.

Irwin, A. J., and M. J. Oliver, 2009: Are ocean deserts getting larger? Geophys. Res. Lett., 36, L18609.

Ishidoya, S., S. Aoki, D. Goto, T. Nakazawa, S. Taguchi, and P. K. Patra, 2012: Time and space variations of the $\mathrm{O}_{2} / \mathrm{N}_{2}$ ratio in the troposphere over Japan and estimation of the global $\mathrm{CO}_{2}$ budget for the period 2000-2010. Tellus B, 64, 18964.

Ishii, M., and M. Kimoto, 2009: Reevaluation of historical ocean heat content variations with time-varying $\mathrm{XBT}$ and $\mathrm{MBT}$ depth bias corrections. J. Oceanogr., 65, 287-299.

Ishii, M., N. Kosugi, D. Sasano, S. Saito, T. Midorikawa, and H. Y. Inoue, 2011: Ocean acidification off the south coast of Japan: A result from time series observations of $\mathrm{CO}_{2}$ parameters from 1994 to 2008. J. Geophys. Res. Oceans, 116, C06022.

Ishii, M., et al., 2009: Spatial variability and decadal trend of the oceanic $\mathrm{CO}_{2}$ in the western equatorial Pacific warm/fresh water. Deep-Sea Res. Pt. II., 56, 591-606.

Jackson, J. M., E. C. Carmack, F. A. McLaughlin, S. E. Allen, and R. G. Ingram, 2010: Identification, characterization, and change of the near-surface temperature maximum in the Canada Basin, 1993-2008. J. Geophys. Res. Oceans, 115, C05021.

Jacobs, S. S., and C. F. Giulivi, 2010: Large multidecadal salinity trends near the Pacific-Antarctic continental margin. J. Clim., 23, 4508-4524.

Jevrejeva, S., A. Grinsted, J. C. Moore, and S. Holgate, 2006: Nonlinear trends and multiyear cycles in sea level records. J. Geophys. Res. Oceans, 111, C09012.

Jevrejeva, S., J. C. Moore, A. Grinsted, and P. L. Woodworth, 2008: Recent global sea level acceleration started over 200 years ago? Geophys. Res. Lett., 35, L08715.

Jochumsen, K., D. Quadfasel, H. Valdimarsson, and S. Jonsson, 2012: Variability of the Denmark Strait overflow: Moored time series from 1996-2011. J. Geophys. Res. Oceans, 117, C12003.

Johns, W. E., et al., 2011: Continuous, array-based estimates of Atlantic Ocean heat transport at $26.5^{\circ} \mathrm{N}$. J. Clim., 24, 2429-2449.

Johnson, G. C., and S. E. Wijffels, 2011: Ocean density change contributions to sea level rise. Oceanography, 24, 112-121. 
Johnson, G. C., S. G. Purkey, and J. L. Bullister, 2008a: Warming and freshening in the abyssal southeastern Indian Ocean. J. Clim., 21, 5351-5363.

Johnson, G. C., S. G. Purkey, and J. M. Toole, 2008b: Reduced Antarctic meridional overturning circulation reaches the North Atlantic Ocean. Geophys. Res. Lett., 35, L22601.

Jónsson, S., and H. Valdimarsson, 2012: Water mass transport variability to the North Icelandic shelf, 1994-2010. Ices J. Mar. Sci., 69, 809-815.

Josey, S. A., J. P. Grist, and R. Marsh, 2009: Estimates of meridional overturning circulation variability in the North Atlantic from surface density flux fields. J. Geophys. Res. Oceans, 114, C09022.

Kalnay, E., et al., 1996: The NCEP/NCAR 40-year reanalysis project. Bull. Am. Meteorol. Soc., 77, 437-471.

Kanamitsu, M., W. Ebisuzaki, J. Woollen, S. K. Yang, J. J. Hnilo, M. Fiorino, and G. L. Potter, 2002: NCEP-DOE AMIP-II reanalysis (R-2). Bull. Am. Meteorol. Soc., 83, $1631-1643$.

Kanzow, T., U. Send, and M. McCartney, 2008: On the variability of the deep meridional transports in the tropical North Atlantic. Deep-Sea Res. Pt. I, 55, 1601-1623.

Kanzow, T., et al., 2007: Observed flow compensation associated with the MOC at $26.5^{\circ} \mathrm{N}$ in the Atlantic. Science, 317, 938-941.

Kawai, Y., T. Doi, H. Tomita, and H. Sasaki, 2008: Decadal-scale changes in meridional heat transport across $24^{\circ} \mathrm{N}$ in the Pacific Ocean. J. Geophys. Res. Oceans, 113, C08021.

Kawano, T., T. Doi, H. Uchida, S. Kouketsu, M. Fukasawa, Y. Kawai, and K. Katsumata, 2010: Heat content change in the Pacific Ocean between the 1990s and 2000s. Deep-Sea Res. Pt. II, 57, 1141-1151.

Kazmin, A. S., 2012: Variability of the large-scale frontal zones: analysis of the global satellite information. Mod. Prob. Remote Sens. Ea. Space, 9, 213-218 (in Russian).

Keeling, C. D., H. Brix, and N. Gruber, 2004: Seasonal and long-term dynamics of the upper ocean carbon cycle at Station ALOHA near Hawaii. Global Biogeochem. Cycles, 18, GB4006.

Keeling, R.F. and A. C. Manning, 2014: Studies of Recent Changes in Atmospheric $\mathrm{O}_{2}$ Content. In: Holland, H.D. and Turekian, K.K., eds. Treatise on Geochemistry, 2nd Edition, Volume 5, pp.385-404. Oxford: Elsevier

Keeling, R. F., A. Kortzinger, and N. Gruber, 2010: Ocean deoxygenation in a warming world. Annu. Rev. Mar. Sci., 2, 199-229.

Key, R. M., et al., 2004: A global ocean carbon climatology: Results from Global Data Analysis Project (GLODAP). Global Biogeochem. Cycles, 18, Gb4031.

Khatiwala, S., F. Primeau, and T. Hall, 2009: Reconstruction of the history of anthropogenic $\mathrm{CO}_{2}$ concentrations in the ocean. Nature, 462, 346-349.

Khatiwala, S., et al., 2013: Global ocean storage of anthropogenic carbon. Biogeosciences, 10, 2169-2191.

Kieke, D., M. Rhein, L. Stramma, W. M. Smethie, D. A. LeBel, and W. Zenk, 2006: Changes in the CFC inventories and formation rates of Upper Labrador Sea Water, 1997-2001. J. Phys. Oceanogr., 36, 64-86.

Kim, T. W., K. Lee, R. G. Najjar, H. D. Jeong, and H. J. Jeong, 2011: Increasing N abundance in the northwestern Pacific Ocean due to atmospheric nitrogen deposition. Science, 334, 505-509.

King, M. A., M. Keshin, P. L. Whitehouse, I. D. Thomas, G. Milne, and R. E. M. Riva, 2012: Regional biases in absolute sea-level estimates from tide gauge data due to residual unmodeled vertical land movement. Geophys. Res. Lett., 39, L14604.

Knorr, W., 2009: Is the airborne fraction of anthropogenic $\mathrm{CO}_{2}$ emissions increasing? Geophys. Res. Lett., 36, L21710.

Kobayashi, T., K. Mizuno, and T. Suga, 2012: Long-term variations of surface and intermediate waters in the southern Indian Ocean along $32^{\circ}$ S. J. Oceanogr., 68, 243-265.

Komar, P. D., and J. C. Allan, 2008: Increasing hurricane-generated wave heights along the US East Coast and their climate controls. J. Coast. Res., 24, 479-488.

Koshlyakov, M. N., Lisina, II, E. G. Morozov, and R. Y. Tarakanov, 2007: Absolute geostrophic currents in the Drake Passage based on observations in 2003 and 2005. Oceanology, 47, 451-463.

Koshlyakov, M. N., S. V. Gladyshev, R. Y. Tarakanov, and D. A. Fedorov, 2011: Currents in the western Drake Passage by the observations in January 2010. Oceanology, 51, 187-198.

Kouketsu, S., M. Fukasawa, D. Sasano, Y. Kumamoto, T. Kawano, H. Uchida, and T. Doi, 2010: Changes in water properties around North Pacific intermediate water between the 1980s, 1990s and 2000s. Deep-Sea Res. Pt. II, 57, 1177-1187.
Kouketsu, S., et al., 2009: Changes in water properties and transports along $24^{\circ} \mathrm{N}$ in the North Pacific between 1985 and 2005. J. Geophys. Res. Oceans, 114, C01008.

Kouketsu, S., et al., 2011: Deep ocean heat content changes estimated from observation and reanalysis product and their influence on sea level change. J. Geophys. Res. Oceans, 116, C03012.

Krueger, O., F. Schenk, F. Feser, and R. Weisse, 2013: Inconsistencies between longterm trends in storminess derived from the $20 \mathrm{CR}$ reanalysis and observations. J. Clim., 26, 868-874.

Large, W. G., and S. G. Yeager, 2009: The global climatology of an interannually varying air-sea flux data set. Clim. Dyn., 33, 341-364.

Large, W. G., and S. G. Yeager, 2012: On the observed trends and changes in global sea surface temperature and air-sea heat fluxes (1984-2006). J. Clim., 25, 6123-6135.

Le Quéré, C., T. Takahashi, E. T. Buitenhuis, C. Roedenbeck, and S. C. Sutherland, 2010: Impact of climate change and variability on the global oceanic sink of $\mathrm{CO}_{2}$. Global Biogeochem. Cycles, 24, Gb4007.

Le Quéré, $\mathrm{C}$., et al., 2007: Saturation of the Southern Ocean $\mathrm{CO}_{2}$ sink due to recent climate change. Science, 316, 1735-8.

Lenton, A., et al., 2012: The observed evolution of oceanic $\mathrm{pCO}_{2}$ and its drivers over the last two decades. Global Biogeochem. Cycles, 26, Gb2021.

Letetrel, C., M. Marcos, B. M. Miguez, and G. Wöppelmann, 2010: Sea level extremes in Marseille (NW Mediterranean) during 1885-2008. Cont. Shelf Res. , 30, 12671274.

Leuliette, E. W., and L. Miller, 2009: Closing the sea level rise budget with altimetry, Argo, and GRACE. Geophys. Res. Lett., 36, L04608.

Leuliette, E. W., and R. Scharroo, 2010: Integrating Jason-2 into a multiple-altimeter climate data record. Mar. Geodesy, 33, 504-517.

Leuliette, E. W., and J. K. Willis, 2011: Balancing the sea level budget. Oceanography, 24, 122-129.

Levitus, S., 1989: Interpentadal variability of temperature and salinity at intermediate depths of the North-Atlantic Ocean, 1970-1974 variabilityersus 1955-1959. J. Geophys. Res. Oceans, 94, 6091-6131.

Levitus, S., J. I. Antonov, T. P. Boyer, R. A. Locarnini, H. E. Garcia, and A. V. Mishonov, 2009: Global ocean heat content 1955-2008 in light of recently revealed instrumentation problems. Geophys. Res. Lett., 36, L07608.

Levitus, S., et al., 2012: World ocean heat content and thermosteric sea level change (0-2000m) 1955-2010. Geophys. Res. Lett., 39, L10603.

Lewis, E. L., and N. P. Fofonoff, 1979: A practical salinity scale. J. Phys. Oceanogr., 9, 446 .

Li, G., B. Ren, J. Zheng, and C. Yang, 2011: Trend singular value decomposition analysis and its application to the global ocean surface latent heat flux and SST anomalies. J. Clim., 24, 2931-2948.

Llovel, W., S. Guinehut, and A. Cazenave, 2010: Regional and interannual variability in sea level over 2002-2009 based on satellite altimetry, Argo float data and GRACE ocean mass. Ocean Dyn., 60, 1193-1204.

Llovel, W., B. Meyssignac, and A. Cazenave, 2011: Steric sea level variations over 2004-2010 as a function of region and depth: Inference on the mass component variability in the North Atlantic Ocean. Geophys. Res. Lett., 38, L15608.

Llovel, W., A. Cazenave, P. Rogel, A. Lombard, and M. B. Nguyen, 2009: Twodimensional reconstruction of past sea level (1950-2003) from tide gauge data and an Ocean General Circulation Model. Clim. Past, 5, 217-227.

Lowe, J. A., and J. M. Gregory, 2006: Understanding projections of sea level rise in a Hadley Centre coupled climate model. J. Geophys. Res. Oceans, 111, C11014.

Lowe, J. A., et al., 2010: Past and future changes in extreme sea levels and waves. In: Understanding Sea-Level Rise and Variability [J. A. Church, P. L. Woodworth, T. Aarup, and W. S. Wilson (eds.)]. Wiley-Blackwell, New York, NY, USA, 326-375.

Lozier, M. S., and N. M. Stewart, 2008: On the temporally varying northward penetration of Mediterranean Overflow Water and eastward penetration of Labrador Sea water. J. Phys. Oceanogr., 38, 2097-2103.

Lumpkin, R., and K. Speer, 2007: Global ocean meridional overturning. J. Phys. Oceanogr., 37, 2550-2562.

Lumpkin, R., and S. Garzoli, 2011: Interannual to decadal changes in the western South Atlantic's surface circulation. J. Geophys. Res. Oceans, 116, C01014.

Lyman, J. M., and G. C. Johnson, 2008: Estimating annual global upper-ocean heat content anomalies despite irregular in situ ocean sampling. J. Clim., 21, 56295641.

Lyman, J. M., et al., 2010: Robust warming of the global upper ocean. Nature, 465, 334-337. 
Macrander, A., U. Send, H. Valdimarsson, S. Jonsson, and R. H. Kase, 2005: Interannual changes in the overflow from the Nordic Seas into the Atlantic Ocean through Denmark Strait. Geophys. Res. Lett., 32, L06606.

Marcos, M., M. N. Tsimplis, and A. G. P. Shaw, 2009: Sea level extremes in southern Europe. J. Geophys. Res. Oceans, 114, C01007.

Marcos, M., M. N. Tsimplis, and F. M. Calafat, 2012: Inter-annual and decadal sea level variations in the north-western Pacific marginal seas. Prog. Oceanogr., 105, 4-21.

Marshall, G. J., 2003: Trends in the southern annular mode from observations and reanalyses. J. Clim., 16, 4134-4143.

Masters, D., R. S. Nerem, C. Choe, E. Leuliette, B. Beckley, N. White, and M. Ablain, 2012: Comparison of global mean sea level time series from TOPEX/Poseidon, Jason-1, and Jason-2. Mar. Geodesy, 35, 20-41.

Masuda, S., et al., 2010: Simulated rapid warming of abyssal North Pacific waters. Science, 329, 319-322.

Matear, R. J., and A. C. Hirst, 2003: Long-term changes in dissolved oxygen concentrations in the ocean caused by protracted global warming. Global Biogeochem. Cycles, 17, 1125.

Mauritzen, C., A. Melsom, and R. T. Sutton, 2012: Importance of density-compensated temperature change for deep North Atlantic Ocean heat uptake. Nature Geosci, 5, 905-910.

Mauritzen, C., et al., 2011: Closing the loop—Approaches to monitoring the state of the Arctic Mediterranean during the International Polar Year 2007-2008. Prog. Oceanogr., 90, 62-89.

McCarthy, G., E. McDonagh, and B. King, 2011: Decadal variability of thermocline and intermediate waters at $24^{\circ} \mathrm{S}$ in the South Atlantic. J. Phys. Oceanogr., 41, 157-165.

McCarthy, G., et al., 2012: Observed interannual variability of the Atlantic meridional overturning circulation at $26.5^{\circ} \mathrm{N}$. Geophys. Res. Lett., 39, L19609.

McDonagh, E. L., H. L. Bryden, B. A. King, R. J. Sanders, S. A. Cunningham, and R. Marsh, 2005: Decadal changes in the south Indian Ocean thermocline. J. Clim., $18,1575-1590$.

McKinley, G. A., A. R. Fay, T. Takahashi, and N. Metzl, 2011: Convergence of atmospheric and North Atlantic carbon dioxide trends on multidecadal timescales. Nature Geosci., 4, 606-610.

McPhee, M. G., A. Proshutinsky, J. H. Morison, M. Steele, and M. B. Alkire, 2009: Rapid change in freshwater content of the Arctic Ocean. Geophys. Res. Lett., 36, L10602.

Mears, C. A., and F. J. Wentz, 2009a: Construction of the RSS V3.2 lower-tropospheric temperature dataset from the MSU and AMSU microwave sounders. J. Atmos. Ocean. Technol., 26, 1493-1509.

Mears, C. A., and F. J. Wentz, 2009b: Construction of the Remote Sensing Systems V3.2 atmospheric temperature records from the MSU and AMSU microwave sounders. J. Atmos. Ocean. Technol., 26, 1040-1056.

Meijers, A. J. S., N. L. Bindoff, and S. R. Rintoul, 2011: Frontal movements and property fluxes: Contributions to heat and freshwater trends in the Southern Ocean. J. Geophys. Res. Oceans, 116, $C 08024$.

Meinen, C. S., M. O. Baringer, and R. F. Garcia, 2010: Florida Current transport variability: An analysis of annual and longer-period signals. Deep-Sea Res. Pt. $1,57,835-846$.

Menéndez, M., and P. L. Woodworth, 2010: Changes in extreme high water levels based on a quasi-global tide-gauge data set. J. Geophys. Res. Oceans, 115, C10011.

Menéndez, M., F. J. Méndez, I. J. Losada, and N. E. Graham, 2008:Variability of extreme wave heights in the northeast Pacific Ocean based on buoy measurements. Geophys. Res. Lett., 35, L22607.

Meredith, M. P., P. L. Woodworth, C. W. Hughes, and V. Stepanov, 2004: Changes in the ocean transport through Drake Passage during the 1980s and 1990s, forced by changes in the Southern Annular Mode. Geophys. Res. Lett., 31, L21305.

Merrifield, M. A., 2011: A shift in western tropical Pacific sea level trends during the 1990s. J. Clim., 24, 4126-4138.

Merrifield, M. A., and M. E. Maltrud, 2011: Regional sea level trends due to a Pacific trade wind intensification. Geophys. Res. Lett., 38, L21605.

Merrifield, M. A., S. T. Merrifield, and G. T. Mitchum, 2009: An anomalous recent acceleration of global sea level rise. J. Clim., 22, 5772-5781.

Merrifield, M. A., P. R. Thompson, and M. Lander, 2012: Multidecadal sea level anomalies and trends in the western tropical Pacific. Geophys. Res. Lett., 39, L13602.
Metzl, N., 2009: Decadal increase of oceanic carbon dioxide in Southern Indian Ocean surface waters (1991-2007). Deep-Sea Res. Pt. II, 56, 607-619.

Meyssignac, B., M. Becker, W. Llovel, and A. Cazenave, 2012: An assessment of two-dimensional past sea level reconstructions over 1950-2009 based on tidegauge data and different input sea level grids. Surv. Geophys., 33, 945-972.

Midorikawa, T., K. Nemoto, H. Kamiya, M. Ishii, and H. Y. Inoue, 2005: Persistently strong oceanic $\mathrm{CO}_{2}$ sink in the western subtropical North Pacific. Geophys. Res. Lett., 32, L05612.

Midorikawa, T., et al., 2010: Decreasing pH trend estimated from 25-yr time series of carbonate parameters in the western North Pacific. Tellus B, 62, 649-659.

Mikaloff-Fletcher, S. E., et al., 2006: Inverse estimates of anthropogenic $\mathrm{CO}_{2}$ uptake, transport, and storage by the ocean. Global Biogeochem. Cycles, 20, Gb2002.

Miller, L., and B. C. Douglas, 2007: Gyre-scale atmospheric pressure variations and their relation to 19th and 20th century sea level rise. Geophys. Res. Lett., 34, L16602.

Mitas, C. M., and A. Clement, 2005: Has the Hadley cell been strengthening in recent decades? Geophys. Res. Lett., 32, L03809.

Mitchum, G. T., R. S. Nerem, M. A. Merrifield, and W. R. Gehrels, 2010: Modern sealevel-change estimates. In: Understanding Sea-Level Rise and Variability [J. A. Church, P. L. Woodworth, T. Aarup, and W. S. Wilson (eds.)]. Wiley-Blackwell, New York, NY, USA, 122-142.

Morison, J., R. Kwok, C. Peralta-Ferriz, M. Alkire, I. Rigor, R. Andersen, and M. Steele, 2012: Changing Arctic Ocean freshwater pathways. Nature, 481, 66-70.

Morrow, R., G. Valladeau, and J. B. Sallee, 2008: Observed subsurface signature of Southern Ocean sea level rise. Prog. Oceanogr., 77, 351-366.

Murphy, D. M., S. Solomon, R. W. Portmann, K. H. Rosenlof, P. M. Forster, and T. Wong 2009: An observationally based energy balance for the Earth since 1950. J. Geophys. Res. Atmos., 114, D17107.

Nakano, T., I. Kaneko, T. Soga, H. Tsujino, T. Yasuda, H. Ishizaki, and M. Kamachi, 2007: Mid-depth freshening in the North Pacific subtropical gyre observed along the JMA repeat and WOCE hydrographic sections. Geophys. Res. Lett., 34, L23608.

Nakanowatari, T., K. Ohshima, and M. Wakatsuchi, 2007: Warming and oxygen decrease of intermediate water in the northwestern North Pacific, originating from the Sea of Okhotsk, 1955-2004. Geophys. Res. Lett., 34, L04602.

Nerem, R. S., D. P. Chambers, C. Choe, and G. T. Mitchum, 2010: Estimating mean sea level change from the TOPEX and Jason altimeter missions. Mar. Geodesy 33, 435-446.

Nerem, R. S., D. P. Chambers, E. W. Leuliette, G. T. Mitchum, and B. S. Giese, 1999: Variations in global mean sea level associated with the 1997-1998 ENSO event: Implications for measuring long term sea level change. Geophys. Res. Lett., 26 3005-3008.

Olafsson, J., S. R. Olafsdottir, A. Benoit-Cattin, M. Danielsen, T. S. Arnarson, and T. Takahashi, 2009: Rate of Iceland Sea acidification from time series measurements. Biogeosciences, 6, 2661-2668.

Olsen, A., A. M. Omar, E. Jeansson, L. G. Anderson, and R. G. J. Bellerby, 2010: Nordic seas transit time distributions and anthropogenic $\mathrm{CO}_{2}$.J. Geophys. Res. Oceans, 115, C05005

Olsen, S. M., B. Hansen, D. Quadfasel, and S. Osterhus, 2008: Observed and modelled stability of overflow across the Greenland-Scotland ridge. Nature, 455, 519-22.

Ono, T., T. Midorikawa, Y. W. Watanabe, K. Tadokoro, and T. Saino, 2001: Temporal increases of phosphate and apparent oxygen utilization in the subsurface waters of western subarctic Pacific from 1968 to 1998. Geophys. Res. Lett., 28 3285-3288.

Orr, J. C., 2011: Recent and future changes in ocean carbonate chemistry. In: Ocean Acidification [J.-P. Gattuso and L. Hansson (eds.)]. Oxford University Press, Oxford, UK, and New York, NY, USA, pp. 41-66.

Orr, J. C., S. Pantoja, and H. O. Pörtner, 2005a: Introduction to special section: The ocean in a high- $\mathrm{CO}_{2}$ world. J. Geophys. Res. Oceans, 110, $\mathrm{C} 09501$.

Orr, J. C., et al., 2005b: Anthropogenic ocean acidification over the twenty-first century and its impact on calcifying organisms. Nature, 437, 681-686.

Orsi, A. H., G. C. Johnson, and J. L. Bullister, 1999: Circulation, mixing, and production of Antarctic Bottom Water. Prog. Oceanogr., 43, 55-109.

Østerhus, S., W. R. Turrell, S. Jonsson, and B. Hansen, 2005: Measured volume, heat, and salt fluxes from the Atlantic to the Arctic Mediterranean. Geophys. Res. Lett. 32, L07603.

Palmer, M., and P. Brohan, 2011: Estimating sampling uncertainty in fixed-depth and fixed-isotherm estimates of ocean warming. Int. J. Climatol., 31, 980-986.

Palmer, M., K. Haines, S. Tett, and T. Ansell, 2007: Isolating the signal of ocean global warming. Geophys. Res. Lett., 34, L23610. 
Park, G. H., et al., 2006: Large accumulation of anthropogenic $\mathrm{CO}_{2}$ in the East (Japan) Sea and its significant impact on carbonate chemistry. Global Biogeochem. Cycles, 20, Gb4013.

Park, J., J. Obeysekera, M. Irizarry, J. Barnes, P. Trimble, and W. Park-Said, 2011: Storm surge projections and implications for water management in South Florida. Clim. Change, 107, 109-128.

Peltier, W. R., 2001: Global glacial isostatic adjustment and modern instrumental records of relative sea level history. In: Sea Level Rise [B. C. Douglas, M. S. Kearney, and S. P. Leatherman (eds.)]. Elsevier, Amsterdam, the Netherlands, and Philadelphia, PA, USA, pp. 65-95.

Peltier, W. R., 2004: Global glacial isostasy and the surface of the ice-age earth: The ice-5G (VM2) model and grace. Annu. Rev. Earth Planet. Sci., 32, 111-149.

Peltier, W. R., R. Drummond, and K. Roy, 2012: Comment on "Ocean mass from GRACE and glacial isostatic adjustment" by D. P. Chambers et al. J. Geophys. Res.-Sol. Ea., 117, B11403.

Pérez, F. F., M. Vázquez-Rodríguez, H. Mercier, A. Velo, P. Lherminier, and A. F. Ríos, 2010: Trends of anthropogenic $\mathrm{CO}_{2}$ storage in North Atlantic water masses. Biogeosciences, 7, 1789-1807.

Pierce, D. W., P. J. Gleckler, T. P. Barnett, B. D. Santer, and P. J. Durack, 2012: The fingerprint of human-induced changes in the ocean's salinity and temperature fields. Geophys. Res. Lett., 39, L21704.

Pierce, D. W., T. P. Barnett, K. M. AchutaRao, P. J. Gleckler, J. M. Gregory, and W. M. Washington, 2006: Anthropogenic warming of the oceans: Observations and model results. J. Clim., 19, 1873-1900.

Pinker, R. T., H. M. Wang, and S. A. Grodsky, 2009: How good are ocean buoy observations of radiative fluxes? Geophys. Res. Lett., 36, L10811.

Polovina, J. J., E. A. Howell, and M. Abecassis, 2008: Ocean's least productive waters are expanding. Geophys. Res. Lett., 35, L03618.

Polyakov, I. V., A. V. Pnyushkov, and L. A. Timokhov, 2012:Warming of the Intermediate Atlantic Water of the Arctic Ocean in the 2000s. J. Clim., 25, 8362-8370.

Polyakov, I. V., V. A. Alexeev, U. S. Bhatt, E. I. Polyakova, and X. D. Zhang, 2010: North Atlantic warming: patterns of long-term trend and multidecadal variability. Clim. Dyn., 34, 439-457.

Polyakov, I. V., U. S. Bhatt, H. L. Simmons, D. Walsh, J. E. Walsh, and X. Zhang, 2005: Multidecadal variability of North Atlantic temperature and salinity during the twentieth century. J. Clim., 18, 4562-4581.

Polyakov, I. V., et al., 2008: Arctic ocean freshwater changes over the past 100 years and their causes. J. Clim., 21, 364-384.

Ponte, R. M., 2012: An assessment of deep steric height variability over the global ocean. Geophys. Res. Lett., 39, L04601.

Potemra, J. T., and N. Schneider, 2007: Interannual variations of the Indonesian throughflow. J. Geophys. Res. Oceans, 112, $\mathrm{C} 05035$.

Proshutinsky, A., et al., 2009: Beaufort Gyre freshwater reservoir: State and variability from observations. J. Geophys. Res. Oceans, 114, C00A10.

Provoost, P., S. van Heuven, K. Soetaert, R. W. P. M. Laane, and J. J. Middelburg, 2010: Seasonal and long-term changes in $\mathrm{pH}$ in the Dutch coastal zone. Biogeosciences, 7, 3869-3878.

Purkey, S. G., and G. C. Johnson, 2010: Warming of global abyssal and deep Southern Ocean waters between the 1990s and 2000s: Contributions to global heat and sea level rise budgets. J. Clim., 23, 6336-6351.

_ 2012: Global contraction of Antarctic Bottom Water between the 1980s and 2000s. J. Clim., 25, 5830-5844.

Purkey, S. G., and G. C. Johnson, 2013: Antarctic Bottom Water warming and freshening: Contributions to sea level rise, ocean freshwater budgets, and global heat gain. J. Clim., doi:10.1175/JCLI-D-12-00834.1.

Qiu, B., and S. Chen, 2006: Decadal variability in the large-scale sea surface height field of the South Pacific Ocean: Observations and causes. J. Phys. Oceanogr., $36,1751-1762$.

Qiu, B., and S. Chen, 2010: Interannual-to-decadal variability in the bifurcation of the North Equatorial Current off the Philippines. J. Phys. Oceanogr., 40, 2525-2538.

Qiu, B., and S. Chen, 2012: Multi-decadal sea level and gyre circulation variability in the northwestern tropical Pacific Ocean. J. Phys. Oceanogr., 42, 193-206.

Quay, P., R. Sonnerup, T. Westby, J. Stutsman, and A. McNichol, 2003: Changes in the $\mathrm{C}-13 / \mathrm{C}-12$ of dissolved inorganic carbon in the ocean as a tracer of anthropogenic $\mathrm{CO}_{2}$ uptake. Global Biogeochem. Cycles, 17, 1004.

Rabe, B., et al., 2011: An assessment of Arctic Ocean freshwater content changes from the 1990s to the 2006-2008 period. Deep-Sea Res. Pt. I, 58, 173-185.
Rahmstorf, S., and M. Vermeer, 2011: Discussion of: Houston, J.R. and Dean, R.G. 2011. Sea-level acceleration based on U.S. tide gauges and extensions of previous global-gauge analyses. J. Coast. Res., 27(3), 409-417. J. Coast. Res., 27, 784-787.

Rawlins, M. A., et al., 2010: Analysis of the Arctic System for freshwater cycle intensification: Observations and expectations. J. Clim., 23, 5715-5737.

Ray, R. D., and B. C. Douglas, 2011: Experiments in reconstructing twentieth-century sea levels. Prog. Oceanogr., 91, 496-515.

Ren, L., and S. C. Riser, 2010: Observations of decadal time scale salinity changes in the subtropical thermocline of the North Pacific Ocean. Deep-Sea Res. Pt. II, 57, 1161-1170.

Reverdin, G., 2010: North Atlantic subpolar gyre surface variability (1895-2009). J. Clim., 23, 4571-4584.

Reverdin, G., F. Durand, J. Mortensen, F. Schott, H. Valdimarsson, and W. Zenk, 2002: Recent changes in the surface salinity of the North Atlantic subpolar gyre. J. Geophys. Res. Oceans, 107, 8010.

Rhein, M., et al., 2011: Deep water formation, the subpolar gyre, and the meridional overturning circulation in the subpolar North Atlantic. Deep-Sea Res. Pt. II, 58, 1819-1832.

Rienecker, M. M., et al., 2011: MERRA: NASA's Modern-Era Retrospective Analysis for Research and Applications. J. Clim., 24, 3624-3648.

Rignot, E., J. L. Bamber, M. R. Van Den Broeke, C. Davis, Y. H. Li, W. J. Van De Berg, and E. Van Meijgaard, 2008: Recent Antarctic ice mass loss from radar interferometry and regional climate modelling. Nature Geosci., 1, 106-110.

Rintoul, S. R., 2007: Rapid freshening of Antarctic Bottom Water formed in the Indian and Pacific oceans. Geophys. Res. Lett., 34, L06606.

Rintoul, S. R., S. Sokolov, and J. Church, 2002: A 6 year record of baroclinic transport variability of the Antarctic Circumpolar Current at $140^{\circ} \mathrm{E}$ derived from expendable bathythermograph and altimeter measurements. J. Geophys. Res. Oceans, 107, 3155.

Robertson, R., M. Visbeck, A. L. Gordon, and E. Fahrbach, 2002: Long-term temperature trends in the deep waters of the Weddell Sea. Deep-Sea Res. Pt. II, 49, 4791-4806.

Roemmich, D., and J. Gilson, 2009: The 2004-2008 mean and annual cycle of temperature, salinity, and steric height in the global ocean from the Argo Program. Prog. Oceanogr., 82, 81-100.

Roemmich, D., and J. Gilson, 2011: The global ocean imprint of ENSO. Geophys. Res. Lett., 38, L13606.

Roemmich, D., W. J. Gould, and J. Gilson, 2012: 135 years of global ocean warming between the Challenger expedition and the Argo Programme. Nature Clim. Change, 2, 425-428.

Roemmich, D., J. Gilson, R. Davis, P. Sutton, S. Wijffels, and S. Riser, 2007: Decadal spinup of the South Pacific subtropical gyre. J. Phys. Oceanogr., 37, 162-173.

Ruggiero, P., P. D. Komar, and J. C. Allan, 2010: Increasing wave heights and extreme value projections: The wave climate of the U.S. Pacific Northwest. Coast. Engng., $57,539-552$.

Sabine, C. L., et al., 2005: Global Ocean Data Analysis Project (GLODAP): Results and data. ORNL/CDIAC-145, NDP-083. Carbon Dioxide Information Analysis Center, Oak Ridge National Laboratory, U.S. Department of Energy, 110 pp.

Sabine, C. L., et al., 2004: The oceanic sink for anthropogenic $\mathrm{CO}_{2}$. Science, 305, 367-371.

Saha, S., et al., 2010: The NCEP Climate Forecast System Reanalysis. Bull. Am. Meteorol. Soc., 91, 1015-1057.

Sallenger, A. H., K. S. Doran, and P. A. Howd, 2012: Hotspot of accelerated sea-level rise on the Atlantic coast of North America. Nature Clim. Change, 2, 884-888.

Santana-Casiano, J. M., M. González-Dávila, M. J. Rueda, O. Llinas, and E. F. González-Dávila, 2007: The interannual variability of oceanic $\mathrm{CO}_{2}$ parameters in the northeast Atlantic subtropical gyre at the ESTOC site. Global Biogeochem. Cycles, 21, GB1015.

Sarafanov, A., A. Falina, A. Sokov, and A. Demidov, 2008: Intense warming and salinification of intermediate waters of southern origin in the eastern subpolar North Atlantic in the 1990s to mid-2000s. J. Geophys. Res. Oceans, 113, C12022.

Sarmiento, J. L., et al., 2010: Trends and regional distributions of land and ocean carbon sinks. Biogeosciences, 7, 2351-2367.

Schanze, J. J., R. W. Schmitt, and L. L. Yu, 2010: The global oceanic freshwater cycle: A state-of-the-art quantification. J. Mar. Res., 68, 569-595.

Schauer, U., and A. Beszczynska-Möller, 2009: Problems with estimation and interpretation of oceanic heat transport - conceptual remarks for the case of Fram Strait in the Arctic Ocean. Ocean Sci., 5, 487-494. 
Schmidtko, S., and G. C. Johnson, 2012: Multi-decadal warming and shoaling of Antarctic Intermediate Water. J. Clim., 25, 201-221.

Schmitt, R. W., 2008: Salinity and the global water cycle. Oceanography, 21, 12-19.

Schneider, T., P. A. O'Gorman, and X. J. Levine, 2010: Water vapor and the dynamics of climate changes. Rev. Geophys., 48, Rg3001.

Schuster, U., and A. J. Watson, 2007: A variable and decreasing sink for atmospheric $\mathrm{CO}_{2}$ in the North Atlantic. J. Geophys. Res. Oceans, 112, C11006.

Schuster, U., et al., 2013: An assessment of the Atlantic and Arctic sea-air $\mathrm{CO}_{2}$ fluxes, 1990-2009. Biogeosciences, 10, 607-627.

Seitzinger, S. P., et al., 2010: Global river nutrient export: A scenario analysis of past and future trends. Global Biogeochem. Cycles, 24, Gb0a08.

Semedo, A., K. Suselj, A. Rutgersson, and A. Sterl, 2011: A global view on the wind sea and swell climate and variability from ERA-40. J. Clim., 24, 1461-1479.

Send, U., M. Lankhorst, and T. Kanzow, 2011: Observation of decadal change in the Atlantic Meridional Overturning Circulation using 10 years of continuous transport data. Geophys. Res. Lett., 38, L24606.

Shepherd, A., D. Wingham, and E. Rignot, 2004: Warm ocean is eroding West Antarctic Ice Sheet. Geophys. Res. Lett., 31, L23402.

Shiklomanov, A. I., and R. B. Lammers, 2009: Record Russian river discharge in 2007 and the limits of analysis. Environ. Res. Lett., 4, 045015.

Smith, D. M., and J. M. Murphy, 2007: An objective ocean temperature and salinity analysis using covariances from a global climate model. J. Geophys. Res. Oceans, $112, \mathrm{C} 02022$.

Smith, R. O., H. L. Bryden, and K. Stansfield, 2008: Observations of new western Mediterranean deep water formation using Argo floats 2004-2006. Ocean Sci, 4, 133-149.

Smith, T. M., P. A. Arkin, and M. R. P. Sapiano, 2009: Reconstruction of near-global annual precipitation using correlations with sea surface temperature and sea level pressure. J. Geophys. Res. Atmos., 114, D12107.

Smith, T. M., P. A. Arkin, L. Ren, and S. S. P. Shen, 2012: Improved reconstruction of global precipitation since 1900. J. Atmos. Ocean. Technol., 29, 1505-1517.

Sokolov, S., and S. R. Rintoul, 2009: Circumpolar structure and distribution of the Antarctic Circumpolar Current fronts: 2. Variability and relationship to sea surface height. J. Geophys. Res. Oceans, 114, C11019.

Spada, G., and G. Galassi, 2012: New estimates of secular sea level rise from tide gauge data and GIA modelling. Geophys. J. Int., 191, 1067-1094.

Spence, P., J. C. Fyfe, A. Montenegro, and A. J. Weaver, 2010: Southern Ocean response to strengthening winds in an eddy-permitting global climate model. J. Clim., 23, 5332-5343.

Sprintall, J., S. Wijffels, T. Chereskin, and N. Bray, 2002: The JADE and WOCE I10/ IR6 Throughflow sections in the southeast Indian Ocean. Part 2: velocity and transports. Deep-Sea Res. Pt. II, 49, 1363-1389.

Sprintall, J., S. E. Wijffels, R. Molcard, and I. Jaya, 2009: Direct estimates of the Indonesian Throughflow entering the Indian Ocean: 2004-2006. J. Geophys. Res. Oceans, 114, C07001.

Stammer, D. et al, 2010: Ocean Information Provided Through Ensemble Ocean Syntheses in Proceedings of OceanObs'09: Sustained Ocean Observations and Information for Society (Vol. 2), Venice, Italy, 21-25 September 2009, Hall, J., Harrison, D.E. \& Stammer, D., Eds., European Space Agency, ESA Publication WPP-306, doi:10.5270/0ceanObs09.cwp.85

Steele, M., and W. Ermold, 2007: Steric sea level change in the Northern Seas. J. Clim., 20, 403-417.

Steinfeldt, R., M. Rhein, J. L. Bullister, and T. Tanhua, 2009: Inventory changes in anthropogenic carbon from 1997-2003 in the Atlantic Ocean between $20^{\circ} \mathrm{S}$ and $65^{\circ} \mathrm{N}$. Global Biogeochem. Cycles, 23, GB3010.

Stendardo, I., and N. Gruber, 2012: Oxygen trends over five decades in the North Atlantic. J. Geophys. Res. Oceans, 117, C11004.

Sterl, A., and S. Caires, 2005: Climatology, variability and extrema of ocean waves: The web-based KNMI/ERA-40 wave atlas. Int. J. Climatol., 25, 963-977.

Stott, P. A., R. T. Sutton, and D. M. Smith, 2008: Detection and attribution of Atlantic salinity changes. Geophys. Res. Lett., 35, L21702.

Stramma, L., A. Oschlies, and S. Schmidtko, 2012: Mismatch between observed and modeled trends in dissolved upper-ocean oxygen over the last $50 \mathrm{yr}$. Biogeosciences, 9, 4045-4057.

Stramma, L., G. C. Johnson, J. Sprintall, and V. Mohrholz, 2008: Expanding oxygenminimum zones in the tropical oceans. Science, 320, 655-658.

Stramma, L., S. Schmidtko, L. A. Levin, and G. C. Johnson, 2010: Ocean oxygen minima expansions and their biological impacts. Deep-Sea Res. Pt. I, 57, 587-595.
Sturges, W., and B. G. Hong, 1995: Wind forcing of the Atlantic thermocline along $32^{\circ} \mathrm{N}$ at low-frequencies. J. Phys. Oceanogr., 25, 1706-1715.

Sturges, W., and B. C. Douglas, 2011: Wind effects on estimates of sea level rise. J. Geophys. Res. Oceans, 116, C06008.

Sugimoto, S., and K. Hanawa, 2010: The wintertime wind stress curl field in the North Atlantic and its relation to atmospheric teleconnection patterns. J. Atmos. Sci., 67, 1687-1694.

Susanto, R. D., A. Ffield, A. L. Gordon, and T. R. Adi, 2012: Variability of Indonesian throughflow within Makassar Strait, 2004-2009. J. Geophys. Res. Oceans, 117, C09013.

Swart, N. C., and J. C. Fyfe, 2012: Observed and simulated changes in the Southern Hemisphere surface westerly wind-stress. Geophys. Res. Lett., 39, L16711.

Swart, S., S. Speich, I. J. Ansorge, G. J. Goni, S. Gladyshev, and J. R. E. Lutjeharms, 2008: Transport and variability of the Antarctic Circumpolar Current South of Africa. J. Geophys. Res. Oceans, 113, C09014.

Swift, J. H., and A. H. Orsi, 2012: Sixty-four days of hydrography and storms: RVIB Nathaniel B. Palmer's 2011 S04P Cruise. Oceanography, 25, 54-55.

Takahashi, T., S. C. Sutherland, R. A. Feely, and R. Wanninkhof, 2006: Decadal change of the surface water $\mathrm{pCO}_{2}$ in the North Pacific: A synthesis of 35 years of observations. J. Geophys. Res. Oceans, 111, C07s05.

Takahashi, T., et al., 2009: Climatological mean and decadal change in surface ocean $\mathrm{pCO}_{2}$, and net sea-air $\mathrm{CO}_{2}$ flux over the global oceans (vol 56, pg 554, 2009). Deep-Sea Res. Pt. I, 56, 2075-2076.

Tanaka, H. L., N. Ishizaki, and A. Kitoh, 2004: Trend and interannual variability of Walker, monsoon and Hadley circulations defined by velocity potential in the upper troposphere. Tellus $A, 56,250-269$.

Tanhua, T., E. P. Jones, E. Jeansson, S. Jutterstrom, W. M. Smethie, D. W. R. Wallace, and L. G. Anderson, 2009: Ventilation of the Arctic Ocean: Mean ages and inventories of anthropogenic $\mathrm{CO}_{2}$ and CFC-11. J. Geophys. Res. Oceans, 114, $\mathrm{C} 01002$.

Terray, L., L. Corre, S. Cravatte, T. Delcroix, G. Reverdin, and A. Ribes, 2012: Nearsurface salinity as nature's rain gauge to detect human influence on the tropical water cycle. J. Clim., 25, 958-977.

Timmermann, A., S. McGregor, and F. F. Jin, 2010: Wind effects on past and future regional sea level trends in the southern Indo-Pacific. J. Clim., 23, 4429-4437.

Tokinaga, H., and S.-P. Xie, 2011: Wave- and Anemometer-based Sea surface Wind (WASWind) for climate change analysis. J. Clim., 24, 267-285.

Toole, J. M., R. G. Curry, T. M. Joyce, M. McCartney, and B. Pena-Molino, 2011: Transport of the North Atlantic Deep Western Boundary Current about $39^{\circ} \mathrm{N}$, 70W: 2004-2008. Deep-Sea Res. Pt. II, 58, 1768-1780.

Trenberth, K. E., and L. Smith, 2005: The mass of the atmosphere: A constraint on global analyses. J. Clim., 18, 864-875.

Trenberth, K. E., J. T. Fasullo, and J. Kiehl, 2009: Earth's global energy budget. Bull. Am. Meteorol. Soc., 90, 311-323.

Trenberth, K. E., J. T. Fasullo, and J. Mackaro, 2011: Atmospheric moisture transports from ocean to land and global energy flows in reanalyses. J. Clim., 24, 49074924.

Trenberth, K. E., et al., 2007: Observations: Surface and atmospheric climate change. In: Climate Change 2007: The Physical Science Basis. Contribution of Working Group I to the Fourth Assessment Report of the Intergovernmental Panel on Climate Change [Solomon, S., D. Qin, M. Manning, Z. Chen, M. Marquis, K. B. Averyt, M. Tignor and H. L. Miller (eds.)] Cambridge University Press, Cambridge, United Kingdom and New York, NY, USA.

Tsimplis, M. N., and A. G. P. Shaw, 2010: Seasonal sea level extremes in the Mediterranean Sea and at the Atlantic European coasts. Nat. Hazards Earth Syst. Sci., 10, 1457-1475.

Uppala, S. M., et al., 2005: The ERA-40 re-analysis. Q. J. R. Meteor. Soc., 131, 29613012.

Våge, K., et al., 2009: Surprising return of deep convection to the subpolar North Atlantic Ocean in winter 2007-2008. Nature Geosci., 2, 67-72.

Valdimarsson, H., O. S. Astthorsson, and J. Palsson, 2012: Hydrographic variability in Icelandic waters during recent decades and related changes in distribution of some fish species. Ices J. Mar. Sci., 69, 816-825.

Vargas-Yáñez, M., et al., 2010: How much is the western Mediterranean really warming and salting? J. Geophys. Res. Oceans, 115, C04001.

Vecchi, G. A., B. J. Soden, A. T. Wittenberg, I. M. Held, A. Leetmaa, and M. J. Harrison, 2006: Weakening of tropical Pacific atmospheric circulation due to anthropogenic forcing. Nature, 441, 73-76.

Vilibic, I., and J. Sepic, 2010: Long-term variability and trends of sea level storminess and extremes in European Seas. Global Planet. Change, 11, 1-12. 
von Schuckmann, K., and P. Y. Le Traon, 2011: How well can we derive Global Ocean Indicators from Argo data? Ocean Sci., 7, 783-791.

Wainwright, L., G. Meyers, S. Wijfels, and L. Pigot, 2008: Change in the Indonesian Throughflow with the climatic shift of 1976/77. Geophys. Res. Lett., 35, L03604.

Wang, C. Z., S. F. Dong, and E. Munoz, 2010: Seawater density variations in the North Atlantic and the Atlantic meridional overturning circulation. Clim. Dyn. 34, 953-968.

Wang, X., Y. Feng, and V. R. Swail, 2012: North Atlantic wave height trends as reconstructed from the Twentieth Century Reanalysis. Geophys. Res. Lett., 39 , L18705.

Wang, X. L. L., and V. R. Swail, 2006: Climate change signal and uncertainty in projections of ocean wave heights. Clim. Dyn., 26, 109-126.

Wang, X. L. L., V. R. Swail, F. W. Zwiers, X. B. Zhang, and Y. Feng, 2009: Detection of external influence on trends of atmospheric storminess and northern oceans wave heights. Clim. Dyn., 32, 189-203.

Wanninkhof, R., W. E. Asher, D. T. Ho, C. Sweeney, and W. R. McGillis, 2009: Advances in quantifying air-sea gas exchange and environmental forcing. Annu. Rev. Mar. Sci., 1, 213-244.

Wanninkhof, R., S. C. Doney, J. L. Bullister, N. M. Levine, M. Warner, and N. Gruber, 2010: Detecting anthropogenic $\mathrm{CO}_{2}$ changes in the interior Atlantic Ocean between 1989 and 2005. J. Geophys. Res., 115, C11028.

Wanninkhof, R., G. H. Park, T. Takahashi, R. A. Feely, J. L. Bullister, and S. C. Doney, 2013: Changes in deep-water $\mathrm{CO}_{2}$ concentrations over the last several decades determined from discrete $\mathrm{pCO}_{2}$ measurements. Deep-Sea Res. Pt. I, 74, 48-63.

WASA-Group, 1998: Changing waves and storm in the Northern Atlantic? Bull. Am. Meteorol. Soc., 79, 741-760.

Watson, A. J., et al., 2009: Tracking the variable North Atlantic sink for atmospheric $\mathrm{CO}_{2}$. Science, 326, 1391-1393.

Watson, P. J., 2011: Is there evidence yet of an acceleration in mean sea level rise around mainland Australia? J. Coast. Res., 27, 368-377.

Waugh, D. M., F. Primeau, T. DeVries, and M. Holzer, 2013: Recent changes in the ventilation of the Southern Oceans. Science, 339, 568-570.

Waugh, D. W., T. M. Hall, B. I. McNeil, R. Key, and R. J. Matear, 2006: Anthropogenic $\mathrm{CO}_{2}$ in the oceans estimated using transit-time distributions. Tellus $B, 58,376-$ 389.

Wentz, F. J., and L. Ricciardulli, 2011: Comment on "Global trends in wind speed and wave height." Science, 334, 905-905.

Wentz, F. J., L. Ricciardulli, K. Hilburn, and C. Mears, 2007: How much more rain will global warming bring? Science, 317, 233-235.

Wenzel, M., and J. Schroeter, 2010: Reconstruction of regional mean sea level anomalies from tide gauges using neural networks. J. Geophys. Res. Oceans, 115, C08013.

Whitney, F. A., H. J. Freeland, and M. Robert, 2007: Persistently declining oxygen levels in the interior waters of the eastern subarctic Pacific. Prog. Oceanogr. 75, 179-199.

Wijffels, S. E., et al., 2008: Changing expendable bathythermograph fall rates and their impact on estimates of thermosteric sea level rise. J. Clim., 21, 5657-5672.

Wild, M., 2009: Global dimming and brightening: A review. J. Geophys. Res. Atmos., 114, D00D16.

Willis, J. K., 2010: Can in situ floats and satellite altimeters detect long-term changes in Atlantic Ocean overturning? Geophys. Res. Lett., 37, L06602.

Willis, J. K., D. Roemmich, and B. Cornuelle, 2004: Interannual variability in upper ocean heat content, temperature, and thermosteric expansion on global scales. J. Geophys. Res. Oceans, 109, C12036.

Willis, J. K., D. P. Chambers, and R. S. Nerem, 2008: Assessing the globally averaged sea level budget on seasonal to interannual timescales. J. Geophys. Res. Oceans, 113, C06015.

Willis, J. K., D. P. Chambers, C.-Y. Kuo, and C. K. Shum, 2010: Global sea level rise: Recent progress and challenges for the decade to come. Oceanography, $\mathbf{2 3}$ 26-35.

Wong, A. P. S., N. L. Bindoff, and J. A. Church, 1999: Large-scale freshening of intermediate waters in the Pacific and Indian oceans. Nature, 400, 440-443.

Wong, C. S., L. S. Xie, and W. W. Hsieh, 2007: Variations in nutrients, carbon and other hydrographic parameters related to the 1976/77 and 1988/89 regime shifts in the sub-arctic Northeast Pacific. Prog. Oceanogr., 75, 326-342.

Woodworth, P. L., 1990: A search for accelerations in records of European mean sealevel. Int. J. Climatol., 10, 129-143.

Woodworth, P. L., 1999: High waters at Liverpool since 1768: the UK's longest sea level record. Geophys. Res. Lett., 26, 1589-1592.
Woodworth, P. L., and D. L. Blackman, 2004: Evidence for systematic changes in extreme high waters since the mid-1970s. J. Clim., 17, 1190-1197.

Woodworth, P. L., N. Pouvreau, and G. Woeppelmann, 2010: The gyre-scale circulation of the North Atlantic and sea level at Brest. Ocean Sci., 6, 185-190.

Woodworth, P. L., M. Menéndez, and W. R. Gehrels, 2011: Evidence for centurytimescale acceleration in mean sea levels and for recent changes in extreme sea levels. Surv. Geophys., 32, 603-618.

Woodworth, P. L., N. J. White, S. Jevrejeva, S. J. Holgate, J. A. Church, and W. R. Gehrels, 2009: Evidence for the accelerations of sea level on multi-decade and century timescales. Int. J. Climatol., 29, 777-789.

Wöppelmann, G., et al., 2009: Rates of sea-level change over the past century in a geocentric reference frame. Geophys. Res. Lett., 36, L12607.

Wu, L., et al., 2012: Enhanced warming over the global subtropical western boundary currents. Nature Clim. Change, 2, 161-166.

Wunsch, C., 2010: Variability of the Indo-Pacific Ocean exchanges. Dyn. Atmos. Oceans, 50, 157-173.

Xue, Y., B. Huang, Z.-Z. Hu, A. Kumar, C. Wen, D. Behringer, and S. Nadiga, 2010: An assessment of oceanic variability in the NCEP climate forecast system reanalysis. Clim. Dyn., 37, 2541-2550.

Xue, Y., et al., 2012: A comparative analysis of upper ocean heat content variability from an ensemble of operational ocean reanalyses. J. Clim., 25, 6905-6929.

Yamamoto-Kawai, M., F. A. McLaughlin, E. C. Carmack, S. Nishino, K. Shimada, and N. Kurita, 2009: Surface freshening of the Canada Basin, 2003-2007: River runoff versus sea ice meltwater. J. Geophys. Res. Oceans, 114, C00A05.

Yang, X. Y., R. X. Huang, and D. X. Wang, 2007: Decadal changes of wind stress over the Southern Ocean associated with Antarctic ozone depletion. J. Clim. 20, 3395-3410.

Yashayaev, I., 2007: Hydrographic changes in the Labrador Sea, 1960-2005. Prog. Oceanogr., 73, 242-276.

Yashayaev, I., and J. W. Loder, 2009: Enhanced production of Labrador Sea Water in 2008. Geophys. Res. Lett., 36, L01606.

Yoshikawa-Inoue, $\mathrm{H}$., and M. Ishii, 2005: Variations and trends of $\mathrm{CO}_{2}$ in the surface seawater in the Southern Ocean south of Australia between 1969 and 2002. Tellus B, 57, 58-69.

Young, I. R., S. Zieger, and A. V. Babanin, 2011a: Global trends in wind speed and wave height. Science, 332, 451-455.

Young, I. R., A. V. Babanin, and S. Zieger, 2011 b: Response to comment on "Global trends in wind speed and wave height". Science, 334, 905-905.

Yu, L., 2011: A global relationship between the ocean water cycle and near-surface salinity. J. Geophys. Res. Oceans, 116, C10025.

Yu, L., and R. A. Weller, 2007: Objectively analyzed air-sea flux fields for the global ice-free oceans (1981-2005). Bull. Am. Meteorol. Soc., 88, 527-539.

Yu, L. S., 2007: Global variations in oceanic evaporation (1958-2005): The role of the changing wind speed. J. Clim., 20, 5376-5390.

Yu, L. S., X. Z. Jin, and R. A. Weller, 2007: Annual, seasonal, and interannual variability of air-sea heat fluxes in the Indian Ocean. J. Clim., 20, 3190-3209.

Zenk, W., and E. Morozov, 2007: Decadal warming of the coldest Antarctic Bottom Water flow through the Vema Channel. Geophys. Res. Lett., 34, L14607.

Zhang, X. B., and J. A. Church, 2012: Sea level trends, interannual and decadal variability in the Pacific Ocean. Geophys. Res. Lett., 39, L21701. 
Appendix 3.A:

\section{Availability of Observations for Assessment of Change in the Oceans}

Sampling of the ocean has been highly heterogeneous since 1950 . The coverage in space, time, depth and number of ocean variables has evolved over time, reflecting changes in technology and the contribution of major oceanographic research programs. Changes in the distribution and quality of ocean measurements over time complicate efforts to detect and interpret change in the ocean. This Appendix provides some illustrative examples of the evolution of the ocean observing system on which the assessment of ocean change in this chapter is based. A more comprehensive discussion of ocean sampling is provided in the literature cited in this chapter. Sampling of sea surface temperature is discussed in Chapter 2.

\section{A.1 Subsurface Ocean Temperature and Heat Content}

Temperature is the best-sampled oceanographic variable, but even for temperature sampling is far from ideal or complete. Early oceanographic expeditions included the Challenger voyage around the world in the 1870s, the Meteor survey of the Atlantic in the 1920s, and the Discovery investigations of the Southern Ocean starting in the 1920s. More frequent basin-scale sampling commenced in the late 1950s with the International Geophysical Year. The number of profiles available for assessment of changes in temperature and ocean heat content in the upper $700 \mathrm{~m}$ generally increases with time since the 1950s (Figure 3.A.1). Near-global coverage of the upper half of the ocean was not achieved until the widespread deployment of Argo profiling floats in the 2000s (Figure 3.A.2).
Early measurements of temperature were made using reversing thermometers and Nansen bottles that were lowered from ships on station (not moving). Starting in the 1960s conductivity-temperature-depth (CTD) instruments with Niskin bottles gradually gained dominance for high-quality data and deep data collected on station during oceanographic cruises. From at least 1950 through about 1970, most subsurface measurements of ocean temperature were made with mechanical bathythermographs, an advance because these instruments could be deployed from a moving ship, albeit a slowly moving one, but these casts were generally limited to depths shallower than $250 \mathrm{~m}$. Expendable bathythermographs (XBTs) that could be deployed from a rapidly moving ship and sampled to $400 \mathrm{~m}$ came into widespread use in the late 1960s, and those that sampled to $700 \mathrm{~m}$ became predominant in the 1990s, greatly expanding oceanographic sampling. Starting in 2000 , Argo floats began sampling the ocean to a target depth of 2000 $\mathrm{m}$, building to near-global coverage by 2005. Prior to the Argo era, sampling of the ocean below $700 \mathrm{~m}$ was almost solely achieved from ships on station deploying Nansen bottles with reversing thermometers or later using CTDs with Niskin bottles. Today ship-based station data still dominates sampling for waters deeper than $2000 \mathrm{~m}$ depth (the maximum depth currently sampled by Argo floats). An illustration of the limited data available for assessment of change in the deep ocean is provided in Figure 3.3, which shows locations of full-depth oceanographic CTD sections that have been occupied more than once since about 1980. The depth coverage of the ocean observing system has changed over time (Figure 3A.2, top panel) with a hemispheric bias (Figure 3.A.2, middle and lower panels). The Northern Hemisphere (NH) has been consistently better sampled than the Southern Hemisphere (SH) prior to the Argo era.

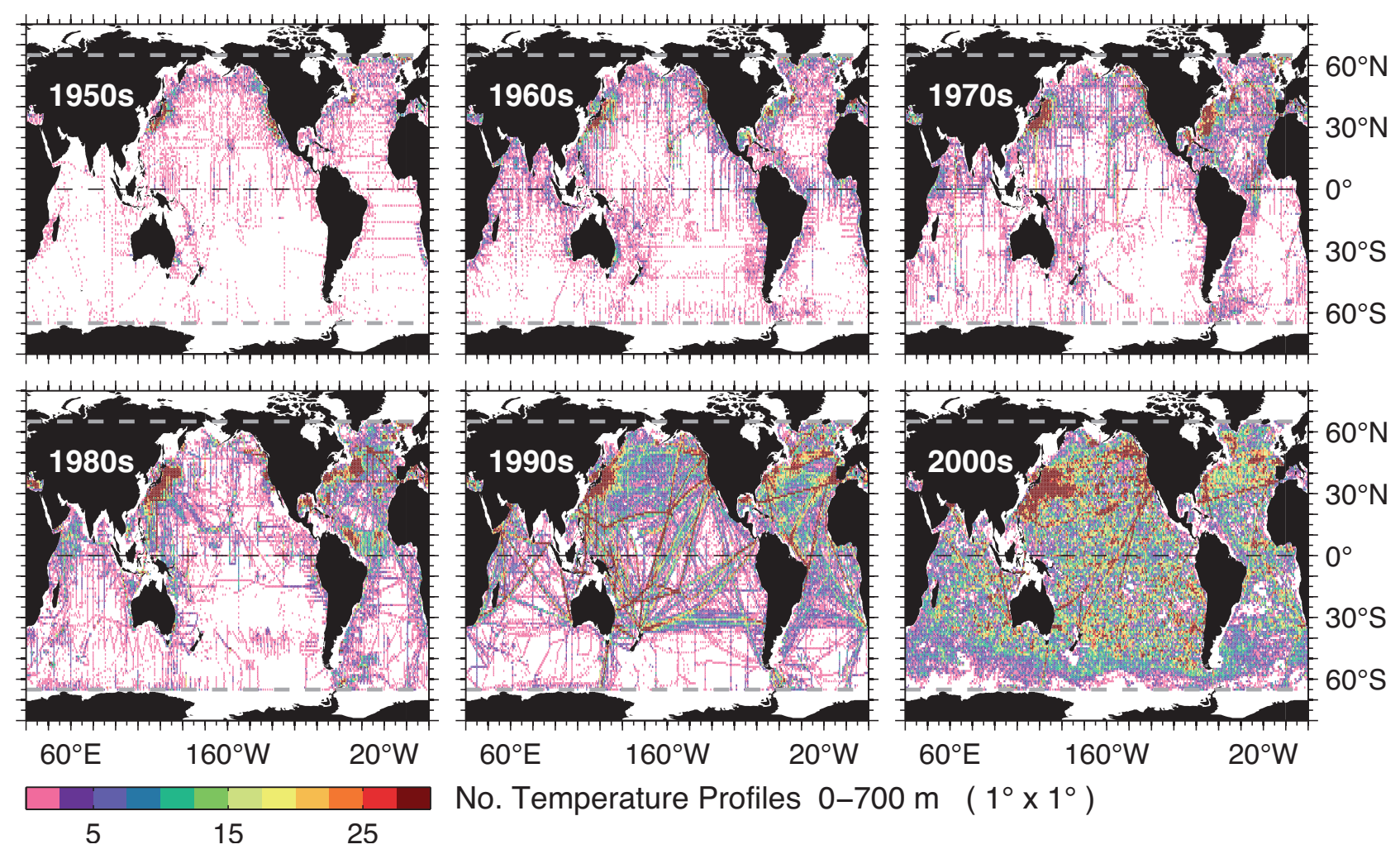

Figure 3.A.1 | Number of temperature profiles extending to $700 \mathrm{~m}$ depth in each $1^{\circ} \times 1^{\circ}$ square, by decade, between $65^{\circ} \mathrm{N}$ and $65^{\circ}$. 
Ocean temperature profiles - Yearly coverage
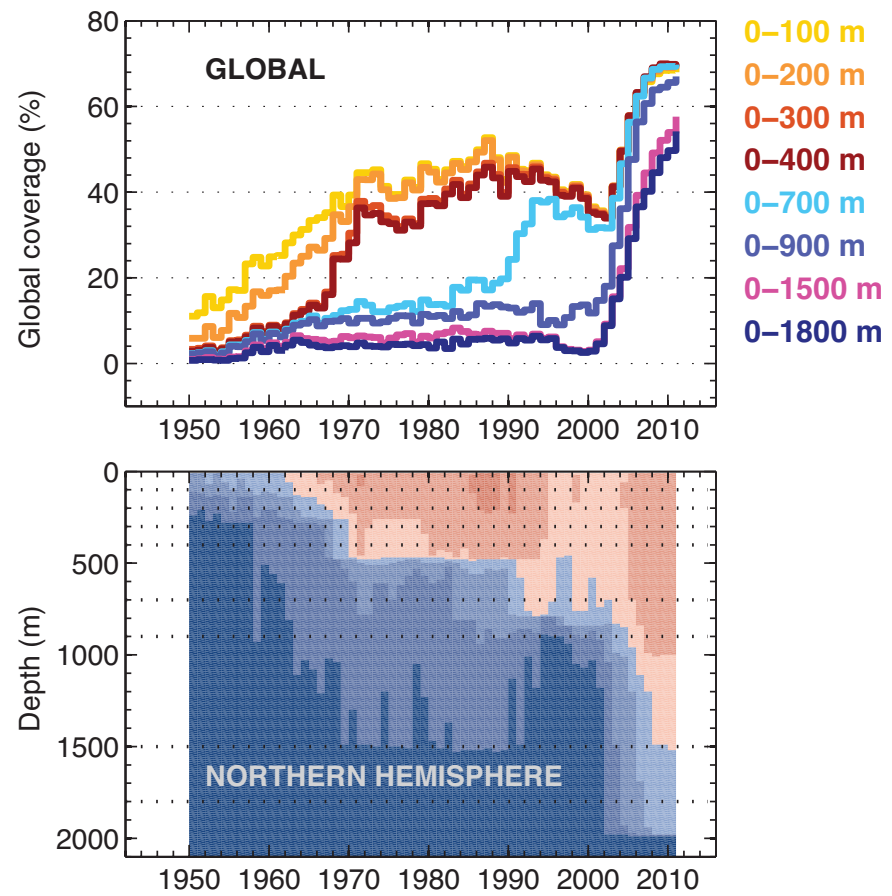

3

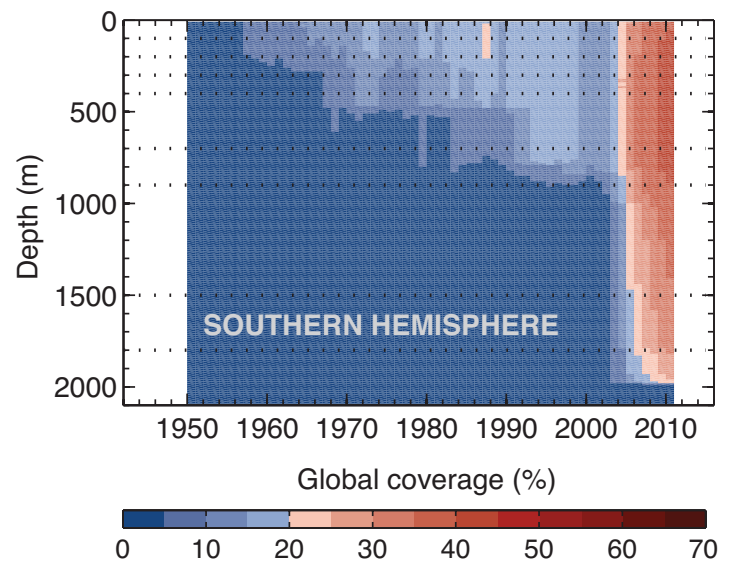

Figure 3.A.2 | (Top) Percentage of global coverage of ocean temperature profiles as a function of depth in $1^{\circ}$ latitude by $1^{\circ}$ longitude by 1 -year bins (top panel) shown versus time. Different colours indicate profiles to different depths (middle panel). Percentage of global coverage as a function of depth and time, for the Northern Hemisphere. (Bottom panel) As above, but for the Southern Hemisphere.

\section{A.2 Salinity}

Measurements of subsurface salinity have relied almost solely on data collected from bottle and CTD casts from ships on station (and, more recently, using profiling floats that sample both temperature and salinity with CTDs). Hence fewer measurements of salinity are available than of temperature (by roughly a factor of 3 ). However, the evolution with time of subsurface salinity sampling shows a progression similar to that of temperature (Figure 3.A.3). Coverage generally improves with time, but there is a strong NH bias, particularly in the North Atlantic. A shift in focus from basin-to-basin as major field programs were carried out is evident. Near-global coverage of ocean salinity above $2000 \mathrm{~m}$ was not achieved until after 2005, when the Argo array approached full deployment. For depths greater than $2000 \mathrm{~m}$, outside the relatively well sampled North Atlantic, information on changes in ocean salinity is largely restricted to the repeat hydrographic transects (see Figure 3.3).

\section{A.3 Sea Level}

Direct observations of sea level are made using tide gauges since the 1700 s and high-precision satellite altimeters since 1992 . Tide gauge measurements are limited to coastlines and islands. There are intermittent records of sea level at Amsterdam from 1700 and at three more sites in Northern Europe starting after 1770. By the late 1800s, more tide gauges were being operated in Northern Europe and in North America, as well as in Australia and New Zealand (Figure 3.A.4). It was not until the late 1970s to early 1980 s that a majority of deepocean islands had operating tide gauges suitable for climate studies. Although tide gauges have continued to be deployed since 1990, they have been complemented by continuous, near-global measurements of sea level from space since 1992. Measurements are made along the satellite's ground track on the Earth surface, typically averaged over approximately $7 \mathrm{~km}$ to reduce noise and improve precision. The maximum latitude extent of the measurement is limited by the inclination of the orbital plane, which has been between $\pm 66^{\circ}$ for the TOPEXI Poseidon and Jason series of altimeters. The spacing between ground tracks is much greater than the spacing along the ground track. As an example, the groundtrack separation of the TOPEX/Poseidon-type of orbits is about $300 \mathrm{~km}$ at the equator, but is less than $100 \mathrm{~km}$ at latitudes poleward of $50^{\circ}$ latitude. On average, the spacing is between 100 and $200 \mathrm{~km}$. Satellites are limited in the temporal sampling as well due to the orbit configuration. For a specific location along a groundtrack, the return time for a TOPEX/Poseidon-type of orbit is 9.9 days. If one relaxes the requirement to a measurement within a $300 \mathrm{~km}$ radius, the return time can be as short as a few hours at high latitudes to about 3 days at the equator. As noted in Section 3.6, satellite altimeter observations of sea level are also an important tool for observing large-scale ocean circulation.

\section{A.4 Biogeochemistry}

The data available for assessing changes in biogeochemical parameters is less complete than for temperature and salinity. The global data base on which the Global Ocean Data Analysis Project (GLODAP, Key et al., 2004) ocean carbon inventory is based is illustrated in Figure 3.A.5. Changes in the ocean inventory of anthropogenic $\mathrm{CO}_{2}$ have been estimated using measurements of carbon parameters and other tracers collected at these roughly 12,000 stations, mostly occupied since 1990 . The majority of these stations extend through the full water depth. A subset of these stations have been repeated one or more times. The distribution of oxygen measurements at $300 \mathrm{~m}$ depth in 10-year periods since 1960 is shown in Figure 3.A.6, as used in the global study of Stramma et al. (2012). As for temperature and salinity, the sampling is heterogeneous, coverage generally improves with time but shifts between basins as major field programs come and go, and tends to be concentrated in the $\mathrm{NH}$. 

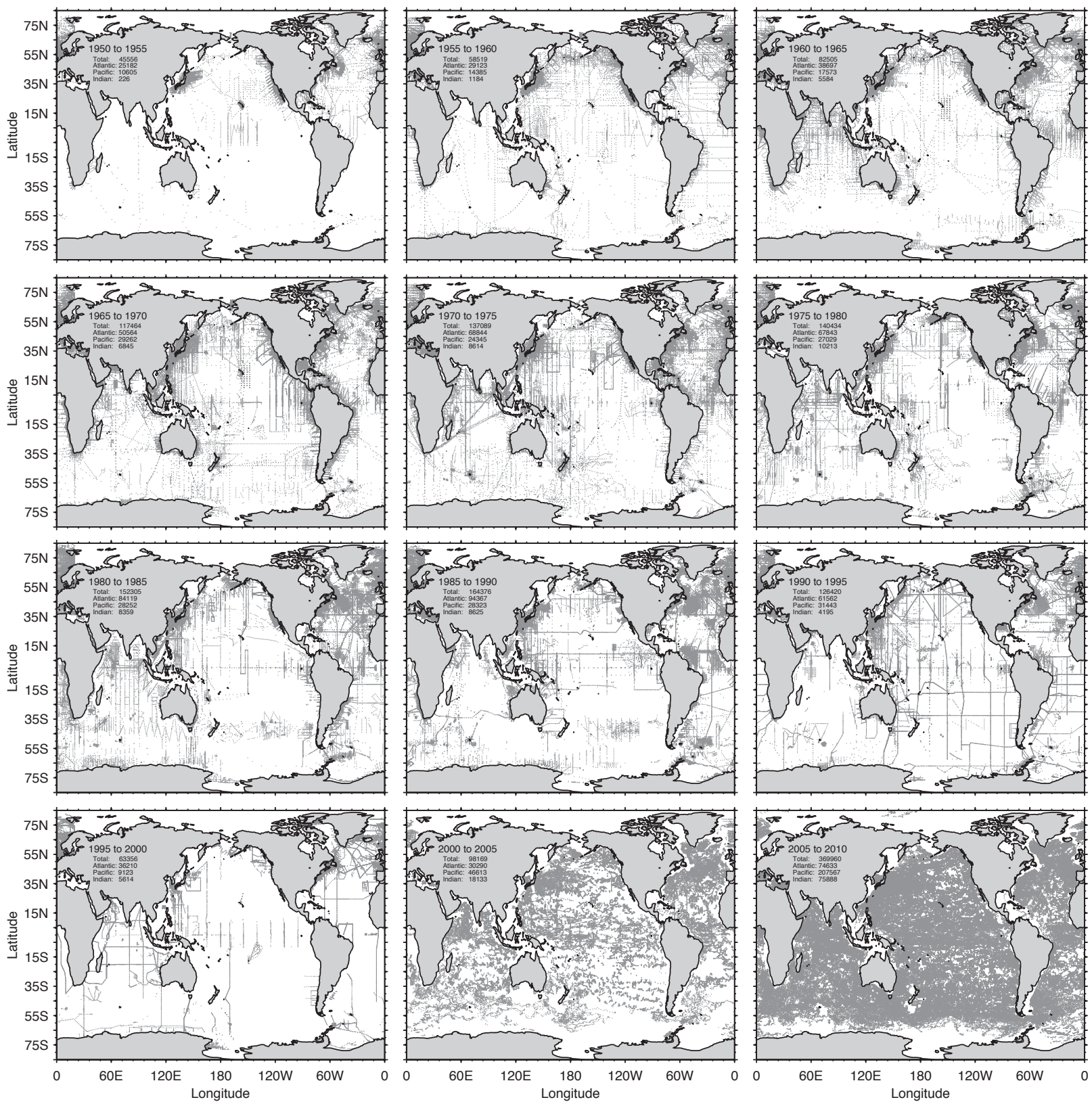

Figure 3.A.3 | Hydrographic profile data used in the Durack and Wijffels (2010) study. Station locations for 5-year temporal bins from 1950-1955 (top left) to 2005-2010 (bottom right). 

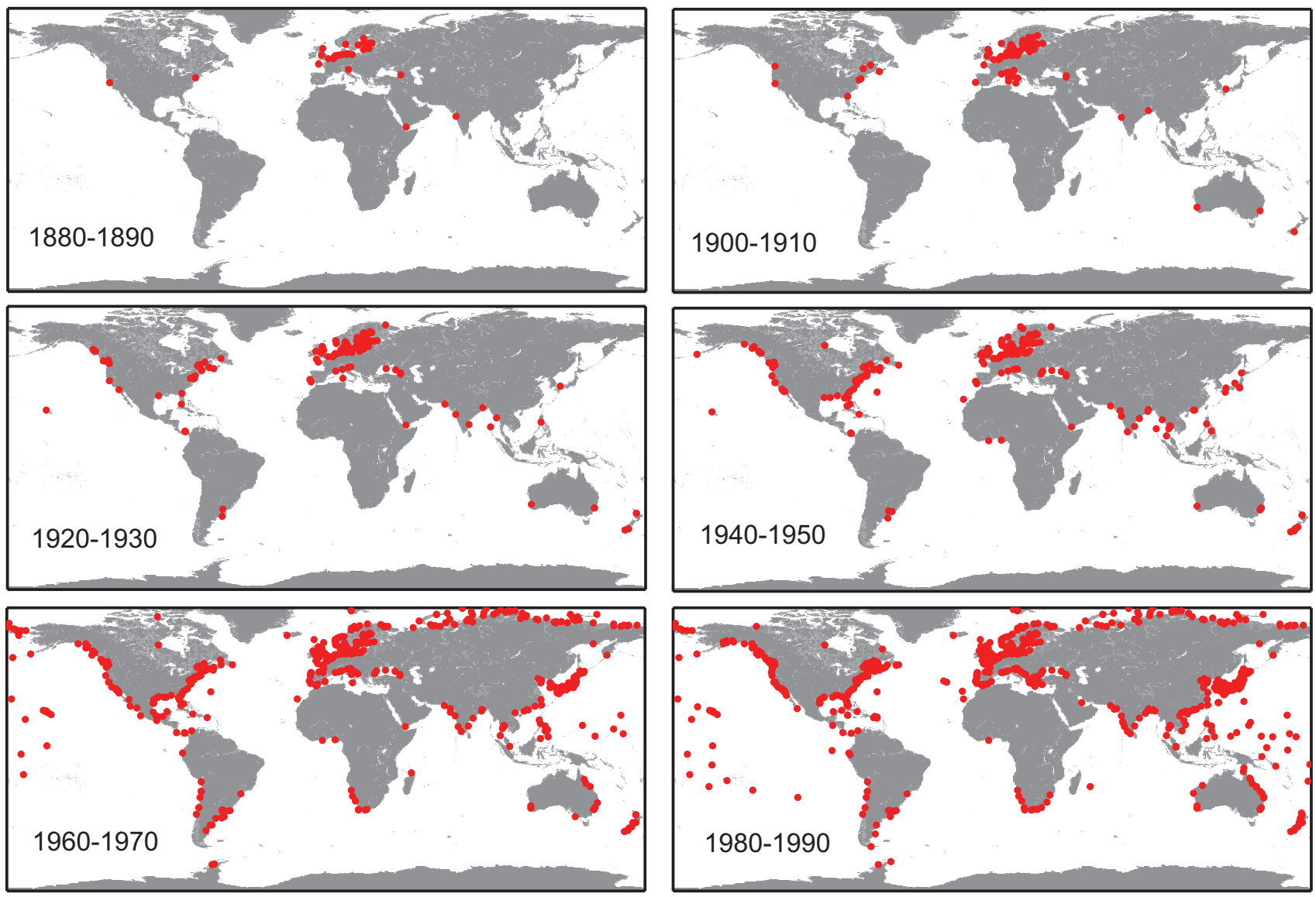

Figure 3.A.4 | Location of tide gauges (red dots) that had at least 1 year of observations within the decade indicated.

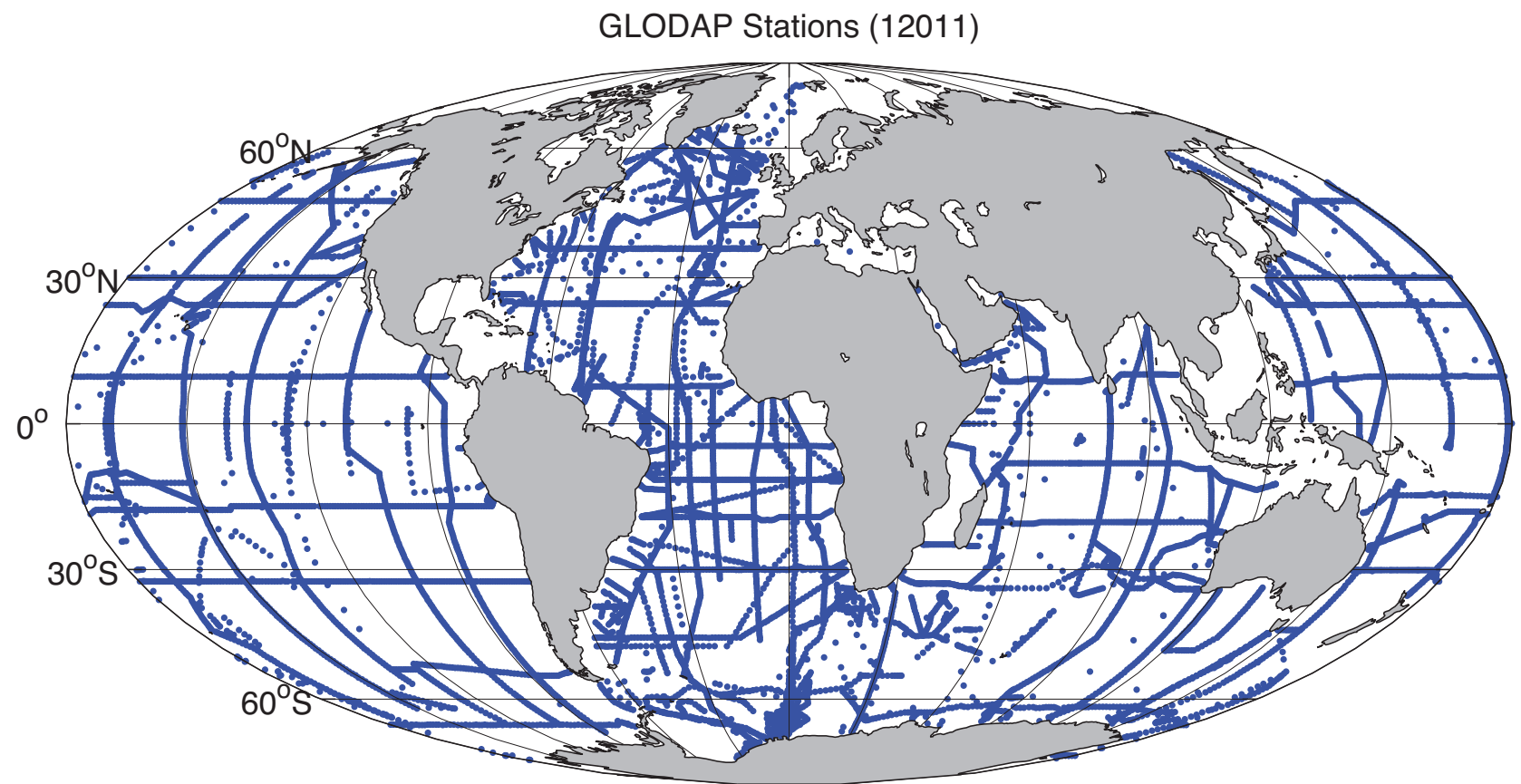

Figure 3.A.5 | Location of profiles used to construct the Global Ocean Data Analysis Project (GLODAP) ocean carbon climatology. 

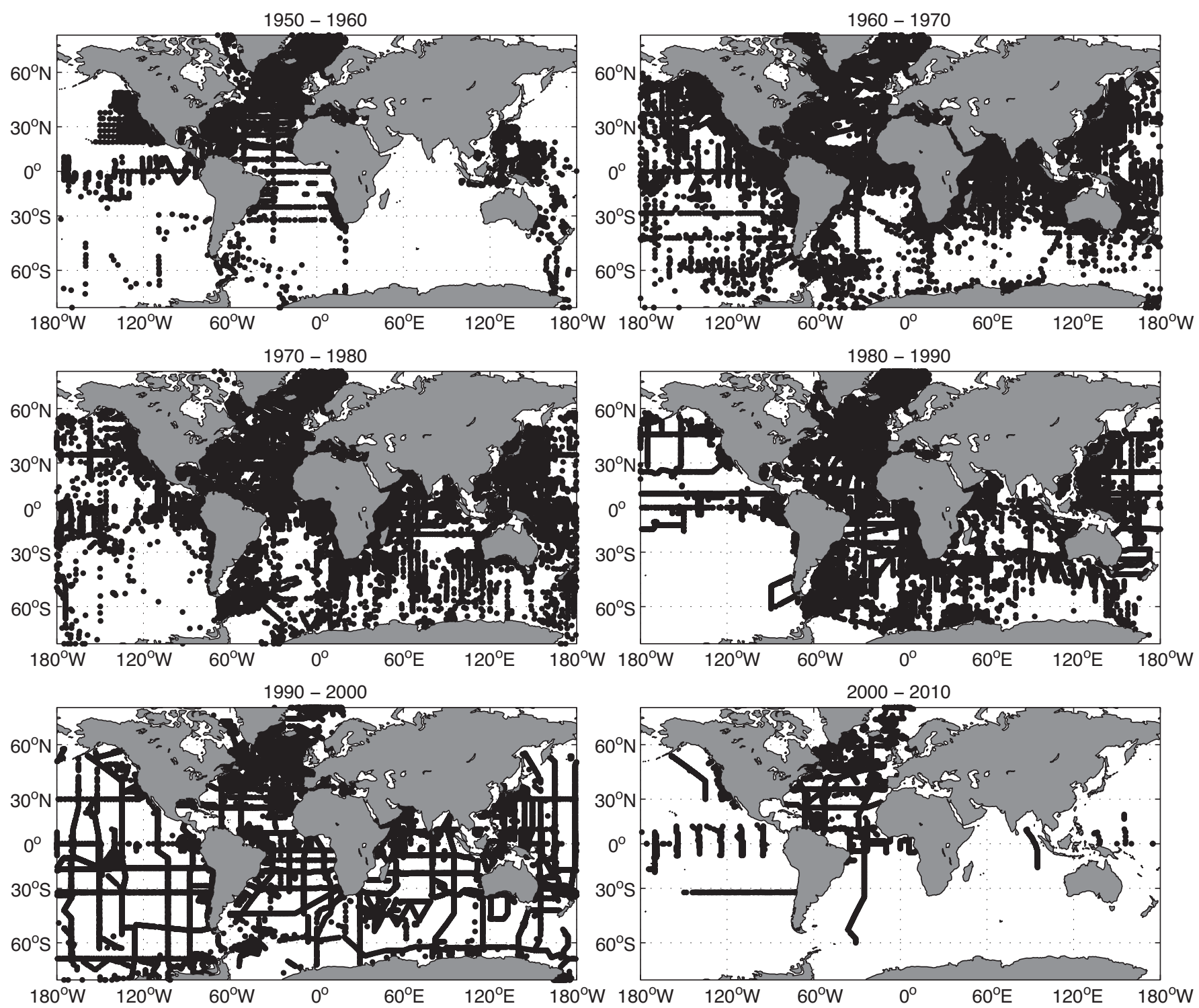

Figure 3.A.6 | Distribution of oxygen measurements at 300 dbar for the decades 1950 to 1960 (upper left) to 2000 to 2010 (lower right frame). (From Stramma et al., 2012.$)$ [Note that additional oxygen data have become available for the 2000-2010 period since that study was completed.] 
